\title{
MITIGATION OF CYLINDER DISTORTION IN ALUMINUM ALLOY ENGINE BLOCKS VIA HEAT TREATMENT PROCESS OPTIMIZATION
}

by

\author{
Anthony Lombardi \\ Bachelor of Engineering, Ryerson University, 2009 \\ Master of Applied Science, Ryerson University, 2011
}

\author{
A dissertation \\ presented to Ryerson University \\ in partial fulfillment of the \\ requirements for the degree of
}

Doctor of Philosophy

in the Program of

Mechanical and Industrial Engineering

Toronto, Ontario, Canada, 2015

C Anthony Lombardi 2015 


\section{Author's Declaration for Electronic Submission of a Dissertation}

I hereby declare that I am the sole author of this dissertation. This is a true copy of the dissertation, including any required final revisions, as accepted by my examiners.

I authorize Ryerson University to lend this dissertation to other institutions or individuals for the purpose of scholarly research.

I further authorize Ryerson University to reproduce this dissertation by photocopying or by other means, in total or in part, at the request of other institutions or individuals for the purpose of scholarly research.

I understand that my dissertation may be made electronically available to the public. 


\title{
Abstract \\ MITIGATION OF CYLINDER DISTORTION IN ALUMINUM ALLOY ENGINE BLOCKS VIA HEAT TREATMENT PROCESS OPTIMIZATION
}

\author{
Doctor of Philosophy, 2015 \\ Anthony Lombardi \\ Mechanical Engineering \\ Ryerson University
}

Lightweighting has become an important factor in the automotive industry due to stringent government regulations on fuel consumption and increased environmental awareness. Aluminum alloys are $65 \%$ lighter than cast iron enabling significant weight reduction. However, there are several significant challenges associated to the use of hypoeutectic Al-Si alloys in engine block applications. This dissertation investigated the factors influencing the susceptibility of in-service cylinder distortion as it is deleterious to engine operating efficiency, leading to environmental (increased carbon emissions) and economic (expensive recalls) repercussions.

The initial segment of this dissertation sought to quantitatively confirm the cause of cylinder distortion by investigating distorted and undistorted service tested engine blocks. This analysis involved measurement of macro-distortion using a co-ordinate measuring machine, in-depth microstructural analysis, measurement of tensile properties, and residual stress mapping along the length of the cylinder bores (neutron diffraction). Upon determining the cause of distortion, the second phase of this project optimized the solution heat treatment parameters to mitigate future distortion in the engine blocks. This optimization was carried out by varying heat treatment parameters to maximize engine block strength. In addition, a pioneering application of in-situ neutron diffraction, along with a unique engine heating system, was used to develop a time-dependent correlation of residual stress relief during heat treatment, assisting in process optimization.

The results indicate that the distorted engine block had high tensile residual stress, specifically at cylinder depths greater than $30 \mathrm{~mm}$, while the undistorted block had mainly compressive stress. The maximum distortion occurred near the center portion of the cylinder $(\sim 60 \mathrm{~mm})$, which had a combination of coarse microstructure (lower strength) and high tensile residual stress. As such, 
distortion can be prevented via maximization of strength and reduction in tensile residual stress. Lab scale castings and in-situ neutron diffraction were used to successfully develop an optimal heat treatment process to increase engine block integrity. These experiments found that solution heat treatment at $500{ }^{\circ} \mathrm{C}$ for $2 \mathrm{~h}$ increased tensile yield strength by $15-20 \%$ over engines produced using the current process. Furthermore, tensile residual stress was completely relieved by this heat treatment, reducing the susceptibility to in-service distortion. Solutionizing at temperatures above $500{ }^{\circ} \mathrm{C}$ was deemed unsuitable for engine block production due to incipient melting, which deteriorates strength. 


\section{Acknowledgements}

There are many people around me in my professional and personal life that deserves credit for the completion of this thesis. I would like to first express my deepest gratitude to Professor C. Ravindran for his constant guidance, support and advice in both technical and nontechnical aspects. Under his guidance, I have learned much on being not only a better researcher but also a better all-around person.

I would also like to thank Mr. Alan Machin and Dr. Francesco D'Elia for their technical knowledge, useful discussions, assistance with experiments and interpretation of results.

The author would also like to express his sincere gratitude to Dr. Robert MacKay and Dr. Glenn Byczynski from Nemak Canada for providing the engine block castings and Al alloy ingots as well their significant technical knowledge to the project.

The author is grateful for the assistance of Dr. Dimitry Sediako of the Canadian Neutron Beam Centre (CNBC) in Chalk River, Canada for use of facilities, assistance with experiments and discussions regarding results, specifically those related to neutron diffraction analysis. The author is also thankful to Mr. Jim Bolduc at CNBC for assistance with setup of the heating and control systems.

Furthermore, the author thanks all the help provided by Dr. Abdallah Elsayed, Mr. Subrata Saha Mr. Eli Vandersluis and Mr. Suleman Ahmad of the Centre for Near-Net-Shape Processing of Materials at Ryerson University

Finally, I am deeply grateful for the undying support I have received from my mother and father, my siblings (Rita and Frank) and the love of my life Allison, during this project. I especially thank Allison for being my pillar of strength throughout the process of completing this dissertation and for providing stimulating technical discussion allowing for a more comprehensive understanding of the examined phenomena.

Without the assistance of all these fantastic people, completion of this work would not have been possible. 


\section{Table of Contents}

Author's Declaration for Electronic Submission of a Dissertation ............................................... ii

Abstract.................................................................................................................................................ii

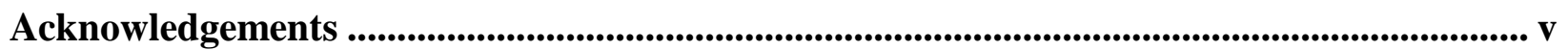

Table of Contents ........................................................................................................................ vi

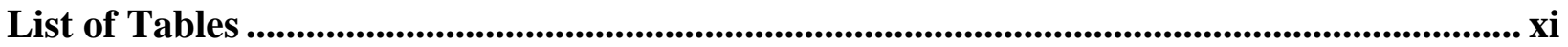

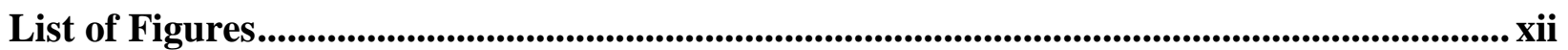

Nomenclature ................................................................................................................................. Xvii

Chapter 1: Introduction ..................................................................................................................... 1

Chapter 2: Literature Review...................................................................................................... 4

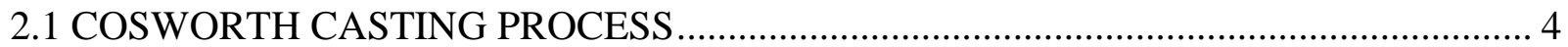

2.2 MICROSTRUCTURE OF ALUMINUM-SILICON-COPPER (319) ALLOY SYSTEM .. 5

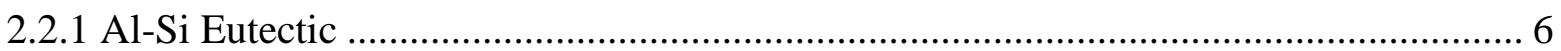

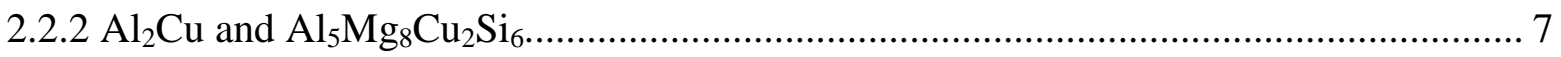

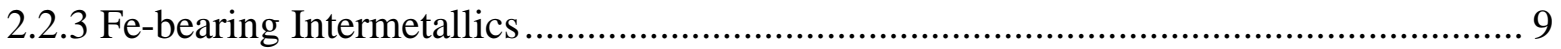

2.3 HEAT TREATMENT OF 319 ALUMINUM ALLOYS ................................................... 11

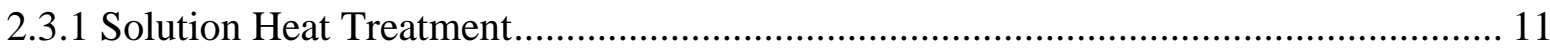

2.3.1.1 Eutectic Si Morphology ...................................................................................... 11

2.3.1.2 Effect of Alloy Composition on Secondary Phase Dissolution ............................. 12

2.3.1.3 Effect of Particle Size on Secondary Phase Dissolution......................................... 13

2.3.1.4 Effect of Particle Morphology on Secondary Phase Dissolution............................ 14

2.3.1.5 Incipient Melting of Secondary Phases.......................................................... 15

2.3.1.6 Effect of Solution Temperature on Mechanical Properties................................... 18

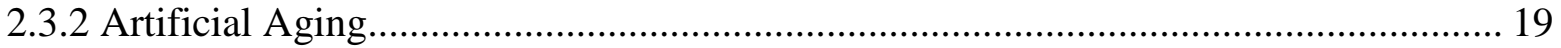

2.3.2.1 Precipitation Sequence during Aging ……………......................................... 20

2.3.2.2 Effect of Heat Treatment Condition on Mechanical Properties.............................. 22

2.3.2.3 Effect of Heat Treatment Condition on Dimensional Stability ............................ 24

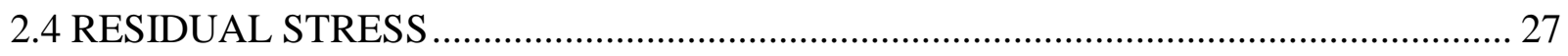

2.4.1 Mechanisms of Residual Stresses Development ........................................................... 27

2.4.1.1 Thermal Gradients ..................................................................................... 27 
2.4.1.2 Thermo-Mechanical Mismatch. 29

2.4.2 Residual Stresses in Aluminum Engine Blocks .................................................. 31

2.4.3 Mechanisms of Residual Stress Relaxation........................................................... 32

2.4.4 Residual Stress Relief in Aluminum Engine Blocks ............................................... 35

Chapter 3: Experimental Methodology ........................................................................... 39

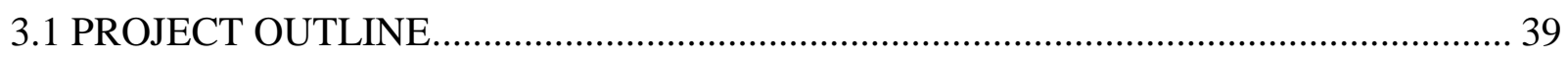

3.2 ANALYSIS OF THE MECHANISM OF CYLINDER DISTORTION ........................ 41

3.2.1 Current Engine Block Production Parameters ..................................................... 41

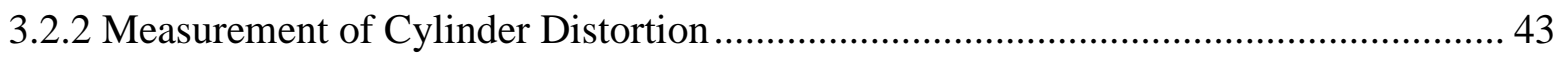

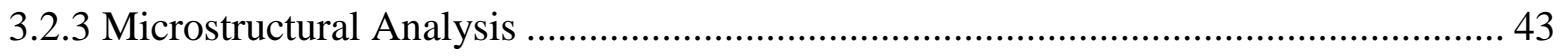

3.2.3.1 Sample Preparation for OM and SEM Analysis .......................................... 45

3.2.3.2 Sample Preparation for TEM Analysis ......................................................... 46

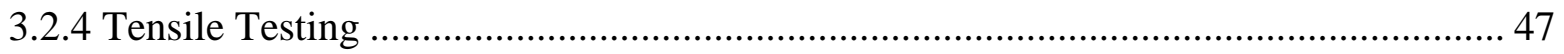

3.2.5 Ex-situ Residual Strain and Stress Measurements................................................ 47

3.3 OPTIMIZATION OF ENGINE BLOCK HEAT TREATMENT PARAMETERS ........... 51

3.3.1 Replication of Engine Block Cylinder Microstructure ........................................ 52

3.3.2 Variation of Solution Heat Treatment Parameters ................................................. 54

3.3.3 In-situ/Ex-situ Residual Strain and Stress Analysis .............................................. 55

3.3.3.1 Investigated Solution Heat Treatment Parameters............................................ 55

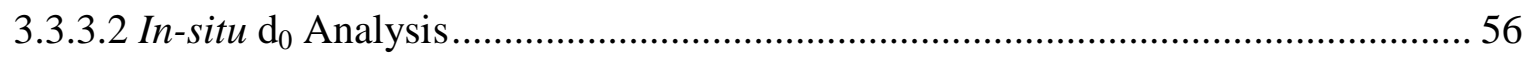

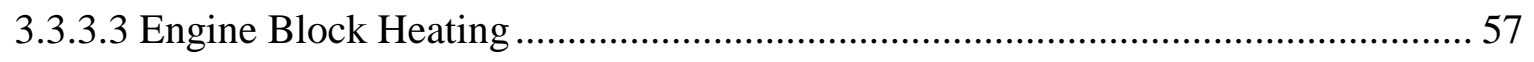

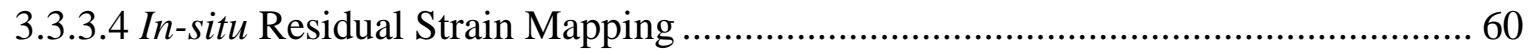

3.3.3.5 Ex-situ Residual Stress Mapping Following T4 Treatment ............................... 61

3.3.3.6 CFD Heat Transfer Modelling of Quenching Process ....................................... 62

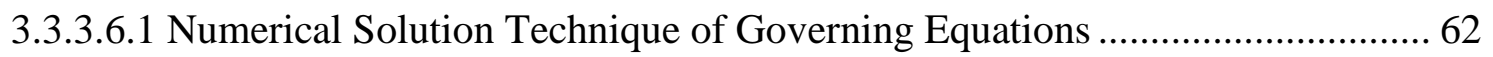

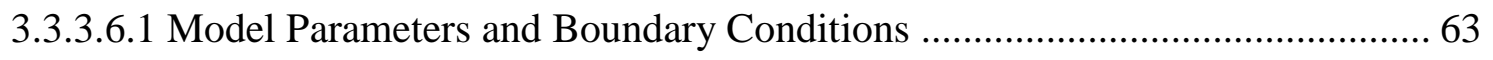

Chapter 4: Determining the Mechanism of Cylinder Distortion....................................... 65

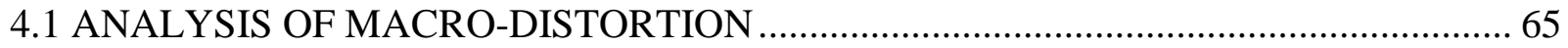

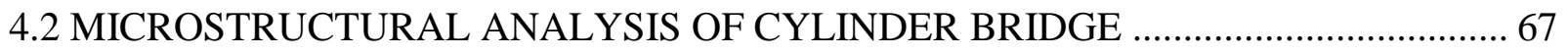

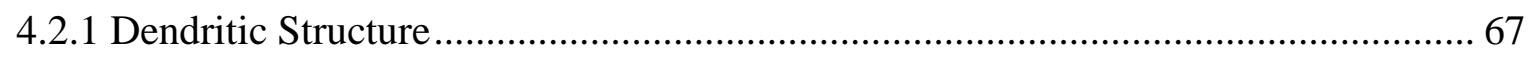

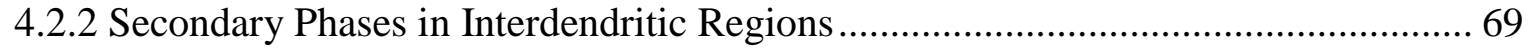


4.2.3 Precipitates in Aluminum Dendrites ....................................................................... 71

4.3 TENSILE PROPERTIES OF CYLINDER BRIDGE ..................................................... 73

4.4 RESIDUAL STRAIN AND STRESS MAPPING ......................................................... 74

4.4.1 Aluminum Cylinder Bridge ................................................................................. 74

4.4.2 Gray Cast Iron Cylinder Liners ........................................................................... 79

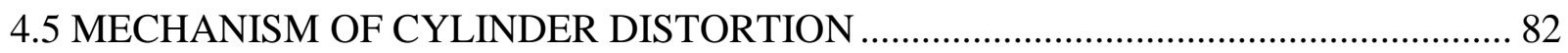

4.5.1 Effect of Phase Transformation on Distortion............................................................ 82

4.5.2 Effect of Microstructure, Mechanical Properties and Residual Stress on Distortion ... 82

Chapter 5: Optimization of Solution Heat Treatment Process .................................................... 86

5.1 MICROSTRUCTURE AND MECHANICAL PROPERTIES............................................ 86

5.1.1 Replication of Cylinder Bridge Microstructure using Billet Castings ......................... 86

5.1.1.1 Billet Casting and Cylinder Bridge Dendritic Structure ......................................... 87

5.1.1.2 Cooling Rate-SDAS Correlation....................................................................... 89

5.1.1.3 Secondary Phase Analysis ............................................................................ 90

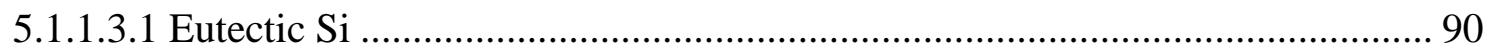

5.1.1.3.2 Morphology of the Al-Cu and Al-Fe-Mn-Si Intermetallics ........................... 92

5.1.1.3.3 Volume Fraction of the Al-Cu and Al-Fe-Mn-Si Intermetallics.................... 95

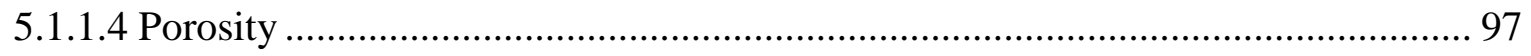

5.1.1.5 Tensile Properties of Replicating Billets .......................................................... 98

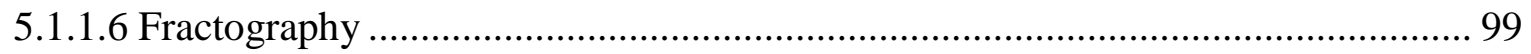

5.1.2 Solution Heat Treatment of Replicating Billet Castings .......................................... 101

5.1.2.1 Effect of SHT on Secondary Phases ................................................................... 101

5.1.2.1.1 SHT Temperature: $470{ }^{\circ} \mathrm{C}$....................................................................... 101

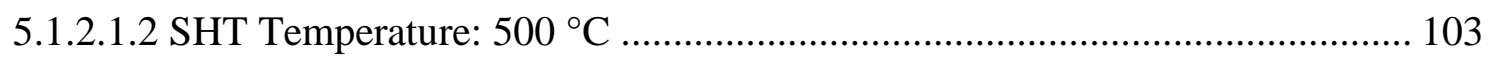

5.1.2.1.3 $\mathrm{Al}_{2} \mathrm{Cu}$ Volume Fraction Following SHT at $500{ }^{\circ} \mathrm{C}$.................................... 105

5.1.2.1.4 SHT Temperatures: 515 and $530{ }^{\circ} \mathrm{C}$........................................................... 107

5.1.2.1.5 Morphology of the Ultra-Fine Eutectic ....................................................... 110

5.1.2.1.6 Intertwining of Secondary Phases .................................................................. 113

5.1.2.1.7 $\mathrm{Al}_{2} \mathrm{Cu}$ Volume Fraction Following SHT at 515 and $530{ }^{\circ} \mathrm{C} . . . \ldots \ldots \ldots \ldots \ldots \ldots . . . . . . . . . .114$

5.1.2.2 Analysis of Incipient Melting using Differential Scanning Calorimetry ............. 116

5.1.2.3 Tensile Properties of Billet Castings.................................................................. 119 


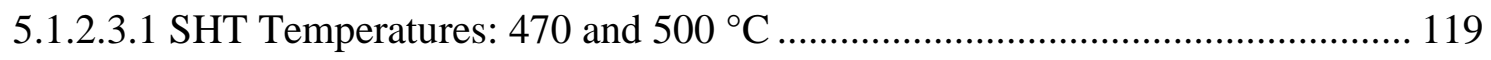

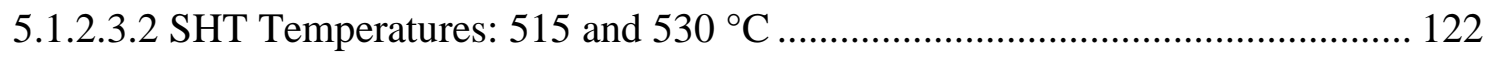

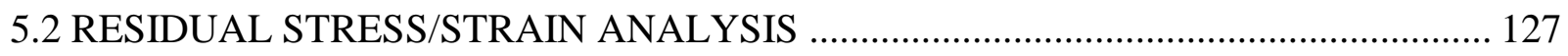

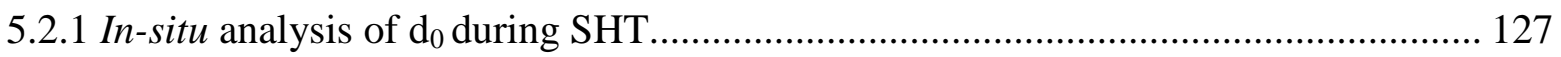

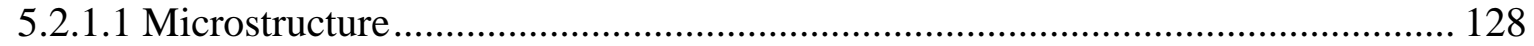

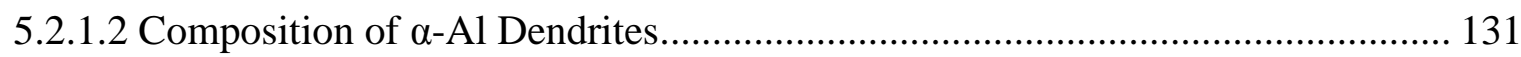

5.2.1.3 Effect of Thermal Expansion on $\mathrm{d}_{0}$ Spacing ...................................................... 132

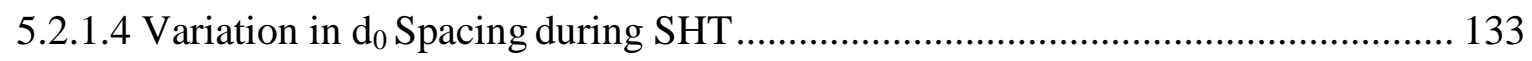

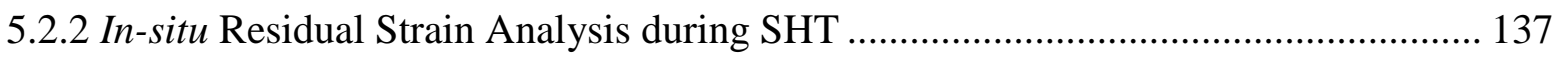

5.2.2.1 Residual Strain Relief during Elevated Temperature Soaking ............................ 137

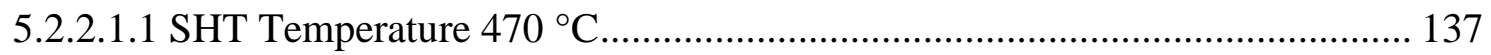

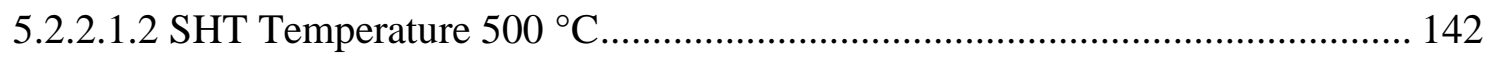

5.2.2.2 Residual Strain Development during Cooling ……………………................. 143

5.2.3 Ex-situ Residual Stress Analysis ............................................................................ 147

5.2.3.1 Residual Stress Prior to In-situ SHT ................................................................. 148

5.2.3.2 Residual Stress Following In-situ SHT ...................................................... 150

5.2.3.3 Residual Stress Following Production T4 Treatment ......................................... 153

5.3 OPTIMAL SOLUTION HEAT TREATMENT SCHEDULE ……................................... 157

Chapter 6: Conclusions .............................................................................................................. 160

6.1 CAUSE OF CYLINDER DISTORTION ………………………………………....... 160

6.2 OPTIMIZATION OF HEAT TREATMENT PARAMETERS....................................... 161

6.3 CONTRIBUTIONS OF DISSERTATION ................................................................ 163

Chapter 7: Recommendations for Future Work........................................................................... 164

Appendix A: Summary of Heat Treatment Conditions for the 319 Al Alloy ........................ 165

Appendix B: Uncertainty Calculations for Neutron Diffraction Residual Strain and Stress

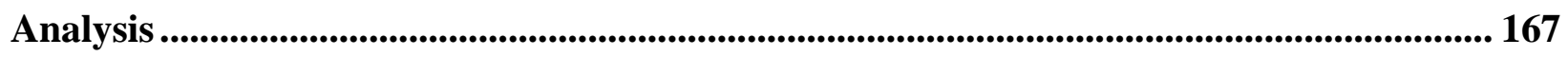

Appendix C: Cooling Curves for Replicating Billet Casting Solidification............................ 170

Appendix D: Thermal Profiles of Billet Casting Heat Treatment Cycle ................................. 172

Appendix E: Engine Block Heating Profiles during In-situ Neutron Diffraction ................ 175

E.1 HEAT TRANSFER SIMULATION OF ENGINE HEAT-UP ........................................ 176

E.2 HEAT TREATMENT TEMPERATURE PROFILE …………………………........... 177 
Appendix F: Calculations of Confidence Limits of Estimated Mean Values ........................ 179

Appendix G: Al Alloy Phase Diagrams.............................................................................................. 181

Appendix H: Calculation of Shear Stress using Mohr's Circle .................................................. 185

Appendix I: Academic Achievements .................................................................................... 187

I.1 PEER-REVIEWED JOURNAL PUBLICATIONS ………………………………....... 188

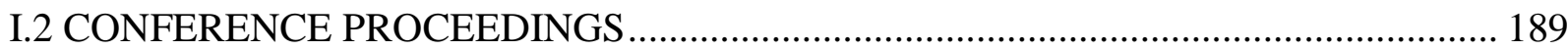

I.3 CONFERENCE PRESENTATIONS ........................................................................ 190

I.4 SCHOLARSHIPS, AWARDS AND FELLOWSHIPS ................................................... 191

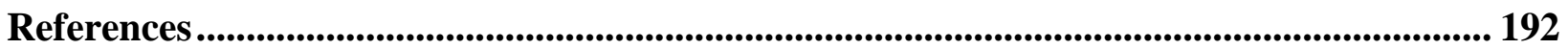




\section{List of Tables}

Table 2.1 List of reactions during solidification of A319 Al alloy containing $0.08 \mathrm{wt} \% \mathrm{Mg}$ [10]. 6 Table 2.2: List of reactions during solidification of A319 Al alloy containing $0.6 \mathrm{wt} \% \mathrm{Mg}$ [10]. 6 Table 3.1: Composition for the top of the cylinder bridge for modified 319 engine blocks (wt \%).

Table 3.2: Composition for the bottom of the cylinder bridge for modified 319 engine blocks (wt \%)

Table 3.3: Current parameters used for heat treatment and service testing of the aluminum engine blocks. 42

Table 3.4: Metallographic polishing procedure 45

Table 3.5: Abrasive grinding procedure used to produce thin plate samples for TEM analysis. . 46

Table 3.6: Optimized parameters used in twin-jet electropolishing. 46

Table 3.7: Parameters used in preliminary experiments to replicate the microstructure of the engine block cylinder bridge.

Table 3.8: Parameters used to produce replicating billet castings for each engine cylinder location. 53

Table 3.9: Proposed experimental solution heat treatment schedules. 54

Table 3.10: Experimental parameters for the heating of the cylinder bridge.

Table 3.11: Identity and location of thermocouples controlling heaters via PID temperature controllers.

Table 4.1: Summary of SDAS along the Al cylinder bridge of the distorted and undistorted engine blocks.

Table 4.2: Results from quantitative phase analysis of $\mathrm{Al}_{2} \mathrm{Cu}$ in the distorted and undistorted engine blocks.

Table 5.1: Estimated residual stresses in principal direction along with maximum shear stress and normalized shear stress for each heat treatment time (SHT $470{ }^{\circ} \mathrm{C}$ ).

Table 5.2: Recommended (optimal) heat treatment schedule for engine block production...... 158 Table A.1: Summary of microstructure and properties associated to each heat treatment condition in the $319 \mathrm{Al}$ alloy. 166 


\section{List of Figures}

Figure 1.1: Cross-section of engine cylinder illustrating the blow-by phenomenon during operation [3].

Figure 2.1: Schematic showing the production of Al engine blocks using the Nemak-Cosworth Process [8] 4

Figure 2.2: Optical micrograph showing Al-Si eutectic morphology: (a) unmodified, (b) partially modified, (c) fully modified [14].

Figure 2.3: Backscattered electron image of $\mathrm{Mg}$-free $319 \mathrm{Al}$ alloy showing morphology of:

(a) eutectic $\mathrm{Al}_{2} \mathrm{Cu}$, (b) blocky $\mathrm{Al}_{2} \mathrm{Cu}$ [12]. 8

Figure 2.4: Backscattered electron image showing the morphology of blocky $\mathrm{Al}_{2} \mathrm{Cu}$ in clusters with blocky $\mathrm{Al}_{5} \mathrm{Mg}_{8} \mathrm{Cu}_{2} \mathrm{Si}_{6}[21]$.

Figure 2.5: Backscattered electron images showing morphology of: (a) $\beta-\mathrm{Al}_{5} \mathrm{FeSi}$,

(b) $\alpha-\mathrm{Al}_{15}(\mathrm{Fe}, \mathrm{Mn})_{3} \mathrm{Si}_{2}$ [26]

Figure 2.6: Influence of solutionizing temperature and time on dissolution of $\mathrm{Al}_{2} \mathrm{Cu}$ in $\mathrm{Mg}$-free $319 \mathrm{Al}$ alloy [35].

Figure 2.7: Amount of dissolved $\mathrm{Cu}$ in $\mathrm{Al}$ matrix showing influence of SDAS and solutionizing time on dissolution of $\mathrm{Al}_{2} \mathrm{Cu}$ [41]. 14

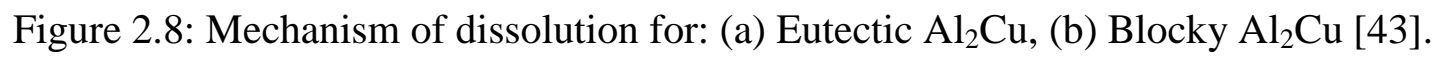
15

Figure 2.9: Incipient melting in: (a) Mg-free 319 Alloy [48], (b) 319 alloy containing 0.3 wt\% $\mathrm{Mg}$ [48]. (c) Backscattered electron image of eutectic cluster resulting from incipient melting in Al-Si-Cu-Mg alloys [49].

Figure 2.10: Schematic showing tensile strength of 319 alloy as a function of solutionizing temperature [47].

Figure 2.11: Precipitation sequence and structure of precipitates formed during aging of Al-Cu alloys. [55]. 20

Figure 2.12: Morphology of $\theta$ ' precipitates for $319 \mathrm{Al}$ alloy following aging at: (a) $190{ }^{\circ} \mathrm{C} / 5 \mathrm{~h}$ (T6 condition), (b) $260^{\circ} \mathrm{C} / 3 \mathrm{~h}$ (T7 condition) [59]. 22

Figure 2.13: Effect of artificial aging on mechanical properties of: (a) $319 \mathrm{Al}$ alloy, (b) $\mathrm{Mg}$ bearing $319 \mathrm{Al}$ alloy [9]. 23

Figure 2.14: (a) Dimensional growth of heat treated W319 aluminum alloy while exposed to $180{ }^{\circ} \mathrm{C}[6]$, (b) Dimensional change due to the formation of precipitates during aging of $\mathrm{Al}-\mathrm{Cu}$ alloys [5].

Figure 2.15: Effect of pre-quenching component temperature on surface residual stress

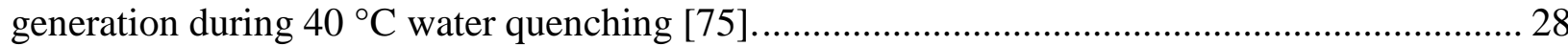

Figure 2.16: Residual stress profile with depth from the surface following quenching [76] ...... 29 Figure 2.17: In-situ neutron diffraction measuring residual hoop strain development during casting of $319 \mathrm{Al}$ alloy containing tubular steel insert [79] ..................................................... 30 Figure 2.18: Finite element model showing residual stress profiles in Al engine block following SHT and quenching [80].... 31 
Figure 2.19: Relief of residual stress as a function of time and temperature during artificial aging of $319 \mathrm{Al}$ alloy [72]. 34

Figure 2.20: Transient relief of residual stress, measured using in-situ neutron diffraction for artificial aging of RR1000 Ni-based superalloy [83]. 35

Figure 2.21: Transient relief of residual stress, measured using in-situ neutron diffraction for post-welding annealing heat treatment of a steel pipe [85]. 35

Figure 2.22: Residual stress profiles for V6 Al alloy engine blocks in: (a) as-cast, (b) T7 heat treated conditions [89]. 36

Figure 3.1: Flow chart showing the proposed analysis to be carried out during this study......... 40 Figure 3.2: (a) Image showing the side view of a gray iron cylinder liner used in the engine blocks, (b) optical micrograph showing the Al-Fe liner interface. 42 Figure 3.3: Top view of the $319 \mathrm{Al}$ alloy engine block indicating analyzed locations and cylinder numbering. 43

Figure 3.4: Cross-section of the cylinder bridge showing sections analyzed along the cylinder depth. 44

Figure 3.5: Schematic of conventional constant flux neutron diffraction spectrometer [94]...... 48 Figure 3.6: Engine block orientation relative to the incident (I) and diffracted (D) neutron beams for: (a) hoop orientation, (b) radial orientation, and (c) axial orientation. The "scattering vector" (Q) is also shown. 50

Figure 3.7: Schematic showing the measured principle stress and strain directions relative to the cylinder axis. 50

Figure 3.8: Image showing dimensioned model of billet mould used in this study (dimensions in

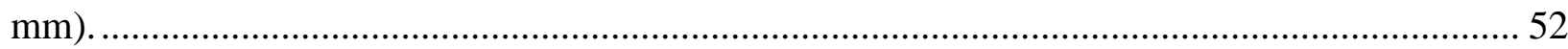

Figure 3.9: Schematic showing the analyzed locations in the billet castings. ........................... 53

Figure 3.10: Experimental setup for in-situ analysis of $\mathrm{d}_{0}$ during solution heat treatment. ......... 56

Figure 3.11: Components of heating system for in-situ neutron diffraction experiment............. 58

Figure 3.12: Image showing engine block equipped with heating coils and strip heaters........... 58 Figure 3.13: Schematic showing thermocouple locations in the engine block for in-situ neutron

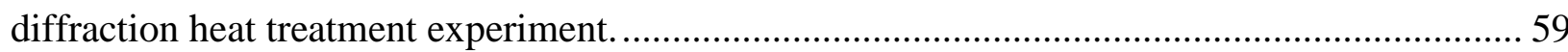
Figure 3.14: Schematic showing boundary locations and conditions in the computational domain (dimensions in $\mathrm{mm}$ ). 64

Figure 4.1: Results from CMM measurements along the cylinders of distorted and undistorted engine blocks showing: (a) maximum radial distortion, (b) roundness. 66 Figure 4.2: Optical micrographs (50x) showing the dendritic structure for undistorted (a, c and e) and distorted (b, d and f) engine blocks: (a) and (b) top of cylinder, (c) and (d) middle of cylinder, (e) and (f) bottom of cylinder. 68 Figure 4.3: Backscattered electron images of the cylinder bridge for: (a) undistorted top (200x), (b) distorted top (200x), (c) undistorted bottom (200x), (d) distorted bottom (200x). 69 Figure 4.4: (a) BF TEM image of the undistorted engine block (12000x), (b) BF TEM image of the distorted engine block (12000x), (c) EDX point spectrum of Al-Cu platelet precipitates 
(d) BF TEM image of rod-shaped precipitates where EDX was carried out (20000x), (e) EDX point analysis of rod-shaped precipitate.

Figure 4.5: Results from tensile testing for the middle of the aluminum cylinder bridge and gray iron liners of service tested engine blocks. 73

Figure 4.6: Residual strain profiles for the aluminum cylinder bridge of: (a) undistorted engine block, (b) distorted engine block. 75

Figure 4.7: Residual stress profiles for the aluminum cylinder bridge of: (a) undistorted engine block, (b) distorted engine block.

Figure 4.8: Residual strain profiles for the gray iron cylinder liners of: (a) undistorted engine block, (b) distorted engine block.

Figure 4.9: Residual stress profiles for the gray iron cylinder liners of: (a) undistorted engine block, (b) distorted engine block.

Figure 5.1: Optical micrographs showing dendritic structure of: (a) top of cylinder, (b) billet casting $\mathrm{CR}=1.5^{\circ} \mathrm{C} / \mathrm{s}$, (c) middle of cylinder, (d) billet casting $\mathrm{CR}=3.8^{\circ} \mathrm{C} / \mathrm{s}$, (e) bottom of cylinder, (f) billet casting $\mathrm{CR}=12.5^{\circ} \mathrm{C} / \mathrm{s}$.

Figure 5.2: SDAS measurements along the engine block cylinder bridge and the Al alloy billet castings. 88

Figure 5.3: Correlation between CR during solidification and SDAS.

Figure 5.4: Optical micrographs of Al-Si eutectic morphology of: (a) top of cylinder, (b) billet casting $\mathrm{CR}=1.5^{\circ} \mathrm{C} / \mathrm{s}$, (c) middle of cylinder, (d) billet casting $\mathrm{CR}=3.8^{\circ} \mathrm{C} / \mathrm{s}$, (e) bottom of cylinder, (f) billet casting $\mathrm{CR}=12.5^{\circ} \mathrm{C} / \mathrm{s}$.

Figure 5.5: Backscattered electron images of engine block cylinder bridge: (a) top, (b) middle, (c) bottom, (d) bottom near interface between $\mathrm{Al}$ cylinder bridge and gray iron liner. 93 Figure 5.6: Backscattered electron images of billet castings: (a) as-cast CR $1.5^{\circ} \mathrm{C} / \mathrm{s}$, (b) TSR CR $1.5^{\circ} \mathrm{C} / \mathrm{s}$, (c) as-cast CR $3.8^{\circ} \mathrm{C} / \mathrm{s}$, (d) TSR CR $3.8^{\circ} \mathrm{C} / \mathrm{s}$, (e) as-cast CR $12.5^{\circ} \mathrm{C} / \mathrm{s}$, (f) TSR CR $12.5^{\circ} \mathrm{C} / \mathrm{s}$.

Figure 5.7: Results from image analysis showing the cylinder bridge and billet casting volume fraction of: (a) $\mathrm{Al}_{2} \mathrm{Cu}$, (b) $\mathrm{Al}_{17}(\mathrm{Fe}, \mathrm{Mn})_{4} \mathrm{Si}_{2}$.

Figure 5.8: Results from porosity measurements for engine block cylinder bridge and billet castings using: (a) Archimedes' principle, (b) image analysis.

Figure 5.9: Results from tensile testing of the billet castings and engine block showing: (a) yield strength, (b) ultimate tensile strength.

Figure 5.10: Backscattered electron images of the fracture surface for: (a) middle of cylinder bridge, (b) higher magnification image of middle cylinder section, (c) billet replicating middle of cylinder, (d) higher magnification image of billet replicating middle of cylinder, (e) EDX analysis of inclusions in billet castings.

Figure 5.11: Backscattered electron images for billets replicating: (a), (c), (e) top, middle and bottom of the cylinder; TSR condition, (b), (d), (f) top, middle and bottom of the cylinder; solutionized at $470{ }^{\circ} \mathrm{C}$. 
Figure 5.12: Eutectic Si morphology following SHT at $500{ }^{\circ} \mathrm{C} / 8 \mathrm{~h}$ for the billets replicating (a) top of the cylinder, (b) middle of the cylinder, (c) bottom of the cylinder. 103 Figure 5.13: Backscattered electron images for solutionized billet castings $\left(500{ }^{\circ} \mathrm{C}\right)$ replicating: (a) Top, (b) Middle, and (c) Bottom of cylinder, (d) Higher magnification image showing $\mathrm{Al}_{2} \mathrm{Cu}$ dissolution. 105

Figure 5.14: Volume fraction of $\mathrm{Al}_{2} \mathrm{Cu}$ following solution heat treatment at $500{ }^{\circ} \mathrm{C}$ for various time intervals. 106 Figure 5.15: Optical micrographs for billets replicating: (a), (c), (e) top, middle and bottom of the cylinder; solutionized at $515^{\circ} \mathrm{C}$, (b), (d), (f) top, middle and bottom of the cylinder; solutionized at $530{ }^{\circ} \mathrm{C}$. 108

Figure 5.16: Backscattered electron images for billets replicating: (a), (c), (e) top, middle and bottom of the cylinder; solutionized at $515^{\circ} \mathrm{C}$, (b), (d), (f) top, middle and bottom of the cylinder; solutionized at $530{ }^{\circ} \mathrm{C}$. 109

Figure 5.17: Higher magnification images showing ultra-fine eutectic (UFE) morphology..... 110 Figure 5.18: (a) Backscattered electron image showing location of line scan in UFE region; EDX linescan results along the UFE region for: (b) $\mathrm{Al}$, (c) $\mathrm{Cu}$, (d) $\mathrm{Mg}$, (e) Si. 112 Figure 5.19: (a) Higher magnification backscattered electron image showing intertwining of $\mathrm{Al}_{2} \mathrm{Cu}$ and $\mathrm{Al}_{17}(\mathrm{Fe}, \mathrm{Mn})_{4} \mathrm{Si}_{2}$, (b) EDX spectrum showing composition of $\mathrm{Al}_{17}(\mathrm{Fe}, \mathrm{Mn})_{4} \mathrm{Si}_{2}$ with intertwined $\mathrm{Al}_{2} \mathrm{Cu}$, (c) EDX spectrum showing composition of $\mathrm{Al}_{17}(\mathrm{Fe}, \mathrm{Mn})_{4} \mathrm{Si}_{2}$ without intertwined $\mathrm{Al}_{2} \mathrm{Cu}$.

Figure 5.20: Volume fraction of $\mathrm{Al}_{2} \mathrm{Cu}$ following solution heat treatment at: (a) $515{ }^{\circ} \mathrm{C}$, (b) $530{ }^{\circ} \mathrm{C}$.

Figure 5.21: DSC analysis of billet castings replicating: (a) top of cylinder $\left(\mathrm{CR}-1.5^{\circ} \mathrm{C} / \mathrm{s}\right)$, (b) middle of cylinder $\left(\mathrm{CR}-3.8^{\circ} \mathrm{C} / \mathrm{s}\right)$, (c) bottom of cylinder $\left(\mathrm{CR}-12.5^{\circ} \mathrm{C} / \mathrm{s}\right)$.....

Figure 5.22: Results from tensile testing of billet castings subjected to solution heat treatment at $500{ }^{\circ} \mathrm{C}$ : (a) YS, (b) UTS. 120

Figure 5.23: Results from tensile testing: (a) YS of billets SHT at $515^{\circ} \mathrm{C}$, (b) YS of billets SHT at $530{ }^{\circ} \mathrm{C}$, (c) UTS of billets SHT at $515^{\circ} \mathrm{C}$, (d) UTS of billets SHT at $530{ }^{\circ} \mathrm{C}$ 122 Figure 5.24: SEM BSE image of fracture surface for billets replicating middle of cylinder solutionized at: (a) $500{ }^{\circ} \mathrm{C}$, (b) $530{ }^{\circ} \mathrm{C}$. 124 Figure 5.25: Higher magnification BSE image showing UFE morphology for billets solutionized at $530{ }^{\circ} \mathrm{C}$ 125

Figure 5.26: BSE image showing fracture surface of billets replicating bottom of cylinder solutionized $530{ }^{\circ} \mathrm{C}$. 126 Figure 5.27: Backscattered electron images of the top and bottom of cylinder bridge, respectively for: (a) and (b) TSR condition, (c) and (d) SHT $470{ }^{\circ} \mathrm{C}$, (e) and (f) SHT $500{ }^{\circ} \mathrm{C}$, (g) and (h) SHT $530{ }^{\circ} \mathrm{C}$. 129

Figure 5.28: Quantitative image analysis showing volume fraction of $\mathrm{Al}_{2} \mathrm{Cu}$. 130 Figure 5.29: WDS analysis showing the composition of the aluminum matrix following solution heat treatment for (a) top of cylinder, (b) bottom of cylinder. 132 
Figure 5.30: Influence of thermal expansion on $\mathrm{d}_{0}$ for the (311) and (331) planes during solution heat treatment.

Figure 5.31: Variation in $\mathrm{d}_{0}$ with time at each solutionizing temperature for (a) (311) plane - top of cylinder, (b) (311) plane - bottom of cylinder, (c) (331) plane - top of cylinder, (d) (331) plane - bottom of cylinder.

Figure 5.32: Axial residual strain relief as a function of time during solution heat treatment of $\mathrm{Al}$ engine blocks.

Figure 5.33: Creep Deformation-mechanism maps for pure Al with grain size of $1000 \mu \mathrm{m}$ [112].

Figure 5.34: Axial residual strain development as a function of temperature during post-heat treatment cooling.

Figure 5.35: Qualitative representation of creep rate using the temperatures and residual stress levels from neutron diffraction in the creep equation.

Figure 5.36: Residual stress profiles for: (a) TSR A, (b) TSR B

Figure 5.37: Residual stress profiles for the engine blocks following SHT at (a) $470{ }^{\circ} \mathrm{C}$,

(b) $500{ }^{\circ} \mathrm{C}$.

Figure 5.38: Residual stress profiles along cylinder bridge of $\mathrm{Al}$ engine blocks solutionized with production heat treatment and quenching schedule.

Figure 5.39: (a) Results from CFD simulation showing temperature profiles at the end $(\sim 3$ minutes) of the forced air quenching process, (b) simulated cooling rate of the (4-6) cylinder bridge during quenching.

Figure B.1: Sample of diffraction data obtained for the Al (331) plane using neutron diffraction.

Figure C.1: Cooling curves during solidification of the billets replicating: (a) top of cylinder,

(b) middle of cylinder, (c) bottom of cylinder. 171

Figure D.1: Representative billet casting simulated TSR treatment cycle. 173

Figure D.2: Representative billet casting solution heat treatment and quenching cycle........... 173

Figure D.3: Representative billet casting T7 aging cycle. 174

Figure E.1: Engine block model showing heater locations and magnitude of heat flux for finite volume conduction heat-up simulation...................................................................... 176

Figure E.2: Result from Finite Volume Conduction Simulation for $1 \mathrm{~h}$ of heating. .................. 176 Figure E.3: Comparison between experimental and simulated engine heat up at the (4-6) cylinder bridge. 177

Figure E.4: Temperature profiles for the $470{ }^{\circ} \mathrm{C}$ in-situ heat treatment experiment at the engine locations outlined in Figure 3.13. 177

Figure E.5: Temperature profiles for the $500{ }^{\circ} \mathrm{C}$ in-situ heat treatment experiment at the engine locations outlined in Figure 3.13. 178

Figure E.6: Temperature profile of the (4-6) cylinder bridge during post-SHT cooling........... 178

Figure H.1: Sample 3-D Mohr's circle plot for residual stress state. 186 


\section{Nomenclature}

\section{Greek}

\section{Units}

$\alpha$

$\Delta \varepsilon$

$\varepsilon_{0}$

$\varepsilon_{\mathrm{H}}$

$\varepsilon_{\mathrm{R}}$

$\varepsilon_{\mathrm{A}}$

$\varepsilon_{\mathrm{T}}$

$\theta$

$\theta$,

$\theta "$

$\lambda$

v

$\rho$

$\sigma_{0}$

$\sigma_{\mathrm{H}}$

$\sigma_{\mathrm{R}}$

$\sigma_{\mathrm{A}}$

$\tau_{\mathrm{ij}}$

$\tau_{\mathrm{ij}}^{\mathrm{R}}$

$\tau_{\max }$

$2 \varphi$

\section{English}

$\mathrm{d}_{\mathrm{hk}}$

$\mathrm{d}_{\text {0hkl }}$

CR

$\mathrm{D}_{0}$

E

$\mathrm{h}$

$\mathrm{L}_{\mathrm{p}}$

$\mathrm{N}_{\mathrm{s}}$
Coefficient of Thermal Expansion

Difference in Thermo-mechanical Strain due to Temperature

Initial Residual Strain

Residual Hoop Strain Component

Residual Radial Strain Component

Residual Axial Strain Component

Turbulent Dissipation

Equilibrium Age Hardening Precipitate in $\mathrm{Cu}$ Containing Al Alloys

Semi-coherent Age Hardening Precipitate in Cu Containing Al Alloys

Coherent Age Hardening Precipitate in $\mathrm{Cu}$ Containing Al Alloys

Wavelength

Poisson's Ratio

Fluid Density

Initial Residual Stress

Residual Hoop Stress Component

Residual Radial Stress Component

Residual Axial Stress Component

Viscous Shear Stress Tensor

Reynolds Stress Tensor for Turbulent Flow

Maximum Shear Stress

Angle of Diffraction
$\mathrm{K}^{-1}$

$\mathrm{mm} / \mathrm{mm}$

$\mathrm{mm} / \mathrm{mm}$

$\mathrm{mm} / \mathrm{mm}$

$\mathrm{mm} / \mathrm{mm}$

$\mathrm{mm} / \mathrm{mm}$

$\AA$

$\mathrm{g} / \mathrm{cm}^{3}$

$\mathrm{MPa}$

$\mathrm{MPa}$

MPa

$\mathrm{MPa}$

$\mathrm{MPa}$

$\mathrm{MPa}$

$\mathrm{MPa}$

degree

Units

Interplanar Spacing of Specimen

Interplanar Spacing of Stress Free Specimen

Á

$\AA$

${ }^{\circ} \mathrm{C} / \mathrm{s}$

Cooling Rate

$\mathrm{m}^{2} / \mathrm{s}$

$\mathrm{GPa}$

J

$\mu \mathrm{m}$

Length of Primary Dendrite

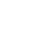




\section{Elements and Intermetallics}

$\mathrm{Al}$

$\mathrm{Al}_{2} \mathrm{Cu}$

$\mathrm{Al}_{5} \mathrm{Mg}_{8} \mathrm{Cu}_{2} \mathrm{Si}_{6}$ $\mathrm{Al}_{15}(\mathrm{Fe}, \mathrm{Mn})_{3} \mathrm{Si}_{2}$ $\mathrm{Al}_{5} \mathrm{FeSi}$

$\mathrm{Al}_{17}(\mathrm{Fe}, \mathrm{Mn})_{4} \mathrm{Si}_{2}$

$\mathrm{Cr}$

$\mathrm{Cu}$

$\mathrm{Fe}$

$\mathrm{Ge}$

$\mathrm{Mg}$

$\mathrm{Mg}_{2} \mathrm{Si}$

$\mathrm{Mn}$

$\mathrm{Ni}$

$\mathrm{Si}$

$\mathrm{Sn}$

$\mathrm{Sr}$

$\mathrm{Ti}$
Aluminum

$\mathrm{Al}-\mathrm{Cu}$ based intermetallic compound in $319 \mathrm{Al}$ alloys

$\mathrm{Al}-\mathrm{Mg}-\mathrm{Cu}-\mathrm{Si}$ based intermetallic compound in $319 \mathrm{Al}$ Alloys

Al-Fe-Mn-Si based intermetallic compound in 319 Al Alloys

Al-Fe-Si based intermetallic compound in 319 Al Alloys

Al-Fe-Mn-Si based intermetallic compound in 319 Al Alloys

Chromium

Copper

Iron

Germanium

Magnesium

Mg-Si based intermetallic compound in $319 \mathrm{Al}$ alloys

Manganese

Nickel

Silicon

Tin

Strontium

Titanium
Abbreviations
BFTEM
Bright Field Transmission Electron Microscopy
BSE
Backscattered Electron
CAFE
Corporate Average Fuel Economy
CALPHAD
Calculation of Phase Diagram Modelling
$\mathrm{CCD}$
Charge-coupled device 


\begin{tabular}{|c|c|}
\hline CFD & Computational Fluid Dynamics \\
\hline DSC & Differential Scanning Calorimetry \\
\hline Dyno & Dynamometer \\
\hline EDX & Energy Dispersive X-ray Spectroscopy \\
\hline FCC & Face Centred Cubic \\
\hline G.P. Zones & Guinier-Preston Zones \\
\hline ND & Neutron Diffraction \\
\hline OEM & Original Equipment Manufacturer \\
\hline $\mathrm{OM}$ & Optical Microscopy \\
\hline PID & Proportional-Integral-Derivative \\
\hline RPM & Revolutions per minute \\
\hline SDAS & Secondary Dendrite Arm Spacing \\
\hline SEM & Scanning Electron Microscopy \\
\hline SHT & Solution Heat Treatment \\
\hline SSSS & Super Saturated Solid Solution \\
\hline $\mathrm{T} 4$ & Solution Heat Treated and Naturally Aged \\
\hline T6 & Solution Heat Treated and Artificially Aged to Peak Strength \\
\hline $\mathrm{T} 7$ & Solution Heat Treated and Stabilized by (Artificial) Overaging \\
\hline TEM & Transmission Electron Microscopy \\
\hline $\mathrm{TC}$ & Thermocouple \\
\hline TSR & Thermal Sand Reclamation \\
\hline UFE & Ultra Fine Eutectic \\
\hline UTS & Ultimate Tensile Strength \\
\hline WDS & Wavelength Dispersive X-ray Spectroscopy \\
\hline XRD & X-ray Diffraction \\
\hline YS & Yield Strength \\
\hline
\end{tabular}




\section{Chapter 1: Introduction}

Development of light weight powertrain components utilizing low density aluminum (Al) alloys $\left(2.7 \mathrm{~g} / \mathrm{cm}^{3}\right)$ have increasingly replaced ferrous materials such as steels and cast irons $\left(7.8 \mathrm{~g} / \mathrm{cm}^{3}\right)$ [1] in order to meet both consumer demand for more fuel efficient vehicles and stricter government legislation on emissions. In the United States (similar standards worldwide), new government legislation mandates that automotive original equipment manufacturers (OEMs) must have a corporate average fuel economy (CAFE) of $6.63 \mathrm{~L} / 100 \mathrm{~km}$ (35.5 US MPG) by 2016 and 4.32 L/100 km (54.5 US MPG) by 2025 [2]. Failure to adhere to these standards will result in exorbitant annual fines to the automotive OEMs, influencing their profit margins and by extension, the economy of areas dependent on the automotive manufacturing sector (i.e. Ontario)

Engine blocks are one particular automotive application where Al alloys have replaced ferrous alloys in recent years to effectively reduce vehicle weight and improve fuel efficiency. However, Al alloy engine blocks have been found to be susceptible to permanent dimensional distortion, during service. Distortion of the cylinder bores prevents effective sealing of the combustion chamber and causes increased leakage of air-fuel mixture during engine operation. This phenomenon is called "blow by" and is illustrated for the engine's compression and power strokes in Figure 1.1 [3].
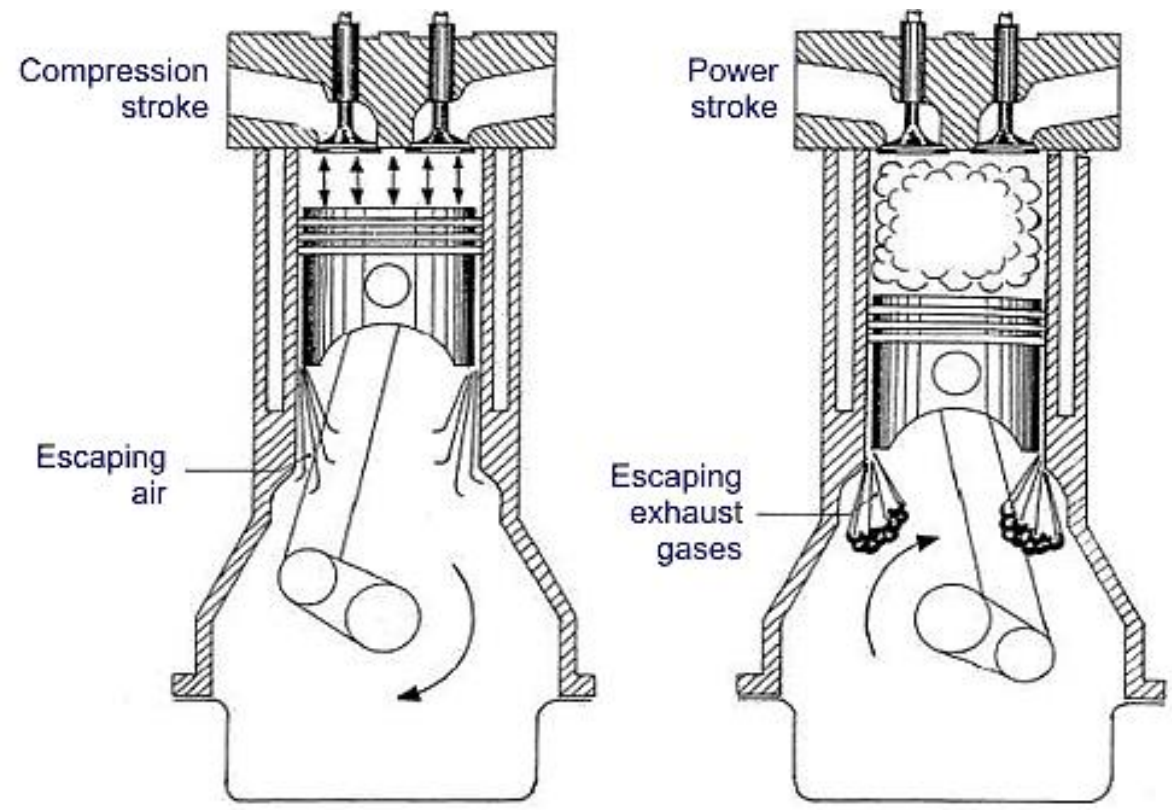

Figure 1.1: Cross-section of engine cylinder illustrating the blow-by phenomenon during operation [3]. 
Blow-by, if excessive, is very detrimental to engine operating efficiency, which reduces overall vehicle fuel efficiency and increases carbon emissions. The reduced vehicle fuel efficiency due to cylinder distortion in the engine block would counteract the effect of lightweight materials, severely increasing the OEM's probability of non-compliance to the 2025 CAFE standards. Distortion may have other economic repercussions to the automotive industry as well, since this issue would result in expensive and damaging recalls. For instance, a severely distorted engine block requires complete replacement which typically has an associated cost of between 6000 and 10,000 USD per warranty replacement engine. Therefore, due to the widespread influence of potential cylinder distortion on energy, environment and the economy, it is necessary to determine the cause of cylinder distortion, allowing for preventative measures to be implemented in production.

Permanent dimensional distortion of heat treatable $\mathrm{Al}$ alloys has been postulated to occur either by phase transformation of precipitates amenable to heat treatment during elevated temperature exposure $\left(\sim 200{ }^{\circ} \mathrm{C}\right)[4-6]$ or due to excessive tensile residual stress relative to the alloy yield strength. In typical Al engine blocks, gray iron cylinder liners, inserted to mitigate the poor wear resistance properties of hypoeutectic Al-Si alloys, cause the development of large tensile residual stresses along the cylinder bore region, due to the difference in thermal expansion coefficient between these dissimilar materials. This tensile residual stress may increase the likelihood of distortion.

A potential solution to this issue is the application of an appropriate heat treatment schedule. Heat treatment, when effectively optimized, is a well-documented and cost-effective technique to increase strength, stabilize the microstructure and reduce the residual stress. Therefore, to improve the integrity of the cast engine block and mitigate potential problems (loss of efficiency, increased emissions and recall costs) for the automotive industry, there is a need to develop a scientific explanation for the cause of cylinder distortion and optimize the heat treatment parameters in order to prevent its formation as well as reduce part manufacturing costs. The objective of this dissertation is to extend the understanding on the relationship between process variables (casting and heat treatment parameters), microstructure, mechanical properties and residual stress with a view to connecting these with the occurrence of macro-distortion. This will enable the effective development and implementation of preventative measures. 
This dissertation has been structured as follows.

Chapter 2 presents a comprehensive literature review that disseminates the state-of-the art knowledge on the $319 \mathrm{Al}$ alloy, precipitation hardening heat treatment processes and residual stress formation and relief during elevated temperature exposure. This chapter also reviews the mechanisms associated with distortion in $\mathrm{Al}$ alloy components.

Chapter 3 outlines the experimental methodology, including casting and heat treatment parameters and the characterization techniques that were be used in this research. This chapter also provides details on the in-situ and ex-situ neutron diffraction experiments (specimen preparation and experimental methodology). Finally, the governing equations and modeling parameters are described for computational fluid dynamics (CFD) simulations of the production forced air quenching process.

Chapter 4 presents the results from the investigation "Determining the Mechanism of Cylinder Distortion". The results include microstructural characterization, assessment of mechanical properties and ex-situ neutron diffraction residual stress profiles for distorted and undistorted engine blocks. This chapter includes the proposed mechanism for cylinder distortion.

Chapter 5 presents the results from "Optimization of Solution Heat Treatment Parameters". The results include microstructural characterization and assessment of mechanical properties for various solution heat treatment parameters using replicating lab-scale billet castings. Further, this chapter presents the results from in-situ and ex-situ neutron diffraction which measures the relief of residual strain as a function of time during solution heat treatment and the subsequent residual stress magnitude following heat treatment. The optimal heat treatment parameters which reduce the susceptibility to potential cylinder distortion are also proposed.

Chapter 6 outlines the major conclusions drawn from this study, while Chapter 7 provides recommendations for future work. 


\section{Chapter 2: Literature Review}

This chapter begins with an introduction to the Cosworth casting process and the Al-Si-Cu 319 type alloy system with respect to its microstructure and phase formation sequence (Sections 2.1 and 2.2, respectively). This is followed by a detailed discussion of solution heat treatment (SHT) and aging for this alloy with regards to the temperature and time required in each process to result in microstructural modification, improved mechanical properties and improved dimensional stability (Section 2.3). The chapter concludes with a detailed discussion related to the mechanisms of residual stress development during thermal processing and those attributed to the relief of residual stress (Section 2.4). These mechanisms are related to residual stresses in Al alloy engine blocks containing gray iron cylinder liners and proposed as a potential cause for inservice cylinder distortion.

\subsection{Cosworth Casting Process}

The Cosworth process is a specialized low pressure casting process designed solely to produce engine blocks. It utilizes precision sand moulds, which uses a chemical binder, enabling higher mould rigidity, reduced machining allowances (due to improved dimensional precision) and a more compact gating system compared to green sand moulding (improving casting yield) [7]. This enables the production of high quality, dimensionally accurate castings. The Cosworth process differs from other casting techniques in that the mould is rotated $180^{\circ}$ upon completion of filling [8]. A schematic of the modified Nemak-Cosworth casting process (which includes an integral chill plate in the bulkhead region of the engine block) is shown in Figure 2.1.

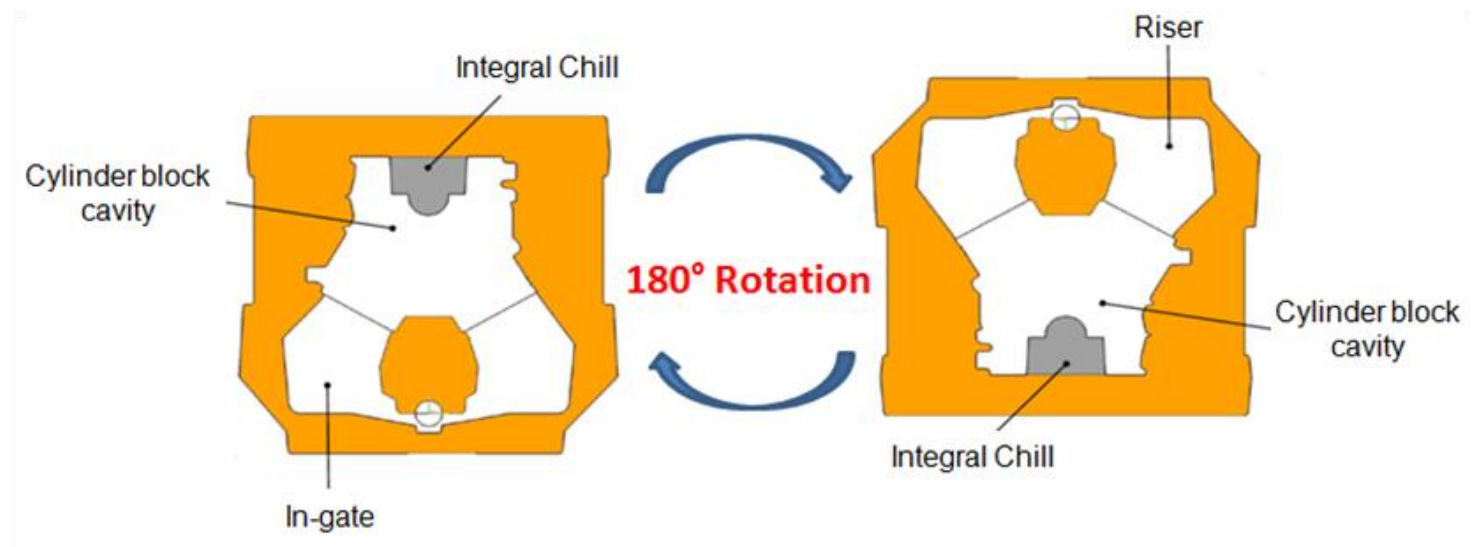

Figure 2.1: Schematic showing the production of Al engine blocks using the Nemak-Cosworth Process [8]. 
The main advantage of the Cosworth process is that it allows for improved feeding of liquid metal into the casting cavity. While bottom-gated moulds are essential to eliminate turbulence, the main draw-back with traditional casting techniques is that the hottest metal remains at the bottom of the mould. This prevents effective feeding from the gating system, resulting in casting defects such as shrinkage porosity [8]. Therefore, separate reservoirs of liquid metal, called risers, are often required to reduce shrinkage porosity. The Cosworth process, however, due to the $180^{\circ}$ rotation after mould filling, utilizes the in-gates as risers which can effectively feed the shrinkage [8]. This eliminates the need for additional risers throughout the casting, which increases the casting yield, thereby reducing production cost. In addition, the integral chill in the bulkhead of the engine block improves casting integrity by accelerating the cooling rate in this region. Without the chill, this region, containing thick sections, would result in low mechanical properties and excessive porosity (in a high stress area) due to the slow cooling rate.

At the completion of solidification, the Nemak-Cosworth process utilizes a thermal sand reclamation (TSR) treatment. The TSR treatment subjects the sand mould (containing the casting within) to elevated temperatures $\left(\sim 480-500^{\circ} \mathrm{C}\right)$ to remove the chemical sand binder, enabling the relatively easy extraction of the casting from the resulting loose sand. This loose sand is also collected (reclaimed) following the TSR treatment, permitting recycling of the sand for use in future castings. A side effect of the TSR treatment is that it provides a partial solution heat treatment effect for the $319 \mathrm{Al}$ alloy (used in engine block production), as seen in Section 5.1.1.3 of this dissertation.

\subsection{Microstructure of Aluminum-Silicon-Copper (319) Alloy System}

The 319 alloy is a commonly used aluminum-silicon-copper (Al-Si-Cu) alloy containing between 6-8 wt.\% Si and 3-4 wt\% Cu [1]. This alloy has good castability, attributed to the relatively high Si concentration, which increases alloy fluidity making these alloys ideal for casting components with complex geometries. In addition, the presence of $\mathrm{Cu}$ and $\mathrm{Mg}$ significantly improves alloy strength, specifically following heat treatment (discussed in Section 2.3) [9]. The microstructure of the 319 type $\mathrm{Al}$ alloy is developed in the phase formation sequence given in Tables 2.1 and 2.2, although the formation temperatures and quantities of these phases are highly dependent on alloy composition and cooling rate during solidification. 
The microstructure of the 319 alloy is composed of primary Al dendrites, Al-Si eutectic, Fe bearing intermetallics such as $\beta-\mathrm{Al}_{5} \mathrm{FeSi}$ and $\alpha-\mathrm{Al}_{15}(\mathrm{Fe}, \mathrm{Mn})_{3} \mathrm{Si}_{2}$, and eutectic and blocky $\mathrm{Al}_{2} \mathrm{Cu}$. Furthermore, in $\mathrm{Mg}$ containing $319 \mathrm{Al}$ alloys, $\mathrm{Mg}$ bearing phases, such as $\mathrm{Al}_{5} \mathrm{Mg}_{8} \mathrm{Cu}_{2} \mathrm{Si}_{6}$ and $\mathrm{Mg}_{2} \mathrm{Si}$ are present, depending on the $\mathrm{Mg}$ concentration [10]. The morphology of phases present in the microstructure of $319 \mathrm{Al}$ alloys and their influence on the mechanical properties are discussed in Sections 2.2.1-2.2.3.

Table 2.1 List of reactions during solidification of $\mathrm{A319} \mathrm{Al}$ alloy containing $0.08 \mathrm{wt} \% \mathrm{Mg}$ [10].

\begin{tabular}{|c|c|c|}
\hline $\begin{array}{l}\text { Reaction } \\
\text { Number }\end{array}$ & $\begin{array}{c}\text { Temperature } \\
\left({ }^{\circ} \mathrm{C}\right) \\
\end{array}$ & Type of Reaction \\
\hline 1 & 611.8 & formation of $\alpha$-Al dendritic network \\
\hline 2 & 600.0 to 572.7 & precipitation of pre-eutectic iron intermetallics $\left(\alpha-\mathrm{Al}_{15}(\mathrm{Fe}, \mathrm{Mn})_{3} \mathrm{Si}_{2}\right.$ and $\left.\beta-\mathrm{Al}_{5} \mathrm{FeSi}\right)$ \\
\hline 3 & 561.8 & precipitation of eutectic $\mathrm{Si}$ \\
\hline 4 & 550.0 to 541.0 & precipitation of posteutectic $\beta-\mathrm{Al}_{5} \mathrm{FeSi}$ \\
\hline 5 & 510.0 & precipitation of $\mathrm{Al}_{2} \mathrm{Cu}$ \\
\hline 6 & 502.7 & precipitation of $\mathrm{Al}_{5} \mathrm{Mg}_{8} \mathrm{Cu}_{2} \mathrm{Si}_{6}$ \\
\hline
\end{tabular}

Table 2.2: List of reactions during solidification of $\mathrm{A319} \mathrm{Al}$ alloy containing $0.6 \mathrm{wt} \% \mathrm{Mg}$ [10].

\begin{tabular}{ccl}
\hline $\begin{array}{c}\text { Reaction } \\
\text { Number }\end{array}$ & $\begin{array}{c}\text { Temperature } \\
\left({ }^{\circ} \mathrm{C}\right)\end{array}$ & \multicolumn{1}{c}{ Type of Reaction } \\
\hline 1 & 608.2 & formation of $\alpha$-Al dendritic network \\
2 & 590.0 & precipitation of pre-eutectic iron intermetallics \\
3 & 546.3 & precipitation of eutectic Si \\
4 & 526.3 & transformation of $\beta-\mathrm{Al}_{5} \mathrm{FeSi}$ into $\mathrm{Al}_{8} \mathrm{Mg}_{3} \mathrm{FeSi}_{6}$ \\
5 & 521.8 & precipitation of $\mathrm{Mg}_{2} \mathrm{Si}$ \\
6 & 501.8 & precipitation of $\mathrm{Al}_{2} \mathrm{Cu}$ \\
7 & 491.8 & precipitation of $\mathrm{Al}_{5} \mathrm{Mg}_{8} \mathrm{Cu}_{2} \mathrm{Si}_{6}$ \\
\hline
\end{tabular}

\subsubsection{Al-Si Eutectic}

The Al-Si eutectic regions consist of nearly pure silicon surrounded by aluminum, which nucleate together in the $319 \mathrm{Al}$ alloy following the formation of the primary aluminum dendrites. The eutectic silicon phase naturally appears in the microstructure as coarse acicular particles, but this morphology can be modified into smaller rod shaped particle clusters (partially modified) or a fibrous structure containing small globular Si particles (fully modified) [11-17]. The morphology of unmodified, partially modified and fully modified Al-Si eutectic is shown in Figure 2.2.

Morphological modification of the Al-Si eutectic region is achieved through the addition of modifying agents such as $\mathrm{Sr}, \mathrm{Na}$ or $\mathrm{Sb}$, or through heat treatment [11-17]. The modifying agents 
induce twins along the growth front of the Si particles, preventing long acicular Si particles by causing changes in crystallographic orientation at the twin plane $[15,17]$. As such, the change in orientation causes multiple Si particles to form in clusters rather than coarse acicular Si particles. Solution heat treatment also modifies the Al-Si eutectic structure [16], which is discussed in Section 2.3.1.
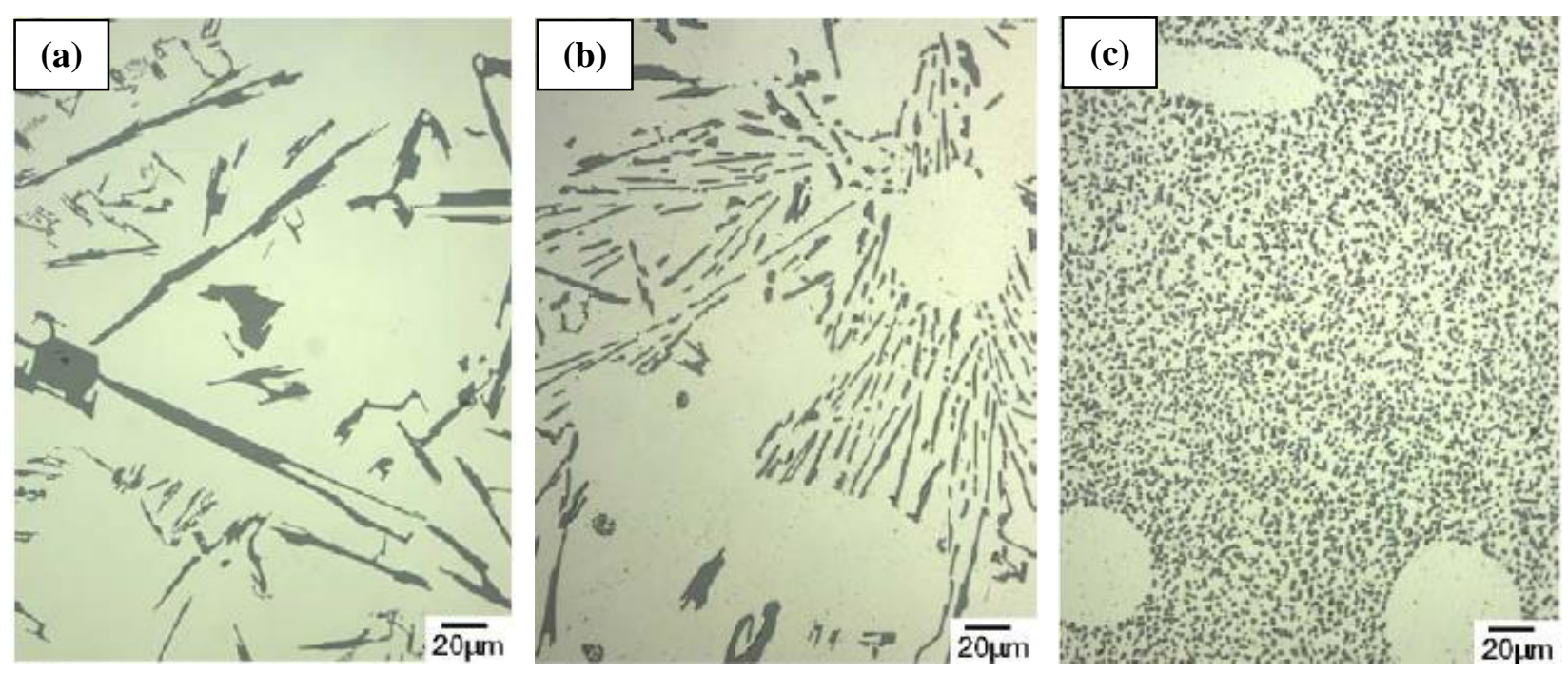

Figure 2.2: Optical micrograph showing Al-Si eutectic morphology: (a) unmodified, (b) partially modified, (c) fully modified [14].

Acicular eutectic Si particles are typically detrimental to the mechanical properties due to the inherent brittleness of this phase as well as stress concentrations occurring at the tip of the silicon needles [11, 12, 18]. Modification of the eutectic silicon morphology into a fibrous structure improves the mechanical properties by removing the stress concentration regions as well as refining the particles size. For this reason, the fully modified fibrous morphology is preferred in components made of hypoeutectic Al-Si alloys.

\subsection{2 $\mathrm{Al}_{2} \mathrm{Cu}$ and $\mathrm{Al}_{5} \mathrm{Mg}_{8} \mathrm{Cu}_{2} \mathrm{Si}_{6}$}

The addition of $\mathrm{Cu}$ to $\mathrm{Al}-\mathrm{Si}$ alloys results in the formation of the $\mathrm{Al}_{2} \mathrm{Cu}$ intermetallic compound. The presence of $\mathrm{Al}_{2} \mathrm{Cu}$ in the microstructure makes the 319 alloy heat treatable resulting in improved mechanical properties following precipitation hardening heat treatments, as will be discussed in Section 2.3. The $\mathrm{Al}_{2} \mathrm{Cu}$ intermetallic phase appears in the microstructure of $\mathrm{Mg}$-free $319 \mathrm{Al}$ alloys in the eutectic and blocky morphologies, as shown in Figure 2.3. 

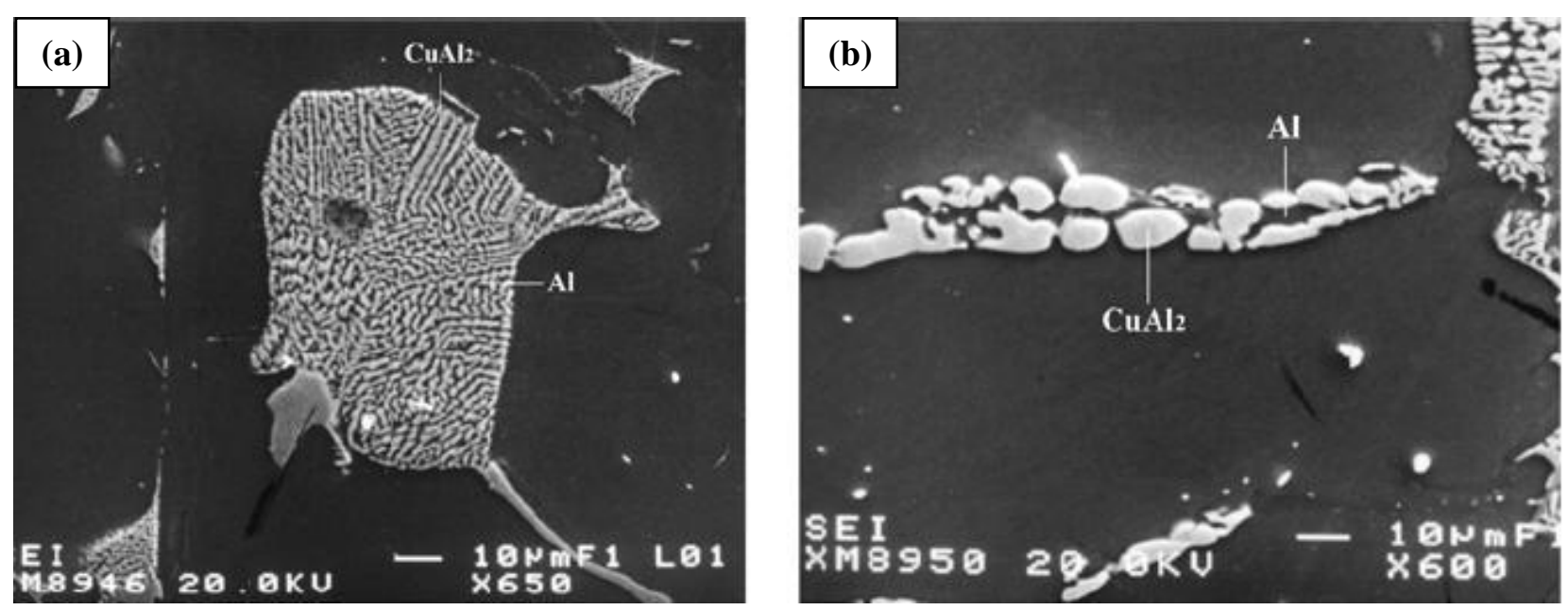

Figure 2.3: Backscattered electron image of $\mathrm{Mg}$-free $319 \mathrm{Al}$ alloy showing morphology of: (a) eutectic $\mathrm{Al}_{2} \mathrm{Cu}$, (b) blocky $\mathrm{Al}_{2} \mathrm{Cu}[12]$.

The eutectic $\mathrm{Al}_{2} \mathrm{Cu}$ morphology is characterized as an alternating lamellar structure consisting of $\mathrm{Al}_{2} \mathrm{Cu}$ and $\alpha$-Al, while blocky $\mathrm{Al}_{2} \mathrm{Cu}$ are large particles $(20-40 \mu \mathrm{m})$ embedded in the $\alpha$ - $\mathrm{Al}$ matrix. Although both morphologies of $\mathrm{Al}_{2} \mathrm{Cu}$ are usually present within the microstructure, $\mathrm{Sr}$ additions, used to modify the morphology of eutectic silicon, have been found to promote the formation of blocky $\mathrm{Al}_{2} \mathrm{Cu}$ by causing macrosegregation of $\mathrm{Cu}$ away from the Al-Si eutectic regions $[12,15]$. For instance, Sokolowski et al. [19] reported that the blocky $\mathrm{Al}_{2} \mathrm{Cu}$ - eutectic $\mathrm{Al}_{2} \mathrm{Cu}$ ratio in the 319 alloy changed from 1:3 for Sr concentration of 8 ppm to 9:1 for Sr concentration of $96 \mathrm{ppm}$.

The $319 \mathrm{Al}$ alloy system also commonly includes additions of $\mathrm{Mg}$, which increase strength and accelerate the dissolution and precipitation kinetics during heat treatment [20]. In the as-cast condition and for low $\mathrm{Mg}$ concentrations (< 0.5 wt\% $\mathrm{Mg}$ ), a quaternary $\mathrm{Al}_{5} \mathrm{Mg}_{8} \mathrm{Cu}_{2} \mathrm{Si}_{6}$ intermetallic phase forms in interdendritic regions along with small globular $\mathrm{Mg}_{2} \mathrm{Si}$ particles clustered with eutectic $\mathrm{Si}$. In contrast, higher $\mathrm{Mg}$ concentrations (>0.5 wt\% $\mathrm{Mg}$ ) results in a combination of $\mathrm{Al}_{5} \mathrm{Mg}_{8} \mathrm{Cu}_{2} \mathrm{Si}_{6}$ and Chinese script $\mathrm{Mg}_{2} \mathrm{Si}$ [10, 21-23]. Since this study focuses on 319 alloys with $\mathrm{Mg}$ concentration less than $0.5 \mathrm{wt} \%$ ( $0.35 \mathrm{wt} \%$ ), only $\mathrm{Al}_{5} \mathrm{Mg}_{8} \mathrm{Cu}_{2} \mathrm{Si}_{6}$ will be discussed. The $\mathrm{Al}_{5} \mathrm{Mg}_{8} \mathrm{Cu}_{2} \mathrm{Si}_{6}$ phase forms at the end of solidification, and according to Samuel et al. [10], grows out from $\mathrm{Al}_{2} \mathrm{Cu}$ particles. Therefore, this phase appears in clusters with blocky $\mathrm{Al}_{2} \mathrm{Cu}$ particles, as shown in Figure 2.4. 


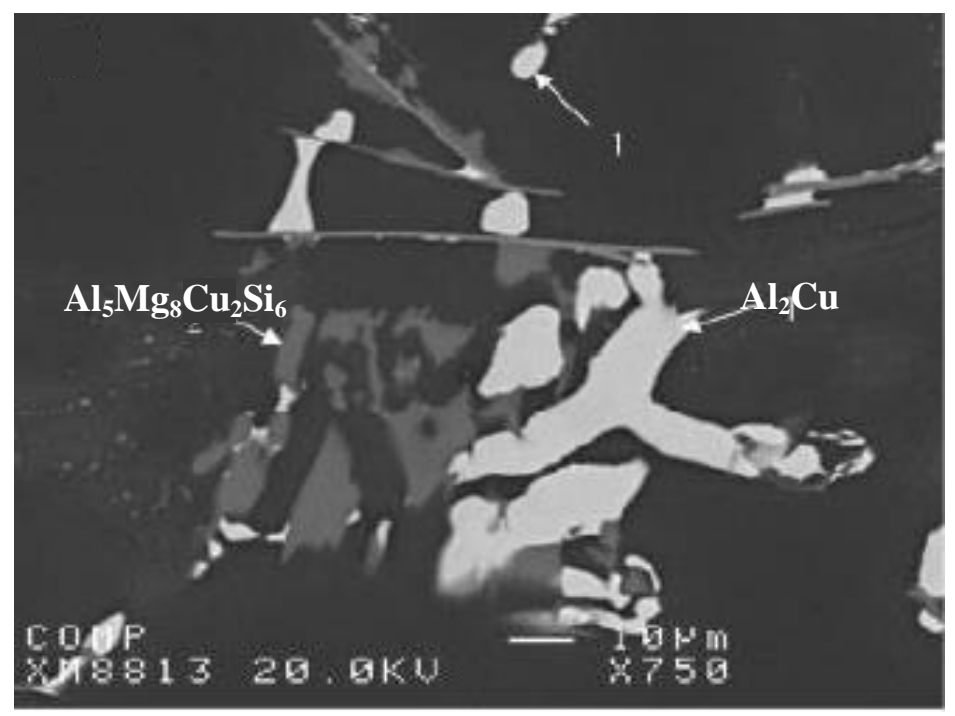

Figure 2.4: Backscattered electron image showing the morphology of blocky $\mathrm{Al}_{2} \mathrm{Cu}$ in clusters with blocky $\mathrm{Al}_{5} \mathrm{Mg}_{8} \mathrm{Cu}_{2} \mathrm{Si}_{6}[21]$.

Additions of $\mathrm{Mg}$, similar to $\mathrm{Sr}$, also promote the formation of blocky $\mathrm{Al}_{2} \mathrm{Cu}$ [10, 21-24]. Previous research by Samuel et al. [10] found that $\mathrm{Mg}$ concentrations of $1.2 \mathrm{wt} \%$ or above resulted in the complete suppression of the $\mathrm{Al}-\mathrm{Al}_{2} \mathrm{Cu}$ eutectic reaction, and the formation of only blocky $\mathrm{Al}_{2} \mathrm{Cu}$. Lower $\mathrm{Mg}$ concentrations, however, result in a combination of blocky $\mathrm{Al}_{2} \mathrm{Cu}$ clustered with $\mathrm{Al}_{5} \mathrm{Mg}_{8} \mathrm{Cu}_{2} \mathrm{Si}_{6}$ as well as eutectic $\mathrm{Al}_{2} \mathrm{Cu}$. The modification in $\mathrm{Al}_{2} \mathrm{Cu}$ morphology occurs due to macrosegregation of $\mathrm{Cu}$ to specific areas within the interdendritic regions. As such, the local $\mathrm{Cu}$ concentration exceeds the required compositional range for the formation of the $\mathrm{Al}-\mathrm{Al}_{2} \mathrm{Cu}$ eutectic. The formation of $\mathrm{Al}_{5} \mathrm{Mg}_{8} \mathrm{Cu}_{2} \mathrm{Si}_{6}$ and the modification of the $\mathrm{Al}_{2} \mathrm{Cu}$ morphology influence the heat treatment characteristics of the 319 alloy, as discussed in Section 2.3.

\subsubsection{Fe-bearing Intermetallics}

Most commercial $\mathrm{Al}$ alloys are prone to the formation of coarse and brittle $\mathrm{Fe}$ bearing intermetallic phases, which are detrimental to the mechanical properties. This is due to the high affinity between $\mathrm{Al}$ and $\mathrm{Fe}$, which allows this impurity element to be introduced into the alloy during handling and pouring of the molten $\mathrm{Al}$. Iron is also introduced into $\mathrm{Al}$ castings through the use of recycled $\mathrm{Al}$ [25]. As such, industrial grade Al alloys may contain a significant concentration of $\mathrm{Fe}$ impurities, depending on the required alloy specifications. 

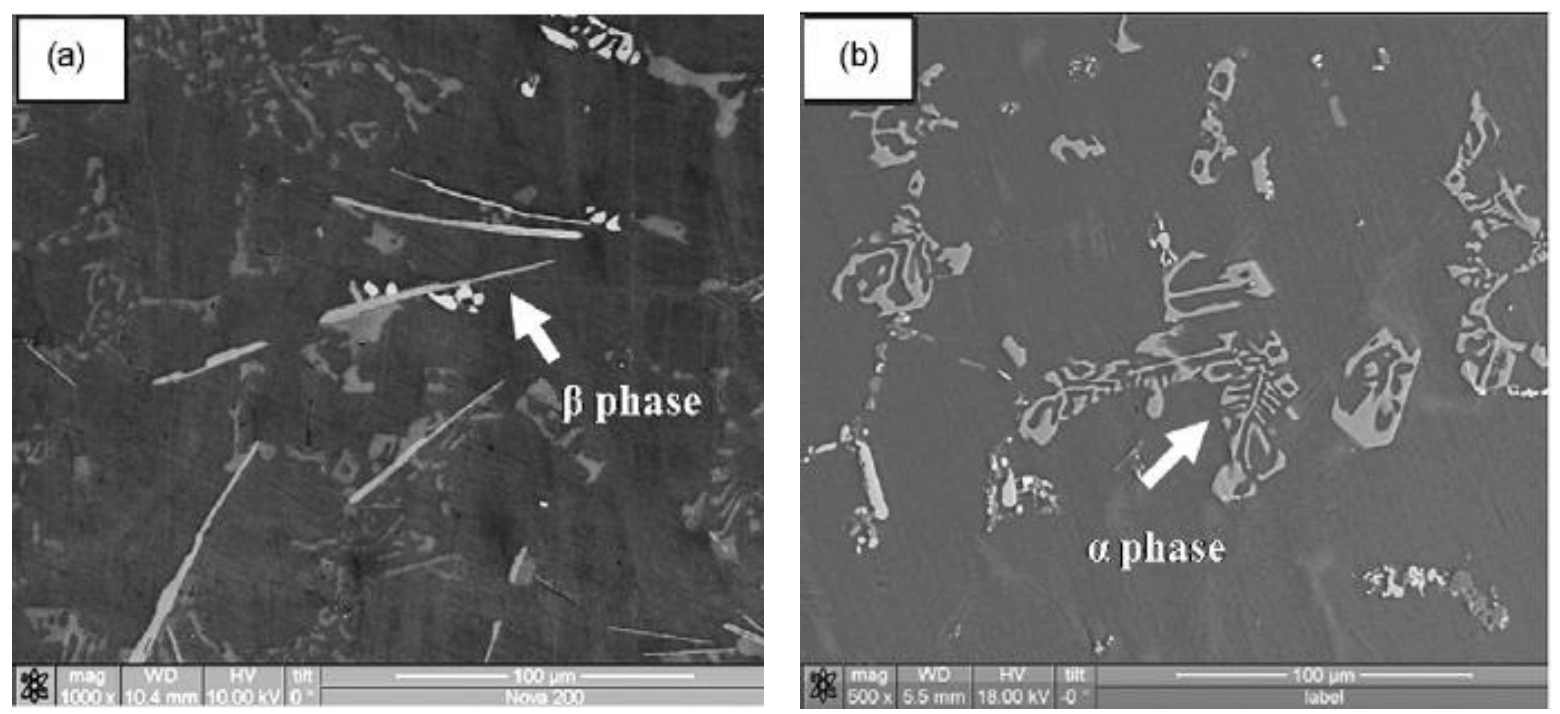

Figure 2.5: Backscattered electron images showing morphology of: (a) $\beta-\mathrm{Al}_{5} \mathrm{FeSi}$, (b) $\alpha-\mathrm{Al}_{15}(\mathrm{Fe}, \mathrm{Mn})_{3} \mathrm{Si}_{2}[26]$.

In $\mathrm{Al}-\mathrm{Si}$ based alloys, $\mathrm{Fe}$ impurities lead to the formation of coarse and acicular $\beta$ - $\mathrm{Al}_{5} \mathrm{FeSi}$ intermetallic particles, as shown in Figure 2.5 (a). This intermetallic phase is hard, brittle and has poor bond strength with the aluminum matrix. In addition, the acicular morphology results in stress concentrations near the tips of the particles, which act as crack nucleation sites. For these reasons, the formation of $\beta-\mathrm{Al}_{5} \mathrm{FeSi}$ is highly deleterious to the mechanical properties of the 319 alloy [26-29]. To mitigate the detrimental effect of $\mathrm{Fe}, \mathrm{Mn}$ is added, to suppress the formation of acicular $\beta-\mathrm{Al}_{5} \mathrm{FeSi}$ in favour of Chinese script $\alpha-\mathrm{Al}_{15}(\mathrm{Fe}, \mathrm{Mn})_{3} \mathrm{Si}_{2}$, as shown in Figure 2.5 (b).

Although the $\alpha-\mathrm{Al}_{15}(\mathrm{Fe}, \mathrm{Mn})_{3} \mathrm{Si}_{2}$ phase is also a hard and brittle intermetallic phase, its more compact morphology reduces the stress concentration at the particle-matrix interface, which improves the mechanical properties of the $319 \mathrm{Al}$ alloy relative to the Mn-free alternatives [2629]. The studies of Hwang et al. [26] and Narayanan et al. [27] found that the ideal Fe:Mn concentration ratio to improve mechanical properties in $\mathrm{Al}-\mathrm{Si}$ alloys ranged between 0.75:1 and $1.5: 1$. Within this range, the $\beta-\mathrm{Al}_{5} \mathrm{FeSi}$ phase is effectively suppressed and the volume fraction and size of Fe-bearing phases is limited, thereby resulting in improved mechanical properties.

\section{Section Summary}

This section discussed the influence of composition on the secondary phases present in the as-cast microstructure of the $319 \mathrm{Al}$ alloy, as well as the size and morphology of these secondary phases. The secondary phases in this alloy significantly influence the mechanical properties of 
the alloy as well as the heat treatment response. The next section will review the current state-ofthe-art knowledge in terms of heat treatment of the $319 \mathrm{Al}$ alloy and discuss areas where additional understanding is required.

\subsection{Heat Treatment of 319 Aluminum Alloys}

Aluminum alloy components, specifically engine blocks, are typically heat treated prior to being exposed to service conditions. Heat treatment is used to obtain a more uniform microstructure compared to the as-cast state (homogenization), improve mechanical properties and reduce residual stresses. This section reviews the precipitation hardening heat treatment process (SHT and artificial aging), incipient melting of secondary phases and the effect of these processes on mechanical properties and dimensional stability of the $319 \mathrm{Al}$ alloy.

\subsubsection{Solution Heat Treatment}

Precipitation hardening heat treatments are commonly applied to $\mathrm{Al}$ engine block castings as a post-casting process prior to in-service use. The first step involves high temperature (near solidus point of the alloy) SHT to: (1) modify Si morphology to more rounded shape, (2) dissolve coarse equilibrium phases amenable to heat treatment, and (3) obtain maximum concentration and homogenization of alloying elements within the matrix [30]. This high temperature treatment is followed by quenching (typically in water or oil) to ambient temperature to form a supersaturated solid solution (SSSS) [31, 32].

\subsubsection{Eutectic Si Morphology}

Modification of the eutectic Si morphology has been reported by several researchers [12, 22, 30, 33-36] to occur during SHT of the $319 \mathrm{Al}$ alloy for temperatures above $480{ }^{\circ} \mathrm{C}$ (thermal modification). This modification of the eutectic Si morphology has been observed to occur in the following sequence during SHT: (1) necking of acicular Si particles, (2) fragmentation of Si particles, (3) spheroidization of fragments, and (4) coarsening of spherical Si particles. The rate of this sequence is highly dependent on the solutionizing temperature, the heating rate to the solutionizing temperature and the pre-heat treatment modification level of the eutectic $\mathrm{Si}$ particles. For instance, higher solutionizing temperatures, higher heating rate and a modified fibrous Al-Si eutectic structure reduces the time required for spheroidization and fragmentation 
of Si particles [12, 36, 37]. The higher solutionizing temperature increases diffusion rates, enhancing the rate morphological modification, while the higher heating rate imparts greater thermal stresses which aids in fragmentation of Si particles [12, 37]. Furthermore, Shivakumar et al. [36] reported that fibrous Al-Si eutectic clusters are more prone to interfacial instabilities than acicular structures, allowing necking, fragmentation and spheroidization to occur more readily [36]. The spheroidization of eutectic Si particles during SHT eliminates crack-initiation sites at the tips of the particles, significantly improving alloy strength and ductility.

\subsubsection{Effect of Alloy Composition on Secondary Phase Dissolution}

Dissolution of secondary phases is a diffusion controlled process and as such the main variables influencing the effectiveness of the SHT process are temperature and time. Other factors that influence the effectiveness of dissolution and the selected solutionizing parameters are alloy chemistry, specifically the $\mathrm{Cu}$ and $\mathrm{Mg}$ concentrations, secondary dendrite arm spacing (SDAS) and the morphology of the secondary phases.

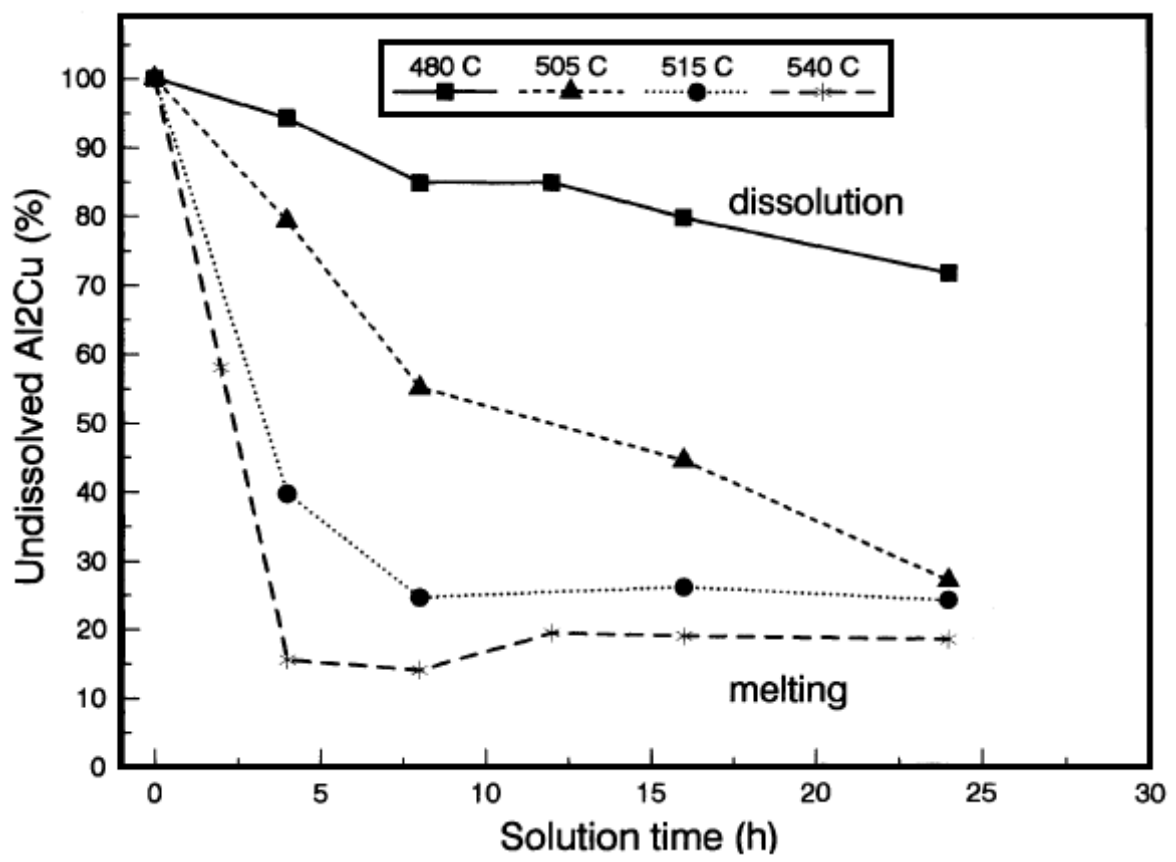

Figure 2.6: Influence of solutionizing temperature and time on dissolution of $\mathrm{Al}_{2} \mathrm{Cu}$ in $\mathrm{Mg}$-free $319 \mathrm{Al}$ alloy [35].

For Mg-free 319 alloys, it has been reported that solutionizing temperatures between 505 and $520{ }^{\circ} \mathrm{C}$ effectively dissolved $\mathrm{Al}_{2} \mathrm{Cu}$ (temperatures approaching $520{ }^{\circ} \mathrm{C}$ significantly accelerated the dissolution kinetics), while temperatures below $480{ }^{\circ} \mathrm{C}$ caused sluggish dissolution of this 
phase $[12,22,35,38,39]$. Solutionizing temperatures above $520^{\circ} \mathrm{C}$ resulted in incipient melting, which is undesirable, as will be discussed further in Section 2.3.1.5. Figure 2.6 elucidates the effect of temperature and time on secondary phase dissolution by showing the change in $\mathrm{Al}_{2} \mathrm{Cu}$ volume fraction as a function of time at different solutionizing temperatures for $\mathrm{Mg}$-free $319 \mathrm{Al}$ alloys.

In contrast, for $\mathrm{Mg}$-bearing $319 \mathrm{Al}$ alloys, containing greater than $2 \mathrm{wt} \% \mathrm{Cu}$, it has been found by several researchers $[19,20,22,30,33,34,37,40-45]$ that a lower solutionizing temperature, in the range of $490-500{ }^{\circ} \mathrm{C}$, is required to effectively dissolve $\mathrm{Al}_{2} \mathrm{Cu}$, while avoiding incipient melting. This reduction in solutionizing temperature is attributed to the formation of the lowmelting point $\mathrm{Al}_{5} \mathrm{Mg}_{8} \mathrm{Cu}_{2} \mathrm{Si}_{6}$ phase. In addition, Lasa and Rodriguez-Ibabe [20] and Han et al. $[43,46]$ found that the $\mathrm{Al}_{5} \mathrm{Mg}_{8} \mathrm{Cu}_{2} \mathrm{Si}_{6}$ phase dissolved very slowly for $\mathrm{Cu}$ concentrations between 3.5 and $4.5 \mathrm{wt} \%$, while it is insoluble for $\mathrm{Cu}$ concentrations below $3 \mathrm{wt} \%$. Colley et al. [42] also found that this phase is only soluble when solutionized at $505{ }^{\circ} \mathrm{C}$, with higher temperatures resulting in localized melting. This observation supports the CALPHAD calculations carried out by Chaudhury et al. [37], which indicated that complete dissolution of $\mathrm{Cu}$ and $\mathrm{Mg}$ bearing phases occurs at temperatures between 505 and $515^{\circ} \mathrm{C}$ for $319 \mathrm{Al}$ alloys containing less than 0.48 wt.\% $\mathrm{Mg}$. However, unlike the $\mathrm{Mg}_{2} \mathrm{Si}$ phase which dissolves readily during SHT, there is significant debate over the amenability of $\mathrm{Al}_{5} \mathrm{Mg}_{8} \mathrm{Cu}_{2} \mathrm{Si}_{6}$ to precipitation hardening heat treatments and its effect on the subsequent mechanical properties.

\subsubsection{Effect of Particle Size on Secondary Phase Dissolution}

Previous research also determined that the size of the $\mathrm{Al}_{2} \mathrm{Cu}$ and $\mathrm{Al}_{5} \mathrm{Mg}_{8} \mathrm{Cu}_{2} \mathrm{Si}_{6}$ particles influenced the dissolution rate. For instance, Li et al. [4] observed that larger $\mathrm{Al}_{2} \mathrm{Cu}$ particles (caused by larger local solidification time) resulted in more undissolved $\mathrm{Al}_{2} \mathrm{Cu}$ following SHT (495 ${ }^{\circ} \mathrm{C}$ for up to 24 hours) of the $319 \mathrm{Al}$ alloy. Furthermore, Sjolander and Seifeddine [41] studied the influence of SDAS (which directly correlates to cooling rate during solidification and therefore the particle size of secondary phases) on phase dissolution. The resulting change in $\mathrm{Cu}$ concentration dissolved in the $\alpha$-Al matrix with solutionizing time is shown in Figure 2.7. 


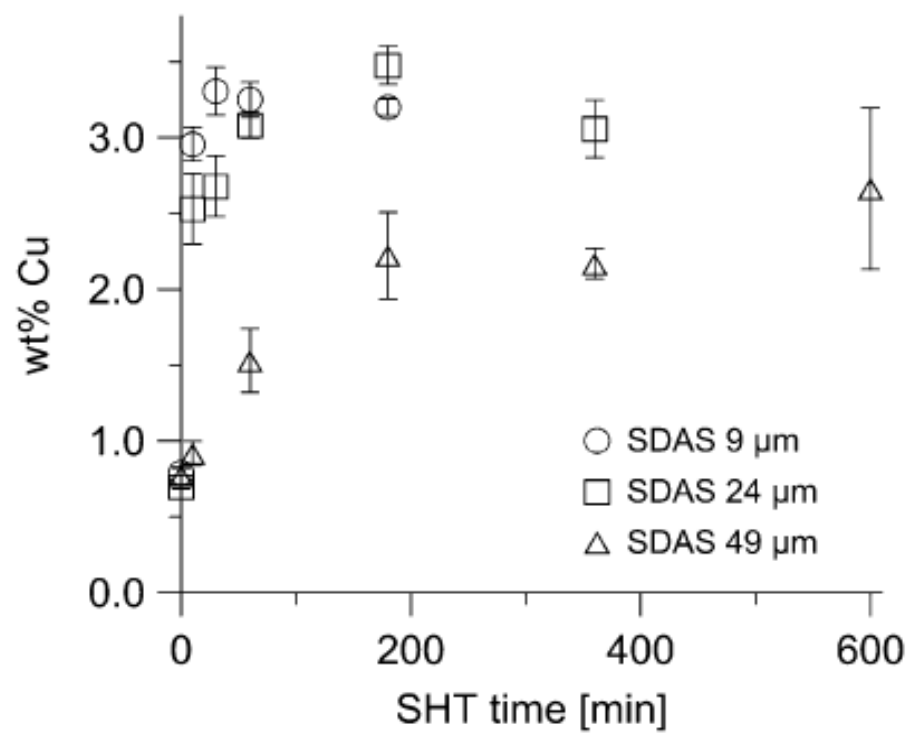

Figure 2.7: Amount of dissolved $\mathrm{Cu}$ in Al matrix showing influence of SDAS and solutionizing time on dissolution of $\mathrm{Al}_{2} \mathrm{Cu}$ [41].

The rapid increase in $\mathrm{Cu}$ concentration during $\mathrm{SHT}$ at $495^{\circ} \mathrm{C}$ indicated that $\mathrm{Al}_{2} \mathrm{Cu}$ was quickly dissolved for samples having SDAS of $9 \mu \mathrm{m}$ (finest). In contrast, the samples with SDAS of $49 \mu \mathrm{m}$ (coarsest) had a significantly slower increase in dissolved $\mathrm{Cu}$ concentration suggesting slower $\mathrm{Al}_{2} \mathrm{Cu}$ dissolution. This observation was also confirmed by microstructural analysis, as $\mathrm{Al}_{2} \mathrm{Cu}$ was completely dissolved after 1 hour of solutionizing for the specimen with the finest microstructure, while even 10 hours of solutionizing did not lead to complete $\mathrm{Al}_{2} \mathrm{Cu}$ dissolution in the samples with the coarsest microstructure [41]. Similar trends were observed for $\mathrm{Al}_{5} \mathrm{Mg}_{8} \mathrm{Cu}_{2} \mathrm{Si}_{6}$, as this phase showed notable dissolution following 3 hours of solutionizing for the samples with the finest microstructure, while no dissolution of this phase took place for those with the coarsest microstructure [41]. The increased susceptibility of secondary phase dissolution for finer particles has been attributed to greater particle-matrix interfacial area, which permits more impurity elements at the surface of the particles to diffuse into the adjacent matrix [37].

\subsubsection{Effect of Particle Morphology on Secondary Phase Dissolution}

Morphology of the secondary phase particles also significantly influences the susceptibility to dissolution. Based on in-depth microstructural characterization, Han et al. [43] found that eutectic $\mathrm{Al}_{2} \mathrm{Cu}$ dissolved more readily than blocky $\mathrm{Al}_{2} \mathrm{Cu}$ due to differences in the mechanism of dissolution. The dissolution mechanisms for eutectic and blocky $\mathrm{Al}_{2} \mathrm{Cu}$ are illustrated in Figures 2.8 (a) and (b) respectively. 

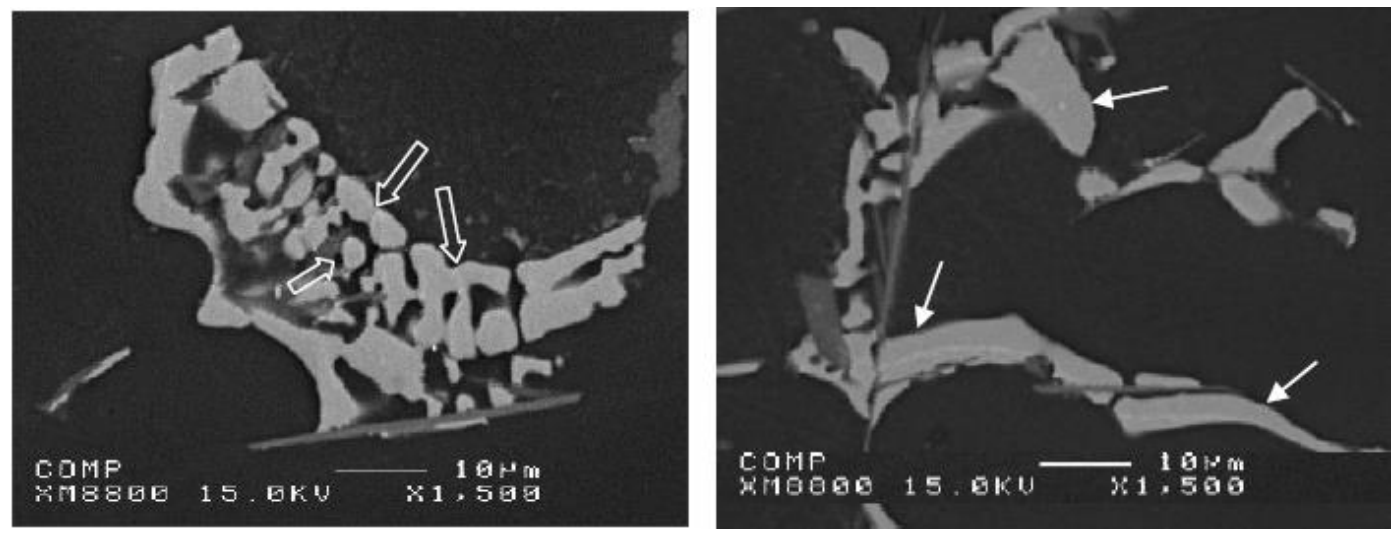

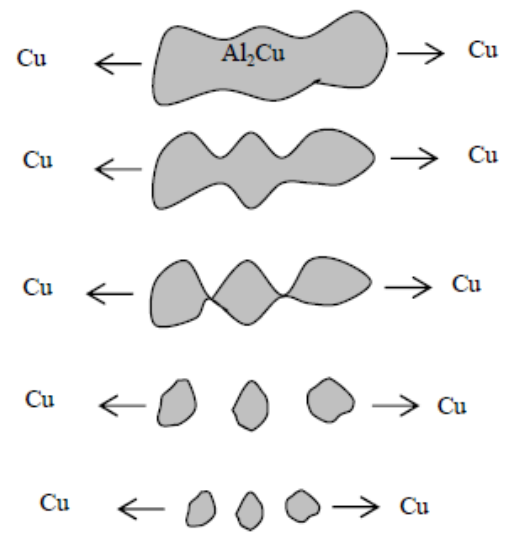

(a)

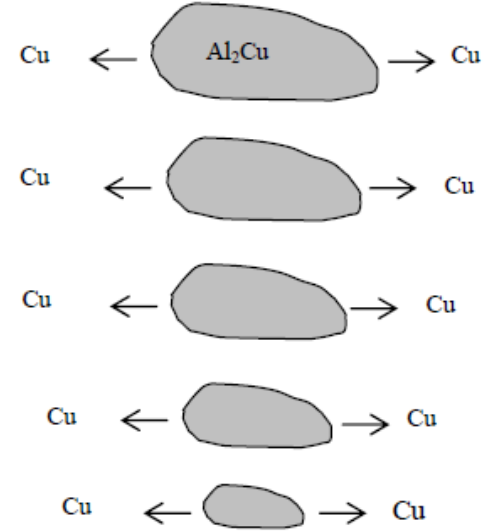

(b)

Figure 2.8: Mechanism of dissolution for: (a) Eutectic $\mathrm{Al}_{2} \mathrm{Cu}$, (b) Blocky $\mathrm{Al}_{2} \mathrm{Cu}$ [43].

Dissolution of eutectic $\mathrm{Al}_{2} \mathrm{Cu}$ (Figure 2.8 (a)) proceeds initially by necking along the particle, which leads to fragmentation into smaller particles. These particles are then spheroidized with continued solutionizing and finally dissolved by radial diffusion of interfacial $\mathrm{Cu}$ atoms into the surrounding $\alpha$-Al matrix [12, 35, 43]. Conversely, the blocky $\mathrm{Al}_{2} \mathrm{Cu}$ morphology does not undergo this same fragmentation process due to the low interfacial energy of this phase [37], which causes these particles to remain relatively large in size during SHT [12, 35, 43]. As such, the larger blocky $\mathrm{Al}_{2} \mathrm{Cu}$ particles only undergo the radial diffusion process and dissolve more slowly due to less particle-matrix interfacial area [37], as compared to the fragmented eutectic $\mathrm{Al}_{2} \mathrm{Cu}$.

\subsubsection{Incipient Melting of Secondary Phases}

The studies on heat treatment of the $319 \mathrm{Al}$ alloy also reveal that there is an upper limit to the solutionizing temperature due to incipient melting of secondary phases. Incipient melting has 
been found to occur at solution temperatures higher than $520^{\circ} \mathrm{C}$ for $\mathrm{Mg}$ free $319 \mathrm{Al}$ alloys [35, 47-49]. This was supported by Samuel [48] using thermal analysis via differential scanning calorimetry (DSC) which found an endothermic peak at $521{ }^{\circ} \mathrm{C}$. This peak was associated with melting of the $\mathrm{Al}-\mathrm{Al}_{2} \mathrm{Cu}$ eutectic $[45,48]$.

For Mg-bearing $319 \mathrm{Al}$ alloys, the onset temperature for incipient melting was found to occur between 510 and $520^{\circ} \mathrm{C}$ for $\mathrm{Mg}$ concentrations less than $0.3 \mathrm{wt} \%$ [34, 40, 50]. Wang et al. [34] confirmed the onset temperature of incipient melting using DSC by observing an endothermic peak at $515^{\circ} \mathrm{C}$ for a $319 \mathrm{Al}$ alloy containing $0.3 \mathrm{wt} \% \mathrm{Mg}$. In contrast, $\mathrm{Mg}$ concentrations greater than $0.3 \mathrm{wt} \%$ had incipient melting initiate at approximately $507^{\circ} \mathrm{C}[22,47-51]$, which was also confirmed with DSC analysis $[45,48]$. The reduction in the melting temperature was likely due to melting of the complex eutectic. The formation of the eutectic, which occurred at approximately $507^{\circ} \mathrm{C}$, as proposed by Backerud et al. [52] is shown in Equation 1. In addition, higher $\mathrm{Mg}$ concentrations have a larger volume fraction of the low melting point $\mathrm{Al}_{5} \mathrm{Mg}_{8} \mathrm{Cu}_{2} \mathrm{Si}_{6}$ phase, which makes the alloy more prone to incipient melting.

$$
L \rightarrow A l+\mathrm{Al}_{2} \mathrm{Cu}+\mathrm{Al}_{5} \mathrm{Mg}_{8} \mathrm{Cu}_{2} \mathrm{Si}_{6}
$$

Incipient melting of the $319 \mathrm{Al}$ alloy results in a significant microstructural modification, as shown in Figure 2.9. For Mg free $319 \mathrm{Al}$ alloys, incipient melting causes the formation of a structureless (glassy) $\mathrm{Cu}$ rich phase (Figure 2.9 (a)) upon quenching, with composition similar to that of equilibrium $\mathrm{Al}_{2} \mathrm{Cu}[35,48]$. Furthermore, shrinkage porosity was found surrounding the structureless $\mathrm{Cu}$ phase, which resulted from the re-solidification of the small liquid pockets in the interdendritic regions.

Incipient melting of the $\mathrm{Mg}$-bearing $319 \mathrm{Al}$ alloy has been observed to form the structureless $\mathrm{Cu}$ phase at the grain boundaries [22, 47, 48, 50], similar to that shown in Figure 2.9 (a), or regions of fine eutectic adjacent to large polyhedral Si particles along interdendritic regions [34, 48, 49], as shown in Figure 2.9 (b). The fine eutectic region, which can be circular in shape or as an interdendritic network, was found to contain $\mathrm{Al}_{2} \mathrm{Cu}$ and $\mathrm{Al}_{5} \mathrm{Mg}_{8} \mathrm{Cu}_{2} \mathrm{Si}_{6}$, as shown in Figure 2.9 (c) [49]. Similar to the structureless phase, the resulting fine eutectic regions also contain macro and 
micro porosity, although the reason for the discrepancy in porosity size following incipient melting is not known conclusively.
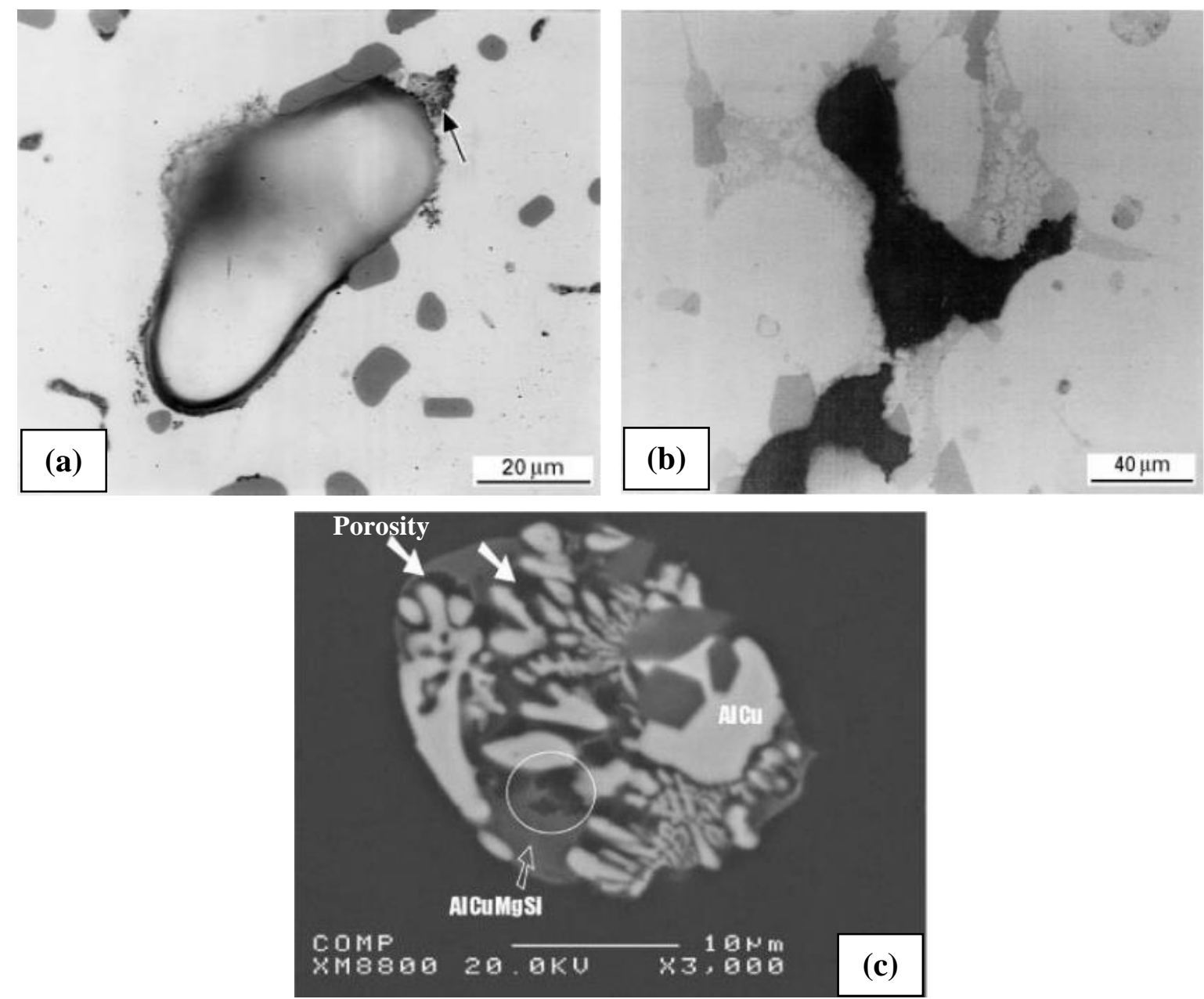

Figure 2.9: Incipient melting in: (a) Mg-free 319 Alloy [48], (b) 319 alloy containing 0.3 wt $\%$ Mg [48]. (c) Backscattered electron image of eutectic cluster resulting from incipient melting in $\mathrm{Al}-\mathrm{Si}$-Cu-Mg alloys [49].

Several studies have found either the structureless phase or the fine eutectic phase when incipient melting of Mg-bearing $319 \mathrm{Al}$ alloy occurred. However, it is not clear as to the conditions, such as alloy composition, solutionizing parameters and quench rate, which favour the formation of one phase over the other. For instance, Samuel [48] found that incipient melting of a 319 Al alloy containing $0.45 \mathrm{wt} \% \mathrm{Mg}$ resulted in the structureless $\mathrm{Cu}$-rich phase along the grain boundaries, while for Mg concentrations of $0.3 \mathrm{wt} \%$, Samuel [48] and Wang et al. [34] observed that fine eutectic clusters were formed along interdendritic regions. Han et al. [49] however, observed both the structureless phase and the fine eutectic clusters in the microstructure of a $319 \mathrm{Al}$ alloy containing $0.6 \mathrm{wt} \% \mathrm{Mg}$, although this alloy was subjected to a 3-stage SHT process. As such, 
additional research is required to determine the factors leading to the formation of each phase following incipient melting.

\subsubsection{Effect of Solution Temperature on Mechanical Properties}

Solution heat treatment temperature greatly influences the mechanical properties of the $319 \mathrm{Al}$ alloy due to factors such as phase dissolution and incipient melting. Figure 2.10 shows a schematic diagram devised by Samuel et al. [47], which illustrates the change in strength (yield or ultimate tensile strength) for the $319 \mathrm{Al}$ alloy ( $\mathrm{Mg}$ content $<0.3 \mathrm{wt} \%$ ) as a function of solutionizing temperature. The diagram was also separated into four distinct regions relating the mechanical properties to microstructural observations.

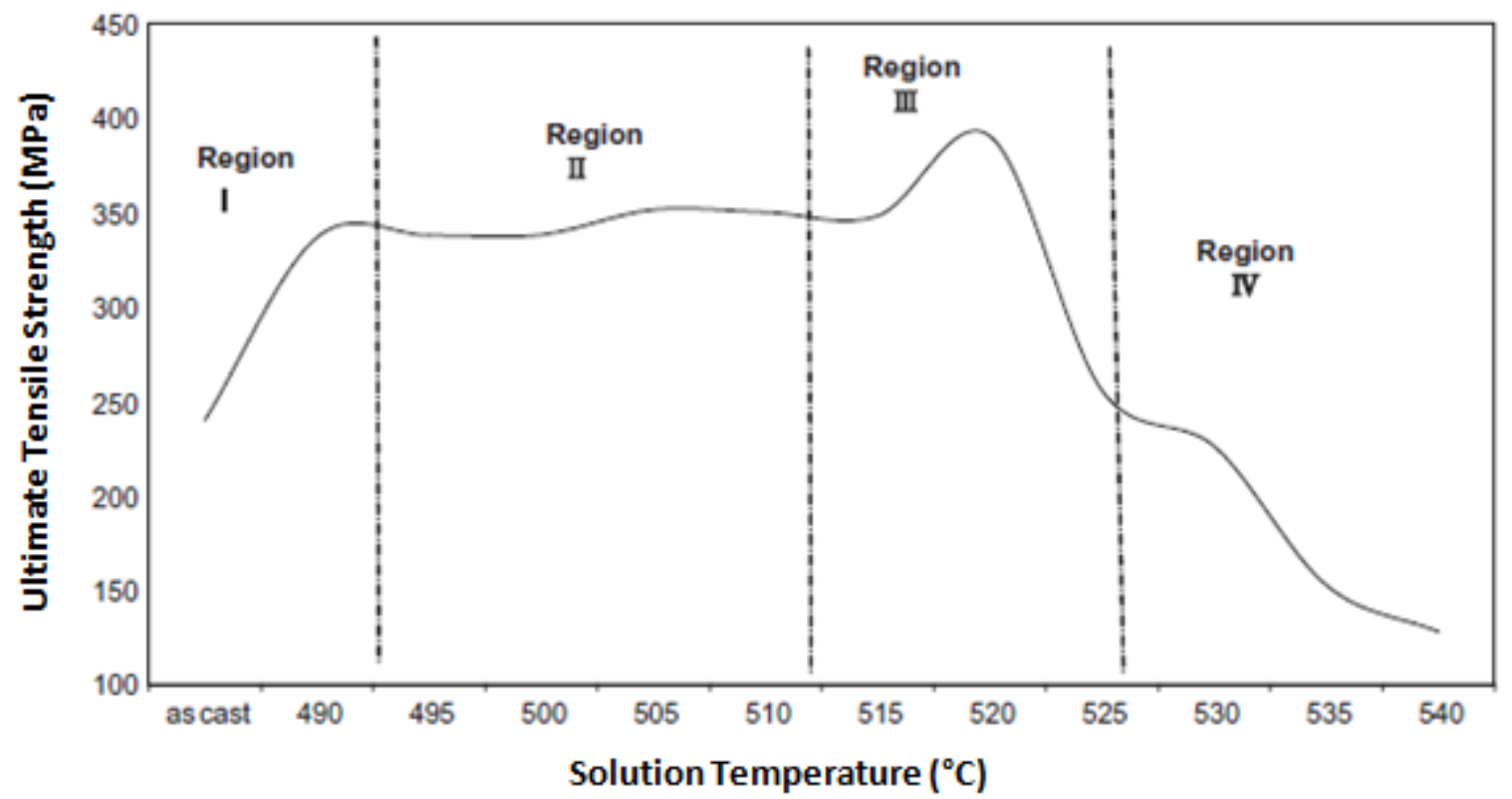

Figure 2.10: Schematic showing tensile strength of 319 alloy as a function of solutionizing temperature [47].

Regions I and II illustrate the increase in alloy strength due to dissolution of $\mathrm{Al}_{2} \mathrm{Cu}$ during SHT. The recommended SHT temperatures for the $319 \mathrm{Al}$ alloy was found within Region II due to the relatively constant mechanical properties over a range of temperatures, which is advantageous for complex components where overheating in specific regions is a concern. Region III is a continuation of the previous region up to the peak condition, which is marked by the onset of incipient melting. This region, although giving the highest strength, has a rapid drop in properties above the critical temperature. Thus, any overheating may significantly deteriorate tensile strength. Finally, Region IV corresponds to the continuation of incipient melting and the 
corresponding deterioration of tensile strength. It is important to note that for higher $\mathrm{Mg}$ concentrations, this schematic is valid, but Regions III and IV are shifted to lower temperatures $\left(505-510^{\circ} \mathrm{C}\right)$, corresponding to the onset of incipient melting for this alloy.

The mechanical properties of the 319 alloy are significantly reduced by incipient melting due to the formation of porosity, brittle glassy phases at the grain boundaries and the formation of coarse polygonal Si particles in the vicinity of the melted phase. This is especially true in Region IV, where melting becomes more pronounced and the volume fraction of porosity increases significantly, which overcomes any strengthening effect from precipitation hardening $[49,50]$.

\section{Section Summary}

Solution heat treatment parameters, as well as factors such as alloy composition, particle size and secondary phase morphology, have been studied extensively for the 319 Al alloy. This past research has provided in-depth characterization of microstructure, proposed mechanisms of phase dissolution and incipient melting, and determined the influence of varying heat treatment parameters on mechanical properties. However, the literature is lacking a comprehensive study examining the combined effects of solutionizing temperature, time and coarseness of microstructure on phase dissolution, incipient melting and mechanical properties. In addition, an understanding on the effect of air quenching on microstructure and mechanical properties is also lacking as water quenching was predominantly used in past research. This comprehensive analysis, which will be presented in Section 5.1 of this dissertation, is critical in developing optimal heat treatment schedules to maximize alloy strength for components, such as engine blocks, with varying microstructures and those where air quenching is required to limit residual stress formation.

\subsubsection{Artificial Aging}

Following SHT (T4 condition), Al alloys are typically artificially aged at elevated temperatures to strengthen the alloys. For Al alloys, the peak aging condition (maximum strength and hardness) is designated as T6, while the overaged condition is designated as T7. The T7 condition however is commonly used in engine block applications due to superior dimensional stability (refer to Appendix A for a summary of microstructure and properties associated to each 
heat treatment condition for the $319 \mathrm{Al}$ alloy). This section will discuss the effect of aging condition on microstructure, mechanical properties and dimensional stability.

\subsubsection{Precipitation Sequence during Aging}

Artificial aging is used following SHT as part of the precipitation hardening process for Al alloys. Aging permits the precipitation of fine metastable particles from the supersaturated solid solution (SSSS). Several researchers have examined the precipitation sequence during artificial aging of Mg-free and Mg-bearing 319 Al alloys. For Mg-free 319 alloys, the main strengthening precipitates formed during aging are $\mathrm{Cu}$-rich phases $[9,23,53,54]$. The proposed precipitation sequence for the evolution of the $\mathrm{Cu}$-rich precipitates is shown in Equation 2. A model showing the crystal structure and lattice spacing of each phase in the precipitation sequence (white and shaded spheres represent copper and Al atoms respectively) is shown in Figure 2.11.

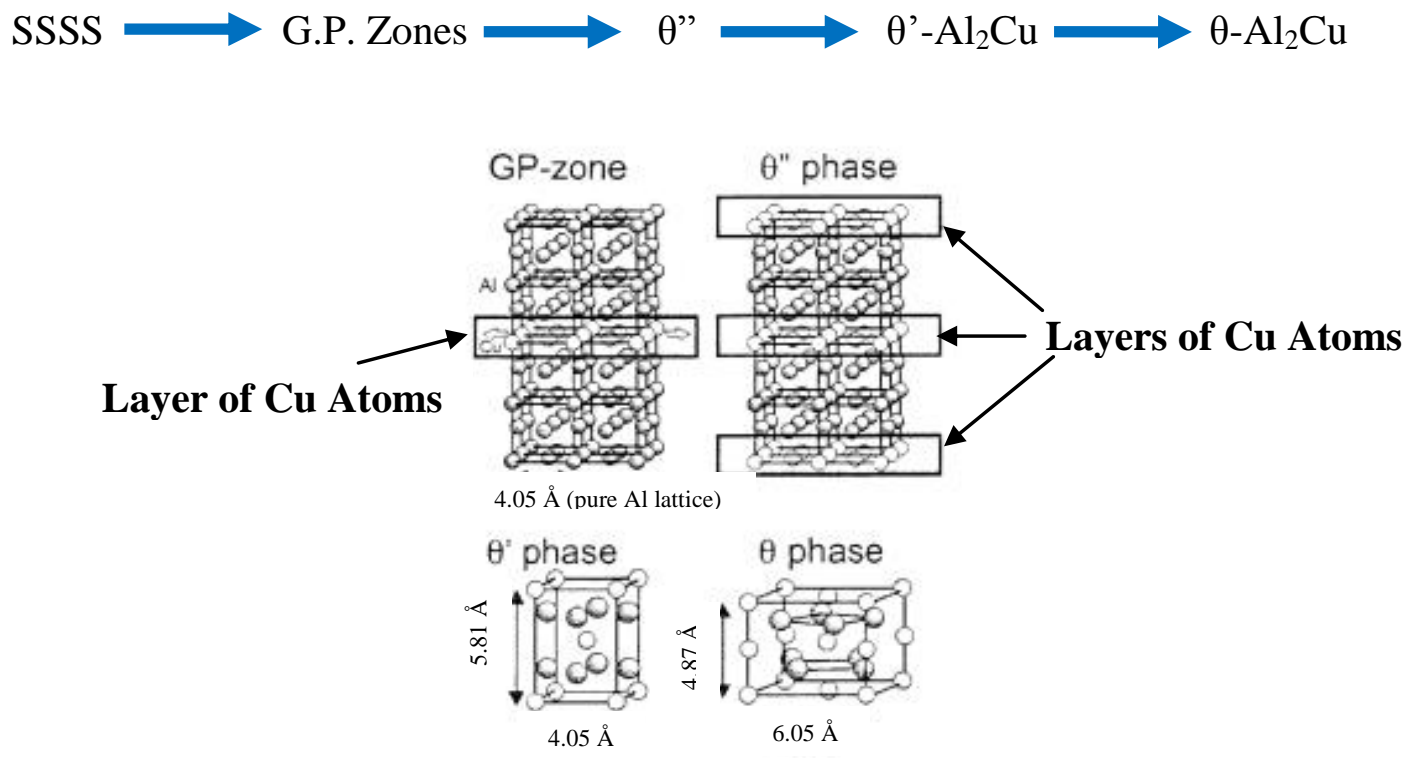

Figure 2.11: Precipitation sequence and structure of precipitates formed during aging of Al-Cu alloys. [55].

The precipitation sequence in $\mathrm{Al}-\mathrm{Si}-\mathrm{Cu}$ alloys (similar to $\mathrm{Al}-\mathrm{Cu}$ binary alloys) begins with the formation of Guinier-Preston (G.P.) zones from the SSSS. G.P. zones are clusters of $\mathrm{Cu}$ atoms which are coherent with the $\alpha$-Al matrix [32]. Continued aging results in the replacement of G.P zones with the coherent $\theta$ " phase (alternating layers of $\mathrm{Al}$ and $\mathrm{Cu}$ atoms along the $\{100\}$ planes). This phase gradually loses coherency during aging due to lattice growth and gives rise to the $\theta^{\prime}$ $\mathrm{Al}_{2} \mathrm{Cu}$ phase [32]. The $\theta^{\prime}$ phase is a semi-coherent (coherent with the matrix in certain planar 
directions) secondary phase which has platelet morphology and a similar stoichiometry to the equilibrium $\mathrm{Al}_{2} \mathrm{Cu}$. Continued growth of these platelets with additional aging eventually causes a complete loss of coherency, resulting in the formation of equilibrium $\theta-\mathrm{Al}_{2} \mathrm{Cu}[31,32]$.

Substantial research has also been carried out on the precipitation sequence of Mg-bearing $319 \mathrm{Al}$ alloys during aging. Several studies have found that in addition to the $\mathrm{Cu}$ rich $\theta^{\prime}$ and $\theta$ phases described above, the microstructure of these alloys contain $\mathrm{Mg}$ rich precipitates $[9,21,23,53,54$, 56-61]. However, there is significant debate as to which Mg-rich phases precipitate during aging. Certain studies have concluded that the presence of $\mathrm{Mg}$ caused the co-precipitation of $\theta^{\prime}-\mathrm{Al}_{2} \mathrm{Cu}$ and $\beta^{\prime}-\mathrm{Mg}_{2} \mathrm{Si}$ during aging to the $\mathrm{T} 6$ condition $[54,56]$. On the other hand, other studies found that aging to the T6 condition resulted in the formation of both the $\theta^{\prime}-\mathrm{Al}_{2} \mathrm{Cu}$ and Q'$\mathrm{Al}_{5} \mathrm{Mg}_{8} \mathrm{Cu}_{2} \mathrm{Si}_{6}$ phases or a combination of $\theta^{\prime}, \beta^{\prime}$ and $\mathrm{Q}^{\prime}$ [9, 23, 53, 55, 59-61]. Wang et al. [56] proposed the precipitation sequence, shown in Equation 3, consisting of $\theta$ and $\mathrm{Q}$ based precipitates for $\mathrm{Al}-\mathrm{Si}-\mathrm{Cu}-\mathrm{Mg}$ alloys having a minimum $\mathrm{Cu}: \mathrm{Mg}$ concentration ratio of 2.5:1.

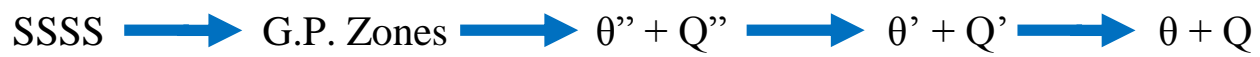

Hwang et al. [23], using high resolution transmission electron microscopy (HRTEM) and 3D atom probe tomography (3DAP), provided an in-depth examination of the phases present following T6 treatment. Their results indicated a microstructure consisting of $60 \mathrm{~nm}$ long platelets with the composition and structure characteristic of $\theta^{\prime}$, clustered with approximately $20 \mathrm{~nm}$ long lath particles having the composition and crystal structure of the Q' phase. In this analysis, no $\beta$ ' was observed in the microstructure following $\mathrm{T} 6$ treatment (supporting the precipitation sequence in Equation 3), suggesting that this phase does not contribute to strengthening in the 319 alloy as reported in other studies [54, 57]. However, it is unclear if the differences in the $\mathrm{Mg}$ phase formation are the result of different experimental methodologies (alloy composition, heat treatment parameters or cooling rate) between studies or misinterpretation of results.

Regarding the T7 condition, Ovono et al. [58] indicated that overaging resulted in the $\theta$ ' phase being replaced with relatively coarse equilibrium $\theta, \mathrm{Q}$ and $\mathrm{Si}$ particles. Other studies observed that the precipitates coarsen rapidly and lose coherency with the $\alpha$-Al matrix during overaging, resulting in the equilibrium variants of the age hardening precipitates, supporting the 
precipitation sequence in Equation 3 [54, 57, 59, 61]. The transition from fine, densely distributed age hardening precipitates in the T6 condition to coarser and more sparsely distributed precipitates following overaging to $\mathrm{T} 7$ condition is illustrated for the $\theta$-based precipitates in Figures 2.12 (a) and (b), respectively [59].
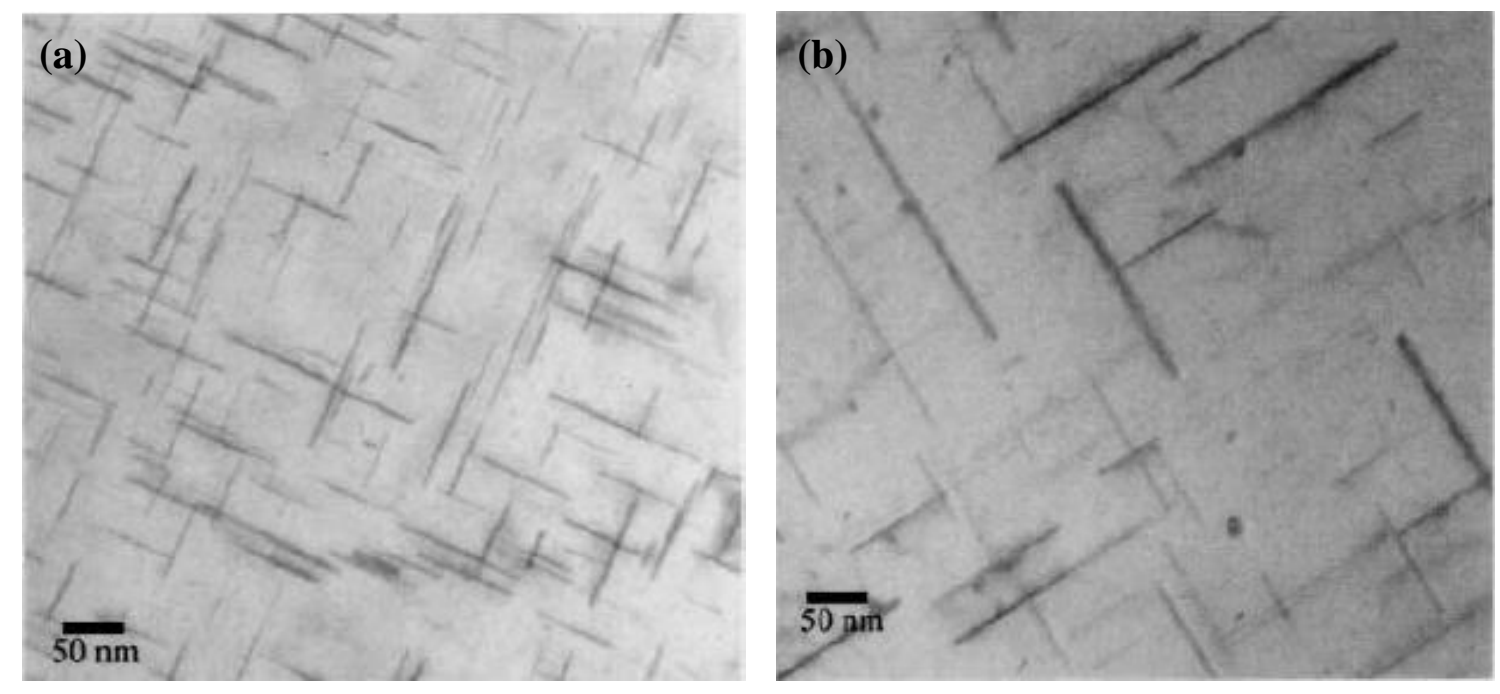

Figure 2.12: Morphology of $\theta$ ' precipitates for $319 \mathrm{Al}$ alloy following aging at: (a) $190{ }^{\circ} \mathrm{C} / 5 \mathrm{~h}$ ( $\mathrm{T} 6$ condition), (b) $260{ }^{\circ} \mathrm{C} / 3 \mathrm{~h}$ ( $\mathrm{T} 7$ condition) [59].

The heat treatment condition, due to the difference in age hardening precipitates present in the microstructure at each stage, greatly influence the mechanical properties and dimensional stability of the $319 \mathrm{Al}$ alloy. These aspects will be discussed in detail in Sections 2.3.2.2 and 2.3.2.3.

\subsubsection{Effect of Heat Treatment Condition on Mechanical Properties}

The artificial aging parameters and the alloy composition greatly influence the mechanical properties of the $319 \mathrm{Al}$ alloy. Previous research has investigated the influence of aging parameters (temperature and time) on the mechanical properties of $\mathrm{Mg}$-free [9, 21, 53, 54, 57] and $\mathrm{Mg}$ bearing [9, 21, 53, 54, 57, 61] $319 \mathrm{Al}$ alloys. Figures 2.13 (a) and (b) elucidate the results obtained by showing the change in YS, UTS and microhardness as a function of aging temperature and time for $\mathrm{Mg}$-free and $\mathrm{Mg}$-bearing $319 \mathrm{Al}$ alloys, respectively.

For Mg-free $319 \mathrm{Al}$ alloys, the peak strengthening occurred at temperatures between $170-190{ }^{\circ} \mathrm{C}$, although the required aging time varied for each study [9, 53, 57]. In addition, higher aging 
temperatures $\left(200-240{ }^{\circ} \mathrm{C}\right)$ were found to reduce the time required to the peak aging condition, but the peak alloy strength was reduced. Alloy strengthening was mainly attributed to the formation of $\mathrm{Cu}$-rich $\theta^{\prime \prime}$ and $\theta$ ' precipitates in the $\mathrm{Mg}$-free $319 \mathrm{Al}$ alloy, via the coherency strengthening and dispersion strengthening mechanisms $[9,23,53,54,57]$.

(a)

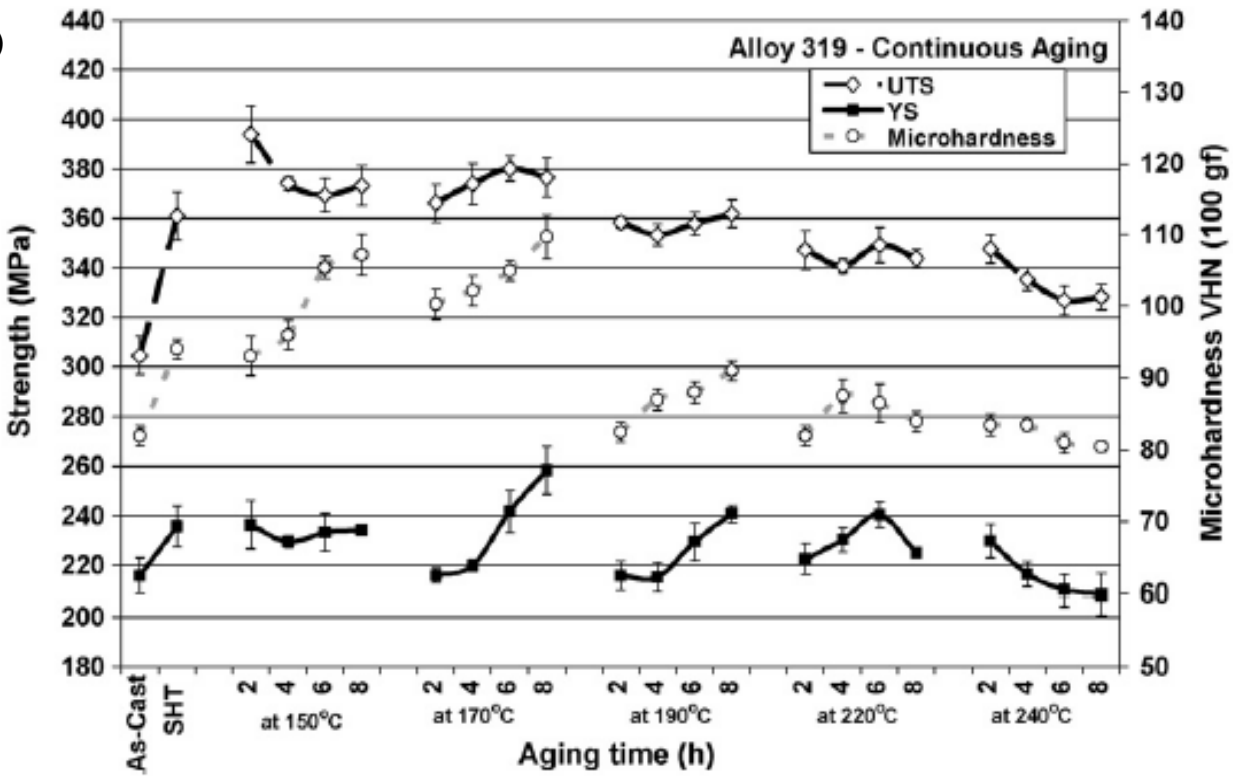

(b)

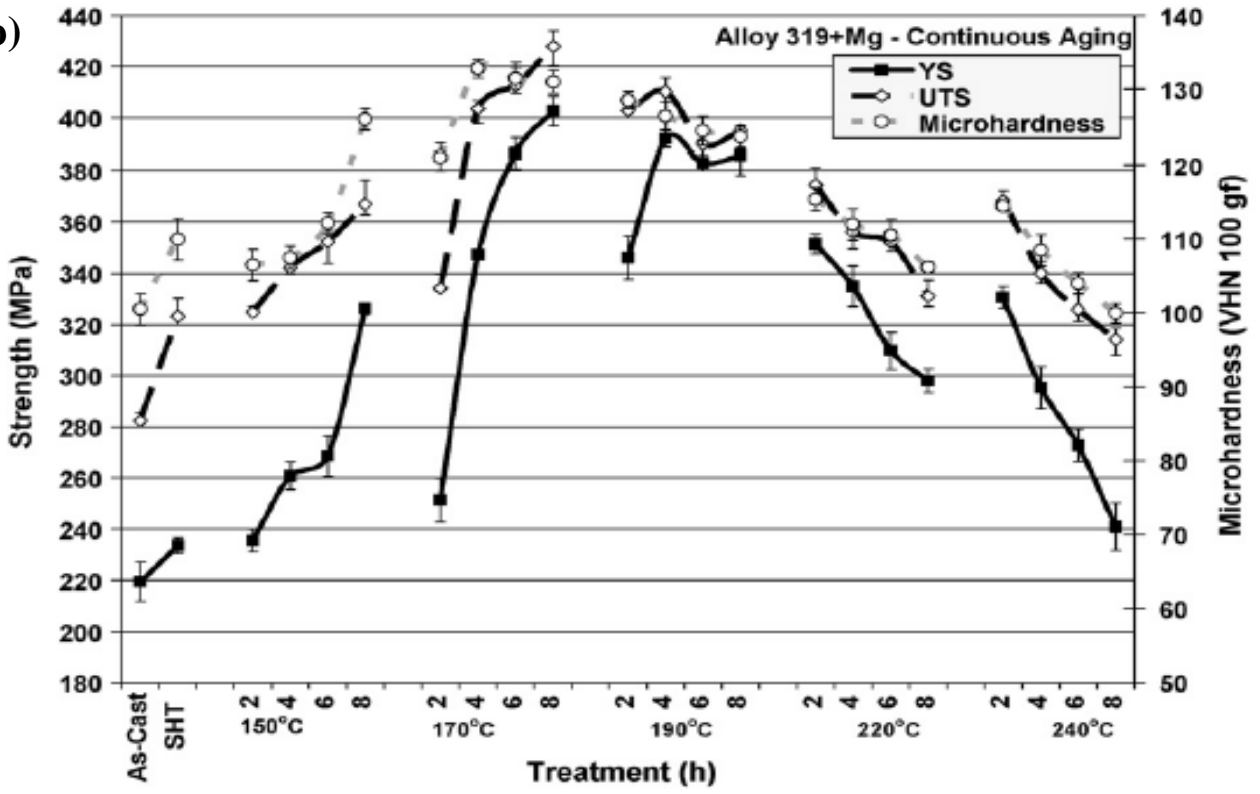

Figure 2.13: Effect of artificial aging on mechanical properties of: (a) $319 \mathrm{Al}$ alloy, (b) Mg-bearing $319 \mathrm{Al}$ alloy [9].

Magnesium-bearing 319 Al alloys were found to have significantly higher YS and UTS, specifically in the T6 condition, compared to the alloys without Mg (up to 50\% increase in YS, 
$20 \%$ increase in UTS) $[9,23,53,57]$. The increased strength of the Mg-bearing $319 \mathrm{Al}$ alloy was due to the co-operative precipitation of $\theta^{\prime}$ and Mg-rich precipitates, such as Q' and $\beta$ ', during artificial aging, which was more effective in inhibiting dislocation movement due to the increased volume fraction of precipitates within the $\alpha$-Al matrix $[9,21,53,54,57,61]$. Furthermore, the time to the peak aging condition was reduced with the addition of $\mathrm{Mg}$, which was likely due to the higher atomic diffusivity of $\mathrm{Mg}$ in $\mathrm{Al}\left(\mathrm{D}_{0}=1.2 \times 10^{-4} \mathrm{~m}^{2} / \mathrm{s}, \mathrm{Q}_{\mathrm{d}}=130 \mathrm{~kJ} / \mathrm{mol}\right)$ compared to $\mathrm{Cu}$ in $\mathrm{Al}\left(\mathrm{D}_{0}=6.5 \times 10^{-5} \mathrm{~m}^{2} / \mathrm{s}, \mathrm{Q}_{\mathrm{d}}=136 \mathrm{~kJ} / \mathrm{mol}\right)[41,62]$, permitting precipitates to nucleate and grow faster compared to the $\mathrm{Mg}$-free $319 \mathrm{Al}$ alloy.

For the $319 \mathrm{Al}$ alloys with and without $\mathrm{Mg}$, the mechanical properties were found to also increase with aging time up to the peak condition, and then decrease upon further aging. The increase in strength was caused by precipitate growth to the optimal size [57, 59, 61]. This prevented particle shearing and promoted the dislocation bypass mechanism which, due to the dense dispersion of precipitates within the Al matrix (Figure 2.12 (a)), effectively inhibited the movement of dislocations [63, 64]. Following the peak, overaging resulted in reduced YS and UTS since the precipitates lose coherency with the matrix and become coarser and more sparsely distributed, which eliminates coherency strengthening and reduces the dispersion strengthening effect (dislocations can bypass precipitates at lower stress levels) [61, 63, 64].

\subsubsection{Effect of Heat Treatment Condition on Dimensional Stability}

The heat treatment condition has also been observed to influence the dimensional stability of 319 Al alloys when exposed to elevated temperatures subsequently following SHT, quenching and aging. Dimensional instability resulting from phase transformation, referred to as the thermal growth mechanism, is associated with a change in alloy volume due to the precipitation and transition of metastable precipitates at elevated temperature [4-6, 65]. This mechanism of permanent dimensional distortion was illustrated by Boileau et al. [6], by subjecting $319 \mathrm{Al}$ alloy to T4, T6 and T7 heat treatments followed by elevated temperature exposure at $180{ }^{\circ} \mathrm{C}$ (Figure 2.14 (a)). This research found that heat treatment to the $T 7$ condition resulted in the highest dimensional stability with a dimensional growth of approximately $0.013 \%$ for exposure times of $1000 \mathrm{~h}$ at $180{ }^{\circ} \mathrm{C}$. In contrast, specimens treated to the T4 and $\mathrm{T} 6$ conditions had dimensional distortion values of $0.094 \%$ and $0.055 \%$, respectively following elevated temperature $\left(180{ }^{\circ} \mathrm{C}\right)$ exposure for $1000 \mathrm{~h} \mathrm{[6].}$ 

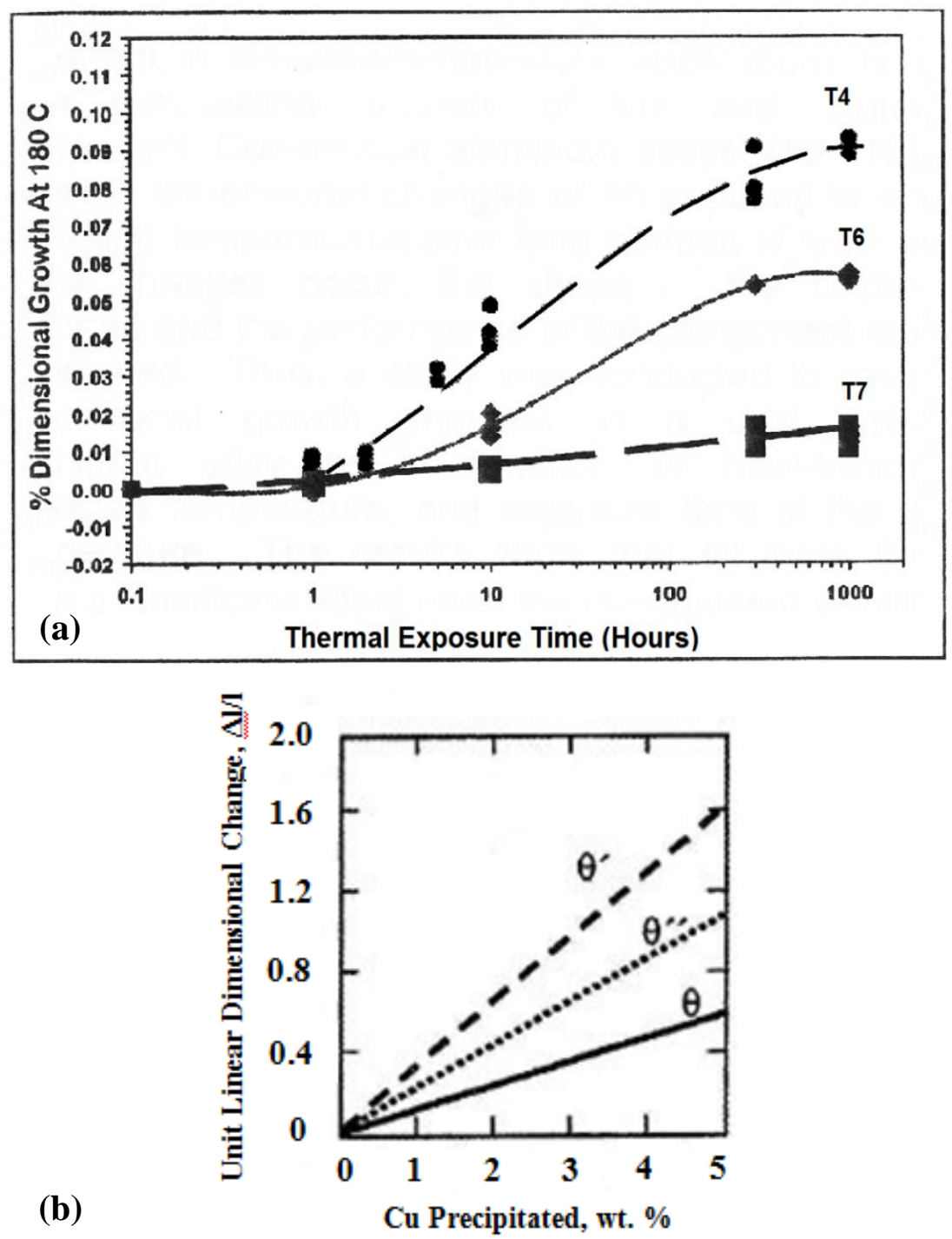

Figure 2.14: (a) Dimensional growth of heat treated W319 aluminum alloy while exposed to $180{ }^{\circ} \mathrm{C}$ [6], (b) Dimensional change due to the formation of precipitates during aging of Al-Cu alloys [5].

The difference in dimensional stability with heat treatment condition was attributed to the age hardening precipitates present in each condition, (Refer to Section 2.3.2.1 for detailed description of the $319 \mathrm{Al}$ alloy precipitation sequence). Boileau et al. [6] found that the $319 \mathrm{Al}$ alloy in the T7 condition (prior to the subsequent elevated temperature exposure) consisted of mainly equilibrium $\theta$ and some $\theta^{\prime}$, while the specimens treated to the T4 and T6 conditions had SSSS and $\theta "$, respectively. As such, when these specimens were held at elevated temperature, the stabilized microstructure from the $\mathrm{T} 7$ condition did not undergo phase transformations. Conversely, the specimens that were in the $\mathrm{T} 4$ condition had the highest dimensional changes during the elevated temperature exposure, which was caused by precipitation of age hardening 
precipitates. This affected the lattice spacing of the $\alpha$-Al matrix (depletion of solute) resulting in initial dimensional changes $[5,9,65]$. Further dimensional changes occurred with the growth and transition of these precipitates, specifically the formation of $\theta^{\prime}$. The T6 condition was also prone to dimensional instability during the elevated temperature exposure, due to the transition of metastable precipitates to $\theta$, but not to the same degree as the T4 condition $[6,65]$.

The formation of the $\theta^{\prime}$ phase is significant with regards to distortion of $\mathrm{Al}-\mathrm{Cu}$ and $\mathrm{Al}-\mathrm{Si}-\mathrm{Cu}$ based alloys via the thermal growth mechanism. Hunsicker [5] found that in Al-Cu alloys, the precipitation of the $\theta^{\prime}$ phase resulted in the largest change in alloy volume, approximately three times larger than that associated to the precipitation of equilibrium $\theta$ (Figure 2.14 (b)) [5]. Therefore, thermal growth will be most significant in components where the $\theta$ ' phase forms during exposure to the elevated temperature service conditions (as for the T4 and T6 conditions) due to continued aging, as opposed to components stabilized prior to exposure to operating conditions (T7). It is important to note that the main consideration of thermal growth is the state of the $\mathrm{Cu}$ rich $\theta$ based phases, even in Mg-bearing $319 \mathrm{Al}$ alloys, since the volume fraction of these precipitates is significantly higher than that of Q' and $\beta^{\prime}$ and will therefore have a greater influence on the overall dimensional stability of the alloy.

\section{Section Summary}

In-depth studies have been carried out characterizing the artificial aging behaviour of the $319 \mathrm{Al}$ alloy. The influence of artificial aging parameters on the precipitation sequence of $\mathrm{Mg}$-free and Mg-bearing 319 alloys, as well as their effect on mechanical properties and dimensional stability was reviewed in-detail. This section indicated that although heat treatment to the T6 condition resulted in the peak mechanical properties for the $319 \mathrm{Al}$ alloy, the lack of dimensional stability makes this treatment condition unsuitable for components used in elevated temperature applications. Therefore, while optimizing the heat treatment parameters to maximize strength and minimize residual stress, it is necessary to ensure a thermally stable microstructure (T7 condition) to prevent distortion by thermal growth. In addition, the information reviewed in this section was used in Chapter 4 to determine if phase transformation contributed to in-service distortion of the $319 \mathrm{Al}$ alloy engine blocks. 


\subsection{Residual Stress}

An important consideration in heat treatment process optimization is the generation and relief of residual stresses. Residual stresses, which exist in an elastic body without the application of an external load, have been documented to be a major cause of warping following machining, dimensional instability and premature failure of engineering components [66, 67]. The development of residual stresses is typically attributed to uneven loading (mechanical or thermal), resulting in non-uniform plastic deformation of neighbouring regions in a constrained material [68]. However, if properly optimized, heat treatment has been observed to effectively relieve residual stress, thereby improving component integrity. The following sections will review the mechanisms of residual stress generation and relief due to thermal processes, such as heat treatment and quenching, and then examine residual stresses in automotive engine block components.

\subsubsection{Mechanisms of Residual Stresses Development}

\subsubsection{Thermal Gradients}

Thermal gradients are typically formed during quenching following heat treatment, which result in residual stress development. Residual stresses are formed by thermal gradients due to incompatibilities between neighbouring regions of the material. When a material is heated or cooled, individual regions of the material expand or contract freely by an amount proportional to $\alpha \Delta \mathrm{T}$, where $\alpha$ is the coefficient of thermal expansion of the material and $\Delta \mathrm{T}$ is the change in temperature $[69,70]$. However, for non-uniform heating or cooling, the different regions of the material expand or contract by differing amounts, which is dependent on the temperature at each specific region of the component. This results in a misfit between neighbouring regions, which restricts dimensional changes in each region and causes the generation of an elastic strain field to maintain continuity of the material $[69,70]$. Typically, however, when the temperature of the component is equilibrated, the thermal stresses disappear, unless localized plasticity induces permanent misfits within the component [71].

Several studies have examined thermally induced residual stresses from temperature gradients, produced due to high quench rates following heat treatment (i.e. cold water quenching) [72-77]. 
Figure 2.15 shows the influence of specimen temperature prior to water quenching on the surface residual stress for a $7010 \mathrm{Al}$ alloy block.

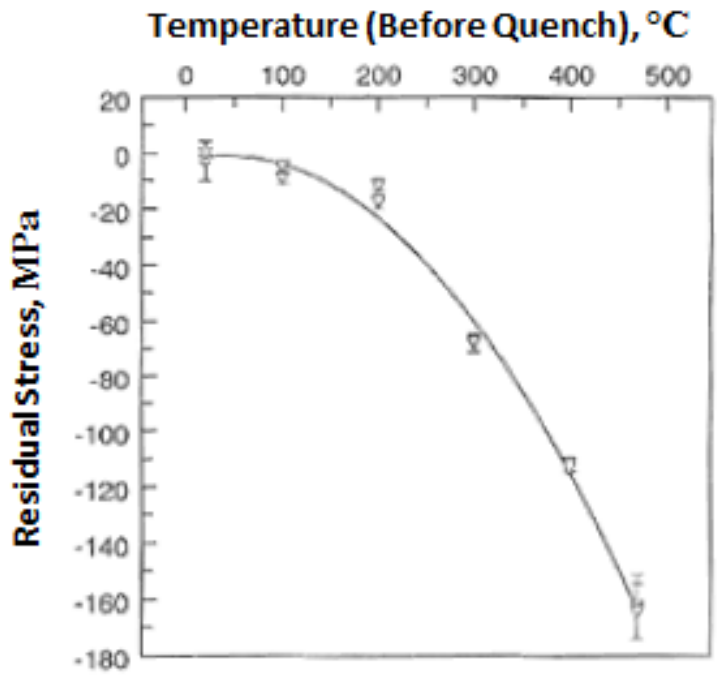

Figure 2.15: Effect of pre-quenching component temperature on surface residual stress generation during $40{ }^{\circ} \mathrm{C}$ water quenching [75].

Robinson and Tanner [75] found that the lower specimen temperature prior to quenching produced smaller thermal gradients between the specimen surface and the interior. In the quenching process, thermal gradients exist between the surface and the interior of the component since the surface is rapidly cooled to the temperature of the quenching medium while the interior cools at a slower rate. This rapid cooling caused the surface to be compressed plastically, with the magnitude of the compressive surface stress being directly related to the thermal gradient between the surface and the interior of the component [66, 72-77]. The plasticized surface then restricted free contraction of the slower cooling interior of the material, resulting in the interior remaining elastically in tension. Therefore, the reduced thermal gradient, produced by quenching at a lower specimen temperature (Figure 2.15), also reduced the compressive surface and bulk tensile residual stresses.

Previous research has also shown that the residual stresses generated from thermal gradients vary gradually in magnitude with depth from the specimen surface [75, 76]. For instance, Li et al. [76] measured the transition from highly compressive ( 200 $\mathrm{MPa})$ to tensile ( 10 MPa) residual stress, from the surface to a depth of $0.6 \mathrm{~mm}$, as shown in Figure 2.16. This component also had increased tensile residual stress with depth into the interior to equilibrate the residual stresses within the component. The residual stress profiles in Figure 2.16, from surface to interior, are 
characteristic of stresses developed due to non-uniform cooling following heat treatment, especially in thicker sections of the component [72-77].

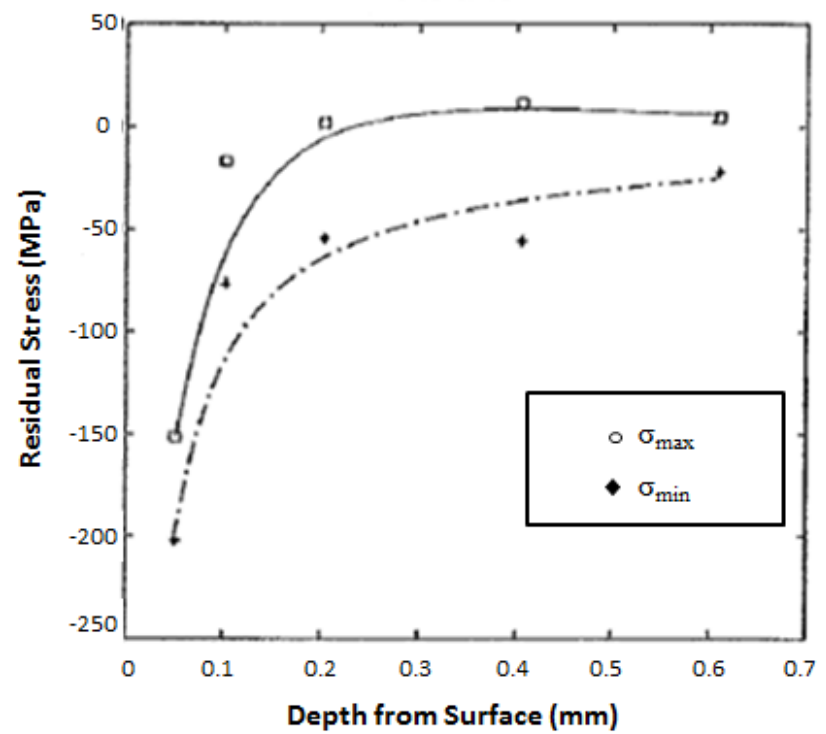

Figure 2.16: Residual stress profile with depth from the surface following quenching [76].

\subsubsection{Thermo-Mechanical Mismatch}

Development of residual stress can also occur for components containing dissimilar materials in direct contact with one another. This thermally induced residual stress has a magnitude that is directly proportional to the difference in thermal expansion coefficient between the dissimilar materials, as shown in Equations 4-a and 4-b [70]. These equations relate the residual stress $(\sigma)$ in each layer to the change in temperature $(\Delta T)$, the thermal expansion coefficient $(\alpha)$, the crosssectional area (A) and the modulus of elasticity (E), for each layer of the component.

$$
\begin{gathered}
\sigma_{1}=\left(\alpha_{1}-\alpha_{2}\right) \Delta T \frac{E_{2} E_{1} A_{1}}{E_{2} A_{2}+E_{1} A_{1}} \\
\sigma_{2}=-\left(\alpha_{1}-\alpha_{2}\right) \Delta T \frac{E_{2} E_{1} A_{2}}{E_{2} A_{2}+E_{2} A_{1}}
\end{gathered}
$$

During heating or cooling, the dissimilar materials change dimensions at different rates resulting in dimensional misfits between the adjacent materials $[66,70]$. However, to maintain continuity, the adjacent materials restrict the dimensional change resulting in the formation of elastic strain fields. Therefore, thermo-mechanical mismatch causes the individual sections of the component to be constrained by the surrounding sections due to differences in the rate of expansion or 
contraction (as a function of temperature) [70]. Development of residual stresses by thermomechanical mismatch is common in component assemblies containing dissimilar materials (e.g. $\mathrm{Al}$ alloy engine blocks with cast iron liners) as well as composite materials where the individual phases present have differences in thermal expansion, stiffness or yield strength [66].

The development of residual stress by thermo-mechanical mismatch was investigated by Carrera et al. [78], by calculating the difference in contraction in the $\mathrm{Al}$ and adjacent gray iron inserts during air quenching. In this study it was assumed that residual stresses were generated following the Al-Si eutectic formation $\left(\sim 550{ }^{\circ} \mathrm{C}\right)$. Based on the mismatch calculations, Carrera et al. [78] estimated that thermo-mechanical mismatch between the $319 \mathrm{Al}$ alloy and gray cast iron caused strains of 5000 microstrain in the Al. However, subsequent strain gauge measurements revealed significantly smaller strains in $\mathrm{Al}$, which was attributed to plastic deformation of $\mathrm{Al}$ during contraction, which reduced the residual stress.

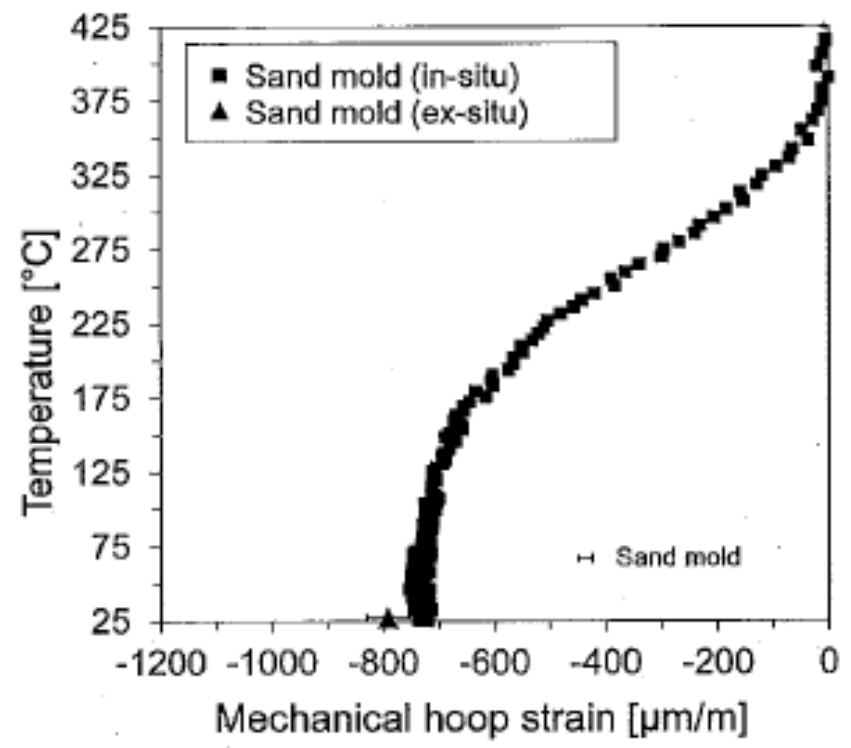

Figure 2.17: In-situ neutron diffraction measuring residual hoop strain development during casting of $319 \mathrm{Al}$ alloy containing tubular steel insert [79].

More recently, Reihle et al. [79] applied in-situ neutron diffraction to measure the development of residual hoop strain during solidification of a 319 type $\mathrm{Al}$ alloy around a cylindrical steel insert (Figure 2.17). Reihle et al. [79] found that solidification of $\mathrm{Al}$ around the steel insert resulted in the development of compressive strain in the steel insert, indicating tensile hoop strain in the surrounding Al. The results from in-situ neutron diffraction also indicated that residual strain from thermo-mechanical mismatch began to develop when the casting was at $350{ }^{\circ} \mathrm{C}$, up to a 
maximum strain of approximately 725 microstrain at $150{ }^{\circ} \mathrm{C}$, where no further strain development occurred with decreased temperature. Although no definitive explanation was given for the observed trends, the results indicate that the increased rigidity of the surrounding Al with decreased temperature reduced the ability of the Al to accommodate the misfit strain by plastic deformation. As such, at temperatures between 350 and $150{ }^{\circ} \mathrm{C}$ there was a build of tensile residual stress in $\mathrm{Al}$ (and equilibrating compressive stress in steel). Below $150{ }^{\circ} \mathrm{C}$, the reduction in system contraction compared to higher temperatures likely limited further stress development.

\subsubsection{Residual Stresses in Aluminum Engine Blocks}

For the reasons discussed in Section 2.4.1, Al alloy engine blocks containing gray iron cylinder liners are prone to the generation of tensile residual stresses in the vicinity of the cylinder bores during cooling following solidification and heat treatment. Previous research by Su et al. [80] illustrated this, using finite element simulations, which showed large tensile residual stress in the cylinder bores with a maximum magnitude of between 150 and $170 \mathrm{MPa}$ in the cylinder bridge region (Figure 2.18).

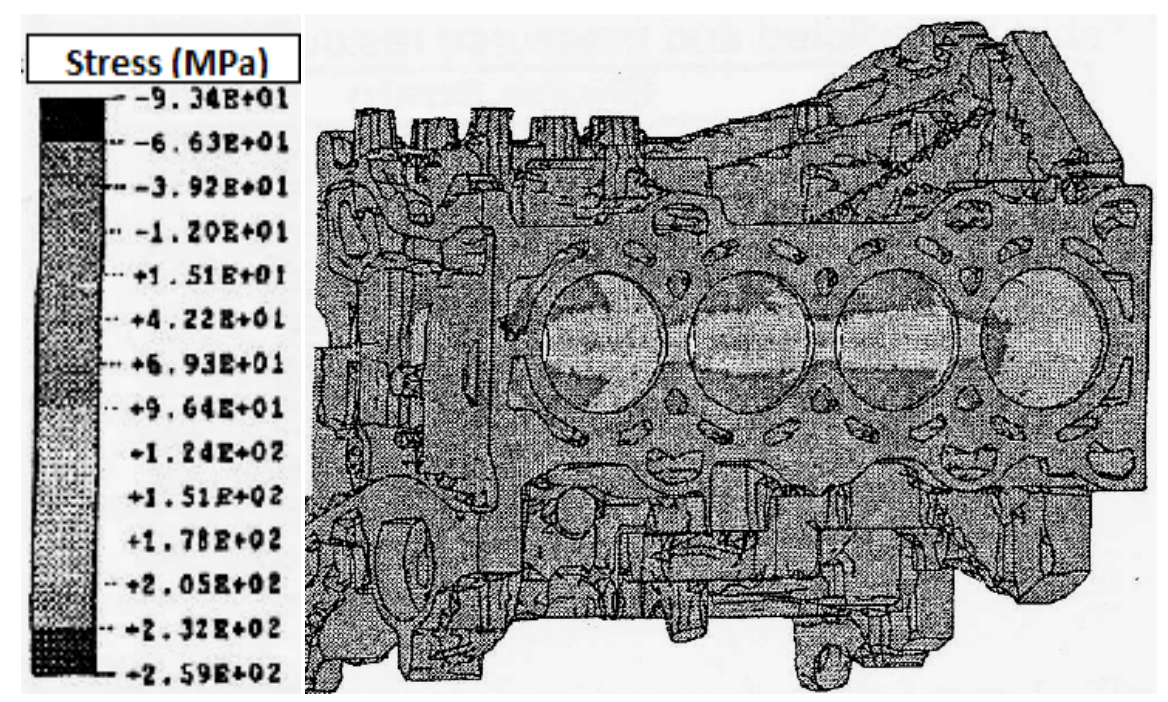

Figure 2.18: Finite element model showing residual stress profiles in Al engine block following SHT and quenching [80].

A similar result was observed by Carrera et al. [78], who found that large tensile residual stresses, with a magnitude of approximately $150 \mathrm{MPa}$, were present at the cylinder bridge following solidification (as-cast engine block). However, since strain gauges were used in this 
study, only the very top portion of the cylinder (near head deck of engine block) could be analysed. A more in-depth study was carried out by Sediako et al. [81] on an as-cast Al engine block using neutron diffraction, which permitted analysis to be completed throughout the entire cylinder depth in the hoop, axial and radial directions. In this study, it was determined that the hoop direction had the highest tensile residual stress magnitude, which approached $200 \mathrm{MPa}$. Residual stress development in $\mathrm{Al}$ alloy engine blocks has been attributed mainly to the thermomechanical mismatch, discussed in Section 2.4.1.2, between $\mathrm{Al}\left(\sim 2.4 \times 10^{-5} \mathrm{~K}^{-1}\right)$ and gray cast iron $\left(\sim 1.5 \times 10^{-5} \mathrm{~K}^{-1}\right)$ with thermal gradients being of secondary importance since these engine blocks are commonly quenched using forced air $[78,80]$.

In addition, previous research revealed that the tensile residual stress in the cylinder bore region approaches or exceeds the $319 \mathrm{Al}$ alloy yield strength ( 170 MPa) [29]. In combination with the service stresses exerted due to rapid expansion of the air-fuel mixture during combustion, the large tensile residual stresses in these engine blocks make them prone to permanent dimensional distortion. As such, stress relieving processes must be implemented prior to in-service use to prevent the occurrence of cylinder distortion.

\section{Section Summary}

Several studies have examined the generation of residual stress due to thermal processes such as post-heat treatment quenching. However, in-situ analysis of stress development during cooling after SHT has not been carried out for complex components containing dissimilar materials. Sections 5.2.2.2 and 5.2.3 of this dissertation develop an in-depth understanding of stress formation following SHT in Al engine blocks. The presence of these large tensile residual stresses may be detrimental to component integrity without methods of controlling stress magnitude. The next section reviews the mechanisms of residual stress relaxation via thermal annealing.

\subsubsection{Mechanisms of Residual Stress Relaxation}

Residual stress relaxation can be achieved via plastic deformation or atomic rearrangement (i.e. phase transformation, recrystallization). The main methods employed to relieve residual stresses are mechanical methods, which involve applying a load to induce plasticity, or thermal methods, 
where elevated temperature exposure reduces alloy yield strength and triggers plastic deformation and creep [82]. In cast components with complex geometries (e.g. engine blocks) thermal methods are used to relieve residual stress, and as such will be the focus of this section.

Heat treatment processes, such as annealing, solutionizing and artificial aging, have been shown to be effective in the relieving residual stresses in several previous studies [72, 75, 80, 83-85]. Regarding thermally induced residual stress relaxation, two main mechanisms account for this phenomenon. The first is plasticity caused by reduced yield strength at elevated temperature. This mechanism results in instantaneous relief of stress as the temperature is increased. The second mechanism is a creep based mechanism, which allows stress relief to occur over time [71]. To model creep-based residual stress relief in stainless steel, Holzapfel et al. [86] developed an empirical Avrami relation for thermally activated stress relief, as shown in Equation 5.

$$
\sigma^{r s}(T, t)=\sigma_{0}^{r s} \exp \left\{-\left[\operatorname{Cexp}\left(\frac{-\Delta H}{K T}\right) t\right]^{m}\right\}
$$

Where, $\sigma^{r s}(T, t)$ is the residual stress following annealing at temperature, $\mathrm{T}$ (in kelvin), for time, $\mathrm{t}$ (in minutes), $\sigma_{0}^{r s}$ is the initial residual stress, $\Delta \mathrm{H}$ is the activation enthalpy for stress relaxation, $\mathrm{K}$ is the Boltzmann's constant and $\mathrm{c}$ and $\mathrm{m}$ are material constants.

Although no extension to the relationship in Equation 5 was developed for other alloys, previous research has indicated that these relaxation mechanisms apply for other alloy systems as well. For instance, Godlewski et al. [72, 87] examined the relief of residual strain as a function of time at varying temperatures during artificial aging of E319 Al alloy (measurements made after each time period, following specimen cooling) using strain gauge rosettes (Figure 2.19). This study found that residual strain relaxation was rapid at the beginning, followed by a region where strain relief was nearly linear with aging time. In addition, increased temperature resulted in accelerated stress relief in the initial region, although the linear region had a similar slope. Godlewski et al. $[72,87]$ characterized the residual stress relief behaviour as following power-law (dislocationclimb controlled) creep, with the rapid initial stress relief being characteristic of primary creep while the linear region is characteristic of secondary (steady-state) creep. 


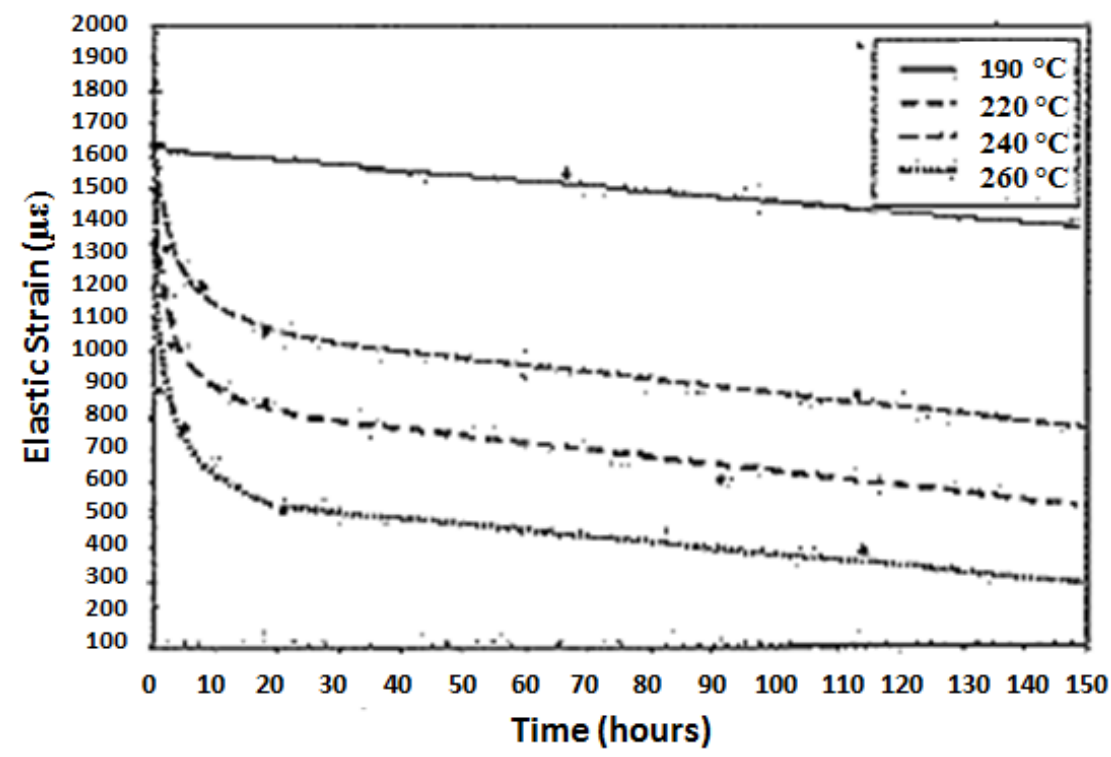

Figure 2.19: Relief of residual stress as a function of time and temperature during artificial aging of $319 \mathrm{Al}$ alloy [72].

Further studies examining residual stress relief during heat treatment were carried out using in-situ neutron diffraction. Rolph et al. [83] examined the relief of residual stress as a function of time during artificial aging of RR1000 Ni-based superalloy (Figure 2.20). This study found that aging at $760{ }^{\circ} \mathrm{C}$ (typical aging temperature for this alloy) resulted in a similar stress relief profile to that observed by Godlewski et al. [72, 87]. The trend included initially rapid stress relief (200 MPa in first 30 minutes) followed by a nearly linear stress relief profile for the remainder of the heat treatment. These trends also supported power-law creep as the principle mechanism of stress relief during artificial aging.

In-situ neutron diffraction was also carried out by Chen et al. [85] to track the relief of strain during post-weld annealing (Figure 2.21). The results of Chen et al. [85] indicated that specimen heating to the heat treatment temperature resulted in approximately $35 \%$ reduction in residual stress. This stress relief was attributed to the reduction of yield strength with increased temperature, producing instantaneous relief of stress. Furthermore, annealing temperatures below $450{ }^{\circ} \mathrm{C}$ did not cause significant stress relief with time, while annealing at $650{ }^{\circ} \mathrm{C}$ produced a relatively large relief of stress with time due to creep. This study illustrated that relief of residual stress during heat treatment was accomplished by instantaneous relaxation and by time-dependant creep, while other previous studies only show the creep portion since the temporal resolution was not sufficient to capture stress relief during heat-up. 


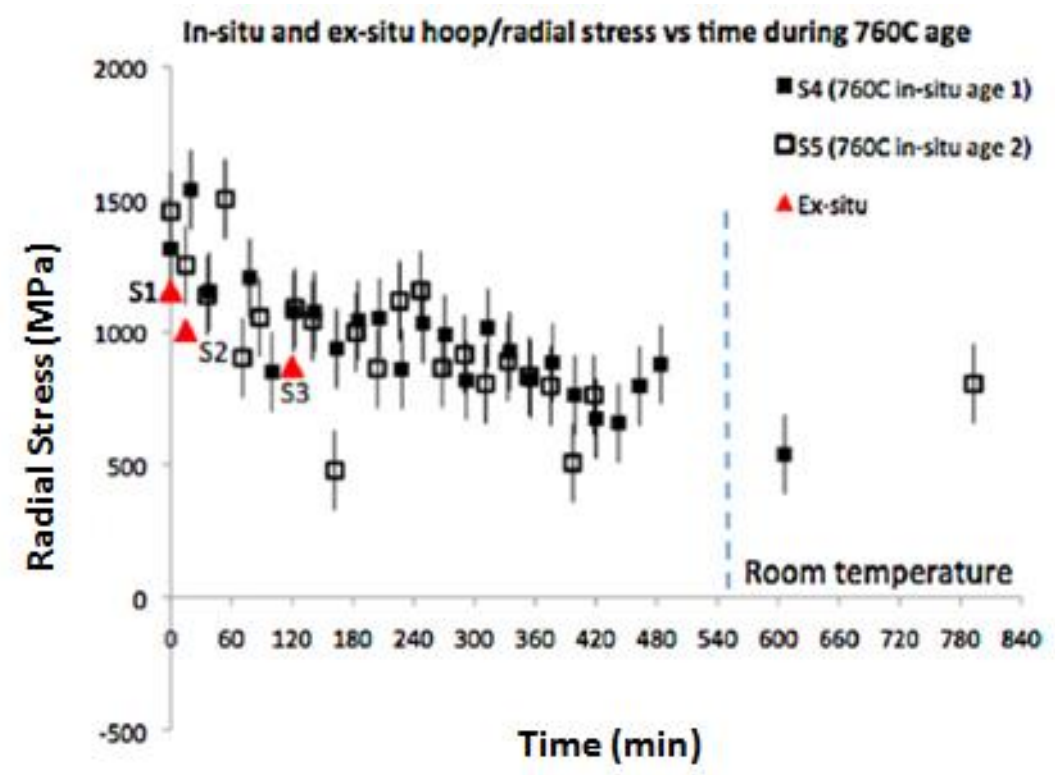

Figure 2.20: Transient relief of residual stress, measured using in-situ neutron diffraction for artificial aging of RR1000 Ni-based superalloy [83].

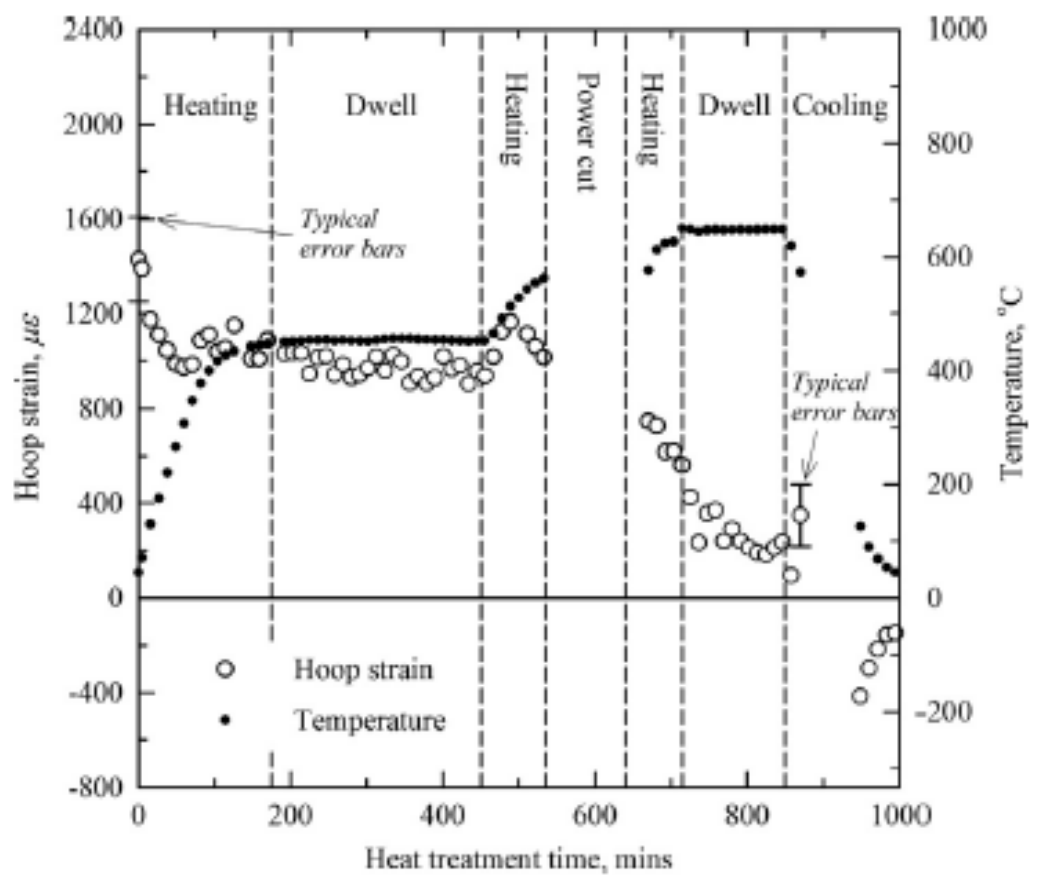

Figure 2.21: Transient relief of residual stress, measured using in-situ neutron diffraction for post-welding annealing heat treatment of a steel pipe [85].

\subsubsection{Residual Stress Relief in Aluminum Engine Blocks}

Similar to the studies discussed in Section 2.4.3, heat treatment influences the residual stress profiles in Al alloy engine blocks. Studies carried out by Wiesner et al. [88], using X-ray and 
neutron diffraction, indicated a significant relief in tensile residual stress in the bulkhead region of the $\mathrm{Al}$ engine block following heat treatment to a T7 temper (commonly used heat treatment schedule for $\mathrm{Al}$ engine blocks). Carrera et al. [78] also observed that T7 heat treatment reduced the magnitude of tensile residual stress at the cylinder bridge of the engine block, although the limitations of strain gauges permitted only the top of the cylinder to be measured.
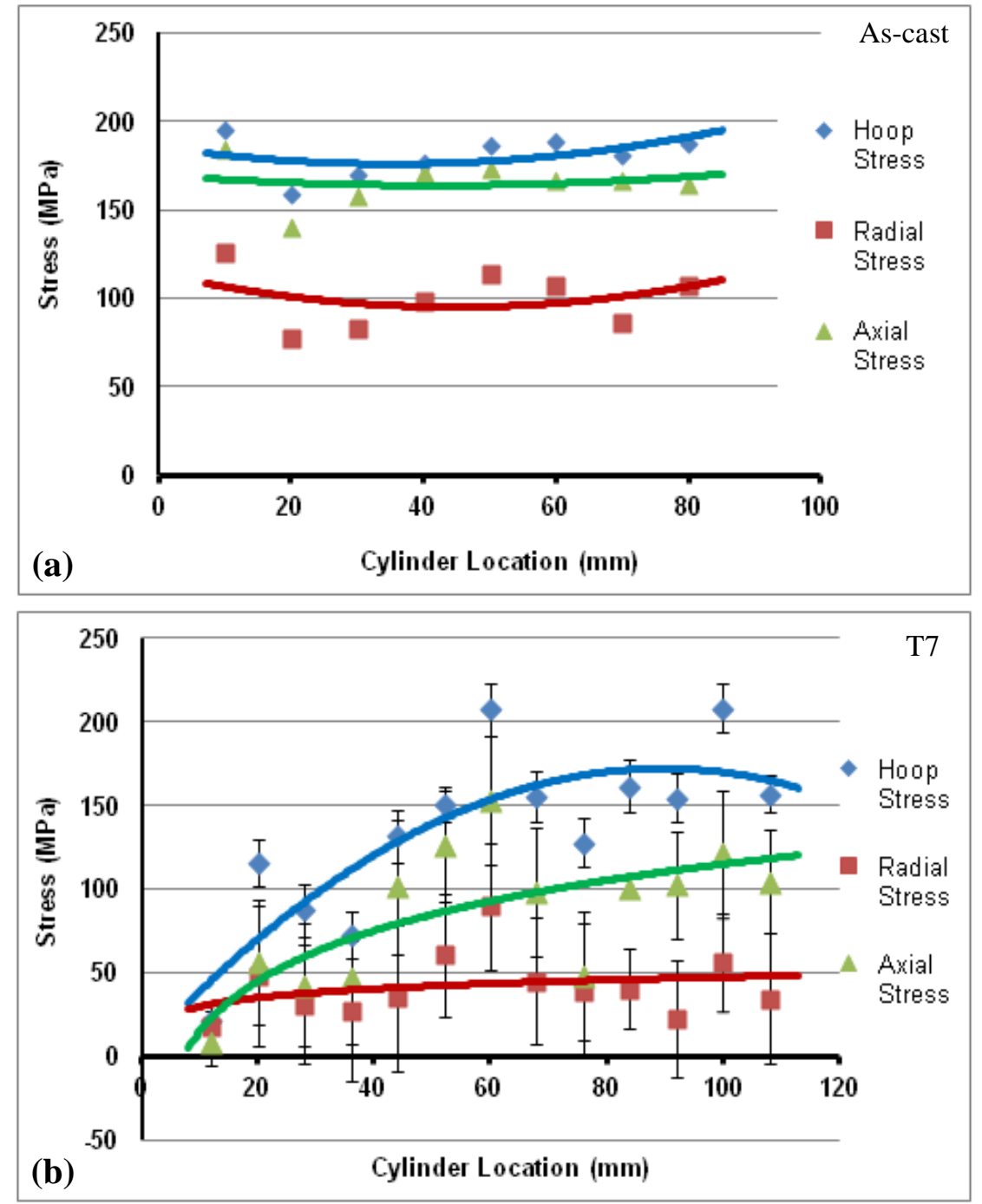

Figure 2.22: Residual stress profiles for V6 Al alloy engine blocks in: (a) as-cast, (b) T7 heat treated conditions [89].

Residual stress relief was assessed from top to bottom along the cylinder bridge by Lombardi [89] (current author) as a precursor study to this dissertation, using ex-situ neutron diffraction (Figure 2.22). This study determined that relief of residual stress during $\mathrm{T} 7$ heat treatment of a $319 \mathrm{Al}$ alloy engine block was dependant on microstructure. Regions of the cylinder that were characterized by coarse microstructure (cylinder depth: 0-40 $\mathrm{mm}$ ) had an approximately $90 \%$ 
reduction in residual stress by $\mathrm{T} 7$ treatment as opposed to regions with fine microstructure (cylinder depth: $90-120 \mathrm{~mm}$ ) that had a $20 \%$ reduction in residual stress. The mechanism governing residual stress relief in $\mathrm{Al}$ engine blocks containing gray iron liners, however, is unknown based on these previous studies [78, 88, 89] and require further examination to develop a more thorough understanding of these phenomena.

\section{Section Summary}

Residual stress relaxation by heat treatment was reviewed with the aim of understanding the mechanisms causing this relief. Previous studies have determined that residual stress is relieved by a combination of instantaneous relief, caused by reduced yield strength with increased temperature, and time-dependant relief due to creep. Although this phenomenon was studied using ex-situ and in-situ methods, there is a lack of information on the transient stress relief behaviour in components with dissimilar materials during SHT. In addition, in Al engine blocks, T7 heat treatment was found to partially relieve residual stress, but these studies did not observe the individual influence of SHT and artificial aging on the overall residual stress relief. For proper heat treatment process optimization, it is important to observe how residual stress is relieved with time during SHT at varying temperatures, enabling reduced stress magnitude, the elimination of related defects (such as distortion) and improved process efficiency. This comprehensive in-situ analysis of residual strain and stress along the cylinder bridge of Al alloy engine blocks containing gray iron liners will be presented in Section 5.2 of this dissertation.

\section{Chapter Summary}

This chapter provided a review of heat treatment of the $319 \mathrm{Al}$ alloy system. Specifically, the factors influencing secondary phase dissolution and incipient melting (alloy composition, temperature, time, particle coarseness and morphology) in these alloys were reviewed with the aim of relating these factors to the mechanical properties. Artificial aging processes (T6 and T7 tempers) were also reviewed in detail and related to both the mechanical properties and elevated temperature dimensional stability. The mechanisms associated to residual stress generation (thermal gradients and thermo-mechanical mismatch) and relief (instantaneous and creep-based) were also reviewed in detail. 
This chapter illustrated the mechanisms related to alloy strengthening and residual stress development and relief. It established the background for a thorough investigation on identifying the cause of distortion in $\mathrm{Al}$ engine blocks containing cast iron cylinder liners and then eliminating this distortion via heat treatment process optimization. This current research uses a novel lab scale approach to replicate the effect of heat treatment on microstructure and mechanical properties. In addition, ex-situ and in-situ neutron diffraction was used to develop a more thorough understanding of residual stress relief during heat treatment. The following chapter describes the experimental methodology of this research. 


\section{Chapter 3: Experimental Methodology}

The experimental methods utilized in this research are presented in this chapter. The project outline, breaking down the analysis that was performed on the engine block and billet castings, is outlined in Section 3.1. Section 3.2 describes the experimental methodology carried out to determine the mechanism of cylinder distortion in $\mathrm{Al}$ engine blocks, which includes the manufacturing parameters (Section 3.2.1), measurement of macro-distortion (Section 3.2.2) microstructural analysis (Section 3.2.3), tensile testing (Section 3.2.4) and ex-situ neutron diffraction residual stress mapping (Section 3.2.5). Section 3.3 shows the experimental procedure for optimizing the heat treatment parameters for the $319 \mathrm{Al}$ alloy engine blocks. This includes the casting parameters to produce replicating billet castings (Section 3.3.1), the investigated SHT parameters (Section 3.3.2) and the methodology and specimen preparation used for in-situ and ex-situ neutron diffraction stress and strain mapping during SHT (Section 3.3.3).

\subsection{Project Outline}

This project was a collaborative study between the Centre for Near-net-shape Processing of Materials at Ryerson University, Nemak of Canada Corporation and the CNL-Canadian Neutron Beam Centre (CNBC). This project aimed to first determine the cause of permanent dimensional distortion in the cylinder bores of $\mathrm{Al}$ alloy engine blocks and then optimize (maximize strength and minimize residual stress) the heat treatment parameters to eliminate distortion and improve process efficiency. This analysis, outlined in the flow chart shown in Figure 3.1, involved indepth microstructural characterization and mechanical testing of engine blocks and replicating billet castings in different heat treatment conditions. Furthermore, extensive ex-situ and in-situ neutron diffraction was carried out on the engine blocks to determine the cause of distortion and the effect of varying heat treatment parameters on residual stress relief. 


\section{Elimination of Cylinder Distortion in Aluminum Engine Blocks}

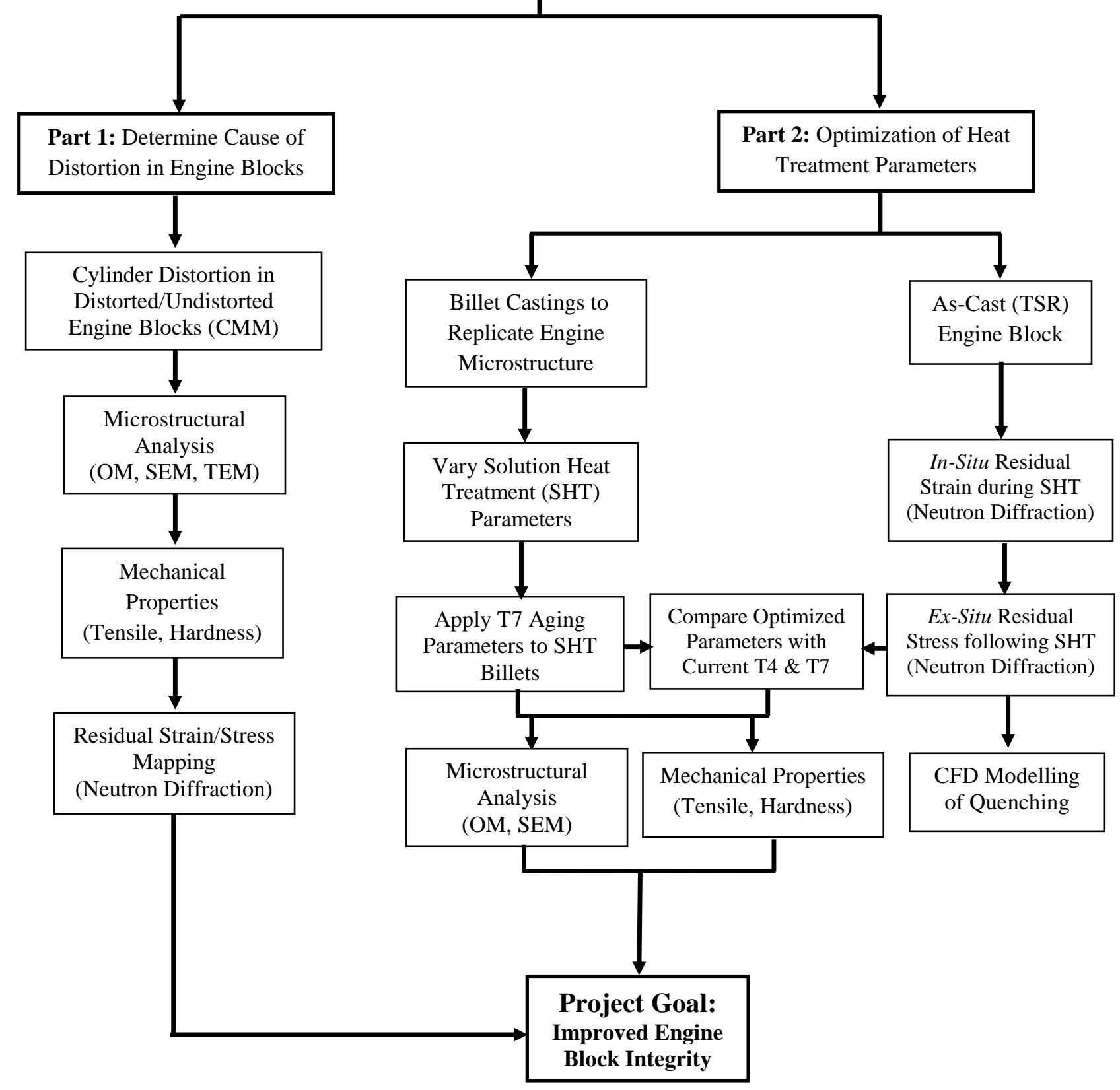

Figure 3.1: Flow chart showing the proposed analysis to be carried out during this study. 


\subsection{Analysis of the Mechanism of Cylinder Distortion}

Determining the cause of cylinder distortion in $\mathrm{Al}$ engine blocks containing gray iron liners was the first part of this project, which involved a comprehensive analysis of macro-distortion, microstructure, mechanical properties and residual stress of distorted and undistorted service tested engine blocks. The experimental methodology for this portion of the project is outlined in Sections 3.2.1 to 3.2.4.

\subsubsection{Current Engine Block Production Parameters}

The composition for the top and bottom of the cylinder of the modified $319 \mathrm{Al}$ alloy engine blocks (measured using an optical emission spectrometer) are shown in Tables 3.1 and 3.2. The composition was measured at these two locations of the cylinder bridge to ensure relative chemical homogeneity throughout the cylinder depth. The error represents the standard deviation of the measurements, taken over a minimum of three samples per cylinder bridge location.

Table 3.1: Composition for the top of the cylinder bridge for modified 319 engine blocks (wt \%).

\begin{tabular}{|c|c|c|c|c|c|c|c|c|c|c|}
\hline Si & $\mathbf{C u}$ & $\mathbf{Z n}$ & $\mathbf{F e}$ & $\mathbf{M g}$ & $\mathbf{M n}$ & $\mathbf{T i}$ & $\mathbf{N i}$ & $\mathbf{C r}$ & $\mathbf{S r}$ & $\mathbf{A l}$ \\
\hline 8.010 & 2.885 & 0.642 & 0.672 & 0.389 & 0.410 & 0.132 & 0.086 & 0.032 & 0.015 & Bal. \\
\pm 0.278 & \pm 0.197 & \pm 0.040 & \pm 0.051 & \pm 0.038 & \pm 0.006 & \pm 0.004 & \pm 0.015 & \pm 0.006 & \pm 0.002 & \\
\hline
\end{tabular}

Table 3.2: Composition for the bottom of the cylinder bridge for modified 319 engine blocks (wt \%).

\begin{tabular}{|c|c|c|c|c|c|c|c|c|c|c|}
\hline $\mathbf{S i}$ & $\mathbf{C u}$ & $\mathbf{Z n}$ & $\mathbf{F e}$ & $\mathbf{M g}$ & $\mathbf{M n}$ & $\mathbf{T i}$ & $\mathbf{N i}$ & $\mathbf{C r}$ & $\mathbf{S r}$ & $\mathbf{A l}$ \\
\hline 7.902 & 2.912 & 0.537 & 0.70 & 0.36 & 0.397 & 0.145 & 0.047 & 0.050 & 0.016 & Bal. \\
\pm 0.198 & \pm 0.382 & \pm 0.16 & \pm 0.128 & \pm 0.093 & \pm 0.055 & \pm 0.025 & \pm 0.022 & \pm 0.006 & \pm 0.005 & \\
\hline
\end{tabular}

The engine blocks of known process history and chemical composition were obtained from the Nemak Centre of Engineering in Windsor, Canada. Manufacturing of the engine blocks was done using the Cosworth casting process in conjunction with precision (chemically bound) sand moulds. The pouring temperature of molten $319 \mathrm{Al}$ alloy was $720{ }^{\circ} \mathrm{C}$. In addition, prior to pouring, gray cast iron cylinder liners (preheated to $400{ }^{\circ} \mathrm{C}$ ) and a $\mathrm{Cu}$ bulkhead chill plate (ambient temperature) were inserted into the sand mould. 
The gray cast iron cylinder liners had circumferential "ribs" along the length of the cylinder, as shown in Figure 3.2 (a). Molten Al flowed around these ribs during casting, enabling a ribbed surface on the $\mathrm{Al}$ side of the $\mathrm{Al}-\mathrm{Fe}$ interface of the cylinder bores following solidification (Figure 3.2 (b)). This facilitated better mechanical interlocking (no metallurgical bond between Al and $\mathrm{Fe}$ ) with the surrounding $\mathrm{Al}$ alloy and held the liners in place during engine service operation.
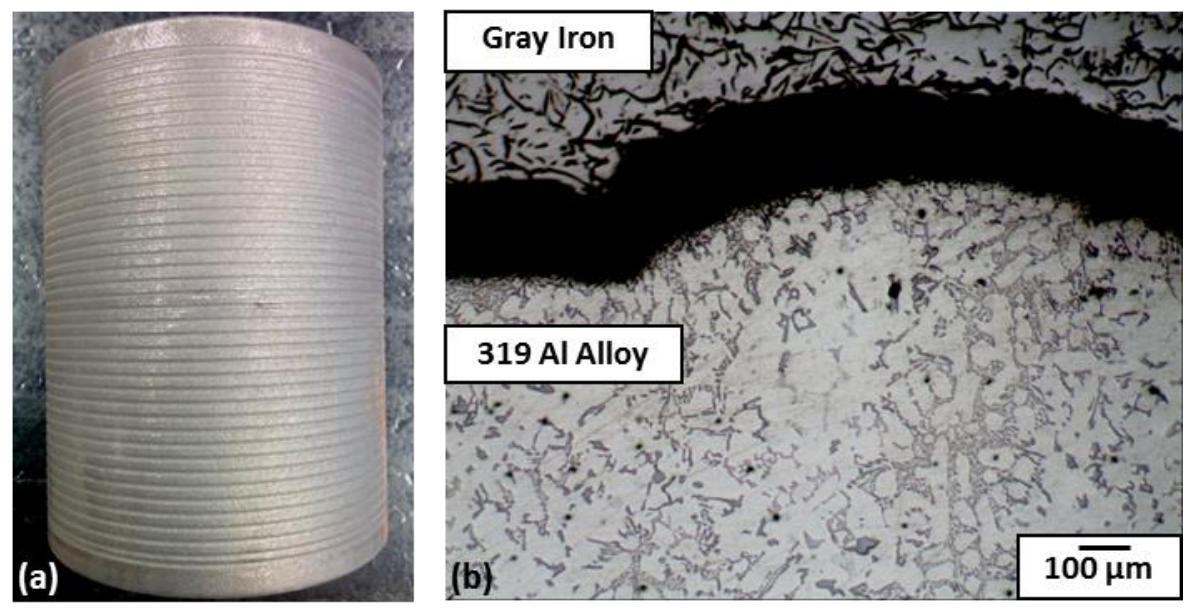

Figure 3.2: (a) Image showing the side view of a gray iron cylinder liner used in the engine blocks, (b) optical micrograph showing the Al-Fe liner interface.

Following casting, the engine blocks were subjected to a thermal sand reclamation (TSR) treatment (to remove engine block casting from sand mould), SHT, forced air quenching ( 3 minutes in duration) and artificial aging to a T7 temper. The average cooling rate during forced air quenching after SHT (calculated during the first 60 seconds of the quenching process) of the distorted and undistorted engine blocks was approximately 40 and $100{ }^{\circ} \mathrm{C} /$ minute, respectively. In addition, select engine blocks were machined to service specifications (including honing of the cylinder bores) and "service tested" on an engine dynamometer, to replicate field operation of an automobile and determine the distortion susceptibility. The processing parameters used in this portion of the study are shown in Table 3.3.

Table 3.3: Current parameters used for heat treatment and service testing of the aluminum engine blocks.

\begin{tabular}{ccc}
\hline Treatment & Temperature $\left({ }^{\circ} \mathbf{C}\right)$ & Time $($ Hours $)$ \\
\hline Thermal Sand Reclamation & 495 & 1 \\
Solution Heat Treatment & 470 & 7.5 \\
Aging to T7 Temper & 240 & 5.5 \\
Dyno Testing & 180 & 20 \\
\hline
\end{tabular}




\subsubsection{Measurement of Cylinder Distortion}

Distortion in the cylinder bore was measured in the distorted and undistorted service tested engine blocks using a co-ordinate measuring machine (CMM). This analysis was carried out up to a maximum cylinder depth of $100 \mathrm{~mm}$ at depth intervals of $10 \mathrm{~mm}$. At each analysed depth, measurements were taken every $15^{\circ}$ along cylinder periphery allowing for the quantification of distortion in terms of radial distortion, roundness (deviation or non-circularity compared to a nominal, undistorted circle [90]) and cylindricity (deviation from a nominal undistorted cylinder with regards to circularity, straightness and taper throughout the surface of the cylinder [90]).

\subsubsection{Microstructural Analysis}

The microstructures of the distorted and undistorted engine blocks were examined at the cylinder bridge locations shown in Figure 3.3. The cylinder bridge was selected for analysis since this region was determined as a critical location in the engine block with regards to tensile residual stress, as illustrated in previous research $[78,80]$.

Microstructural analysis was performed at the top, middle and bottom of the $\mathrm{Al}$ cylinder bridge to observe variations in microstructure with increased cylinder depth and between the distorted and undistorted engine blocks. The analyzed regions are illustrated with a cross-section of the cylinder bridge in Figure 3.4.

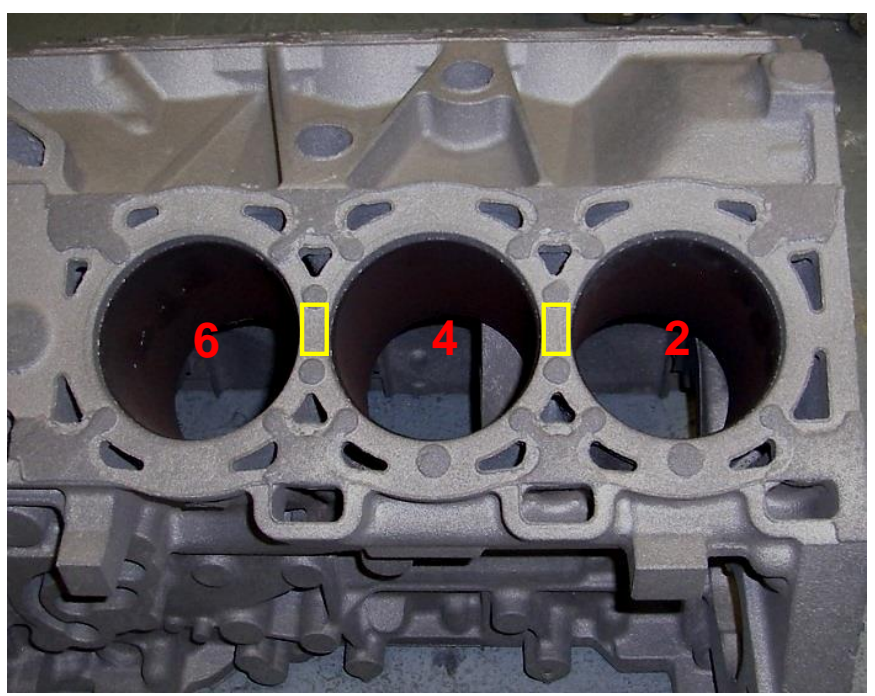

Figure 3.3: Top view of the $319 \mathrm{Al}$ alloy engine block indicating analyzed locations and cylinder numbering. 


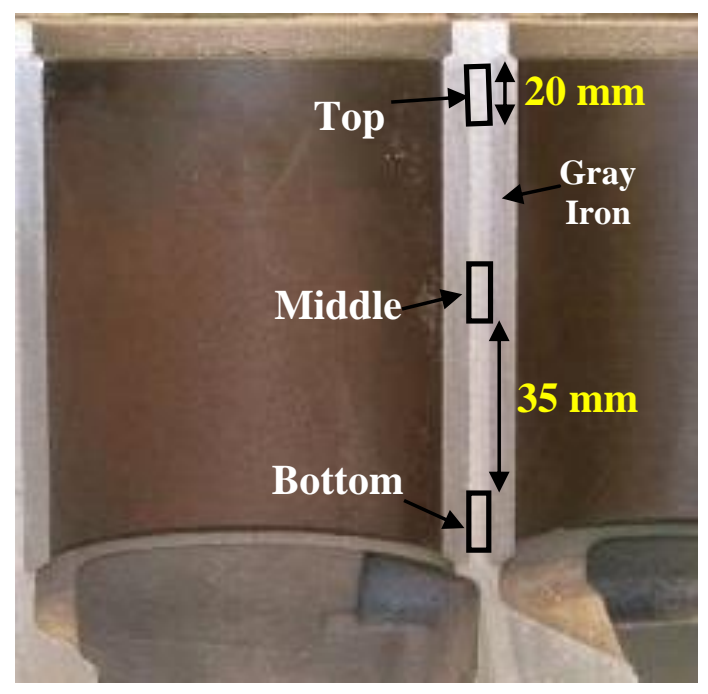

Figure 3.4: Cross-section of the cylinder bridge showing sections analyzed along the cylinder depth.

Optical microscopy $(\mathrm{OM})$ was first used to observe the dendritic structure and measure the secondary dendrite arm spacing (SDAS) at each section of the cylinder bridge. A Buehler Viewmet optical microscope instrumented with a charge-coupled device (CCD) camera was used to measure the SDAS in conjunction with Buehler Omnimet image analysis software. The average SDAS was then calculated using Equation 6, where $L_{p}$ is the length of the primary dendrite and $\mathrm{N}_{\mathrm{s}}$ is the number of secondary dendrite arms [91]. The SDAS results were obtained by measuring a minimum of 25 dendrites per sample, and a minimum of two samples per condition.

$$
S D A S=\frac{L_{p}}{N_{S}-1}
$$

Scanning electron microscopy (SEM) was then carried out to characterize the morphology of intermetallic phases (JEOL JSM-6380LV scanning electron microscope) while OM was used to observe the Al-Si eutectic morphology. In addition, energy dispersive X-ray spectroscopy (EDX) was performed on the secondary phases to determine the composition of phases in the microstructure (minimum 5 particles of each phase), which assisted in determining the stoichiometry of secondary phases using X-ray diffraction (XRD).

The $\mathrm{Al}_{2} \mathrm{Cu}$ volume fraction was quantified along the cylinder bores of the distorted and undistorted engine blocks using a minimum of 50 SEM backscattered electron images (magnification of 200x) in conjunction with quantitative image analysis. Backscattered electron images were used due to the good contrast between $\mathrm{Al}_{2} \mathrm{Cu}$ particles and the $\mathrm{Al}$ matrix. 
Following optical and scanning electron microscopy, the precipitates within the Al dendrites of the age hardened engine blocks (distorted and undistorted) were characterized using transmission electron microscopy (TEM). The morphology of the precipitates was analysed using bright field TEM images, while the composition of the precipitates were analysed using EDX. This analysis was carried out to determine whether cylinder distortion was caused by phase transformation induced thermal growth, as reviewed in Section 2.3.2.3.

\subsubsection{Sample Preparation for OM and SEM Analysis}

The specimens for optical and scanning electron microscopy were extracted from the cylinder bridge (locations shown in Figure 3.4) by initially using a horizontal bandsaw and subsequently a Buehler abrasive cut off wheel to section the cylinder bridge into individual samples. Once sectioning was completed, the samples were ground and polished using the procedure summarized in Table 3.4.

Table 3.4: Metallographic polishing procedure

\begin{tabular}{cccc}
\hline Step & Abrasive Grit/ Polishing Cloth & RPM & Time (minutes) \\
\hline 1 & $320 \mathrm{SiC}$ paper & 200 & Until plane \\
2 & $600 \mathrm{SiC}$ paper & 200 & 2 \\
3 & $1200 \mathrm{SiC}$ paper & 200 & 2 \\
4 & $5 \mu \mathrm{m} \mathrm{Al} \mathrm{O}_{3} /$ Leco Lecloth & 150 & 3 \\
5 & $3 \mu \mathrm{m} \mathrm{diamond} \mathrm{suspension} \mathrm{/} \mathrm{Leco} \mathrm{Lecloth}$ & 150 & 2 \\
6 & $0.05 \mu \mathrm{m}$ colloidal silica / Buehler Chemomet & 150 & 1 \\
\hline
\end{tabular}

For the initial grinding stages (steps 1-3), the samples were cleaned using water and dried with compressed air. In contrast, the coarse polishing stage (steps 4 and 5) used an ultrasonic cleaner with water to remove excess $\mathrm{Al}_{2} \mathrm{O}_{3}$ or diamond particles that may have been stuck to the surface. Furthermore, prior to the completion of the final (fine) polishing stage (step 6), the polishing cloth (Buehler Chemomet) was flushed with water for 10 seconds to remove the colloidal silica from the sample surface and prevent the formation of a surface film. At the end of the polishing procedure, the samples were thoroughly washed with ethanol and dried with compressed air. 


\subsubsection{Sample Preparation for TEM Analysis}

Samples for TEM analysis were extracted from the top, middle and bottom of the cylinder of distorted and undistorted engine blocks. A low speed saw at approximately $200 \mathrm{rpm}$ was used to cut $500 \mu \mathrm{m}$ thick plates from bulk samples that were previously used in OM and SEM analysis. The plates were mounted on $20 \mathrm{~mm}$ diameter cylindrical sample holders using double sided tape and thinned with successively finer SiC papers on a polishing wheel. The samples were held with minimal applied pressure to prevent specimen bending. The abrasive grinding procedure to produce $120 \mu \mathrm{m}$ thick foils is given in Table 3.5 .

Table 3.5: Abrasive grinding procedure used to produce thin plate samples for TEM analysis.

\begin{tabular}{cccc}
\hline Step & Abrasive Grit & RPM & Time (minutes) \\
\hline 1 & $320 \mathrm{SiC}$ & 200 & Until plane \\
2 & $600 \mathrm{SiC}$ & 200 & 5 \\
3 & $1200 \mathrm{SiC}$ & 200 & Until sample thickness $<120 \mu \mathrm{m}$ \\
\hline
\end{tabular}

Following the thinning process, the samples were immersed in toluene for 12 hours to dissolve the glue on the double sided tape, allowing easy removal of the samples from the sample holder without risk of bending. Once removed, the sample thickness was measured using a digital calliper to ensure the samples were thinned below $120 \mu \mathrm{m}$. For samples that did not meet the required thickness, the 1200 grit $\mathrm{SiC}$ step was repeated.

Table 3.6: Optimized parameters used in twin-jet electropolishing.

\begin{tabular}{cc}
\hline Parameter & Description \\
\hline Electrolyte & $30 \% \mathrm{HNO}_{3}, 70 \% \mathrm{CH}_{3} \mathrm{OH}$ \\
Electrolyte Temperature & $-30{ }^{\circ} \mathrm{C}($ Cooled with liquid nitrogen) \\
Electrolyte Flow Rate & 10 flow units (on a full scale of 50) \\
Electrolyte Flow Mode & Dual flow \\
Voltage & $12.5 \mathrm{~V}$ \\
Process Time & Varies depending on initial foil thickness \\
\hline
\end{tabular}

The thin foil samples were cut into $3 \mathrm{~mm}$ diameter disks using a Gatan Model 659 disc punch and placed in a Struers TenuPol-5 twin-jet electropolisher. The electropolishing parameters used to obtain the transmission region in the samples are outlined in Table 3.6. The temperature, flow 
rate and composition of the electrolyte control the material removal rate along with the applied voltage [92]. Therefore, initial trials were carried out to optimize these process parameters.

\subsubsection{Tensile Testing}

Tensile testing was performed on samples extracted from the Al cylinder bridge and adjacent gray iron cylinder liners of distorted and undistorted engine blocks. This analysis was carried out at ambient temperature and at the temperature to which the cylinder bridge is heated to when the engine is exposed to operating conditions $\left(\sim 180{ }^{\circ} \mathrm{C}\right.$, Courtesy of Dr. Robert MacKay, Nemak of Canada Corp.). The engine operating temperature was measured by the industrial partner by inserting thermocouples into the cylinder bridge (near the top of the cylinder) during dyno testing. A range of temperatures with cylinder depth is expected due to combustion occurring near the top of the cylinder, however, thermocouples could not be feasibly inserted at increasing depths to confirm the degree of this gradient. As such, the measured value was used as an approximated cylinder bridge temperature.

Although size restrictions prevented the top and bottom of the cylinder bridge from being tested separately, the gauge length of the tensile samples (ASTM B557M subsized standard [93]) was in the centre of the cylinder to estimate the average strength of the cylinder bridge, while also differentiating the tensile properties of the distorted and undistorted engine blocks. Tensile testing at the operating temperature enabled engine block strength during service conditions to be determined, allowing the development of the relationship between distortion, microstructure, yield strength at operating temperature and residual stress.

\subsubsection{Ex-situ Residual Strain and Stress Measurements}

Residual strains and stresses were measured for undistorted and distorted (dyno tested) engine blocks using ex-situ neutron diffraction (ND) at the Canadian Neutron Beam Centre (CNBC) in Chalk River, Ontario, Canada. This analysis was referred to as ex-situ since it was carried out at ambient temperature following heat treatment and service testing. A schematic of the neutron diffraction setup, showing the "scattering vector" (Q), for the constant flux source spectrometer used in this study is shown in Figure 3.5. 
The neutron diffraction technique enabled non-destructive examination of residual stress within the specimen. The constant flux source spectrometer at CNBC used a Ge monochromating crystal to convert the "white" neutrons (many wavelengths) from the reactor into a monochromated incident beam with a fixed wavelength $(\lambda)$.

The specimens were arranged such that the gauge (sampling) volume, formed by the intersection of the incident and diffracted beams, was located at each region of interest. In addition, the specimens were oriented such that the $\mathrm{Q}$ vector was parallel to the direction of the strain component (i.e. hoop, radial, axial) being measured.

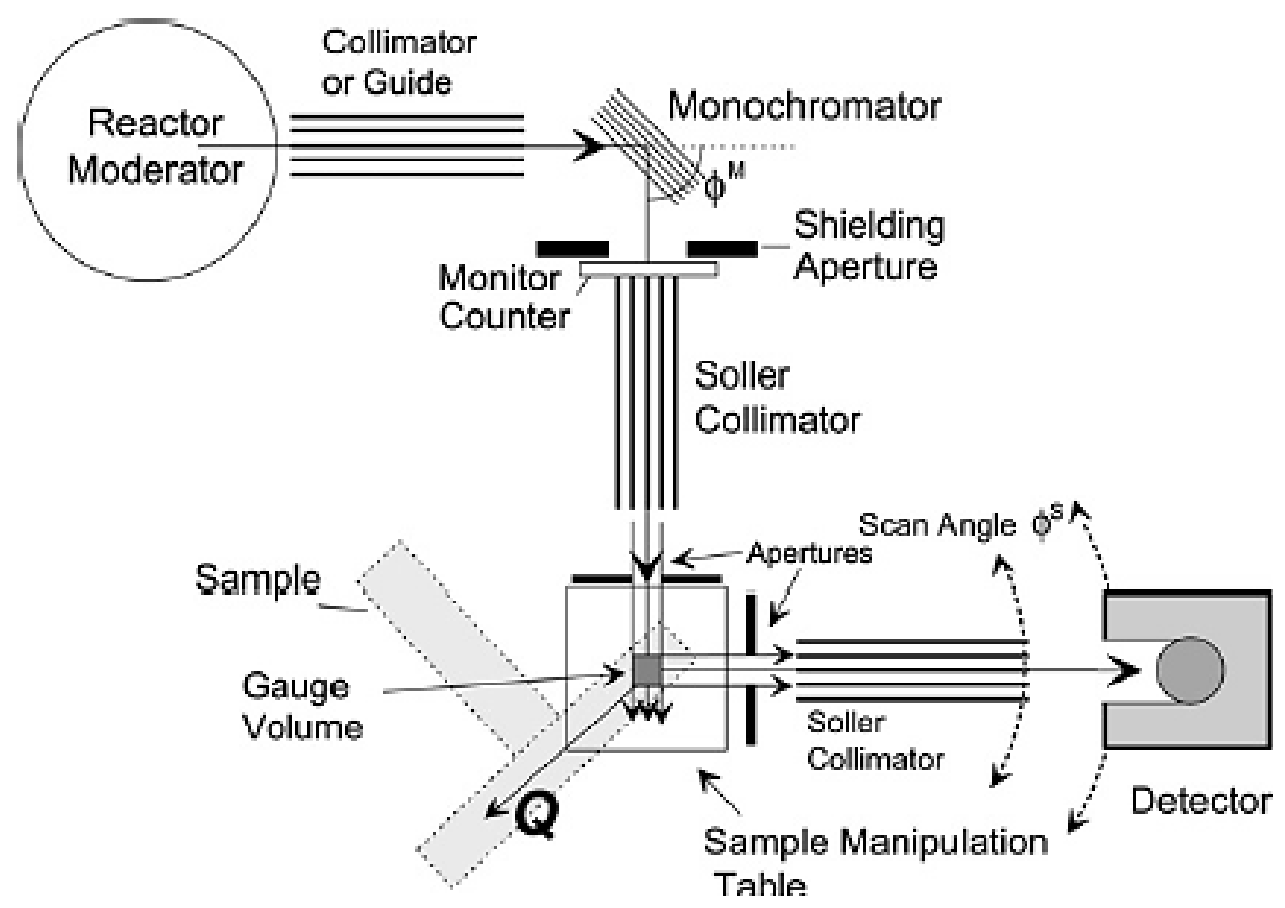

Figure 3.5: Schematic of conventional constant flux neutron diffraction spectrometer [94].

The angle of diffraction $(2 \varphi)$ was determined using a detector, which measured the diffracted beam intensity at angles around the expected peak location (detector moved in steps of $0.14^{\circ}$ ). This enabled a plot of intensity (counts) against angle of diffraction (example shown in Appendix B). A Gaussian distribution was fit to the resulting diffraction data to determine the diffraction angle of the peak (equations used to calculate uncertainty are shown in Appendix B), which was used to calculate the interplanar (d) spacing with Bragg's law (first order diffraction) (Equation 7). 


$$
\lambda=2 d \sin \varphi
$$

Neutron diffraction scans were performed using a monochromated neutron beam with a wavelength of $1.55 \AA$. The (311) $\left(2 \varphi=78.73^{\circ}\right)$ and $(331)\left(2 \varphi=112.95^{\circ}\right)$ reflections from $\mathrm{Al}$ as well as the (211) $\left(2 \varphi=82.95^{\circ}\right)$ reflection from iron were used in this analysis due to the strong diffraction intensity and a higher angle of diffraction. Furthermore, it is generally more favourable to have a rectangular sampling volume than a trapezoidal sampling volume to limit spatial variations along different directions in the area of interest [94]. The elongated trapezoidal sampling volume, which is formed when the angle of diffraction is greater than or less than $90^{\circ}$, gives poor spatial resolution between the crystallographic planes perpendicular to the scattering vector, which are required to measure strain [95]. For these reasons, the Al (311) planes were selected instead of $\mathrm{Al}$ (111) planes even though the (111) reflection has a stronger diffraction intensity. The $\mathrm{Al}$ (331) reflection, although not ideal with regards to the shape of the sampling volume, was also selected, specifically for the radial and axial strain measurements, since the higher diffraction angle of this reflection reduced the path length of the neutron beam through the sample to the location of interest, which enabled reduced beam attenuation compared to the (311) reflection, as confirmed by preliminary experiments. In addition, the diffraction angle for the (331) reflection is far from that of the strong Fe reflections thereby preventing secondary Fe peaks (generated when the sampling volume encompassed the Al cylinder bridge and the gray iron liners) on the shoulders of the $\mathrm{Al}$ peak. This reduced the uncertainty associated to fitting a Gaussian distribution to the diffraction data.

Stain and stress measurements were carried out from top to bottom, at intervals of approximately $10 \mathrm{~mm}$ along the $\mathrm{Al}$ cylinder bridge and adjacent gray iron liner in the hoop, axial and radial directions relative to the cylinder axis. The engine block positioning on the neutron spectrometer for strain and stress measurements in the hoop, radial and axial directions are shown Figures 3.6 (a)-(c), respectively. A schematic indicating each principal stress component relative to the cylinder axis is shown in Figure 3.7. In addition, to ensure that the measured residual stresses were representative of the stresses present during engine service, unsectioned engine blocks were placed in the neutron beam. 

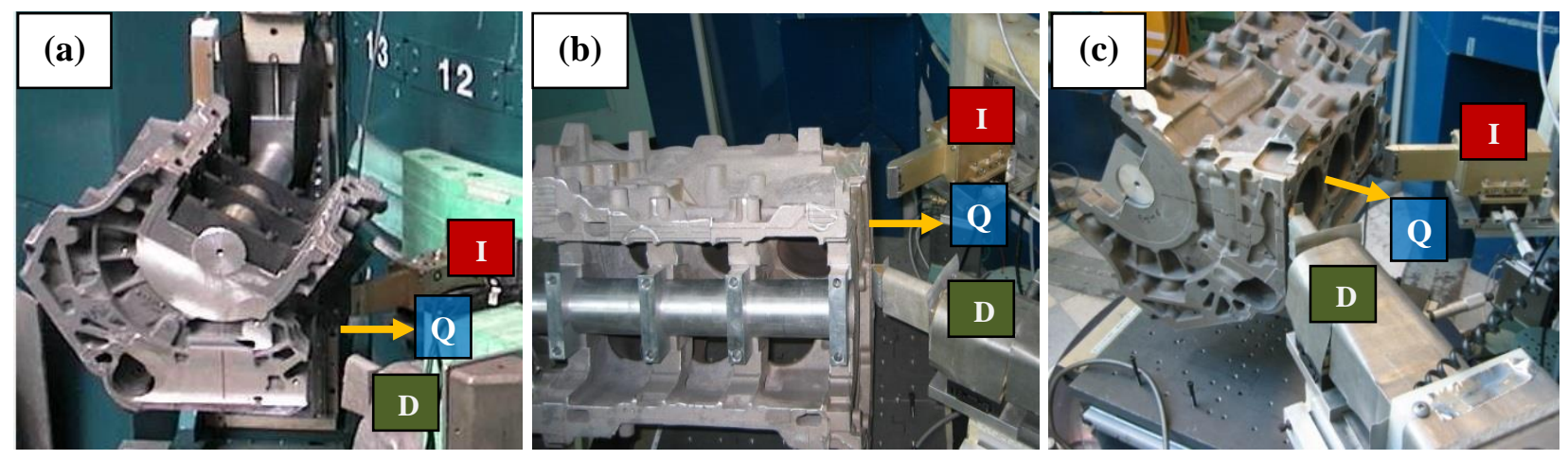

Figure 3.6: Engine block orientation relative to the incident (I) and diffracted (D) neutron beams for: (a) hoop orientation, (b) radial orientation, and (c) axial orientation. The "scattering vector" $(Q)$ is also shown.

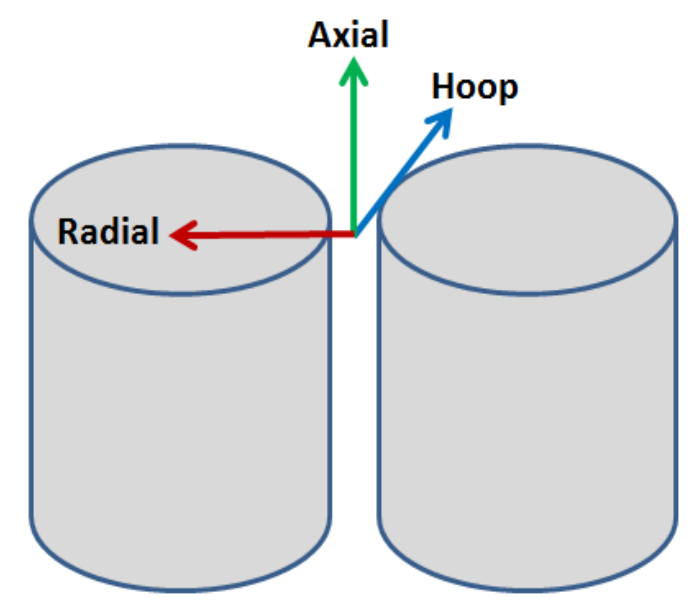

Figure 3.7: Schematic showing the measured principle stress and strain directions relative to the cylinder axis.

The residual strain was calculated using the "peak shift" method, shown in Equation 8. The peak shift method related the d-spacing of the specimen to that of a stress free specimen $\left(\mathrm{d}_{0}\right)$ of the same composition and processing history. This enabled the crystal lattice to be used as a strain gauge, since tensile strain causes expansion in d-spacing relative to the stress-free condition, while compressive strain results in contraction

$$
\varepsilon=\frac{d_{h k l}-d_{0, h k l}}{d_{0, h k l}}
$$

The reference $\mathrm{d}_{0}$-spacing was determined from neutron scans of stress free "match stick" samples cut from the cylinder bridge. Although the cylinder bridge is a high stress region in the engine block, it was assumed that residual stress in the material would be relieved during machining of the (3 mm x $3 \mathrm{~mm}$ x $20 \mathrm{~mm}$ ) samples, as supported by Withers [71] and Robinson and Tanner [75]. Ideally, the smaller the machined specimen geometry, the more likely the sample is stress 
free. However, the $3 \mathrm{~mm}$ x $3 \mathrm{~mm}$ x $20 \mathrm{~mm}$ geometry was selected as the smallest geometry enabling the machining of the samples without risk of bending. Furthermore, to ensure strain free $\mathrm{d}_{0}$ measurements, the match stick samples were rotated at $6 \mathrm{rpm}$ during the neutron diffraction scan in order to obtain an "averaged" d-spacing across the sample. This reduced the influence of any remaining stresses from the hoop and radial directions, and was a practical alternative to measuring $\mathrm{d}_{0}$ in all principle directions considering the limited beam time. In addition, since the cooling rates in each orientation were similar (determined via microstructural observation), the error associated to averaging $\mathrm{d}_{0}$ across the principal directions was likely insignificant.

Residual stresses in the hoop $\left(\sigma_{\mathrm{H}}\right)$, axial $\left(\sigma_{\mathrm{A}}\right)$ and radial $\left(\sigma_{\mathrm{R}}\right)$ orientations were then calculated using generalized Hooke's law (Equation 9). This allowed for the development of a scientific explanation for distortion by relating this stress to the microstructural variation along the cylinder, the mechanical properties and the measured distortion.

$$
\sigma_{H, R, A}=\frac{E}{1+v}\left[\varepsilon_{H, R, A}+\frac{v}{1-2 v}\left(\varepsilon_{H}+\varepsilon_{R}+\varepsilon_{A}\right)\right]
$$

Where, $\mathrm{E}$ is the modulus of elasticity, $v$ is Poisson's ratio.

The study utilized the average E and $v$ values in Hooke's law calculations rather than the plane specific values since the ISO/TS 21432 Technical Specification [96] indicates that the (311) plane has a low sensitivity to intergranular strain. As such, the elastic response to applied strain of this plane is representative of the bulk response. Furthermore, according to Clausen et al. [97], the Al FCC lattice has weak elastic anisotropy (aside from the (200) plane which is susceptible to significant intergranular strain [96]), suggesting that the difference between the plane specific elastic constants $\left(\mathrm{E}_{(311)}=70.2 \mathrm{GPa}, \mathrm{E}_{(331)}=72.3 \mathrm{GPa}\right)$ and the bulk constants $\left(\mathrm{E}_{\mathrm{avg}}=71 \mathrm{GPa}\right)$ are insignificant and will not largely affect the Hooke's Law calculations.

\subsection{Optimization of Engine Block Heat Treatment Parameters}

Following the determination of the cause of cylinder distortion, the SHT parameters were systematically optimized with the aim of maximizing strength, reducing residual stress and obtaining a thermally stable microstructure. It was envisaged that these optimal parameters not 
only mitigate distortion, but also improve process efficiency and reduce production cost. The methodology used to optimize the SHT parameters are outlined in the following sections.

\subsubsection{Replication of Engine Block Cylinder Microstructure}

Optimization of heat treatment parameters using a large quantity of engine block castings is expensive and time consuming. For these reasons, a small scale casting method, which replicated the microstructure at different depths along the cylinder region of the engine block, was developed. Replication of the engine block cylinder bridge microstructure was carried out by pouring molten $319 \mathrm{Al}$ alloy (composition shown in Tables 3.1 and 3.2) into a steel billet mould as shown in Figure 3.8. The dimensions of the billet mould were $153 \mathrm{~mm}$ x $88 \mathrm{~mm}$ x $30 \mathrm{~mm}$.

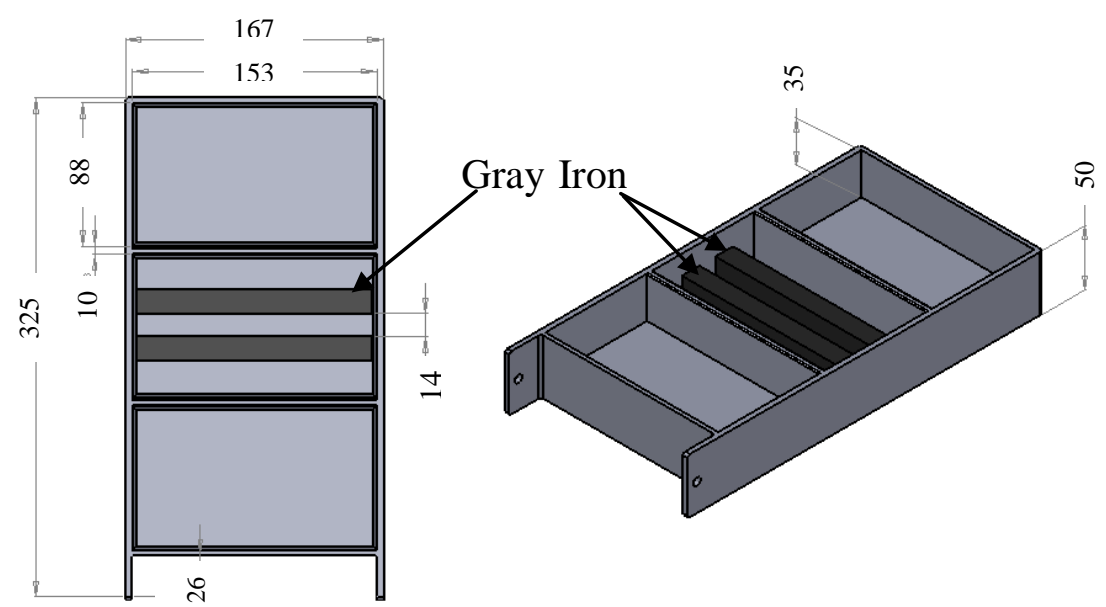

Figure 3.8: Image showing dimensioned model of billet mould used in this study (dimensions in mm).

As will be discussed in Section 4.2, a variation in microstructure was observed along the cylinder depth of the engine blocks. To account for the variation in microstructure, billets were cast to replicate the top, middle and bottom of the cylinder by varying the billet mould temperature and billet casting section thickness. In addition, gray iron inserts (thermal conductivity ranges between 46 and $79 \mathrm{w} / \mathrm{m} \cdot \mathrm{k}$ [98]) were placed in the mould to manipulate the cooling rates (Figure 3.8). The cooling rate of the billets was measured using thermocouples placed at the centre of the casting which allowed the thermal history to be captured during solidification. The cooling curves for select billet castings are shown in Appendix C. The parameters that were used in the preliminary experiments are shown in Table 3.7, while the parameters which successfully replicated cylinder bridge microstructure are shown in Table 3.8. It is important to note that all of the thermocouples used in the experiments (casting, heat treatment and neutron diffraction) 
throughout this dissertation were type-K (Omega Engineering Inc.) (Temperature range: 0-1250 ${ }^{\circ} \mathrm{C}$, Error range: $\pm 2.2^{\circ} \mathrm{C}$, reference junction of $\left.0{ }^{\circ} \mathrm{C}[99]\right)$.

Table 3.7: Parameters used in preliminary experiments to replicate the microstructure of the engine block cylinder bridge.

\begin{tabular}{ccccc}
\hline $\begin{array}{c}\text { Cylinder Section } \\
\text { to be Replicated }\end{array}$ & $\begin{array}{c}\text { Required } \\
\text { Cooling } \\
\text { Rate }\left({ }^{\circ} \mathbf{C} / \mathbf{s}\right)\end{array}$ & $\begin{array}{c}\text { Pouring } \\
\text { Temperature } \\
\left({ }^{\circ} \mathbf{C}\right)\end{array}$ & $\begin{array}{c}\text { Experimental } \\
\text { Mould } \\
\text { Temperatures }\left({ }^{\circ} \mathbf{C}\right)\end{array}$ & $\begin{array}{c}\text { Section } \\
\text { Thickness (mm) }\end{array}$ \\
\hline Top & 1.5 & 720 & $500,600,700$ & 28 \\
Middle & 4 & 720 & $100,170,300$ & 28 \\
Bottom & 12 & 720 & 100,200 & $\begin{array}{c}12,14,18,21 \\
\text { (using gray iron inserts) }\end{array}$ \\
\hline
\end{tabular}

Table 3.8: Parameters used to produce replicating billet castings for each engine cylinder location.

\begin{tabular}{cccc}
\hline Engine Cylinder Location & Top & Middle & Bottom \\
\hline Cooling Rate & $1.5{ }^{\circ} \mathrm{C} / \mathrm{s}$ & $3.8^{\circ} \mathrm{C} / \mathrm{s}$ & $12.5^{\circ} \mathrm{C} / \mathrm{s}$ \\
Billet Mould Temperature & $600{ }^{\circ} \mathrm{C}$ & $170{ }^{\circ} \mathrm{C}$ & $100{ }^{\circ} \mathrm{C}$ \\
Billet Dimensions & $153 \times 88 \times 28 \mathrm{~mm}$ & $153 \times 88 \times 28 \mathrm{~mm}$ & $153 \times 14 \times 20 \mathrm{~mm}$ \\
\hline
\end{tabular}

Engine Block Cylinder

Replicating Billets
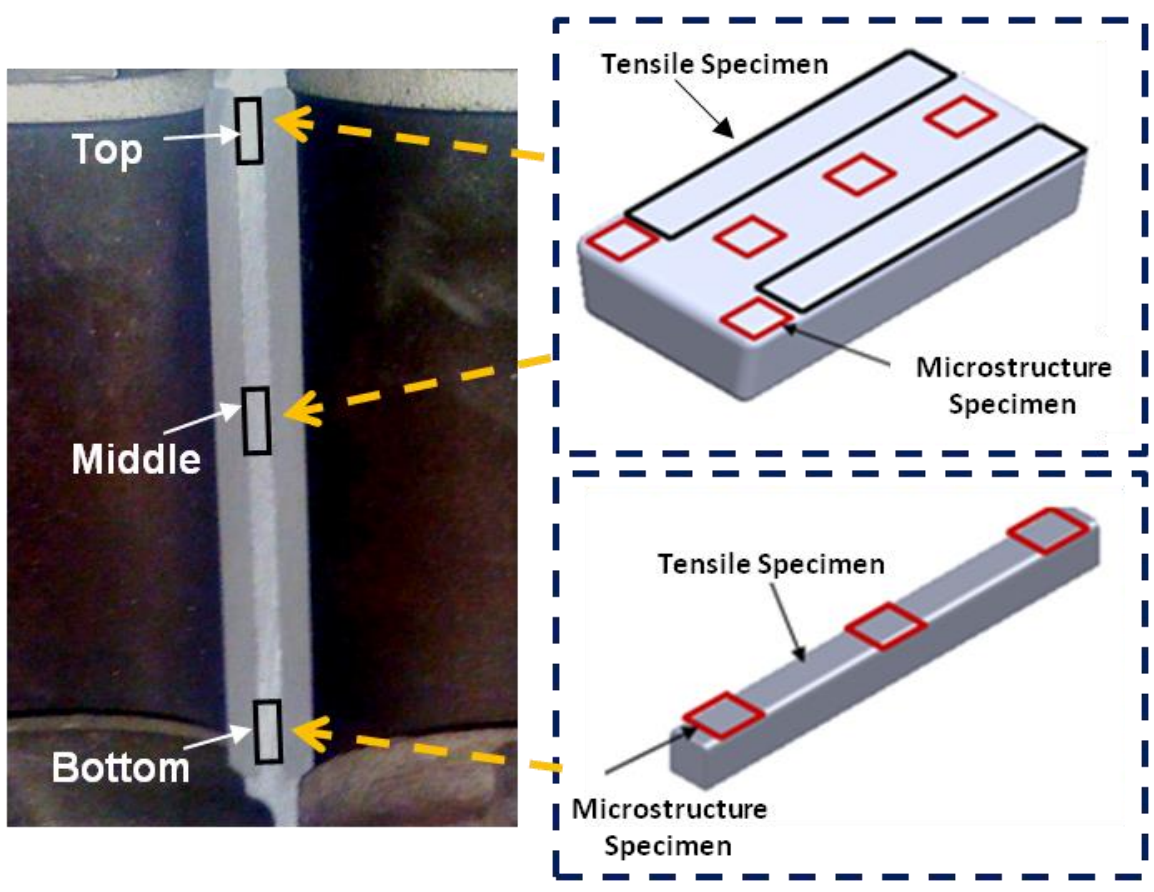

Figure 3.9: Schematic showing the analyzed locations in the billet castings. 
Successful replication was assessed by comparing the dendritic structure, SDAS, secondary phase morphology and volume fraction, and the hardness and tensile properties between the TSR treated billet castings and engine blocks. This analysis was carried out using OM, SEM, image analysis and ambient temperature tensile testing. Specimens for microstructural characterization and mechanical testing were extracted from multiple locations in the billet castings, as shown in Figure 3.9, to confirm the homogeneity of properties. Meanwhile, the locations analysed and the methodology of microstructural characterization used in the engine blocks were the same as those outlined in Sections 3.2.3 and 3.2.4.

\subsubsection{Variation of Solution Heat Treatment Parameters}

The billet castings which best replicated the engine block microstructure were then used to optimize the SHT parameters. This portion of the project varied the solutionizing temperature and time to attain maximum dissolution of $\mathrm{Al}_{2} \mathrm{Cu}$ in the minimum time period while avoiding incipient melting. The current and proposed experimental SHT parameters are shown in Table 3.9.

At the conclusion of the heat treatment, the specimens were quenched using forced air for approximately three minutes, consistent with industrial practice. Furthermore, the T7 aging treatment, used in engine block production $\left(240{ }^{\circ} \mathrm{C}\right.$ for $5.5 \mathrm{~h}$ ), was applied to each solutionized billet to compare the strengthening potential of each solutionizing parameter to the current industrial SHT schedule. To ensure that the heat treatment temperatures were consistently maintained throughout the experiments, thermocouples (type-K) were inserted into the billets to record the heat treatment thermal profile (Appendix D).

Table 3.9: Proposed experimental solution heat treatment schedules.

\begin{tabular}{ccc}
\hline Trial & Temperature $\left({ }^{\circ} \mathbf{C}\right)$ & Time (Hours) \\
\hline Current Solution Heat Treatment & 470 & 7.5 \\
Proposed Solution Heat Treatment & 500,515 and 530 & $2,4,6$ and 8 \\
\hline
\end{tabular}

Following heat treatment, microstructural characterization of the billet castings was carried out using OM and SEM (in conjunction with image analysis software). In addition, to determine the 
temperature corresponding to the onset of incipient melting of the $\mathrm{Al}-\mathrm{Al}_{2} \mathrm{Cu}-\mathrm{Al}_{5} \mathrm{Mg}_{8} \mathrm{Cu}_{2} \mathrm{Si}_{6}$ complex eutectic and further elucidate the microstructural observations, initially TSR treated billet castings (replicating the top, middle and bottom of the cylinder) were analyzed using differential scanning calorimetry (DSC). This analysis involved heating small specimens up to approximately $600{ }^{\circ} \mathrm{C}$ at a rate of $10^{\circ} \mathrm{C} /$ minute. Finally, the mechanical properties of the $\mathrm{T} 7$ heat treated billet castings were evaluated using ambient temperature tensile testing (using the same sample geometry to that outlined in Section 3.2.4).

\subsubsection{In-situ/Ex-situ Residual Strain and Stress Analysis}

Heat treatment has been documented to effectively relieve residual strain and stress as discussed in Sections 2.4.3 and 2.4.4. However, these previous studies did not separate the effect of SHT, quenching and aging on residual stress relief. In addition, the influence of dissimilar materials and thermo-mechanical mismatch were not considered. Therefore, to effectively optimize the SHT parameters, in-situ neutron diffraction data (at the solutionizing temperatures) was required to determine the effect of temperature on the residual strain relief as a function of time. This section outlines the design of the heating system and the parameters used in the in-situ and ex-situ neutron diffraction experiments.

\subsubsection{Investigated Solution Heat Treatment Parameters}

Residual strain was examined for 319 type Al alloy engine blocks, initially in the TSR condition. The engine blocks were heated to the target temperatures outlined in Table 3.10. The ramp time to the target solution treatment temperatures was selected as 1 hour ( \pm 10 minutes) in order to conform to the current SHT procedure employed by the industrial partner (Nemak of Canada). This will enable a more accurate representation of the change in residual stress and strain along the cylinder bridge during heat treatment.

Table 3.10: Experimental parameters for the heating of the cylinder bridge.

\begin{tabular}{ccc}
\hline Target Temperature $\left({ }^{\circ} \mathbf{C}\right)$ & $\begin{array}{c}\text { Ramp Time to Target } \\
\text { Temperature (h) }\end{array}$ & $\begin{array}{c}\text { Holding Time at Target } \\
\text { Temperature (h) }\end{array}$ \\
\hline 470 & 1 & 8 \\
500 & 1 & 8 \\
\hline
\end{tabular}


It is important to note that the 515 and $530{ }^{\circ} \mathrm{C}$ solutionizing temperatures (used on the billet castings) were not included in the in-situ strain analysis, since preliminary microstructural analysis of the stress-free specimens found signs of significant incipient melting following heat treatment at these temperatures. Although the stress free $\left(\mathrm{d}_{0}\right)$ analysis included the $530{ }^{\circ} \mathrm{C}$ solutionizing temperature to relate to the microstructural observations made from billet castings, temperatures above $515^{\circ} \mathrm{C}$ were deemed unsuitable for engine block production.

\subsubsection{In-situ $\mathrm{d}_{0}$ Analysis}

Prior to in-situ residual strain analysis, the change in the $\mathrm{d}_{0}$ spacing during SHT was examined to account for factors such as thermal expansion and phase dissolution (causing solute enrichment in the Al lattice). This analysis utilized stress free samples extracted from the top and bottom of the Al cylinder bridge due to the microstructural differences found between these cylinder regions, as discussed in Section 3.2.5.

In-situ neutron diffraction was carried out on the "match stick" samples to test the influence of SHT on the $\mathrm{d}_{0}$ spacing. The specimens, which were initially in the TSR condition, were heated to the experimental solutionizing temperature $\left(470,500\right.$ and $\left.530{ }^{\circ} \mathrm{C}\right)$ using the NRC quench furnace, installed at the neutron spectrometer, as shown in Figure 3.10.

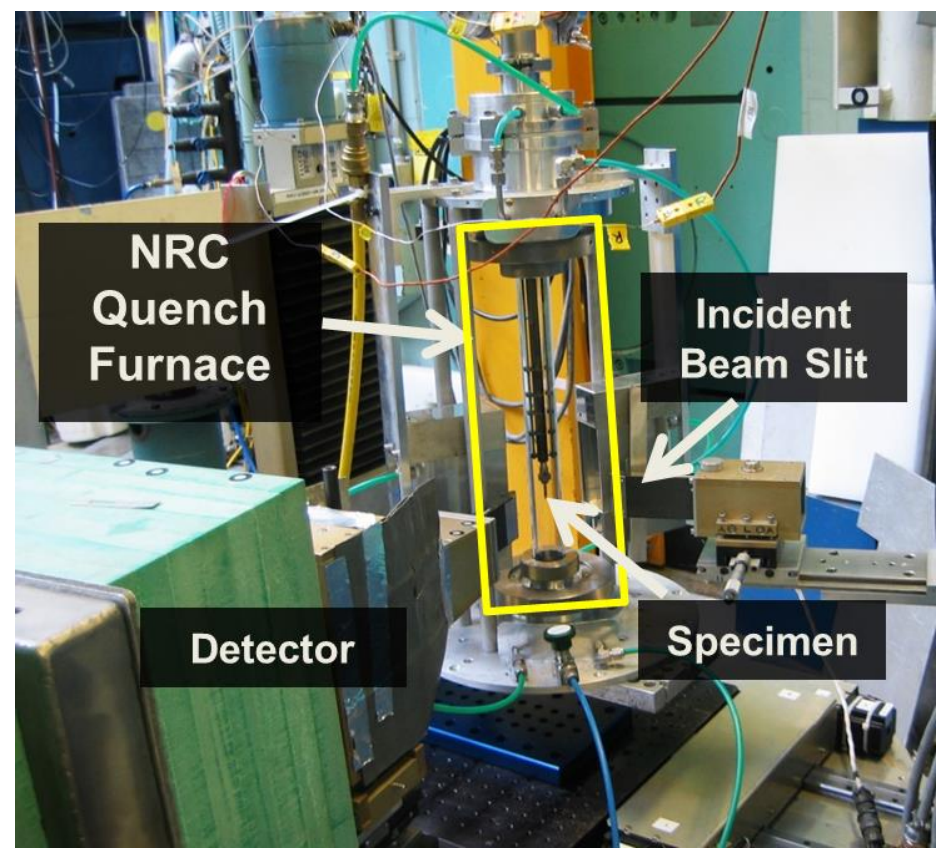

Figure 3.10: Experimental setup for in-situ analysis of $d_{0}$ during solution heat treatment. 
Thermocouples (type-K), connected to PID temperature controllers, were inserted into the specimen to monitor and control the temperature to within $1{ }^{\circ} \mathrm{C}$ of the set point throughout the experiment. The specimens were held at each solutionizing temperature for approximately 8 hours to correspond to the typical heat treatment soaking time used in engine block production.

The neutron diffraction experiments were carried out using a monochromated neutron beam with a wavelength of $1.55 \AA$. The Al (311) and (331) planes were examined (for reasons outlined in Section 3.2.5) and the resulting $\mathrm{d}_{0}$ spacings were calculated using Bragg's Law. It is important to note that in these experiments, the stress-free specimens were not rotated, as was described in Section 3.2.5, due to equipment constraints. This prevented the $\mathrm{d}_{0}$ averaging that was achieved previously and may have contributed to error in the true stress-free d-spacing at the beginning of the experiment. However, thermal annealing likely relaxed any remaining stresses during SHT.

Microstructural analysis, using OM and SEM, examined the secondary phase morphology prior to and following heat treatment of the stress free samples. The composition of the secondary phases was assessed using energy dispersive X-ray spectroscopy (EDX). In addition, to observe the influence of SHT on secondary phase dissolution, image analysis software was used in conjunction with SEM backscattered electron images to quantify the volume fraction of $\mathrm{Al}_{2} \mathrm{Cu}$ (refer to Section 3.2.3 for further details on microscopy and sample preparation). Finally, to relate the changes in interplanar spacing during heat treatment to microstructural changes, the composition of the aluminum dendrites was determined using wavelength dispersive X-ray spectroscopy (WDS). The WDS spectrometer was calibrated using standard samples for each element present in the alloy prior to taking compositional measurements.

\subsubsection{Engine Block Heating}

The engine block heating system contained the power and control system components shown in Figure 3.11. The power system (Figure 3.11) consisted of six 140 VAC / 15 A (output) variac variable transformers, which powered the heaters until the engine block reached approximately 5 ${ }^{\circ} \mathrm{C}$ below the set point. At this point, the variacs were removed and the heaters were connected to 120 VAC / 8 A (output) power supplies, which contained built-in PID temperature controllers, to reach the set point and maintain this temperature for the remainder of the experiment. The PID temperature controllers were operated using a personal computer with LabView software. 
Preliminary experiments, in which the engine block was heated to each set point temperature shown in Table 3.10, enabled the variation of PID parameters such as gain (proportional) and approach (integral) during these heating tests. Through these experiments, the gain $\left(\mathrm{T}_{\mathrm{p}}=0.5\right)$ and approach $\left(\mathrm{T}_{\mathrm{i}}=0.5\right)$ were optimized, preventing significant temperature overshoot $\left( \pm 1{ }^{\circ} \mathrm{C}\right)$ or oscillation about the set point during the in-situ neutron diffraction experiments. It must be noted that variacs were used during the initial engine block heat up since the temperature controllers did not provide sufficient power output to heat the engine to the set point in the required $1 \mathrm{~h}$ time period.

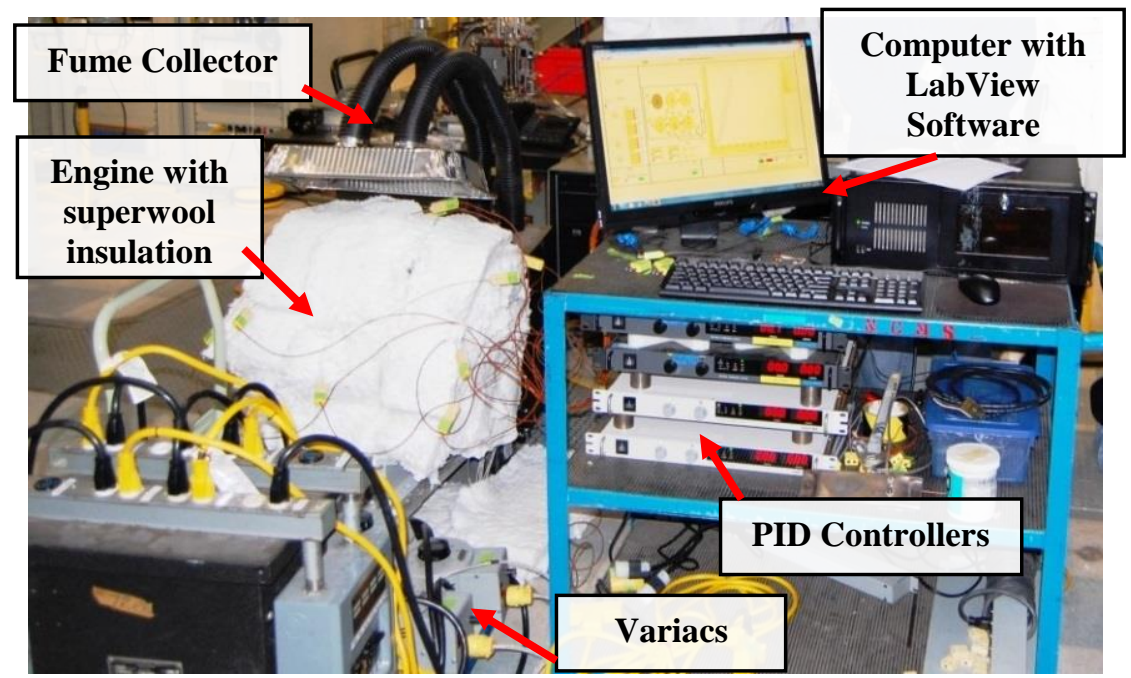

Figure 3.11: Components of heating system for in-situ neutron diffraction experiment.

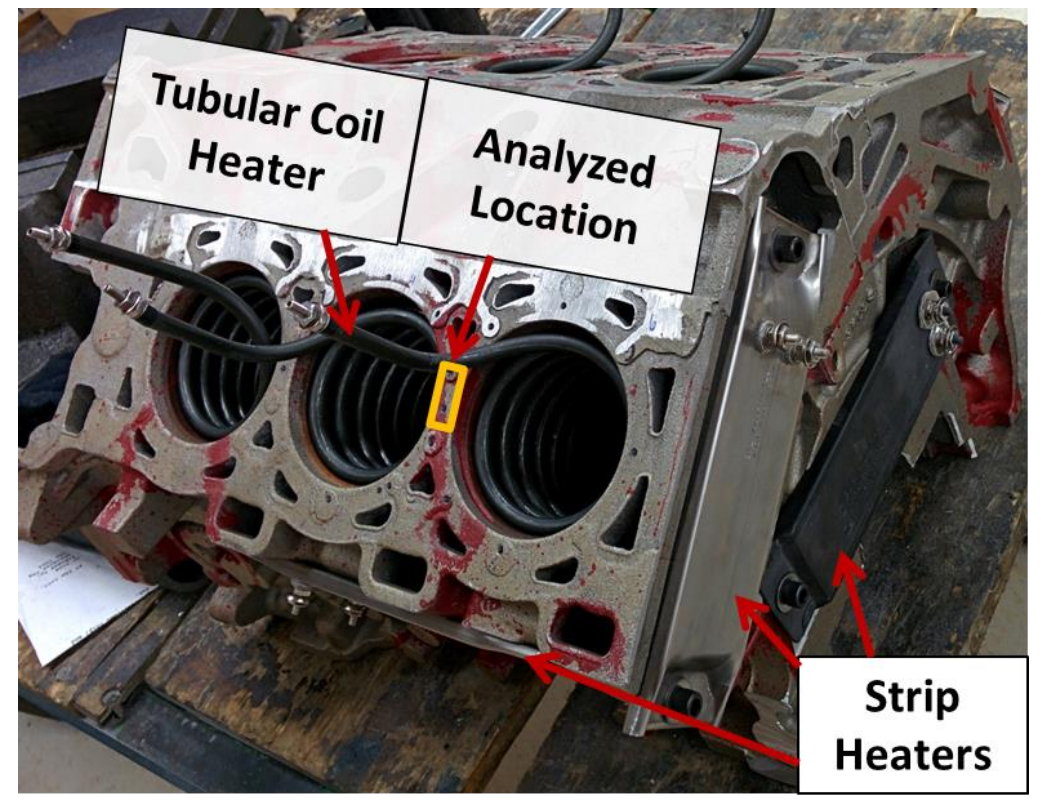

Figure 3.12: Image showing engine block equipped with heating coils and strip heaters. 
Heating of the cylinder bridge to the target temperatures, shown in Table 3.10, was accomplished using an array of coiled tubular heaters and strip heaters. These heaters were mounted along the circumference of the cylinder bores and select outer surfaces, as illustrated in an image of the experimental setup in Figure 3.12. Furthermore, insulating "Superwool Plus" blankets $(\sim 2.5 \mathrm{~cm}$ thick) were wrapped around the entire component (2 layers) as shown in Figure 3.11, to minimize heat loss due to convection and radiation.

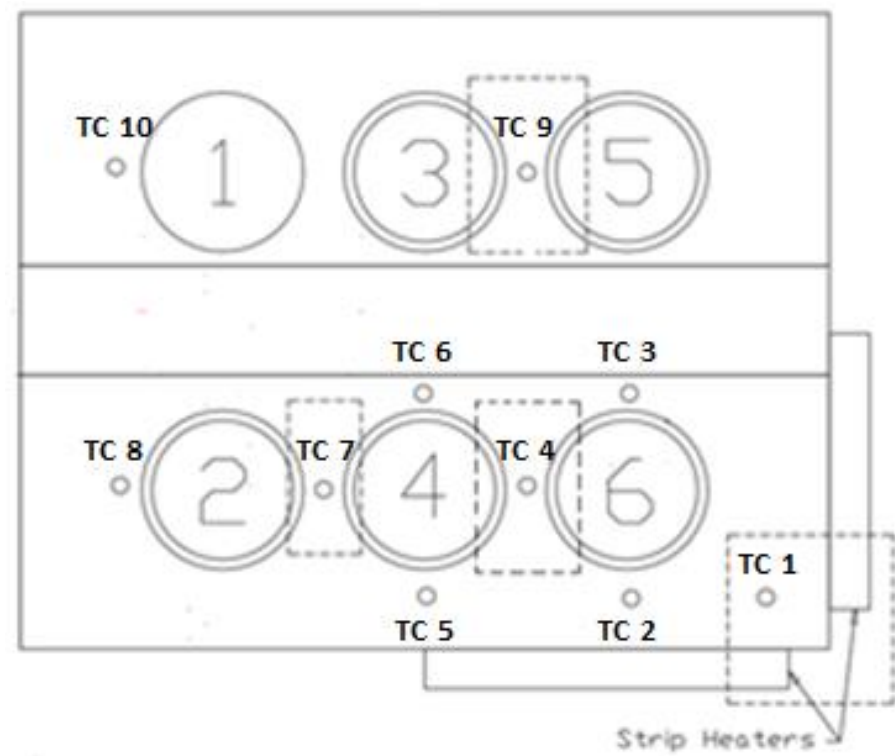

Figure 3.13: Schematic showing thermocouple locations in the engine block for in-situ neutron diffraction heat treatment experiment.

Type-K thermocouples (TC) were inserted at various locations in the engine block (Figure 3.13), which served to monitor the temperature of different regions around the cylinder bores. Select thermocouples, outlined in Table 3.11, provided the input temperature signal (feedback) for the PID temperature controllers connected to the specific heaters. This setup ensured that the target temperature was maintained throughout the cylinder for the entire heat treatment process.

Table 3.11: Identity and location of thermocouples controlling heaters via PID temperature controllers.

\begin{tabular}{cc}
\hline Thermocouple (TC) Number & Heaters controlled by Input Thermocouple \\
\hline TC1 & Strip Heaters \\
TC4 & Coil heaters in Cylinders 4 and 6 \\
TC7 & Coil Heater in Cylinder 2 \\
TC9 & Coil Heaters in Cylinders 3 and 5 \\
\hline
\end{tabular}


The heating configuration, shown in Figure 3.12, was designed with the assistance of finite volume transient conduction simulations (Solidworks ${ }^{\circledR}$, Dassault Systems) with a view to obtain a relatively uniform temperature distribution $\left( \pm 20{ }^{\circ} \mathrm{C}\right)$ in the regions adjacent to the bridge between cylinders 4 and 6 . These heat transfer simulations also facilitated the determination of the heat input required to achieve the target temperature in a ramp time that simulated the industrial engine block heat treatment process $(1 \mathrm{~h})$.

The finite volume simulation was setup by applying a constant heat flux to each heated surface, as shown in Figure E.1 (Appendix E). All other surfaces were approximated as adiabatic, for simplification of the model, due to the engine being wrapped in superwool insulation. The resulting temperature profiles obtained from the simulation for the approximately $1 \mathrm{~h}$ heating process is shown in Figure E.2 (a). Experimental thermal data, used to validate the model, is shown in Figure E.3. In addition, thermal data for the entire heat treatment (neutron diffraction) experiment at the thermocouple locations, specified in Figure 3.13, is shown in Figures E.4 and E.5 for the 470 and $500{ }^{\circ} \mathrm{C}$ solutionizing temperatures, respectively. Post-SHT cooling profiles are shown in Figure E.6.

\subsubsection{In-situ Residual Strain Mapping}

Once the (4-6) cylinder bridge of the engine block reached the target temperature, in-situ neutron diffraction experiments were performed near the middle (50 $\mathrm{mm}$ depth) of the cylinder (refer to Figure 3.4) to determine the change in residual strain as a function of time. Only one section of the cylinder bridge was analysed for the in-situ experiments to maximize the temporal resolution of strain measurements. The middle of the cylinder was selected for analysis since this region was found to be most susceptible to distortion, as discussed in Chapter 4 of this dissertation.

In-situ residual strain analysis was carried out using the $\mathrm{Al}$ (331) reflection and a monochromated neutron beam with a wavelength of 1.55 Á. In this study, residual strain was measured in the axial orientation only due to limitations in equipment, which prevented simultaneous measurement of the other principle directions. Furthermore, the axial orientation (refer to Figure 3.6 (c) for engine positioning on spectrometer) was selected since this orientation was found to have the lowest beam attenuation in preliminary experiments, which reduced the required counting time for each measurement, thus improving the temporal resolution of the strain-time 
curves. During the experiments, the beam was held at the location of interest for 20 minutes for each measurement to ensure good statistics. This process was repeated for the $8 \mathrm{~h}$ time period to obtain strain relief profiles at this section of the engine block cylinder bridge.

Upon completion of heat treatment, in-situ neutron diffraction was used to observe the change in residual strain during engine cooling. This was done from the solutionizing temperature to ambient temperature. Since this analysis was carried out with the superwool insulation wrapped around the engine block, the cooling rate was very slow $\left(<1{ }^{\circ} \mathrm{C} /\right.$ minute $)$, preventing stress development due to thermal gradients. This enabled a better understanding of the development of lattice residual strain with decreasing temperature due to thermo-mechanical mismatch in components with dissimilar materials.

\subsubsection{Ex-situ Residual Stress Mapping Following T4 Treatment}

Following the in-situ strain experiments at the solutionizing temperatures, ex-situ residual stress analysis was carried out on the engine blocks that were solutionized at 470 and $500{ }^{\circ} \mathrm{C}$ using $e x$ situ neutron diffraction. The specimen setup, neutron beam wavelength and analysed Al reflections were the same as those outlined in Section 3.2.5. This analysis quantified the change in residual stress in the hoop, radial and axial directions for each solutionizing temperature, as compared to the TSR condition. These results were also correlated to the in-situ axial strain analysis to observe whether similar stress/strain relief occurred in the other 2 principal stress directions. Finally, since the engine blocks cooled (following in-situ neutron diffraction) in still air while wrapped in superwool insulation (quench rate $<1{ }^{\circ} \mathrm{C} /$ minute), the $e x$-situ residual stress analysis was compared the current production T4 schedule (SHT $\left.470{ }^{\circ} \mathrm{C} / 7.5 \mathrm{~h}\right)$, which utilized forced air cooling (quench rate between $80-100{ }^{\circ} \mathrm{C} /$ minute). As such, this allowed the effect of cooling rate on residual stress to be determined in components with dissimilar materials.

Computational fluid dynamics (CFD) simulations were used to assist in explaining the discrepancies in stress profiles between the engine blocks which were cooled in still air while insulated and those which were forced air cooled. Section 3.3.3.6 outlines the model parameters and governing equations used to simulate the forced air quenching process. 


\subsubsection{CFD Heat Transfer Modelling of Quenching Process}

Production of $\mathrm{Al}$ engine blocks involves quenching following elevated temperature soaking using forced air convective cooling. Computational fluid dynamics (CFD) modelling, using Solidworks ${ }^{\circledR}$ Flow Simulation, determined the temperature gradients along the cylinder regions following quenching to relate to residual stress measurements. This section outlines the numerical solution method used by the CFD software to solve the governing equations as well as the model parameters and boundary conditions used in this simulation.

\subsection{Numerical Solution Technique of Governing Equations}

Solidworks ${ }^{\circledR}$ Flow Simulation simultaneously solved the governing equations for conservation of mass, momentum and energy (Continuity, Navier-Stokes and Energy equations), as shown in Equations 10-12, respectively.

$$
\begin{gathered}
\frac{\partial \rho}{\partial \mathrm{t}}+\frac{\partial}{\partial x_{i}}\left(\rho u_{i}\right)=0 \\
\frac{\partial \rho u_{i}}{\partial \mathrm{t}}+\frac{\partial}{\partial x_{j}}\left(\rho u_{i} u_{j}\right)+\frac{\partial \mathrm{P}}{\partial x_{i}}=\frac{\partial}{\partial x_{j}}\left(\tau_{i j}+\tau_{i j}^{R}\right) \\
\frac{\partial \rho H}{\partial \mathrm{t}}+\frac{\partial u_{i} H}{\partial x_{i}}=\frac{\partial}{\partial x_{i}}\left[u_{j}\left(\tau_{i j}+\tau_{i j}^{R}\right)+q_{i}\right]+\frac{\partial \mathrm{P}}{\partial x_{i}}-\tau_{i j}^{R} \frac{\partial u_{i}}{\partial x_{j}}\left(\tau_{i j}+\tau_{i j}^{R}\right)+\rho \varepsilon_{T}
\end{gathered}
$$

Where, $\mathrm{u}$ is the fluid velocity, $\rho$ is the fluid density, $\mathrm{P}$ is the fluid pressure, $\mathrm{h}$ is the enthalpy of the

fluid, $H=h+\frac{1}{2} u, q_{i}$ is the diffusive heat flux, $\tau_{i j}$ is the viscous shear stress tensor, $\tau_{i j}{ }^{R}$ is the Reynold's stress tensor for turbulent flow and $\varepsilon_{\mathrm{T}}$ is the turbulent dissipation. It must be noted that the subscript indices represent summation over the three Cartesian co-ordinate directions.

Equations 10-12 are the general equations which govern turbulent flow. The time dependant fluctuations in the flow parameters as a result of turbulence were addressed in this CFD software by introducing the Reynold's stress terms which require additional information to close the system. The turbulent kinetic energy-dissipation rate model, known as the "k- $\varepsilon$ model", was used in this software to solve the turbulent flow problem. Additional information on the "k- $\varepsilon$ turbulence model" is provided in $[100,101]$. 
Solidworks ${ }^{\circledR}$ Flow Simulation solved the governing equations using the numerical "finite volume" method with a mesh consisting of rectangular elements [100]. In this CFD package, direct control of the mesh size was not possible, however, a mesh refinement scale, ranging between 1 and 8, was available to the user to input the desired level of mesh refinement. In this simulation, the finest mesh (level 8) was used to ensure an adequate number of nodes to accurately model the quenching process. The computational mesh was refined locally near the solid-liquid interface and the adjacent fluid regions. Furthermore, in order to accurately predict important features (e.g. flow trajectories) the mesh was refined during the calculation. Regions which have large spatial gradients had the grid cells split into smaller cells, while regions with small spatial gradients resulted in the grid cells being merged.

Utilizing the rectangular mesh, the finite volume method first discretized the governing equations in a conservative form. Spatial partial derivatives were approximated using implicit difference, which gives second order accuracy in space. Time derivatives were approximated using explicit (Euler) method, which results in first order accuracy in time [100].

\subsection{Model Parameters and Boundary Conditions}

The post-heat treatment quenching process (approximately 3 minutes in duration) was simulated using a 3-dimensional, transient forced convective heat transfer model with turbulent flow. The problem definition is shown in Figure 3.14. As a result of the relatively large cooling rates associated to quenching, a time step of $0.2 \mathrm{~s}$ was employed in the model to ensure sufficient temporal resolution. The problem consisted of three-dimensional airflow over the engine block with the incident air stream being perpendicular to the top face of the engine block. The computational domain boundaries were placed $1200 \mathrm{~mm}$ upstream of the engine block and $1000 \mathrm{~mm}$ downstream to simulate the industrial air quenching station. The left and right far field boundaries were $700 \mathrm{~mm}$ apart, while the depth of the computational domain was $700 \mathrm{~mm}$ (3-dimensional simulation).

For the left and right far field boundaries, the default settings of Solidworks ${ }^{\circledR}$ Flow Simulation were used, which correspond to ambient boundary conditions [100]. The ambient boundary conditions were used for external flow problems in Solidworks ${ }^{\circledR}$ Flow Simulation to specify the fluid properties, pressure and temperature. At the top of the computational domain, the flow inlet 
boundary conditions specified the ambient fluid flow properties. The fluid used in this study was air at a temperature $\left(\mathrm{T}_{\infty}\right)$ of $20^{\circ} \mathrm{C}$ and pressure of $101.3 \mathrm{kPa}$ (constant fluid properties). The inlet airflow velocity $\left(\mathrm{U}_{\infty, \mathrm{z}}\right)$ was $34 \mathrm{~m} / \mathrm{s}\left(\mathrm{U}_{\infty, \mathrm{x}}=\mathrm{U}_{\infty, \mathrm{y}}=0\right)$. In contrast, the boundary condition at the bottom of the computational domain (flow outlet boundary condition) could not be specified in Solidworks ${ }^{\circledR}$ Flow Simulation. Therefore, the default settings were used for this outlet boundary condition.

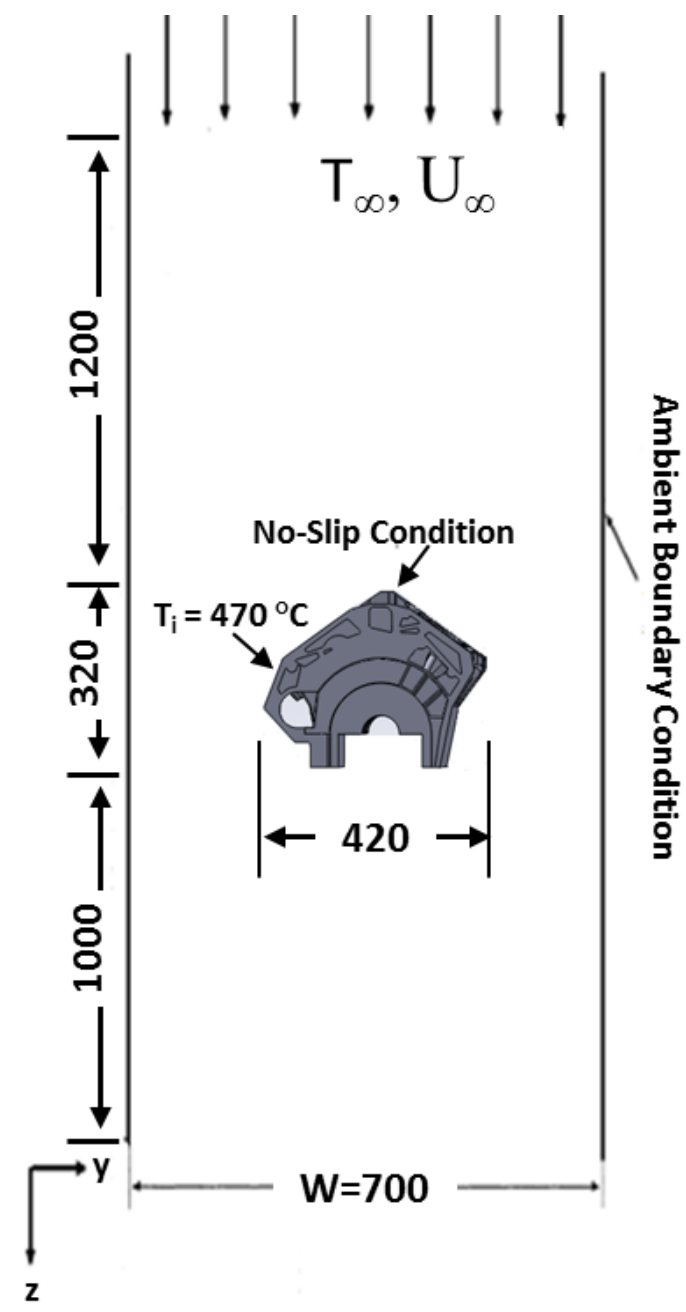

Figure 3.14: Schematic showing boundary locations and conditions in the computational domain (dimensions in mm).

The problem analysed in this study also required boundary conditions specified for the solid. The walls of the engine block were defined with "real wall" boundary conditions. The wall conditions were specified with an initial temperature of $470{ }^{\circ} \mathrm{C}$ (SHT temperature during engine production). No slip boundary conditions $\left(\mathrm{u}_{\mathrm{s}}=0\right)$ and non-permeability $\left(\mathrm{v}_{\mathrm{s}}=0\right)$ were also applied to the fluid flow at the cylinder wall locations. 


\section{Chapter 4: Determining the Mechanism of Cylinder Distortion}

This chapter presents the results from the analysis of distorted and undistorted $319 \mathrm{Al}$ alloy engine blocks with cast-in gray iron cylinder liners. The cylinder profiles were measured to estimate the macro-distortion along the cylinder of each engine block as discussed in Section 4.1. The microstructure-mechanical property relationships are elucidated in Sections 4.2 and 4.3 while the residual strain and stress measurements along the cylinder bridge are discussed in Section 4.4. Finally, the experimental data and analysis were used to determine the mechanism of cylinder distortion in Section $4.5^{*}$

\subsection{Analysis of Macro-Distortion}

The overall distortion in the cylinder bores was quantified by performing least squares regression analysis with the CMM data to determine the cylindricity (deviation from a nominal undistorted cylinder with regards to circularity, straightness and taper throughout the surface of the cylinder [90]. The results from CMM analysis suggest that cylinder 6 had the highest cylindricity of $47 \mu \mathrm{m}$, while cylinders 2 and 4 had a cylindricity of approximately $40 \mu \mathrm{m}$. This magnitude of distortion, while appearing small, was determined to be sufficient to cause significant leakage of air-fuel mixture from the combustion chamber during dynamometer testing of the experimental engine blocks. In contrast, the undistorted engine block had cylindricity values of $9 \mu \mathrm{m}$ for cylinders 2 and 4, and $16 \mu \mathrm{m}$ for cylinder 6 . However, this magnitude of distortion was not significant when accounting for the $5 \mu \mathrm{m}$ of uncertainty associated with the CMM probe.

Analysis of macro-distortion along the cylinder also allowed the location of maximum distortion to be determined. Figures 4.1 (a) and (b) show the results (for each individual depth in the cylinder) of maximum deviation from the nominal radius of the cylinder bores and the cylinder roundness (where higher value represents a higher degree of deviation from perfect circularity), respectively.

\footnotetext{
* Much of the data presented in this chapter was published in:

Lombardi, A., Ravindran, C., Sediako, D., MacKay, R., "Determining the Mechanism of In-Service Cylinder Distortion in Aluminum Engine Blocks with Cast-in Gray Iron Liners", Metallurgical and Materials Transactions A., vol. 45, pp. 6291-6303 (2014).

Lombardi, A., Ravindran, C., Sediako, D., MacKay, R., “Analysis of Residual Strain Profiles in Distorted Aluminum Engine Blocks by Neutron Diffraction”, SAE International Journal of Materials and Manufacturing, vol. 6, pp. 135-140 (2013).

Lombardi, A., D’Elia, F., Ravindran, C., Sediako, D., Murty, B.S., MacKay, R., "Interplay between Residual Stresses, Microstructure, Process Variables and Engine Block Casting Integrity", Metallurgical and Materials Transactions A., vol. 43, pp. 5258-5270 (2012).
} 

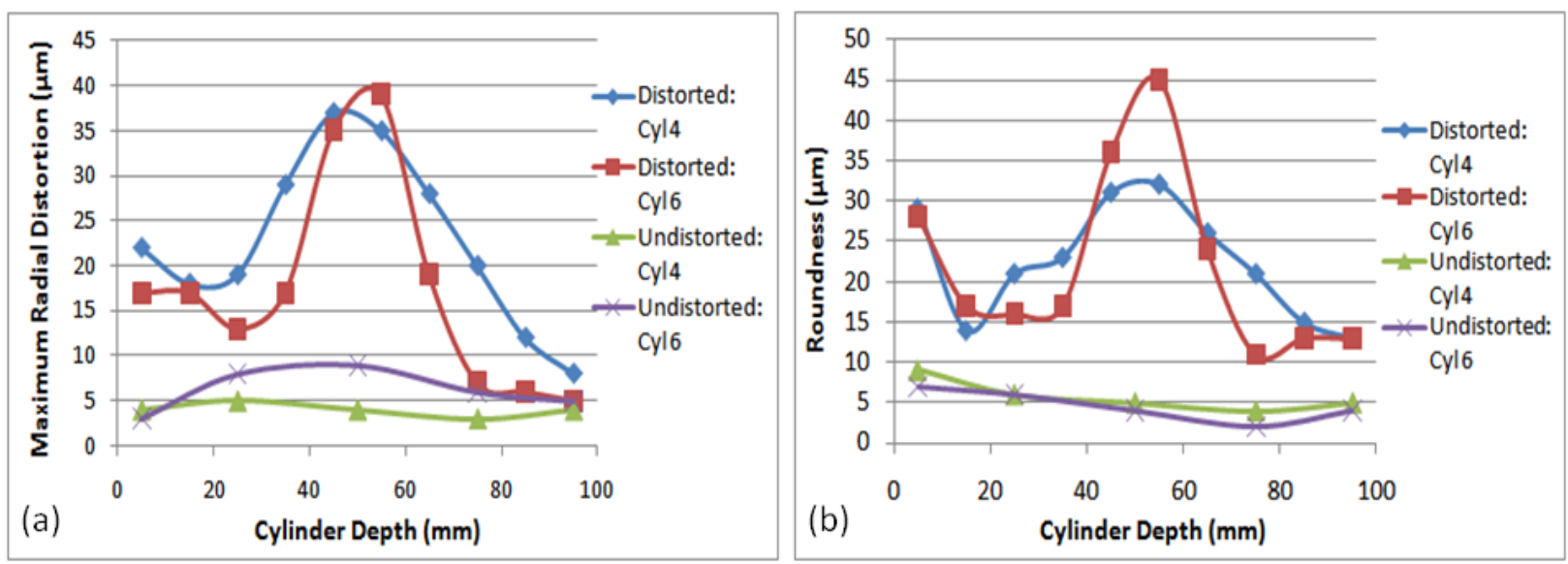

Figure 4.1: Results from CMM measurements along the cylinders of distorted and undistorted engine blocks showing: (a) maximum radial distortion, (b) roundness.

For the distorted engine block, the magnitude of radial distortion in cylinder 6 (Figure 4.1 (a)) varied from approximately $15 \mu \mathrm{m}$ at a cylinder depth of $5 \mathrm{~mm}$ (top of cylinder) to $40 \mu \mathrm{m}$ at a depth of approximately $55 \mathrm{~mm}$ (middle of cylinder). The magnitude of radial distortion subsequently decreased to approximately $5 \mu \mathrm{m}$ at cylinder depths approaching $100 \mathrm{~mm}$ (near the bottom of the cylinder). Similarly, roundness measurements, shown in Figure 4.1 (b), (which is a measure of deviation from a nominal least squares circle) indicated a similar trend with the maximum roundness value of $46 \mu \mathrm{m}$ occurring at a depth of $55 \mathrm{~mm}$, while regions near the top and bottom of the cylinder had roundness values of approximately 27 and $13 \mu \mathrm{m}$, respectively. The close relationship between the maximum radial distortion and roundness measurements indicates that the non-circularity, shown by roundness, was mainly the result of relatively large perturbations in select cylinder locations, rather than a more uniform distribution of smaller perturbations. Similar trends were observed in the other cylinders of the distorted engine block. However, the magnitude of distortion was slightly lower compared to that in cylinder 6 .

The undistorted engine block, on the other hand, had relatively constant values of radial distortion and roundness along the depth of the cylinder, ranging between 3 and $10 \mu \mathrm{m}$. This low magnitude of distortion further confirms that large scale permanent deformation did not occur during service operation of this engine block. 


\subsection{Microstructural Analysis of Cylinder Bridge}

In this section, the microstructural analysis along the cylinder bridge of undistorted and distorted engine blocks, using optical microscopy, SEM and TEM are discussed. The dendritic structure and SDAS at various depths along the cylinder is given in Section 4.2.1. Secondary phase morphology in interdendritic regions and volume fraction of $\mathrm{Al}_{2} \mathrm{Cu}$ along the cylinders of both engine blocks are presented in Section 4.2.2. Finally, the age hardening precipitates within the $\alpha-\mathrm{Al}$ dendrites are analyzed in Section 4.2.3.

\subsubsection{Dendritic Structure}

Microstructural analysis was first carried out using optical microscopy to observe the dendritic structure in both the distorted and undistorted engine blocks. Figure 4.2 presents the results for the top, middle and bottom sections of the cylinder bridge. The results from optical microscopy suggest that both the undistorted and distorted engine blocks contained similar microstructures at the top, middle and bottom of the cylinder. This was expected since both blocks were manufactured with the same casting parameters. For the undistorted and distorted engine blocks, the SDAS near the top of the cylinder were $34.4 \pm 2.4$ and $34.1 \pm 2.7 \mu \mathrm{m}$, respectively. At the bottom of the cylinder, the SDAS were $19.1 \pm 1.2$ and $18.5 \pm 1.0 \mu \mathrm{m}$ for the undistorted and distorted engine blocks respectively. The SDAS results are summarized in Table 4.1 (where the error represents the 95\% confidence interval of the SDAS sample mean (error analysis methodology is shown in Appendix F)) and confirm the refinement in microstructure with increased cylinder depth for both the distorted and undistorted engine blocks.

Table 4.1: Summary of SDAS along the Al cylinder bridge of the distorted and undistorted engine blocks.

\begin{tabular}{|c|c|c|}
\hline \multirow{2}{*}{ Cylinder Location } & \multicolumn{2}{|c|}{ SDAS $(\boldsymbol{\mu m})$} \\
\cline { 2 - 3 } & Undistorted & Distorted \\
\hline Top & $34.4 \pm 2.4$ & $34.1 \pm 2.7$ \\
\hline Middle & $28.3 \pm 1.7$ & $26.2 \pm 2.1$ \\
\hline Bottom & $19.1 \pm 1.2$ & $18.5 \pm 1.0$ \\
\hline
\end{tabular}

The refinement in microstructure along the cylinder was likely due to the top of the cylinder being in proximity to risers, while the bottom of the cylinder was located nearest to the bulkhead 
chill plate. For this reason, the cylinder bore region experienced a variation in cooling rate during solidification, similar to the observations of Torres et al. [102] in V8 Al alloy engine blocks.

\section{Undistorted}
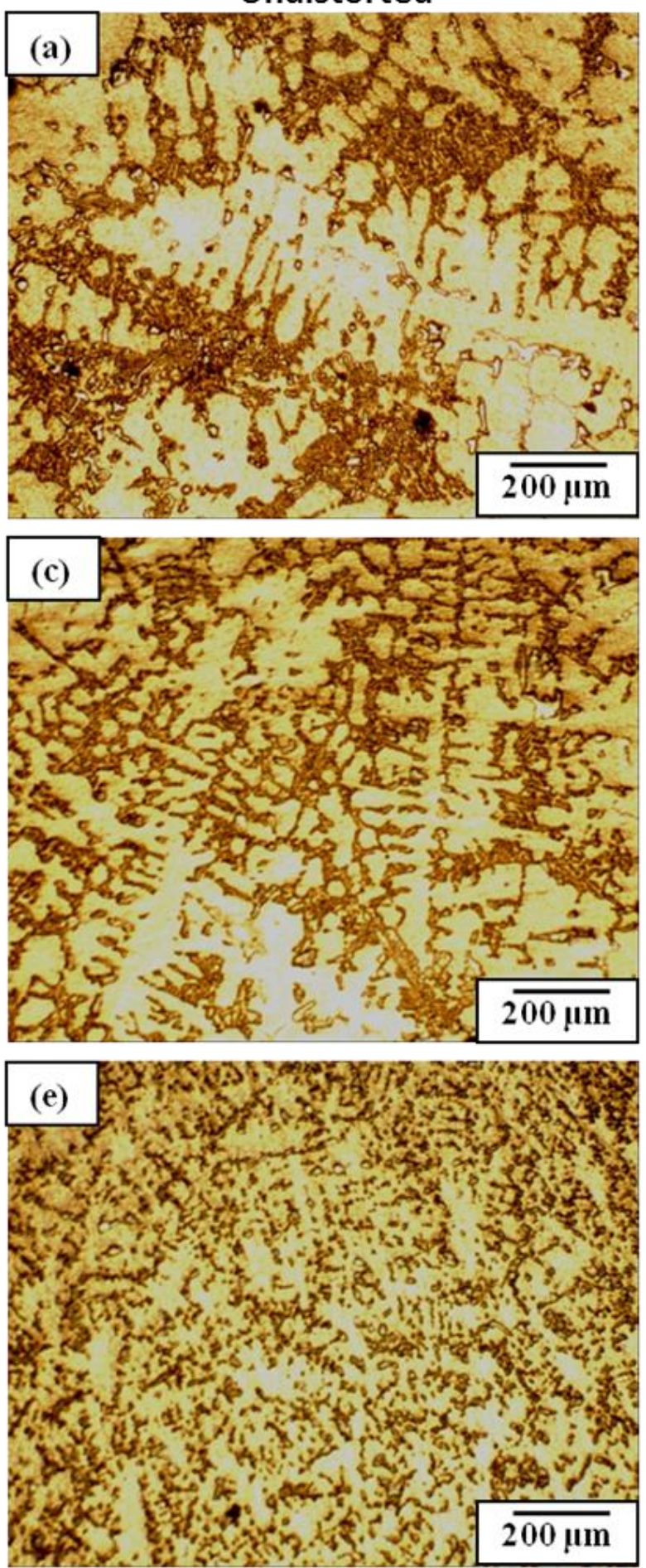

\section{Distorted}
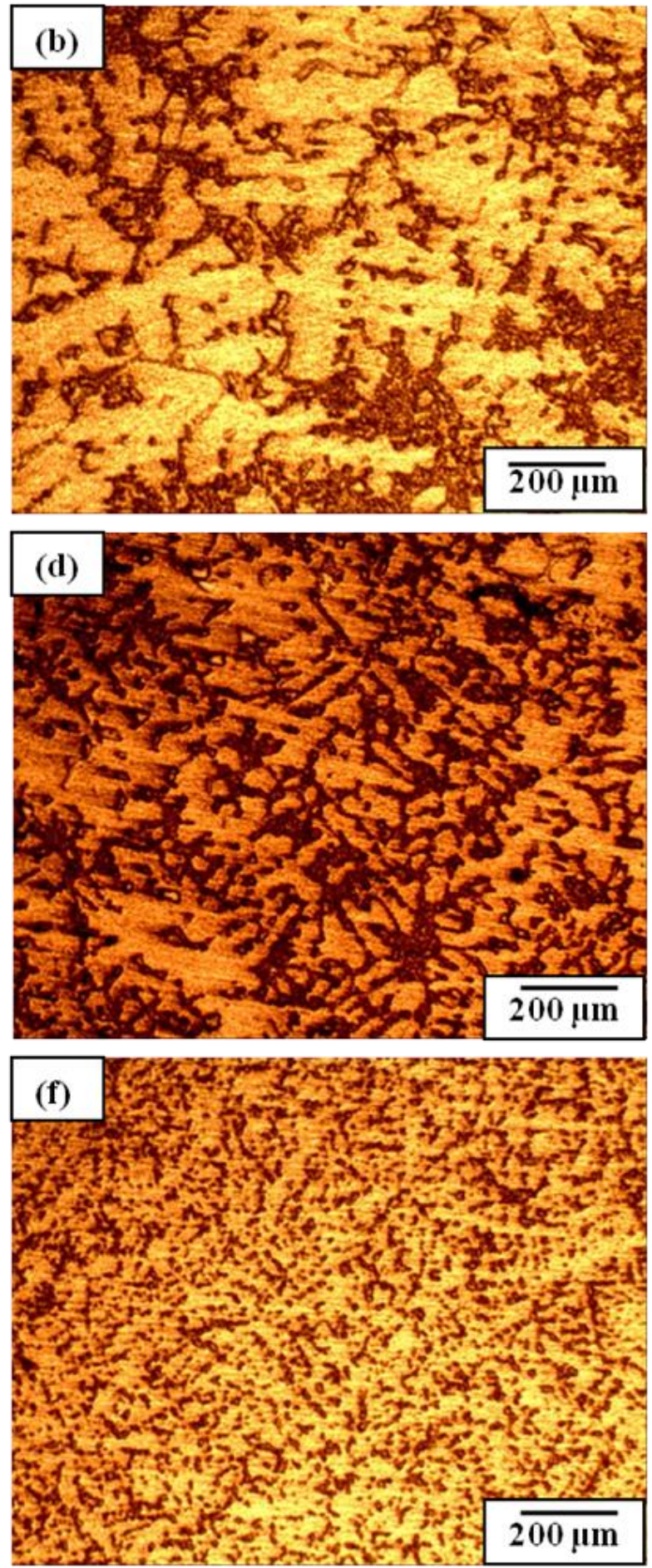

Figure 4.2: Optical micrographs (50x) showing the dendritic structure for undistorted (a, $c$ and e) and distorted (b, $d$ and f) engine blocks: (a) and (b) top of cylinder, (c) and (d) middle of cylinder, (e) and (f) bottom of cylinder. 


\subsubsection{Secondary Phases in Interdendritic Regions}

Distortion in heat treatable Al alloy components has been shown to occur by phase transformation during post-casting heat treatments and subsequent elevated temperature exposure $[5,6]$. For this reason, an in-depth analysis of the secondary phases amenable to heat treatment (such as $\mathrm{Cu}$ and $\mathrm{Mg}$ bearing intermetallics) was conducted for both the distorted and undistorted engine blocks.

\section{Undistorted}
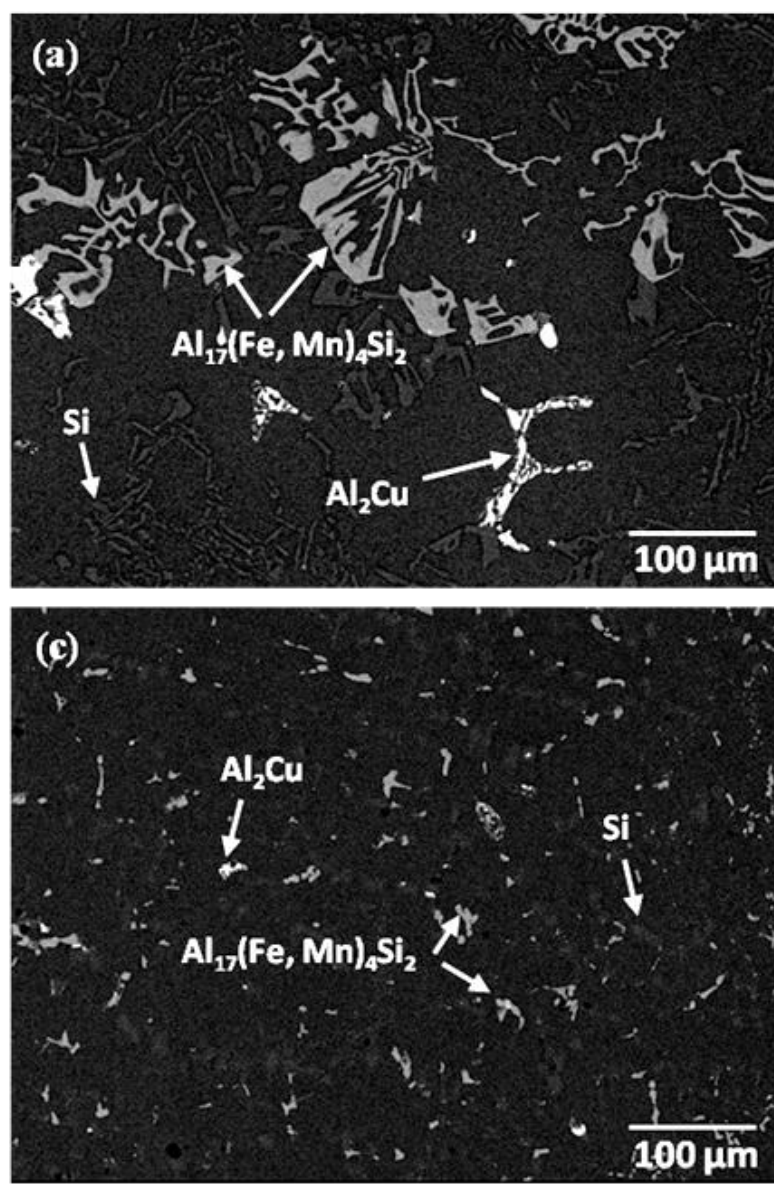

\section{Distorted}
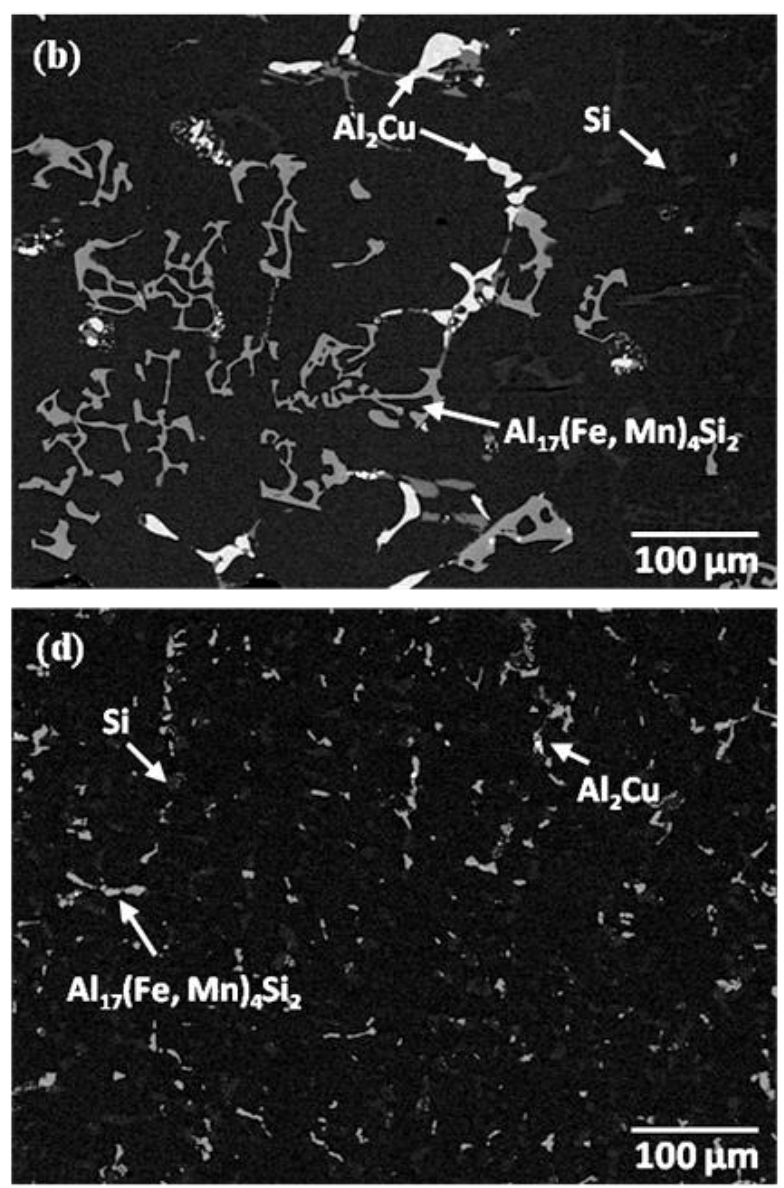

Figure 4.3: Backscattered electron images of the cylinder bridge for: (a) undistorted top (200x), (b) distorted top (200x), (c) undistorted bottom (200x), (d) distorted bottom (200x).

Secondary phase analysis was first carried out using SEM for the phases in the interdendritic regions from top to bottom along the cylinder bridge of the distorted and undistorted engine blocks. The results, shown in Figure 4.3, suggest that the microstructure of both the distorted and undistorted engine blocks contain $\mathrm{Al}-\mathrm{Si}$ eutectic, Chinese script $\mathrm{Al}_{17}\left(\mathrm{Fe}, \mathrm{Mn}_{4} \mathrm{Si}_{2}\right.$, blocky $\mathrm{Al}_{2} \mathrm{Cu}$ and a small quantity of $\mathrm{Al}_{5} \mathrm{Mg}_{8} \mathrm{Cu}_{2} \mathrm{Si}_{6}$ intermetallic particles. The stoichiometry of these phases 
was determined using X-ray diffraction in preliminary work by the current author [89]. In addition, the secondary phase particles in both engine blocks were significantly finer and had a more globular morphology at the bottom of the cylinder compared to the top. Similar to the refinement of the dendrite structure, the refinement in secondary phase particle morphology was attributed to the increased cooling rate near the bottom of the cylinder, which resulted from the bulkhead chill plate.

To obtain a quantitative measurement of the effectiveness of SHT on dissolution of $\mathrm{Al}_{2} \mathrm{Cu}$ (in interdendritic regions, formed during solidification) the volume fraction of $\mathrm{Al}_{2} \mathrm{Cu}$ for the distorted and undistorted engine blocks was measured using Buehler Omnimet image analysis software, in conjunction with a minimum of 25 backscattered electron (BSE) images. This analysis focused on the $\mathrm{Al}_{2} \mathrm{Cu}$ phase since this phase is amenable to heat treatment and unlike the $\mathrm{Al}_{5} \mathrm{Mg}_{8} \mathrm{Cu}_{2} \mathrm{Si}_{6}$ phase, has sufficient contrast to accurately measure the volume fraction using image analysis. As summarized in Table 4.2 (error represents the 95\% confidence interval of the $\mathrm{Al}_{2} \mathrm{Cu}$ volume fraction sample mean), the $\mathrm{Al}_{2} \mathrm{Cu}$ volume fraction ranged from approximately 1 vol.\% near the top of the cylinder to 0.3 vol.\% near the bottom for both the distorted and undistorted engine blocks.

Table 4.2: Results from quantitative phase analysis of $\mathrm{Al}_{2} \mathrm{Cu}$ in the distorted and undistorted engine blocks.

\begin{tabular}{|c|c|c|}
\hline \multirow{2}{*}{$\begin{array}{c}\text { Cylinder } \\
\text { Location }\end{array}$} & \multicolumn{2}{|c|}{ Volume Fraction of $\mathbf{A l}_{2} \mathbf{C u}($ vol.\%) } \\
\cline { 2 - 3 } & Undistorted & Distorted \\
\hline Top & $1.09 \pm 0.38$ & $0.99 \pm 0.33$ \\
\hline Middle & $1.14 \pm 0.33$ & $0.85 \pm 0.22$ \\
\hline Bottom & $0.30 \pm 0.07$ & $0.25 \pm 0.05$ \\
\hline
\end{tabular}

The variation in the interdendritic $\mathrm{Al}_{2} \mathrm{Cu}$ volume fraction from the top to bottom of the $\mathrm{Al}$ cylinder bridge was partially the result of cooling rate since it has been documented by Li et al. [12] that increased cooling rate reduces the volume fraction of $\mathrm{Al}_{2} \mathrm{Cu}$ in the interdendritic regions. Further, as supported by the results in Section 5.1.2 of this dissertation and those of Sjolander and Seifeddine [41] and Li et al. [4], finer secondary phase particles at the bottom of the cylinder likely led to more effective $\mathrm{Al}_{2} \mathrm{Cu}$ dissolution during the TSR and SHT processes, which contributed to lower $\mathrm{Al}_{2} \mathrm{Cu}$ volume fraction at the bottom of the cylinder compared to the top. Finally, macrosegregation of $\mathrm{Cu}$ to the interface between the $\mathrm{Al}$ cylinder bridge and gray iron 
liners at the bottom of the cylinder was also observed, which is documented in Section 5.1.1.3 of this dissertation. This segregation of $\mathrm{Cu}$ likely reduced the amount of $\mathrm{Al}_{2} \mathrm{Cu}$ in the centre portion of the bottom cylinder bridge region.

\subsubsection{Precipitates in Aluminum Dendrites}

The lack of changes in both the morphology and volume fraction of the second phase particles (shown in Figure 4.3 and Table 4.2 respectively) when comparing the distorted and undistorted engine blocks indicate that the microstructure of both engine blocks was stabilized by $\mathrm{T} 7$ heat treatment. However, to fully determine if thermal growth contributed to distortion, TEM analysis was carried out to observe the morphology and type of age hardening precipitates within the $\mathrm{Al}$ dendrites (Figure 4.4) and confirm the microstructural stability of both engine blocks.

Bright field (BF) TEM images for the middle of the Al cylinder bridge of the undistorted and distorted engine blocks are shown in Figures 4.4 (a) and (b), respectively, while Figure 4.4 (c) shows an EDX point spectrum of the Al-Cu platelet precipitates. In addition, a BF TEM image showing an exposed coarse rod shaped precipitate and its corresponding EDX point spectrum are shown in Figures 4.4 (d) and (e), respectively.

The results from TEM analysis indicate that for the Al cylinder bridge of the distorted and undistorted engine blocks, the microstructure within the primary $\mathrm{Al}$ dendrites consisted of $\mathrm{Al}-\mathrm{Cu}$ platelet precipitates, confirmed from the EDX spectrum in Figure 4.4 (c), and $\mathrm{Al}-\mathrm{Si}-\mathrm{Cu}-\mathrm{Mg}$ rod-shaped precipitates, as confirmed from the EDX spectrum in Figure 4.4 (e). These rodshaped precipitates were possibly the $\mathrm{Q}-\mathrm{Al}_{5} \mathrm{Mg}_{8} \mathrm{Cu}_{2} \mathrm{Si}_{6}$ phase as described by Ovono et al. [58]. The Al-Cu platelet precipitates were approximately $250 \mathrm{~nm}$ in length, while the $\mathrm{Al}_{5} \mathrm{Mg}_{8} \mathrm{Cu}_{2} \mathrm{Si}_{6}$ rod-shaped precipitates were approximately $400 \mathrm{~nm}$ in length. The microstructure for the distorted and undistorted engine blocks was similar to the results of Tavitas-Medrano et al. [61]. The microstructure indicates that analogous to the previous studies [61, 89], the Al-Cu platelets were equilibrium $\theta$ (confirmed using selected area diffraction patterns in [61] and [89]). The similarity in microstructures between these engine blocks indicates that the overaging treatments, applied during production of the engine blocks, resulted in fully stabilized equilibrium $\theta$, mitigating the effect of continued phase transformation during service operation. 

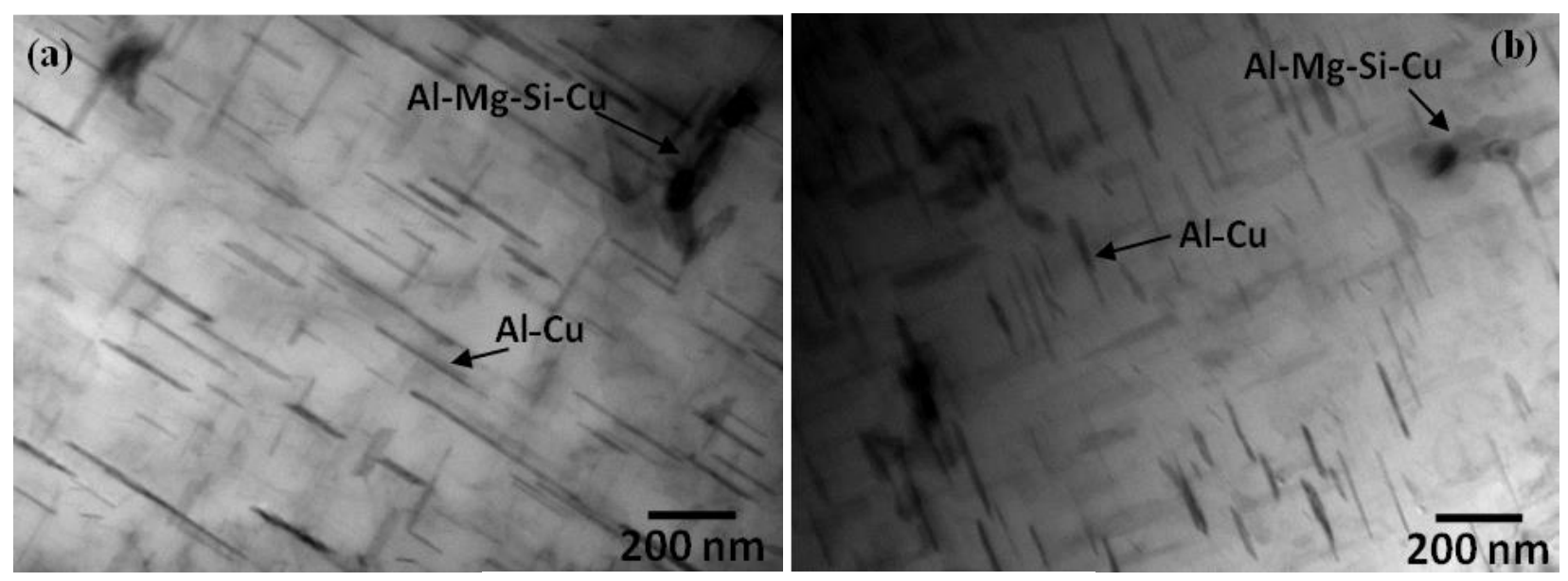

(c)
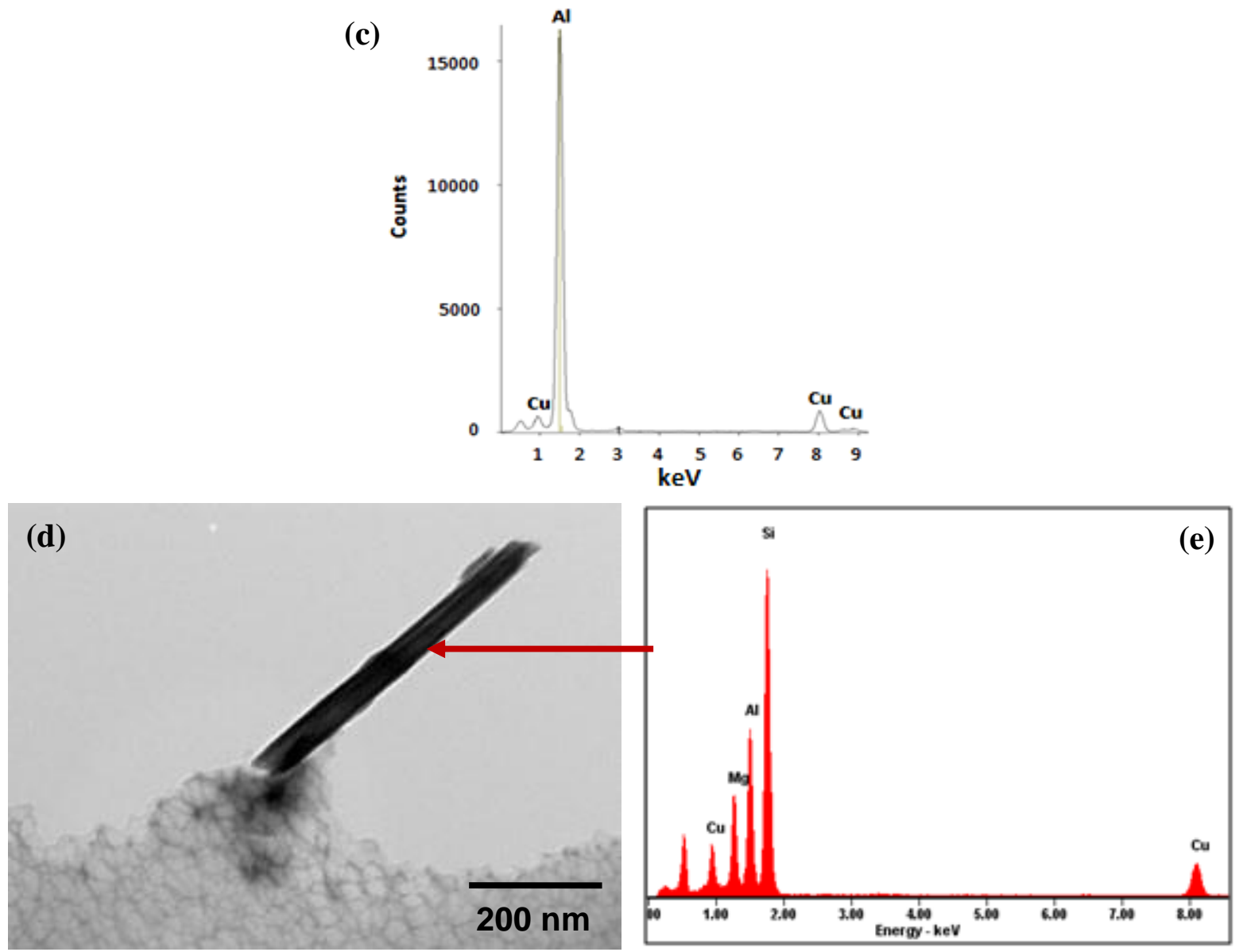

Figure 4.4: (a) BF TEM image of the undistorted engine block (12000x), (b) BF TEM image of the distorted engine block (12000x), (c) EDX point spectrum of Al-Cu platelet precipitates (d) BF TEM image of rodshaped precipitates where EDX was carried out (20000x), (e) EDX point analysis of rod-shaped precipitate.

It is important to note that although the BF TEM images in Figures 4.4 (a) and (b) were from samples extracted from the middle of the Al cylinder bridge, the top and bottom regions for both engine blocks had similar microstructures within the Al dendrites to that shown in Figure 4.4. This further suggests that the precipitates were formed by precipitation hardening heat treatment 
rather than during solidification, since there were no morphological changes in these precipitates for the top and bottom of the cylinder bridge (variation in cooling rate in these regions).

\subsection{Tensile Properties of Cylinder Bridge}

Tensile testing was carried out on the middle portion of the Al cylinder bridge and gray iron liners of service tested engine blocks (undistorted and distorted) at ambient and cylinder bridge temperatures when exposed to service conditions $\left(\sim 180{ }^{\circ} \mathrm{C}\right.$, refer to Section 3.2 .4 for an explanation on the operating temperature). This analysis was done (using a minimum of five samples per condition) to relate the residual stresses (Section 4.4) with the mechanical properties during engine service. The results are shown in Figure 4.5 with the error bars representing the $95 \%$ confidence interval of the yield and ultimate tensile strength sample means.

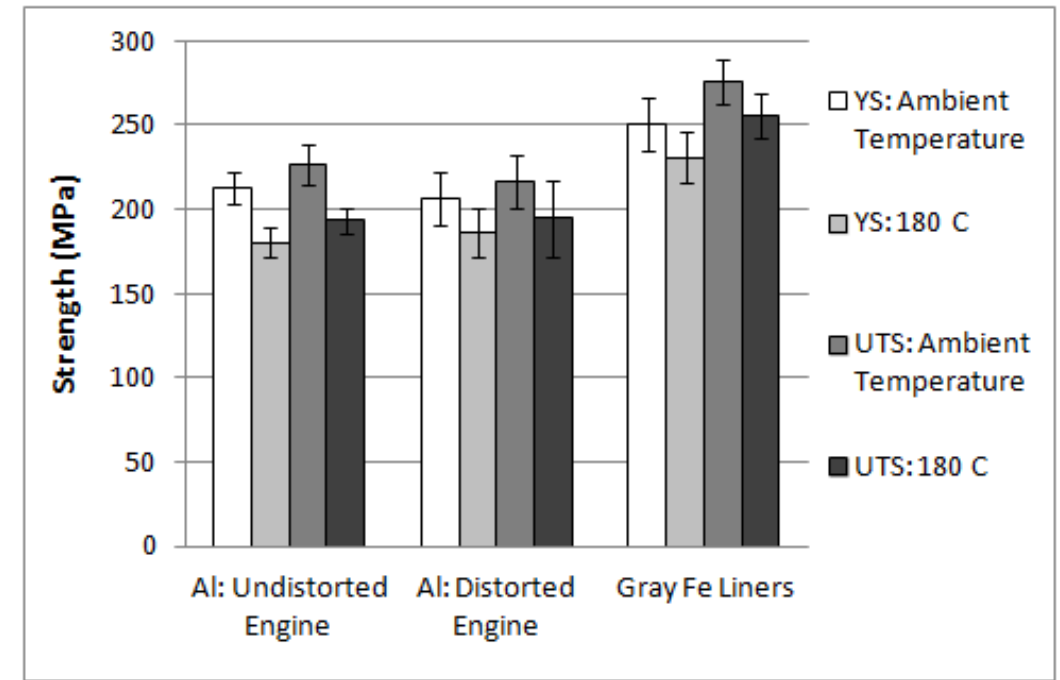

Figure 4.5: Results from tensile testing for the middle of the aluminum cylinder bridge and gray iron liners of service tested engine blocks.

The results indicate that the ambient temperature yield strength (YS) and ultimate tensile strength (UTS) of the Al cylinder bridge in the undistorted engine block was 215 and $230 \mathrm{MPa}$, respectively. Similarly, the distorted engine block had ambient temperature YS and UTS values of approximately 215 and $225 \mathrm{MPa}$, respectively. At the estimated operating temperature in the cylinder bridge $\left(\sim 180^{\circ} \mathrm{C}\right)$, the YS and UTS of the Al cylinder bridge in both engine blocks decreased to approximately 180 and $195 \mathrm{MPa}$, respectively. The similarity in tensile properties between the distorted and undistorted engine blocks was expected due to their similar microstructures, specifically the stabilized equilibrium $\theta$ age hardening precipitates shown in the BF TEM images (Figures 4.4 (a) and (b)). 
The tensile properties of the gray iron cylinder liners were also evaluated, as shown in Figure 4.5. At ambient temperature, the gray iron liners had YS and UTS values of 250 and $275 \mathrm{MPa}$, respectively, which is similar to the UTS values found for pearlitic gray iron [62]. At the engine operating temperature of $180{ }^{\circ} \mathrm{C}$, the YS and UTS decreased to approximately 230 and $255 \mathrm{MPa}$, respectively. In addition, unlike the heat treatable $\mathrm{Al}$ cylinder bridge, the tensile properties of the gray iron liners did not change for each production stage (i.e.as-cast, heat treated and service tested). This was expected since the heat treatment and service temperatures used for Al engine blocks is significantly lower than the temperature that results in microstructural modification of gray iron $\left(\sim 740{ }^{\circ} \mathrm{C}\right)$ according to the Fe-C phase diagram [62]).

\subsection{Residual Strain and Stress Mapping}

Distortion is commonly caused due to excessive residual stresses. The ambient temperature residual strain and stress profiles (ex-situ analysis which followed dynamometer testing) of the undistorted and distorted engine blocks are presented in this section to illustrate the effect of residual stress on permanent dimensional distortion. The processing history of these engine blocks, as discussed in Section 3.2, includes TSR treatment, solution heat treatment, forced air quenching, T7 artificial aging, machining of the cylinder bores, and dynamometer testing. The residual strain and stress profiles along the Al cylinder bridge of the engine blocks in both conditions are shown in Section 4.4.1, while the residual strain and stress profiles in the adjacent gray iron liners are shown in Section 4.4.2.

\subsubsection{Aluminum Cylinder Bridge}

Residual strain and stress mapping was carried out from top to bottom along the Al cylinder bridge using neutron diffraction. The residual strain profiles for the undistorted and distorted engine blocks are shown in Figures 4.6 (a) and (b), respectively. The error bars represent the uncertainty of neutron diffraction measurements associated with fitting a Gaussian distribution to the Bragg peak (refer to Appendix B). It is important to note, that residual strain measurements using the neutron diffraction technique have an accuracy of approximately 100 microstrain.

The results illustrate that for both the distorted and undistorted engine blocks, the hoop strain was tensile. However, the distorted engine block had a hoop strain increasing from approximately 200 
microstrain at the top of the cylinder to 1800 microstrain at the bottom, whereas the undistorted block had hoop strains increasing from 500 to 1100 microstrain from top to bottom.
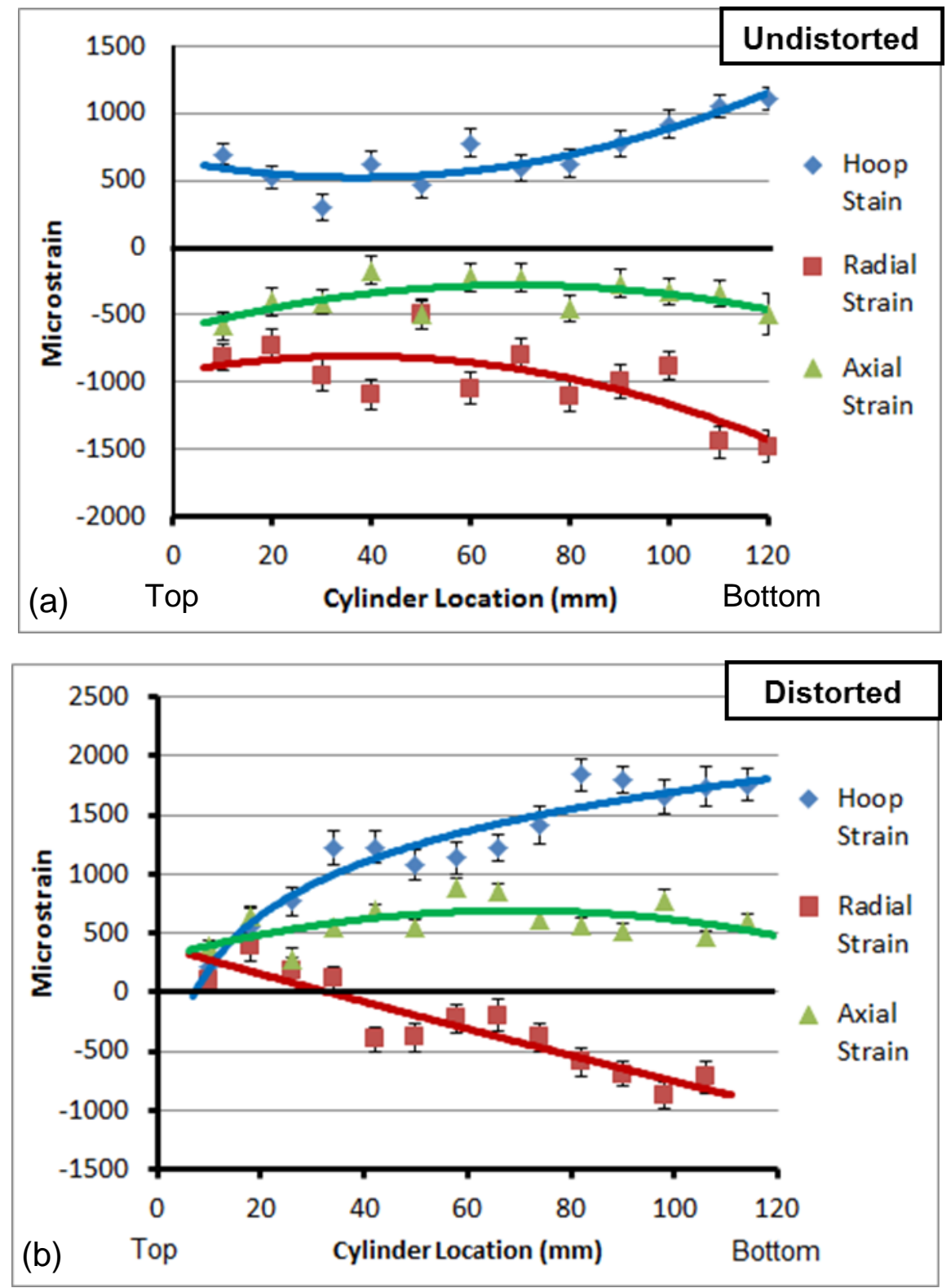

Figure 4.6: Residual strain profiles for the aluminum cylinder bridge of: (a) undistorted engine block, (b) distorted engine block.

The reduced tensile residual strain in the undistorted block was also observed in the radial orientation. The radial strain in the distorted block was tensile (400 microstrain) at the top of the cylinder but decreased and became compressive with increasing cylinder depth up to a magnitude of approximately 800 microstrain. Conversely, for the undistorted engine block, the radial strain was compressive with magnitudes ranging between 700 and 1500 microstrain. Finally, the axial 
strain was found to be fully tensile in the distorted engine block with magnitudes ranging between 400 and 800 microstrain. In contrast, the undistorted engine block had fully compressive axial strain with magnitudes between 200 and 500 microstrain.

Residual stress profiles were calculated using the strain profiles and generalized Hooke's law to relate the stress magnitudes along the cylinder to the mechanical properties, discussed in Section 4.3. The resulting residual stress profiles for the undistorted and distorted engine blocks are shown in Figures 4.7 (a) and (b), respectively. A horizontal line depicting the YS at the middle cylinder bridge temperature during service operation (from Figure 4.5) is also shown in Figure 4.7 (b). This YS line, however, was developed using the measured operating temperature at the top of the cylinder $\left(\sim 180^{\circ} \mathrm{C}\right)$ which may be a conservative estimate for the middle and bottom of the cylinders, where the lower temperatures during operation (combustion occurs near the top of the cylinder) may have led to a higher YS in these regions than is shown in Figure 4.7 (b).

The undistorted engine block had compressive residual stresses in the radial and axial orientations. The compressive radial stress in the undistorted engine block varied between 80 and $120 \mathrm{MPa}$ along the cylinder bridge, while the compressive axial stress varied between 50 and $70 \mathrm{MPa}$. The hoop stress, in contrast, had a stress magnitude near zero for the entire depth of the cylinder.

Analysis of the distorted engine block revealed significantly different residual stress profiles in comparison to the undistorted block. The results for the distorted engine block suggest highly tensile residual stresses along the cylinder bridge for the hoop, radial and axial orientations. The hoop stress, which had the highest tensile residual stress magnitude, showed a gradually increasing stress profile from approximately $50 \mathrm{MPa}$ near the top of the cylinder to $170 \mathrm{MPa}$ near the bottom. Similarly, the axial stress component increased from $60 \mathrm{MPa}$ at the top of the cylinder to $140 \mathrm{MPa}$ near the middle of the cylinder, which subsequently decreased to approximately $100 \mathrm{MPa}$ near the bottom of the cylinder. Finally the radial component had a residual stress profile which gradually decreased in magnitude from approximately $70 \mathrm{MPa}$ at the top of the cylinder to $40 \mathrm{MPa}$ near the bottom. 

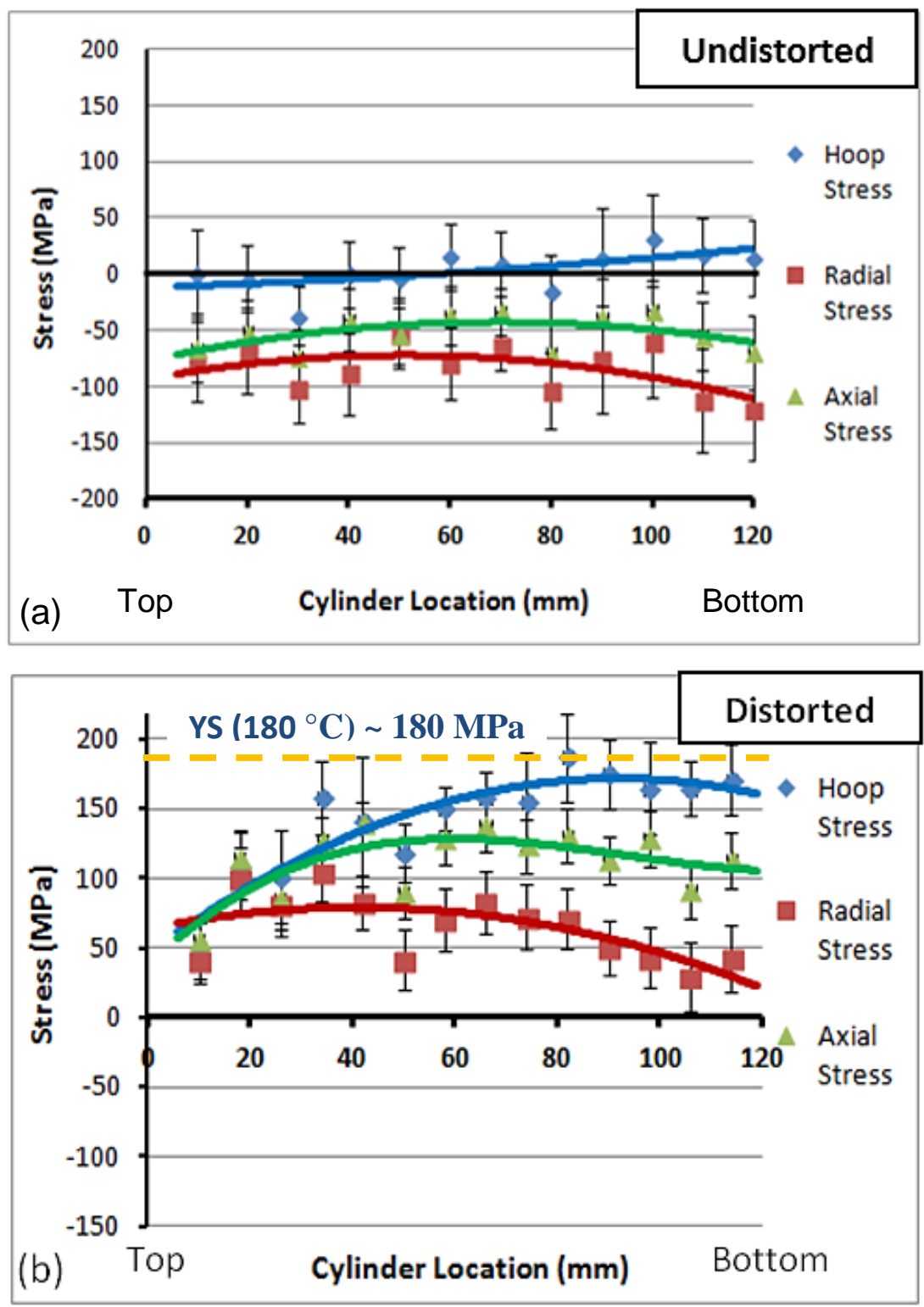

Figure 4.7: Residual stress profiles for the aluminum cylinder bridge of: (a) undistorted engine block, (b) distorted engine block.

Unlike the relatively constant residual strain and stress profiles for the undistorted block, the distorted engine block showed a large variation in residual strain and stress along the cylinder bridge. The discrepancies in residual strain and stress magnitude between the undistorted and distorted engine blocks can be explained by the different quench rates following T4 treatment. Since the engine blocks contain dissimilar materials with significant differences in thermal expansion coefficient $\left(\alpha_{\mathrm{Al}} \sim 2.4 \times 10^{-5} \mathrm{~K}^{-1}, \alpha_{\mathrm{Fe}} \sim 1.5 \times 10^{-5} \mathrm{~K}^{-1}[78]\right)$, the rate of contraction during quenching will differ if cooling is maintained at the same rate for the gray iron liners and the surrounding Al. For the distorted engine block, the large tensile residual stresses were likely 
generated because the slow quench rate $\left(40{ }^{\circ} \mathrm{C} /\right.$ minute $)$ obviated any significant gradient in temperature between the gray iron liners and the Al. Since Al contracts to a greater extent with decreasing temperature, there is a thermo-mechanical mismatch between the gray iron liners and the surrounding $\mathrm{Al}$ cylinder. This prevents free contraction of $\mathrm{Al}$ and causes the development of tensile residual stress, specifically in the hoop orientation.

Conversely, the undistorted engine block, produced with a faster quench rate $\left(100{ }^{\circ} \mathrm{C} / \mathrm{minute}\right)$, enabled a higher cooling rate in the gray iron liners as compared to the surrounding Al since the airflow was in direct contact with the liners. The faster cooling rate in the gray iron liners reduced the thermo-mechanical mismatch since the liners and the surrounding Al likely contracted at similar rates. The reduced restriction to free contraction in Al by the gray iron liners likely led to less tensile residual stress generation during cooling in the undistorted engine block. Further, due to the relatively small contraction of both $\mathrm{Al}$ and the gray iron liners following quenching (as compared to during quenching) the thermal stress generated following the quenching process was likely significantly lower and may have been accommodated and redistributed to other regions of the engine block, resulting in negligible residual stress generation. It is important to note that the quench rates were not large enough to generate significant residual stress due to thermal gradients along the cylinder for the undistorted and distorted engine blocks, since the engine block with lower quench rate (and lower thermal gradients) had higher tensile residual stress. Furthermore, the T7 aging treatment, applied to both engine blocks after SHT and quenching, also likely influenced the residual stress profiles in the distorted and undistorted blocks, preventing the influence of different quenching rate from being completely isolated.

While there is a clear relationship between heat treatment, quenching and the resulting residual stress profiles, further research into the influence of heat treatment parameters and quench rates in components containing dissimilar materials and complex geometries is required to fully understand residual stress relief and generation in this process. To further develop this theory, Section 5.2 of this dissertation examines residual strain relief as a function of time during SHT and residual strain development as a function of temperature during post-heat treatment cooling using in-situ neutron diffraction. 


\subsubsection{Gray Cast Iron Cylinder Liners}

Residual strain and stress mapping was also carried out from top to bottom along the gray iron cylinder liners using neutron diffraction. The resulting residual strain profiles in the undistorted and distorted engine blocks are shown in Figures 4.8 (a) and (b), respectively. The resulting residual hoop strain indicates that both the distorted and undistorted engine blocks have compressive strains along the gray iron liners. The distorted block had a strain magnitude that varied from 800 microstrain at the top of the cylinder to approximately 180 microstrain at the bottom. The undistorted engine block, conversely had hoop strains varying between 1400 and 1700 microstrain.
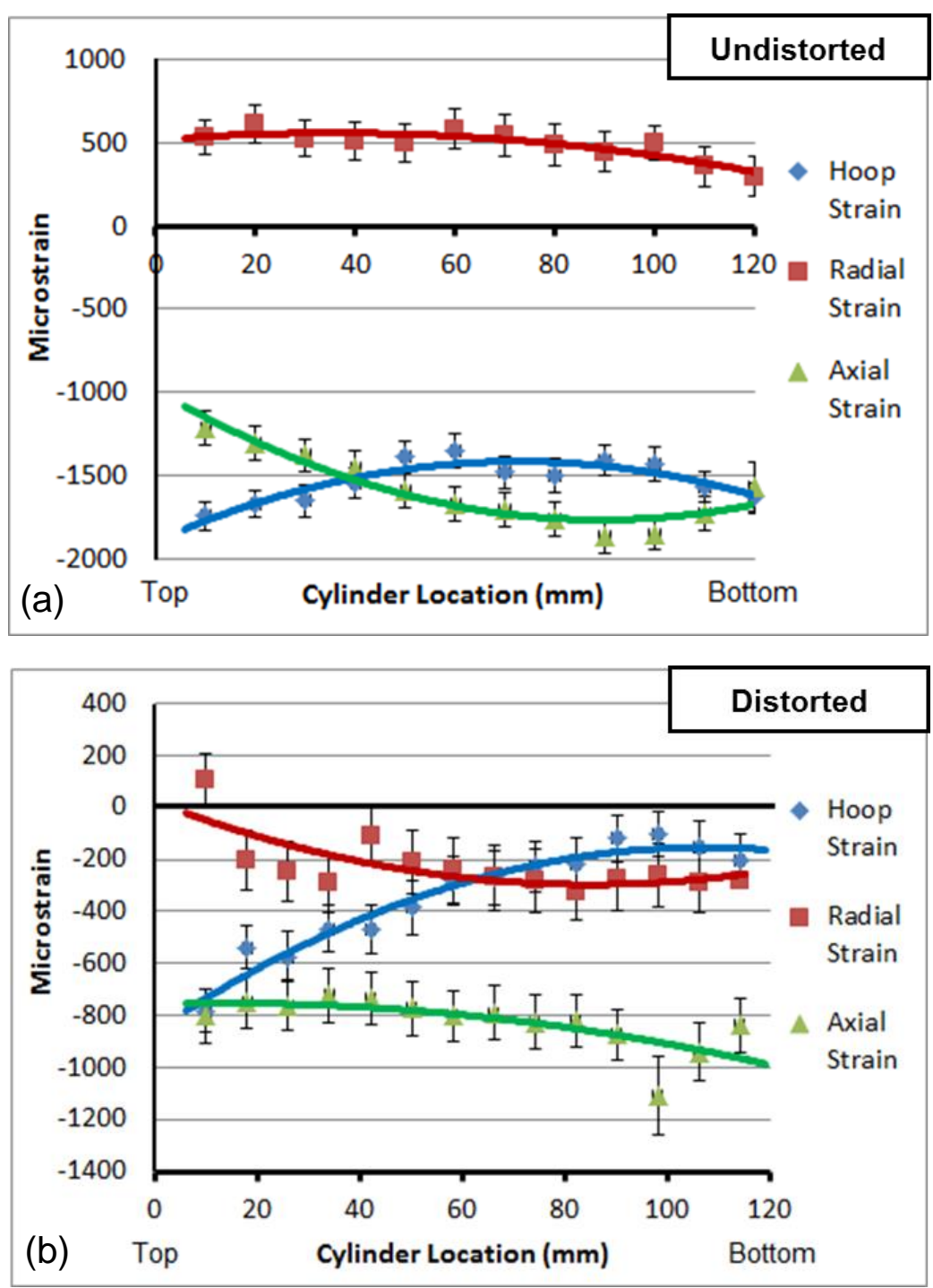

Figure 4.8: Residual strain profiles for the gray iron cylinder liners of: (a) undistorted engine block, (b) distorted engine block. 
Similar to the hoop strain component, the axial strain was found to be highly compressive for the gray iron cylinder liners of both the distorted and undistorted engine blocks. The axial strain magnitude along the gray iron liner of the distorted block ranged between 800 and 1000 microstrain. For the undistorted block, the strain magnitude increased from 1200 microstrain at the top of the cylinder to 1800 microstrain near the bottom of the cylinder.

In contrast to the other two strain components, the radial strain was found to be slightly compressive for the distorted engine block and slightly tensile for the undistorted engine block. The compressive radial strain magnitude in the distorted engine block ranged between 200 and 300 microstrain, while the tensile strain magnitude in the undistorted block ranged between 300 and 600 microstrain.

Generalized Hooke's law was also used in conjunction with the strain profiles to calculate the residual stress along the gray iron cylinder liners of the undistorted and distorted engine blocks. The residual stress profiles for the undistorted and distorted engine blocks are shown in Figures 4.9 (a) and (b), respectively.

The residual stresses were compressive along the gray iron liners of the distorted and undistorted engine blocks. The undistorted engine block had a compressive radial stress that was $30 \mathrm{MPa}$ at the top of the cylinder and gradually increased to $50 \mathrm{MPa}$ at the bottom of the cylinder. In addition, the axial stress varied from $150 \mathrm{MPa}$ near the top of the cylinder liner to approximately $210 \mathrm{MPa}$ near the bottom. Similarly, the compressive hoop stress had a magnitude of $200 \mathrm{MPa}$ near the top and bottom of the cylinder, while the middle of the cylinder had a magnitude of approximately $175 \mathrm{MPa}$.

The distorted engine block, while also compressive, had lower residual stress magnitudes (i.e. closer to zero) for the hoop and axial components. For instance, the radial stress varied from $20 \mathrm{MPa}$ near the top of the cylinder to $50 \mathrm{MPa}$ near the bottom. Furthermore, the axial stress had a magnitude of $80 \mathrm{MPa}$ near the top of the cylinder, which gradually increased to $100 \mathrm{MPa}$ near the bottom. The hoop stress had a gradually decreasing compressive stress magnitude from $100 \mathrm{MPa}$ at the top of the cylinder to $50 \mathrm{MPa}$ at the bottom. 

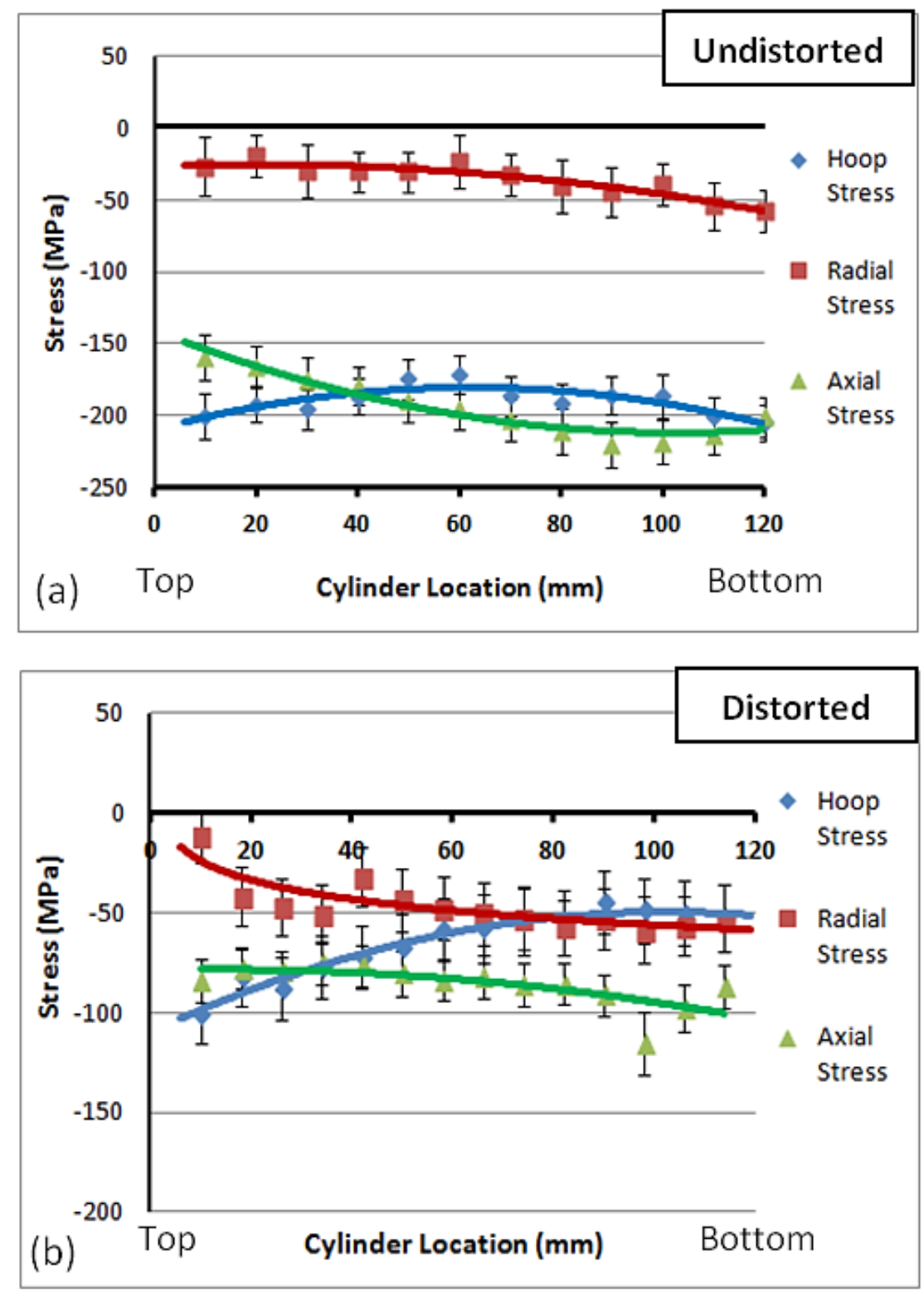

Figure 4.9: Residual stress profiles for the gray iron cylinder liners of: (a) undistorted engine block, (b) distorted engine block.

The compressive residual strains and stresses in the cylinder liners of both engine blocks were likely the result of the post-casting machining and honing process that was carried out on the engine blocks prior to dyno testing. In the precursor study to this dissertation [89], it was found that machining of the cylinder bores caused relief of the tensile residual stresses in the cylinder liners of a T7 heat treated and dyno tested engine block. Although machining typically imparts near surface compressive stress, rather than bulk stress as measured by neutron diffraction, this machining process removed approximately $50 \%$ of the liner thickness, resulting in significant macro-stress redistribution. As such, engine blocks that were subjected to this machining process, 
such as the distorted and undistorted engine blocks in this study, contained highly compressive residual stress in the gray iron cylinder liners.

\subsection{Mechanism of Cylinder Distortion}

\subsubsection{Effect of Phase Transformation on Distortion}

The first aspect that was examined was the microstructure to determine if distortion was caused by phase transformation (as a result of continued aging) during exposure to service conditions. Analysis using SEM revealed a similar morphology and volume fraction of secondary phase particles in interdendritic regions for all depths of the cylinder of both the distorted and undistorted engine blocks (Section 4.2.2). In addition, TEM bright field images suggest that for all depths along the cylinder of both the distorted and undistorted engine blocks, the $\mathrm{Al}-\mathrm{Cu}$ age hardening precipitates were fully stabilized $(\theta)$ by the T7 heat treatment schedule (Section 4.2.3). Therefore, the microstructure is thermally stable, indicating that service testing at approximately $180{ }^{\circ} \mathrm{C}$ did not cause further aging. Thus, the phase transformation based thermal growth mechanism, described by Hunsicker [5] and Boileau et al. [6] was likely not responsible for significant permanent dimensional distortion of the cylinder bores during service operation. An alternative cause of distortion could be related to residual stress, which is discussed in the next section.

\subsubsection{Effect of Microstructure, Mechanical Properties and Residual Stress on Distortion}

The cause of distortion and the reason for the varying distortion magnitude at different depths along the cylinder was likely the result of the interplay between the residual stress profiles, the variation in microstructure with cylinder depth and the associated variation in YS.

Comparison of the residual stress profiles between the distorted and undistorted engine blocks indicated that the distorted engine block had high tensile residual stresses along the cylinders, while the undistorted block had a negligible hoop stress and compressive axial and radial stresses. The large tensile residual stresses in the distorted block in combination with service stress (combustion process) likely exceeded the $319 \mathrm{Al}$ alloy YS (180 MPa, shown in Figure 4.5) at the operating temperature $\left(\sim 180{ }^{\circ} \mathrm{C}\right)$ causing plastic deformation and permanent cylinder distortion $[67,103]$. It is also important to note that plastic deformation results in partial 
instantaneous residual stress relief [71], indicating that the residual stress was likely higher prior to in-service distortion, specifically in the region of maximum measured distortion (middle of the cylinder). In addition, following the instantaneous relief of residual stress discussed above, the tensile residual stress in the distorted engine block was likely near the YS at the engine operating temperature $\left(\sim 180{ }^{\circ} \mathrm{C}\right)$ for the complete dyno testing process. This large residual stress, in combination with service stresses from combustion and elevated temperature exposure during the 20 hour dyno test, likely resulted in appreciable permanent distortion due to creep [71]. This is supported by the homologous temperature (ratio of the specimen and alloy liquidus temperatures) at the cylinder bridge, in absolute units, being approximately 0.52 during operation and the fact that creep deformation rate increases significantly for homologous temperatures above 0.4 [62]. Additional research, however, is required to determine the relative contributions of the instantaneous and creep-based mechanisms on overall cylinder distortion. Section 5.2.2 of this dissertation further discusses the implications of creep using creep deformation mechanism maps at high temperatures and residual stress levels.

In contrast, the undistorted block had low tensile residual hoop stress and compressive axial and radial stresses providing a large safety buffer between the YS at the engine operating temperature and the combined residual and service stresses. This resulted in minimal permanent distortion since both the instantaneous deformation and time-dependant creep based deformation were likely suppressed.

Although cylinder distortion was caused by large tensile residual stresses along the cylinder, the non-uniform distortion in the distorted block was explained by a gradient of coarse to fine microstructure from top to bottom (Figures 4.2 and 4.3) of the cylinder respectively, and the gradual increase of tensile residual stress with cylinder depth. For instance, the results in Figure 4.7 (b) revealed that the tensile residual hoop stress gradually increased with cylinder depth, reaching a maximum of approximately $170 \mathrm{MPa}$ near the bottom of the cylinder. Despite the high tensile hoop stress, the measured distortion at the bottom of the cylinder was negligible $(<10 \mu \mathrm{m})$. This negligible distortion was likely caused by a combination of decreased axial and radial stress at the bottom of the cylinder relative to the middle (partially mitigating the increased hoop stress) and microstructural refinement at the bottom of the cylinder which increased the YS. The increased YS at the bottom of the cylinder eliminated instantaneous deformation since the 
residual stress did not exceed the YS in this section of the cylinder. Furthermore, the contribution of creep in overall distortion would be largely reduced (slower creep rate) at the bottom of the cylinder since the residual stress level was significantly lower than the YS in this region.

The relative increase in YS with microstructural refinement was shown using lab scale castings which replicate the microstructure along the cylinder. As discussed in-detail in Sections 5.1.1 and 5.1.2 of this dissertation, the YS of the $319 \mathrm{Al}$ alloy, following the same $\mathrm{T} 7$ treatment schedule as the engine blocks, was approximately $30 \%$ higher for the castings which replicated the bottom of the cylinder (fine microstructure) as compared to those which replicated the top (coarse microstructure). Furthermore, the lower cylinder bridge temperature during engine operation for this region (far from combustion event) compared to the top of the cylinder may have also contributed to a higher YS at the bottom of the cylinder. As such, despite the high tensile residual stress, the increase in YS likely prevented appreciable in-service distortion at the bottom of the cylinder.

Similarly, the top of the cylinder of the distorted engine block also had a low distortion magnitude. However, since this region had coarse microstructure and lower strength, the lack of distortion was caused by lower residual stress magnitudes ( $60 \mathrm{MPa})$ in all the principal stress directions, which again prevented instantaneous plastic deformation (YS not exceeded) and reduced the contribution of creep based deformation during service testing (lower constant stress level at elevated temperature).

The middle portion of the cylinder ( $\sim 50-60 \mathrm{~mm}$ depth) had the highest magnitude of distortion which was caused by the combination of a higher tensile residual stress compared to the top of the cylinder and lower strength compared to the bottom. Lab scale replication castings (T7 condition) indicated that the YS at the middle of the cylinder was approximately $20 \%$ lower than the bottom. Therefore, the middle portion of the cylinder had the unfortunate combination of high residual stress and lower strength that induced permanent cylinder distortion, likely by both the instantaneous and creep deformation mechanisms.

The residual stress profiles in the gray iron cylinder liners may have also influenced the distortion susceptibility of the cylinder bores. Since both the distorted and undistorted engine blocks had fully compressive residual stress profiles for all orientations, these stresses were significantly 
lower than the YS at the operating temperature ( $230 \mathrm{MPa})$ and thus did not directly contribute to increased distortion susceptibility. On the other hand, the undistorted engine block had a significantly higher compressive stress magnitude, especially for the hoop and axial orientations. This suggests that the compressive residual stress in the gray iron liners may have counteracted the applied tensile stress from combustion. In contrast, the lower compressive stresses in the distorted block likely counteracted less of the applied stress, which in combination with the high tensile residual stress in $\mathrm{Al}$, increased the susceptibility to distortion. Therefore, the combination of high compressive residual stress in the gray iron liners and negligible tensile residual stress in the Al cylinder bridge likely reduced the susceptibility to in-service cylinder distortion for the undistorted engine block.

\section{Chapter Summary}

This chapter presented the results from in-depth analysis of microstructure, mechanical properties and residual stress of undistorted and distorted service tested $\mathrm{Al}$ alloy engine blocks containing gray iron cylinder liners. Permanent cylinder distortion was likely the result of the combination of tensile residual stress (approaching YS) and service stresses from the combustion process. These combined stresses likely exceeded the $319 \mathrm{Al}$ alloy YS at the engine operating temperature leading to instantaneous deformation. In addition, creep-based deformation may also have contributed to distortion due to the high residual stress level (near the alloy YS) and a homologous cylinder bridge temperature of 0.52 (creep becomes significant for homologous temperatures above 0.4) during the $20 \mathrm{~h}$ dyno test. Since heat treatment is effective in both increasing alloy strength and relaxing tensile residual stress, the efficient elimination of distortion is contingent on the optimization of heat treatment parameters. For this reason, Chapter 5 of this

dissertation will discuss the optimization of the SHT process, whereby the alloy strength along the cylinder bores is increased (examined using lab-scale replicating billet castings in Section 5.1) and tensile residual stress is reduced (examined using in-situ and ex-situ neutron diffraction in Section 5.2), resulting in improved engine block casting integrity. 


\section{Chapter 5: Optimization of Solution Heat Treatment Process}

Permanent cylinder distortion was found to be dependent on the alloy strength and the magnitude of tensile residual stress. This chapter presents the results from experiments designed to optimize the SHT parameters in Al engine blocks to maximize strength, minimize residual stress and thereby eliminate distortion. The results showing the effect of varying SHT parameters on microstructure and mechanical properties of the 319 Al alloy are presented in Section 5.1. Relaxation of tensile residual stress during SHT is shown in Section 5.2. The chapter concludes by providing the optimal SHT parameters for the $319 \mathrm{Al}$ alloy engine blocks (Section 5.3).

\subsection{Microstructure and Mechanical Properties}

This section aims to determine the optimal SHT parameters to improve the mechanical properties of $319 \mathrm{Al}$ alloy engine blocks using lab-scale replicating castings. Development of a lab-scale method for engine block heat treatment optimization via replication of the cylinder bridge microstructure (as-cast and TSR treated) is discussed in Section 5.1.1. The influence of varying SHT parameters on microstructure and mechanical properties of the replicating billet castings are shown in Section 5.1.2."

\subsubsection{Replication of Cylinder Bridge Microstructure using Billet Castings}

Replication of the engine block microstructure was accomplished by casting 319 Al alloy billets of the same composition as that of the engine block. The cooling rate of the castings was varied in order to obtain billets which replicated each depth of the cylinder. This subsection compares the engine block microstructure and mechanical properties to billets which successfully approximated the microstructure at the top, middle and bottom of the cylinder bridge.

\footnotetext{
* The data presented in this section was published in:

Lombardi, A., Ravindran, C., MacKay, R., "Optimization of the Solution Heat Treatment Process to Improve Mechanical Properties of 319 Al Alloy Engine Blocks using the Billet Casting Method", Materials Science and Engineering A., vol. 633, pp. 125-135 (2015).

Lombardi, A., Ravindran, C., MacKay, R., "Application of the Billet Casting Method to Determine the Onset of Incipient Melting of 319 Al Alloy Engine Blocks", Journal of Materials Engineering and Performance, vol. 24, pp. $2179-2184$ (2015).

Lombardi, A., D'Elia, F., Ravindran, C., MacKay, R., "Replication of Engine Block Cylinder Bridge Microstructure and Mechanical Properties with Lab Scale 319 Al Alloy Billet Castings”, Materials Characterization, vol. 87, pp. 125-137 (2014).

Lombardi, A., Ravindran, C., MacKay, R., "Improvements in Mechanical Properties of 319 Al Alloy Engine Blocks through Cost-Effective Heat Treatment", Journal of Materials Engineering and Performance, vol. 23, pp. 2766-2771 (2014).
} 


\subsubsection{Billet Casting and Cylinder Bridge Dendritic Structure}

The cylinder bridge of the engine blocks and the billet castings were examined by preliminary optical microscopy to observe the dendritic structure. The cylinder bridge showed a gradual refinement in dendrite size from top to bottom (Figures 5.1 (a), (c), (e)), similar to the observations of the undistorted and distorted engine blocks in Section 4.2.1. This was expected as all of the engine blocks were cast using the same process parameters.
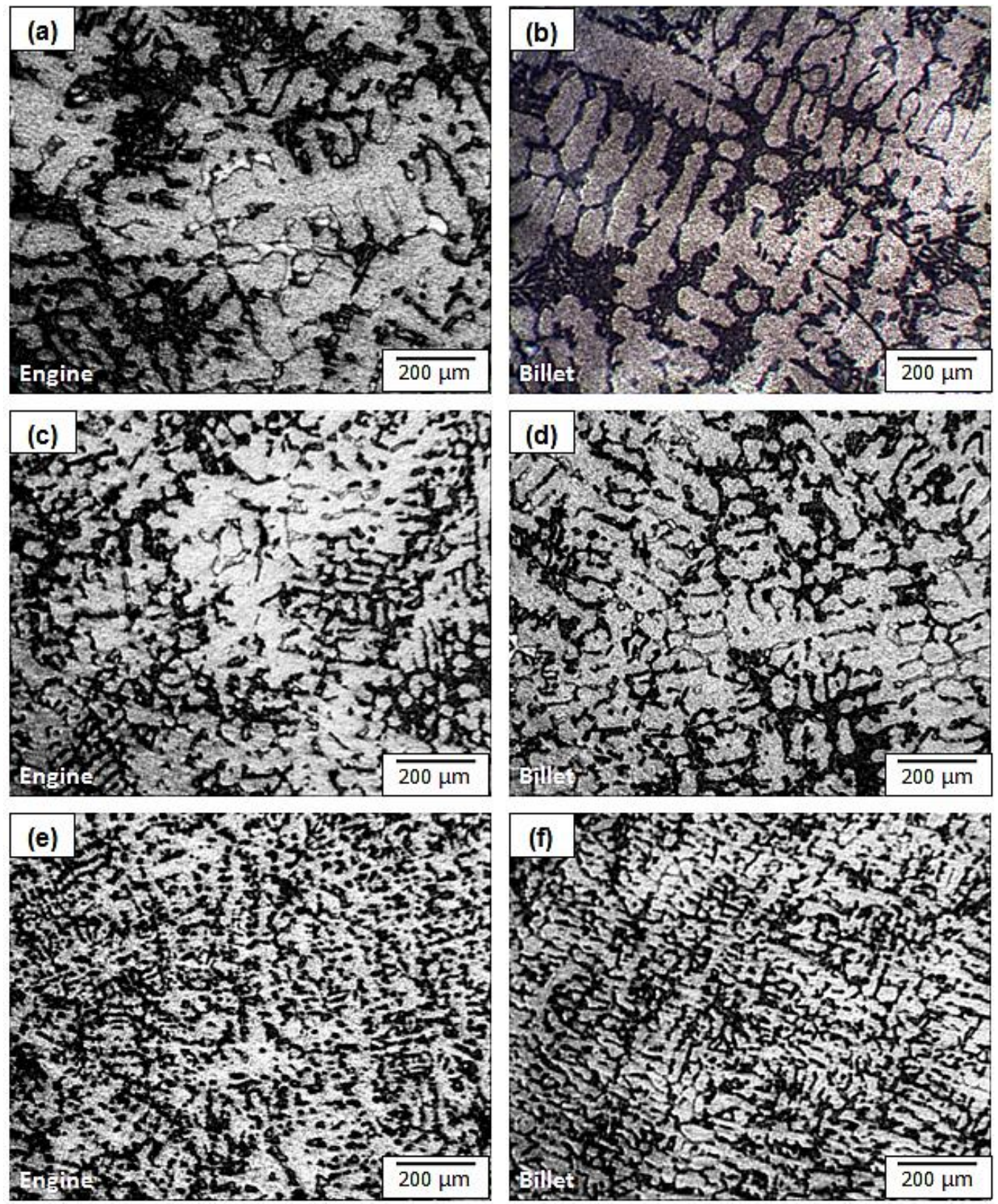

Figure 5.1: Optical micrographs showing dendritic structure of: (a) top of cylinder, (b) billet casting $\mathrm{CR}=1.5^{\circ} \mathrm{C} / \mathrm{s}$, (c) middle of cylinder, (d) billet casting $\mathrm{CR}=3.8^{\circ} \mathrm{C} / \mathrm{s}$, (e) bottom of cylinder, (f) billet casting $\mathrm{CR}=12.5^{\circ} \mathrm{C} / \mathrm{s}$. 
Based on the observations above, the replication of the cylinder bridge microstructure involved determining the cooling rates which produced a similar dendrite size to that observed in the cylinder bridge. Through several iterations of varying casting parameters, it was determined that cooling rates (CR) of $1.5,3.8$ and $12.5^{\circ} \mathrm{C} / \mathrm{s}$ during solidification of the billet castings effectively replicated the dendritic structure of the top, middle and bottom sections of the cylinder bridge, respectively (Figures 5.1 (b), (d), (f)). Representative cooling curves for each of these casting parameters are shown in Appendix C. The 1.5 and $3.8^{\circ} \mathrm{C} / \mathrm{s}$ cooling rates were obtained using a billet casting geometry of $153 \times 88 \times 28 \mathrm{~mm}$ with billet mould temperatures of 600 and $170{ }^{\circ} \mathrm{C}$, respectively. The $12.5^{\circ} \mathrm{C} / \mathrm{s}$ cooling rate was obtained utilizing gray iron inserts spaced $14 \mathrm{~mm}$ apart and a billet mould temperature of $150{ }^{\circ} \mathrm{C}$. Other configurations, using gray iron inserts spaced 21 and $25 \mathrm{~mm}$ apart yielded a similar dendritic structure to that shown in Figure 5.1 (f). However, these configurations resulted in coarser secondary phase particles than those of the bottom of the cylinder, suggesting that the configuration with gray iron inserts spaced $14 \mathrm{~mm}$ apart provided the best approximation to the microstructure of the bottom of the cylinder.

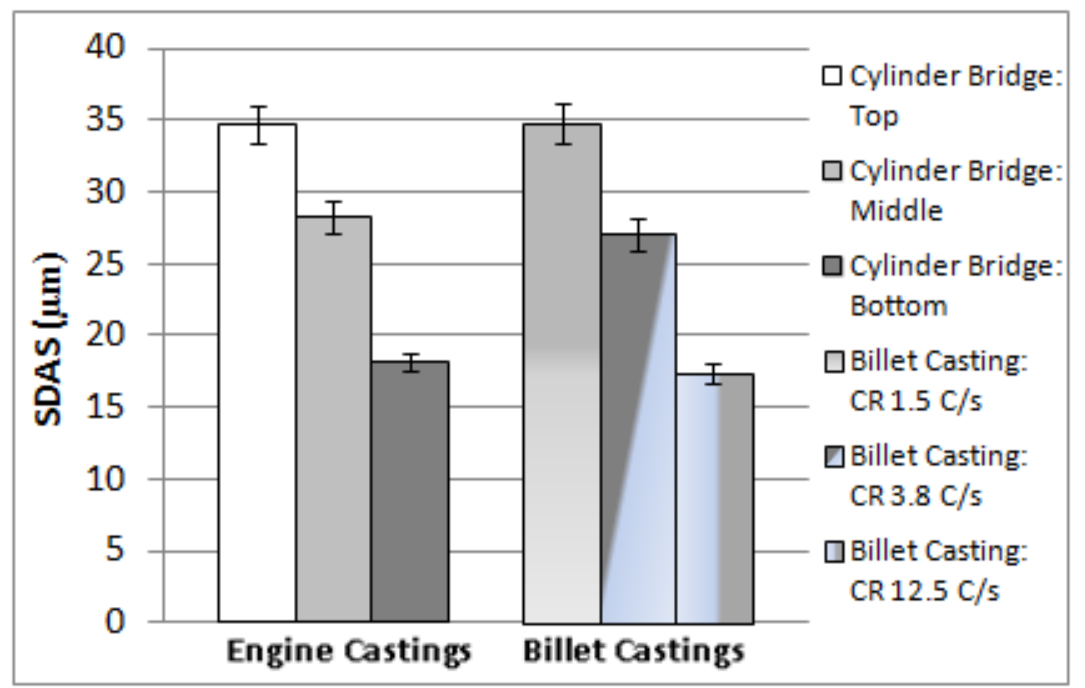

Figure 5.2: SDAS measurements along the engine block cylinder bridge and the Al alloy billet castings.

Secondary dendrite arm spacing (SDAS) was measured for the cylinder bridge and the billet castings. The SDAS at the top, middle and bottom of the cylinder bridge was compared directly with the three corresponding cooling rates of the billet castings. The results, with the error bars denoting the 95\% confidence interval of the sample mean, are shown in Figure 5.2. The SDAS of the top, middle and bottom sections of the cylinder bridge were approximately 35, 27 and $18 \mu \mathrm{m}$, respectively. This compared closely to the billet castings with $\mathrm{CR}$ of $1.5,3.8$ and $12.5{ }^{\circ} \mathrm{C} / \mathrm{s}$, 
respectively, indicating that the top, middle and bottom sections of the cylinder bridge solidified with cooling rates similar to those shown by the billet castings. This was also in agreement with the optical micrographs shown in Figure 5.1.

\subsubsection{Cooling Rate-SDAS Correlation}

Replication of the engine block cylinder bridge microstructure involved much iteration of varying mould temperature and casting section thickness to adjust the cooling rate and obtain the required dendritic structure and SDAS. In addition to replicating the cylinder bridge microstructure, the preliminary experiments allowed for the development of a correlation between SDAS and CR for the modified $319 \mathrm{Al}$ alloy. This facilitated the estimation of the $\mathrm{CR}$ of various sections of the engine block by measuring SDAS. Figure 5.3 shows a graph illustrating the variation in SDAS with CR. These results were compared with the SDAS-CR correlations developed by VazquezLopez et al. [104], Spear and Gardner [105] and Caceres et al. [106], respectively for Al-Si type casting alloys.

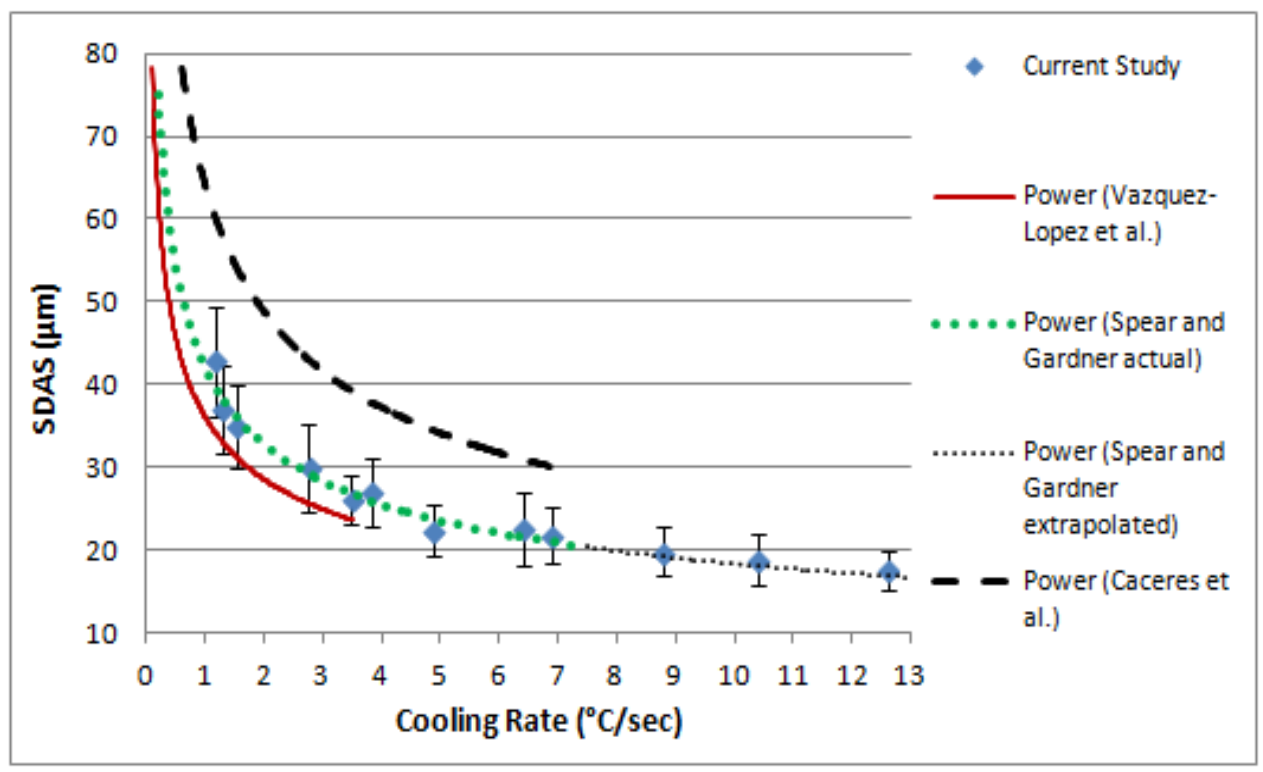

Figure 5.3: Correlation between CR during solidification and SDAS.

The results, shown in Figure 5.3, suggest that the SDAS of the billet castings decreased from approximately $43 \mu \mathrm{m}$ to $18 \mu \mathrm{m}$ by a power relationship with increasing CR from 1.3 to $12.5^{\circ} \mathrm{C} / \mathrm{s}$. The power function relating SDAS and CR for the $319 \mathrm{Al}$ alloy, obtained from least squares curve fitting, is shown in Equation 13. 


$$
S D A S=41.8(C R)^{-0.346}
$$

The correlation between CR and SDAS, obtained in this study, relates closely to the power function correlations developed by Spear and Gardner [105] and Vazquez-Lopez et al. [104]. While these correlations were only developed for cooling rates up to $7{ }^{\circ} \mathrm{C} / \mathrm{s}$, the current study confirmed that if extrapolated, the correlation of Spear and Gardner [105] would fit the experimental data for cooling rates above $7{ }^{\circ} \mathrm{C} / \mathrm{s}$ with minimal deviations. Differences between the correlations may be attributed to compositional variations between the alloys used in the respective studies, which may have slightly altered the thermophysical properties of the alloys.

\subsubsection{Secondary Phase Analysis}

\subsection{Eutectic Si}

The Al-Si eutectic phase morphology for the engine block cylinder bridge (Figures 5.4 (a), (c), (e)) and the billet castings (Figures 5.4 (b), (d), (f)) was analyzed using optical microscopy. The optical micrograph in Figure 5.4 (a) revealed a partially modified (Rating 3 according to Apelian et al. [13]) Al-Si eutectic structure for the top of the cylinder bridge. The middle of the cylinder had a similar partially modified Al-Si eutectic morphology, although the Al-Si eutectic areas in interdendritic regions were finer and distributed more uniformly throughout the microstructure (Figure 5.4 (c)). In contrast, the microstructure at the bottom of the cylinder bridge contained relatively fine and globular eutectic silicon particles in the interdendritic regions (Figure 5.4 (e)).

The billet castings with $\mathrm{CR}$ of 1.5 and $3.8{ }^{\circ} \mathrm{C} / \mathrm{s}$ also contained partially modified Al-Si eutectic (Rating 3) within the microstructure, as shown in Figures 5.4 (b) and (d), respectively. This compares reasonably well to the $\mathrm{Si}$ particle distribution observed at the top and middle of the engine block cylinder bridge. Conversely, the billet castings with $\mathrm{CR}$ of $12.5^{\circ} \mathrm{C} / \mathrm{s}$ (Figure 5.4 (f)) contained mainly platelet-like eutectic Si particles. This Al-Si eutectic structure differs from the mainly globular eutectic silicon particles found at the bottom of the cylinder bridge, suggesting that the structure observed at the bottom of the cylinder was not solely the result of increased cooling rate. These globular eutectic Si particles may have formed as a result of the rapid $180^{\circ}$ rotation of the mould during the Cosworth casting process, which, in turn, may have fractured eutectic Si particles during the formation of this phase. 

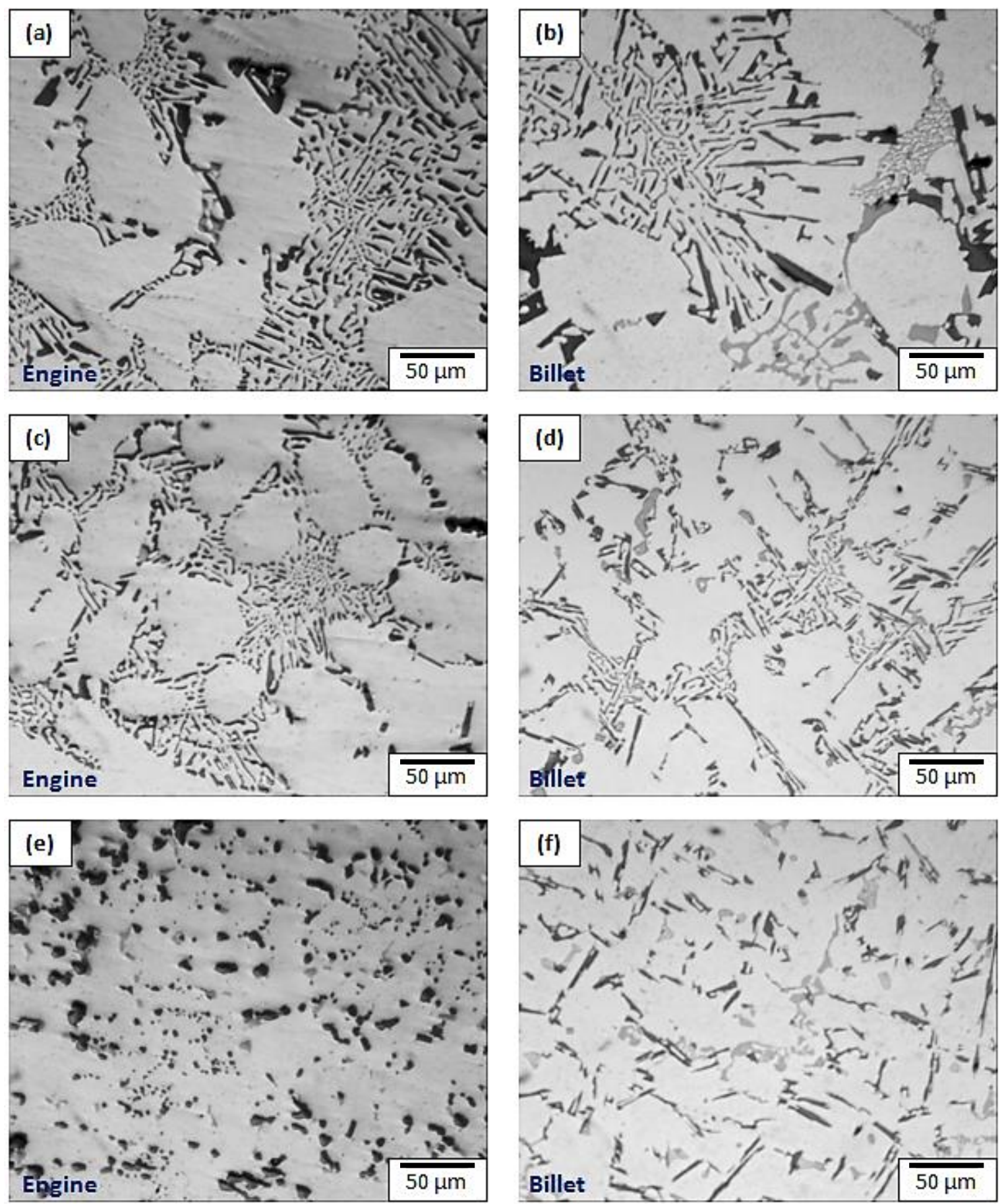

Figure 5.4: Optical micrographs of Al-Si eutectic morphology of: (a) top of cylinder, (b) billet casting $\mathrm{CR}=1.5^{\circ} \mathrm{C} / \mathrm{s}$, (c) middle of cylinder, (d) billet casting $\mathrm{CR}=3.8^{\circ} \mathrm{C} / \mathrm{s}$, (e) bottom of cylinder, (f) billet casting $\mathrm{CR}=12.5^{\circ} \mathrm{C} / \mathrm{s}$.

The modification of the Al-Si eutectic to a partially modified structure, shown for the cylinder bridge and billet castings in Figures 5.4 (a)-(d), was likely caused by the addition of Sr prior to pouring of the castings. The addition of $\mathrm{Sr}$ to the melt induced twin planes during solidification causing eutectic $\mathrm{Si}$ areas to nucleate and form a fibrous structure rather than a needle-like 
morphology [107]. However, full modification of Al-Si eutectic was not observed since the modified $319 \mathrm{Al}$ alloy, used in engine block production, contained a larger amount of Si than the standard A319 alloy. As such, a larger Sr content than the typical range between 80 and $120 \mathrm{ppm}$ is required to achieve full modification. In addition, cooling rate also determines the degree of modification of eutectic Si $[107,108]$. In the engine block casting, the relatively slow cooling rate at the top of the cylinder resulted in larger $\mathrm{Si}$ particles within the Al-Si eutectic clusters compared to the middle of the cylinder bridge. This was also observed when comparing the billet castings with $\mathrm{CR}$ of 1.5 and $3.8^{\circ} \mathrm{C} / \mathrm{s}$, respectively.

Eutectic Si particle modification has also been found to occur during SHT by fragmentation and spheroidization of $\mathrm{Si}$ particles [35, 108]. In this portion of the research project, select billet castings were subjected to a heat treatment which replicated the TSR treatment parameters. Microstructural characterization, however, revealed no significant changes in the Al-Si eutectic morphology between the as-cast and TSR conditions, suggesting that this treatment did not have sufficient time near the solutionizing temperature to induce morphological modification of eutectic Si. Further analysis of heat treatment induced Al-Si eutectic modification is given in Section 5.1.2.1.

\subsection{Morphology of the Al-Cu and Al-Fe-Mn-Si Intermetallics}

The Al-Cu and Al-Fe-Mn-Si type intermetallics were characterized from top to bottom along the cylinder bridge of TSR treated engine blocks using BSE images in conjunction with EDX analysis, as shown in Figure 5.5. The stoichiometry of the intermetallic phases was determined using X-ray diffraction, as indicated in Section 4.2.2.

Backscattered electron images of the cylinder bridge (following TSR treatment) showed coarse and mainly blocky $\mathrm{Al}_{2} \mathrm{Cu}$ particles as well as coarse Chinese script $\mathrm{Al}_{17}(\mathrm{Fe}, \mathrm{Mn})_{4} \mathrm{Si}_{2}$ intermetallics at the top and middle of the cylinder (Figures 5.5 (a) and (b)). The bottom of the cylinder had significantly finer and more globular $\mathrm{Al}_{2} \mathrm{Cu}$ and $\mathrm{Al}_{17}(\mathrm{Fe}, \mathrm{Mn})_{4} \mathrm{Si}_{2}$ particles, which was attributed to a significant increase in cooling rate at this section of the cylinder bridge (Figure 5.5 (c)). The microstructure at the bottom of the cylinder also contained large $\mathrm{Al}_{2} \mathrm{Cu}$ particles that segregated to the interface between the Al cylinder bridge and the gray cast iron liners (Figure 5.5 (d)). This was likely caused by a combination of increased cooling rate at the this section of the cylinder 
and the heavier $\mathrm{Cu}$ atoms moving towards the interface due to the centrifugal force during the $180^{\circ}$ rotation of the mould (Cosworth process).
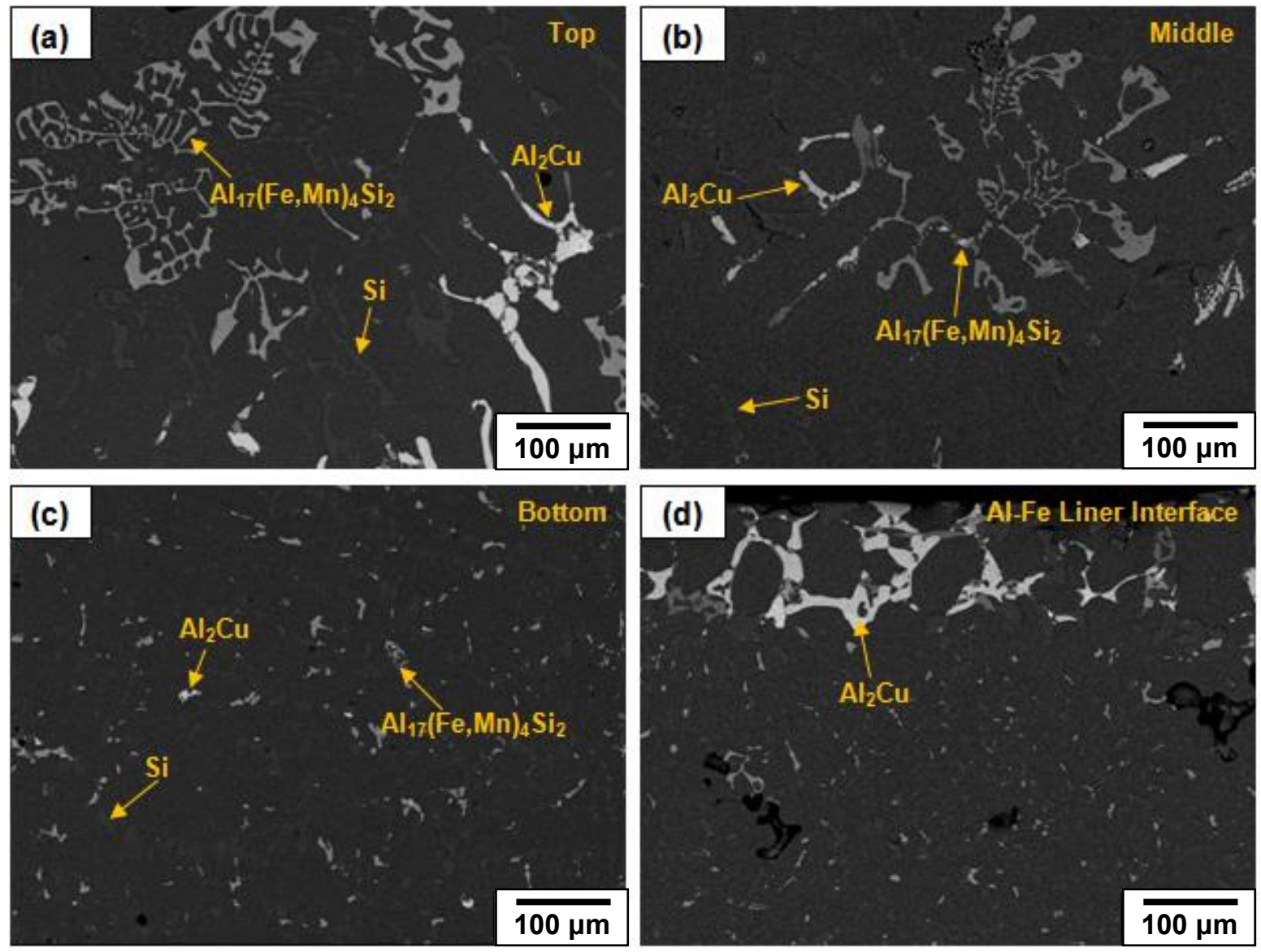

Figure 5.5: Backscattered electron images of engine block cylinder bridge: (a) top, (b) middle, (c) bottom, (d) bottom near interface between Al cylinder bridge and gray iron liner.

Analysis of the intermetallics was also carried out on the billet castings in the as-cast (Figures 5.6 (a), (c), (e)) and TSR (Figures 5.6 (b), (d), (f)) conditions using backscattered electron images. The results shown in Figure 5.6 (a) suggest that the billet castings with $\mathrm{CR}$ of $1.5^{\circ} \mathrm{C} / \mathrm{s}$ had a combination of blocky and eutectic $\mathrm{Al}_{2} \mathrm{Cu}$ as well as Chinese script $\mathrm{Al}_{17}(\mathrm{Fe}, \mathrm{Mn})_{4} \mathrm{Si}_{2}$ particles in the as-cast condition. The needle-like $\beta-\mathrm{Al}_{5} \mathrm{FeSi}$ phase was not found in the microstructure of both the billet castings and the cylinder bridge, which was likely due to the alloy having an Fe:Mn concentration ratio below 1.5:1 [26, 27]. Furthermore, the microstructure of the billet castings with $\mathrm{CR}$ of $3.8^{\circ} \mathrm{C} / \mathrm{s}$ had similar intermetallic particle morphology (Figure 5.6 (c)) as the billet castings with $\mathrm{CR}$ of $1.5^{\circ} \mathrm{C} / \mathrm{s}$, although the size of the particles was reduced. 
Approximation of the bottom of the cylinder microstructure involved utilizing a billet mould with gray iron inserts that were spaced approximately $14 \mathrm{~mm}$ apart $\left(\mathrm{CR}=12.5{ }^{\circ} \mathrm{C} / \mathrm{s}\right)$. The results, shown in Figure 5.6 (e), suggest that $\mathrm{Al}_{2} \mathrm{Cu}$ and $\mathrm{Al}_{17}(\mathrm{Fe}, \mathrm{Mn})_{4} \mathrm{Si}_{2}$ were significantly refined using this casting configuration due to increased cooling rate. In addition, the intermetallic particle morphology was mainly particulate for $\mathrm{Al}_{17}(\mathrm{Fe}, \mathrm{Mn})_{4} \mathrm{Si}_{2}$ while a combination of fine eutectic and blocky $\mathrm{Al}_{2} \mathrm{Cu}$ were present in the microstructure of the as-cast billet castings.
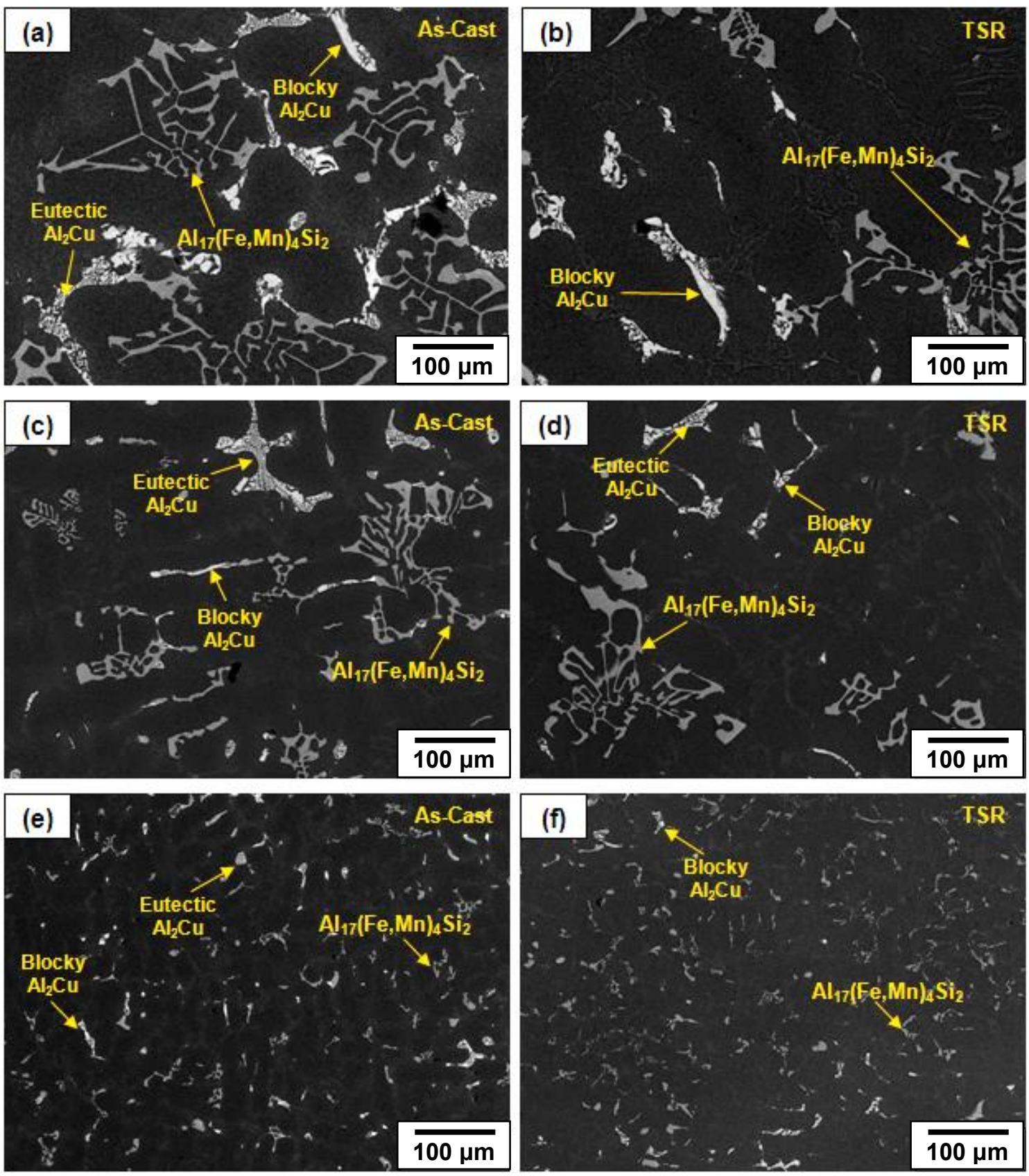

Figure 5.6: Backscattered electron images of billet castings: (a) as-cast $\mathrm{CR} 1.5^{\circ} \mathrm{C} / \mathrm{s}$, (b) TSR CR $1.5{ }^{\circ} \mathrm{C} / \mathrm{s}$, (c) as-cast CR $3.8^{\circ} \mathrm{C} / \mathrm{s}$, (d) $\mathrm{TSR}$ CR $3.8^{\circ} \mathrm{C} / \mathrm{s}$, (e) as-cast CR $12.5^{\circ} \mathrm{C} / \mathrm{s}$, (f) TSR CR $12.5^{\circ} \mathrm{C} / \mathrm{s}$. 
Heat treatment of the billet castings $\left(\mathrm{CR}=1.5\right.$ and $\left.3.8^{\circ} \mathrm{C} / \mathrm{s}\right)$, using the production $\mathrm{TSR}$ treatment parameters, resulted in microstructures containing mostly blocky $\mathrm{Al}_{2} \mathrm{Cu}$ particles and Chinese script $\mathrm{Al}_{17}(\mathrm{Fe}, \mathrm{Mn})_{4} \mathrm{Si}_{2}$, as shown in Figures 5.6 (b) and (d). The TSR treated billet castings with $\mathrm{CR}$ of $12.5{ }^{\circ} \mathrm{C} / \mathrm{s}$, on the other hand, contained mostly blocky $\mathrm{Al}_{2} \mathrm{Cu}$ and particulate $\mathrm{Al}_{17}(\mathrm{Fe}, \mathrm{Mn})_{4} \mathrm{Si}_{2}$ particles, as shown in Figure 5.6 (f).

\subsection{Volume Fraction of the Al-Cu and Al-Fe-Mn-Si Intermetallics}

Quantitative analysis on the volume fraction of the $\mathrm{Al}_{2} \mathrm{Cu}$ and $\mathrm{Al}_{17}(\mathrm{Fe}, \mathrm{Mn})_{4} \mathrm{Si}_{2}$ intermetallic phases was carried out in both the cylinder bridge and the billet castings (as-cast and TSR conditions) using image analysis software and a minimum of 50 backscattered electron images. The results are shown in Figure 5.7. The error bars denoting the 95\% confidence interval of the sample mean.
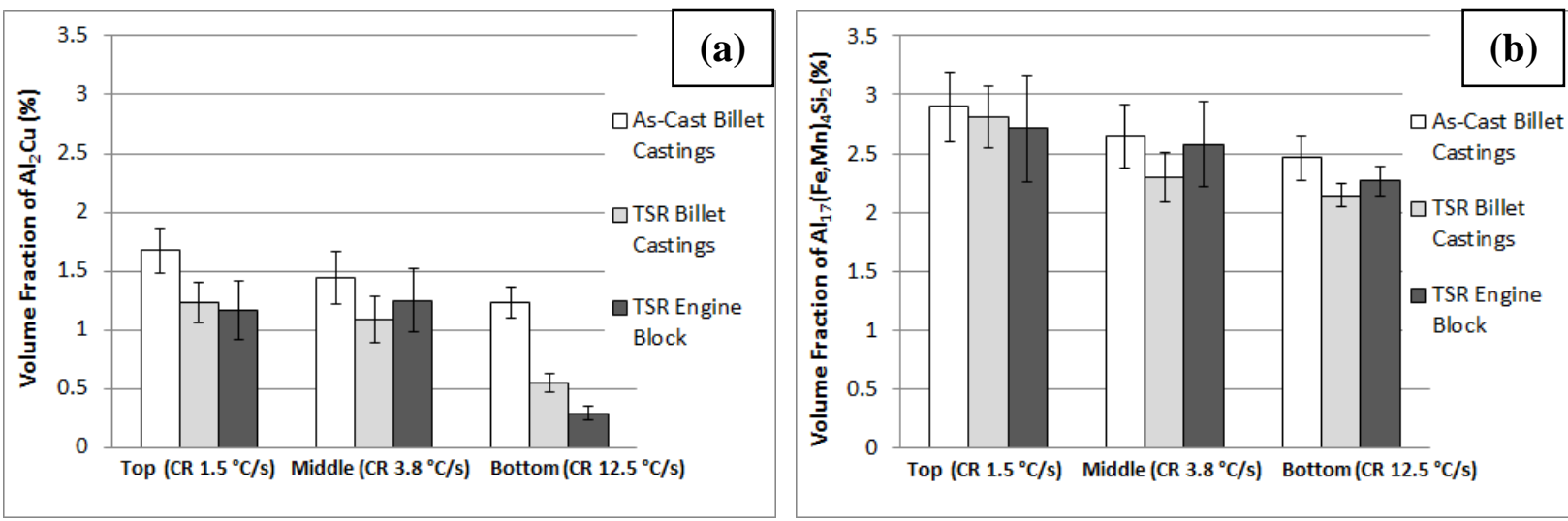

Figure 5.7: Results from image analysis showing the cylinder bridge and billet casting volume fraction of: (a) $\mathrm{Al}_{2} \mathrm{Cu}$, (b) $\mathrm{Al}_{17}(\mathrm{Fe}, \mathrm{Mn})_{4} \mathrm{Si}_{2}$.

The results in Figure 5.7 (a) suggest that in the as-cast condition, the billet castings with CR of 1.5 and $3.8{ }^{\circ} \mathrm{C} / \mathrm{s}$ contained $\mathrm{Al}_{2} \mathrm{Cu}$ volume fractions of approximately 1.7 and $1.5 \%$, respectively. Furthermore, the as-cast billets with $\mathrm{CR}$ of $12.5{ }^{\circ} \mathrm{C} / \mathrm{s}$ had an $\mathrm{Al}_{2} \mathrm{Cu}$ volume fraction of approximately $1.4 \%$, which confirmed the reduction in $\mathrm{Al}_{2} \mathrm{Cu}$ volume fraction with increased cooling rate, as observed by Li et al. [12].

The results in Figure 5.7 (b) show that the amount of $\mathrm{Al}_{17}(\mathrm{Fe}, \mathrm{Mn})_{4} \mathrm{Si}_{2}$ decreased from approximately $2.8 \%$ to $2.5 \%$ with increased cooling rate. This change in volume fraction, however, was slight due to the overlap in statistical error associated with these measurements. Heat treating the billet castings to the TSR condition resulted in a small decrease in the 
$\mathrm{Al}_{17}(\mathrm{Fe}, \mathrm{Mn})_{4} \mathrm{Si}_{2}$ volume fraction, however, this change was not statistically significant. This small decrease in volume fraction supports the work of Garcia-Garcia et al. [30] and Naranyanan et al. [27], which observed that the morphology and volume fraction of $\mathrm{Al}_{17}(\mathrm{Fe}, \mathrm{Mn})_{4} \mathrm{Si}_{2}$ is virtually unchanged by SHT, unless held at the solutionizing temperature for a very prolonged soaking time. For this reason, the volume fraction of this thermally stable phase was not quantified with varying SHT parameters in Section 5.1.2.

The TSR treatment reduced the $\mathrm{Al}_{2} \mathrm{Cu}$ volume fractions to $1.25,1.1$ and $0.5 \%$ for the billet castings with $\mathrm{CR}$ of $1.5,3.8$ and $12.5{ }^{\circ} \mathrm{C} / \mathrm{s}$, respectively. These results correspond well with the volume fraction of $\mathrm{Al}_{2} \mathrm{Cu}$ found at the top and middle sections of the cylinder bridge. Conversely, the bottom of the cylinder had a lower $\mathrm{Al}_{2} \mathrm{Cu}$ volume fraction than that observed in the billet castings. This was likely the result of macrosegregation of $\mathrm{Cu}$ to the interface between the $\mathrm{Al}$ cylinder bridge and the gray iron liners, which resulted in reduced $\mathrm{Al}_{2} \mathrm{Cu}$ at the centre of the cylinder and increased $\mathrm{Al}_{2} \mathrm{Cu}$ volume fraction at the $\mathrm{Al}-\mathrm{Fe}$ liner interface (Figure 5.5 (d)).

The reduction in the $\mathrm{Al}_{2} \mathrm{Cu}$ volume fraction following TSR treatment of the billet castings was likely the result of dissolution of eutectic $\mathrm{Al}_{2} \mathrm{Cu}$, since microstructural observations (Figure 5.5) confirmed that the as-cast billets contained both blocky and eutectic $\mathrm{Al}_{2} \mathrm{Cu}$, while the TSR billets contained mostly blocky $\mathrm{Al}_{2} \mathrm{Cu}$. This result also suggests that the production TSR treatment likely dissolved the eutectic $\mathrm{Al}_{2} \mathrm{Cu}$ that was present in the cylinder bridge following casting. In addition, the results confirm the work of Li et al. [12], Samuel et al. [35] and Han et al. [43], which indicated that eutectic $\mathrm{Al}_{2} \mathrm{Cu}$ dissolves more readily than blocky $\mathrm{Al}_{2} \mathrm{Cu}$ when exposed to temperatures approaching the solutionizing temperature.

Comparison of the cylinder bridge microstructure with that of the billet castings confirmed that the TSR treated billet castings with $\mathrm{CR}$ of 1.5 and $3.8^{\circ} \mathrm{C} / \mathrm{s}$, effectively replicated the morphology of intermetallic particles in the microstructure of the top and middle sections of the cylinder bridge. The bottom of the cylinder, while similar in intermetallic particle size and shape, had small differences in distribution and volume fraction of phases compared to the billet castings $\left(\mathrm{CR}=12.5^{\circ} \mathrm{C} / \mathrm{s}\right)$. 


\subsubsection{Porosity}

The effectiveness of microstructural replication was also assessed by comparing the volume fraction of porosity in the billet castings and along the cylinder bridge of the engine block. The results from porosity measurements, carried out using Archimedes' principle (three-dimensional macro analysis) and image analysis (two-dimensional micro analysis), are shown in Figures 5.8 (a) and (b), respectively (error bars represent the $95 \%$ confidence interval of the porosity sample mean).

The results in Figure 5.8 (a), obtained using Archimedes' principle, indicate that the average volume fraction of porosity varied between 2.1 and $3.5 \%$ for sections along the cylinder bridge and the billet castings. In addition, the results from image analysis for the cylinder bridge and the billet castings (Figure 5.8 (b)) indicated similar average porosity values, ranging between 1.7 and $3.1 \%$.
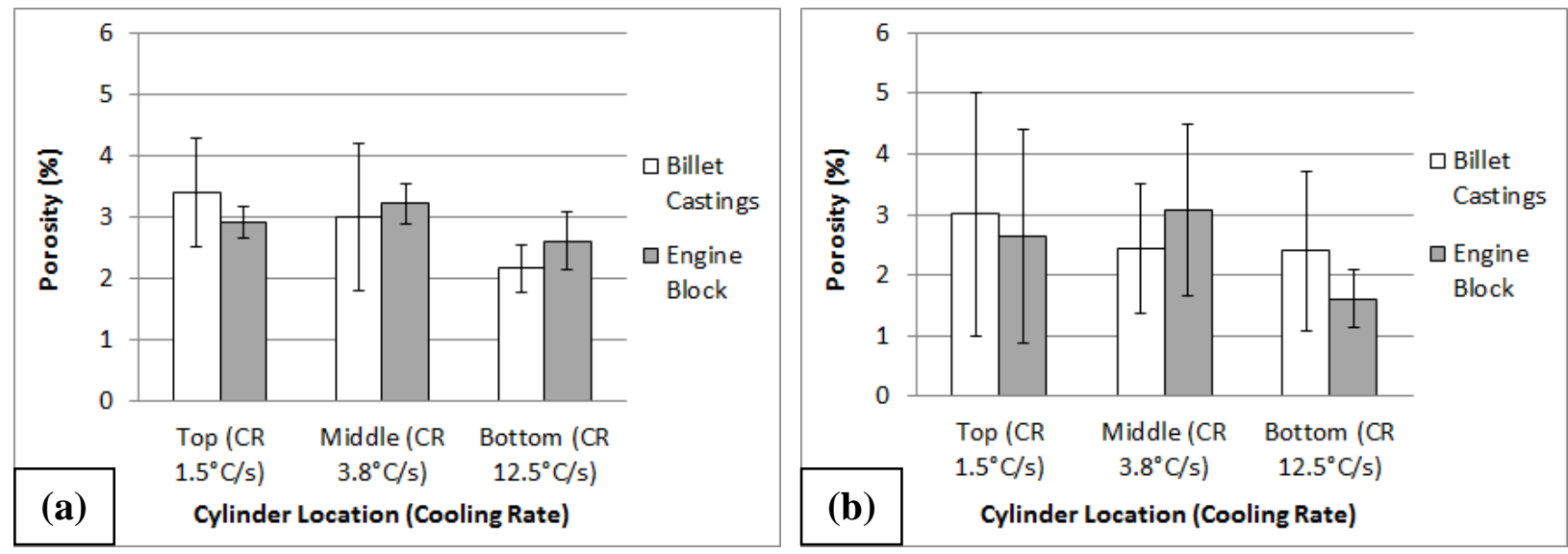

Figure 5.8: Results from porosity measurements for engine block cylinder bridge and billet castings using:

(a) Archimedes' principle, (b) image analysis.

Additional analysis of the porosity data in Figures 5.8 (a) and (b) suggests that the variance in porosity from sample to sample was significantly lower in the engine block which is likely the result of the risers and gating system from the Cosworth mould feeding shrinkage more evenly throughout the engine and reducing regions of excessive turbulence. In contrast, the billet mould did not have risers or a gating system designed to reduce turbulence, causing certain regions of the castings to have higher amounts of porosity, specifically in the center of the billet, which was the last portion to solidify. It is important to note however, that the billet castings with CR of 
$12.5^{\circ} \mathrm{C} / \mathrm{s} \mathrm{had} \mathrm{a} \mathrm{lower} \mathrm{average} \mathrm{porosity,} \mathrm{as} \mathrm{well} \mathrm{as} \mathrm{a} \mathrm{lower} \mathrm{variation} \mathrm{in} \mathrm{porosity,} \mathrm{which} \mathrm{is} \mathrm{expected}$ for alloys with fast cooling rates during solidification.

The data obtained from image analysis indicated a similar volume fraction of porosity to that obtained from Archimedes' principle. However, this data set had relatively large error bars for both the billet castings and the engine block cylinder bridge. This analysis suggests that the shrinkage porosity within individual regions of both the engine and billet castings was highly clustered on a micro scale. However, when considering a macro scale, using a large number of samples taken from various engine blocks and different cylinders (as was done with Archimedes' principle), the data indicates a more uniform distribution of porosity in the engine blocks compared to the billet castings.

\subsubsection{Tensile Properties of Replicating Billets}

Ambient temperature tensile testing was carried out on the as-cast and TSR treated billet castings. The tensile properties obtained from the billet castings were then compared to the middle section of the engine block cylinder bridge. The results for the YS and UTS are shown in Figures 5.9 (a) and (b), respectively. The error bars represent the 95\% confidence interval of the YS and UTS sample means.
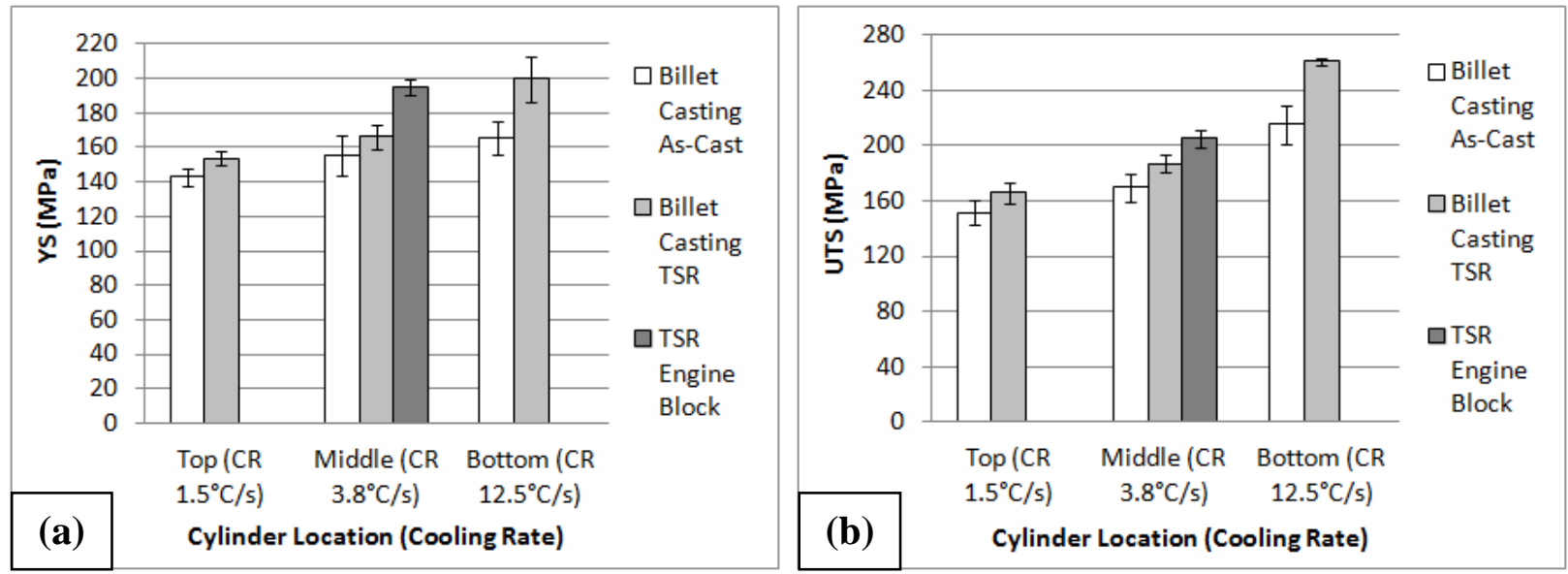

Figure 5.9: Results from tensile testing of the billet castings and engine block showing: (a) yield strength, (b) ultimate tensile strength.

In the as-cast condition, the YS was found to increase from approximately $142 \mathrm{MPa}$ for the billet castings replicating the top of the cylinder $\left(\mathrm{CR} \sim 1.5^{\circ} \mathrm{C} / \mathrm{s}\right)$, to $167 \mathrm{MPa}$ for the billet casting replicating the bottom $\left(\mathrm{CR} \sim 12.5{ }^{\circ} \mathrm{C} / \mathrm{s}\right)$. For the TSR-treated billet castings, the YS increased 
from 154 to $200 \mathrm{MPa}$ with increased cooling rate. Similarly, for the as-cast and TSR-treated billet castings, the UTS varied from 152 to $215 \mathrm{MPa}$ and 166 to $270 \mathrm{MPa}$, respectively with increased cooling rate of the billet castings. These results indicate that both increased cooling rate during solidification (due to reduced SDAS and size of secondary phase particles) and the TSR treatment increased YS and UTS, specifically for the billet castings which approximate the bottom of the cylinder. The increase in strength following TSR treatment was highest for the billet castings with $\mathrm{CR}$ of $12.5{ }^{\circ} \mathrm{C} / \mathrm{s}$, since these castings had the highest dissolution of $\mathrm{Al}_{2} \mathrm{Cu}$ (Figure 5.7) resulting in a higher degree of strengthening (solution strengthening and natural aging). The other billet castings had a lower amount of dissolved $\mathrm{Al}_{2} \mathrm{Cu}$ following TSR treatment and thus, there was less $\mathrm{Cu}$ in solid solution with $\mathrm{Al}$ to increase strength.

Comparison of the tensile properties between the billet castings (CR of $3.8^{\circ} \mathrm{C} / \mathrm{s}$ ) and the middle portion of the engine block cylinder bridge revealed that the UTS was lower for billets compared to the cylinder bridge, with values of $188 \pm 5 \mathrm{MPa}$ and $204 \pm 6 \mathrm{MPa}$, respectively. Similarly, the YS was also lower for the billets compared to the cylinder bridge, with a difference of approximately $25 \mathrm{MPa}$. Since the microstructures of the cylinder bridge and the billet castings were found to be similar, differences in the tensile properties were likely caused by the casting techniques. The Cosworth process is designed to minimize inclusions, porosity and other defects that are detrimental to alloy strength [8]. However, the mould used for the billet castings does not have risers or filters to minimize defects, which likely resulted in reduced strength compared to the engine block castings. This was evidenced by the porosity measurements, which, despite showing similar average porosity content between the engine block and the billet castings, showed a greater variation in porosity for the billet castings, suggesting that porosity was less uniformly distributed in the billet castings. This was likely one of the contributing factors to the reduced strength in the billet castings compared to the engine block castings. Fractography was carried out to observe defects (such as inclusions) that may have affected the mechanical properties. The results are presented in Section 5.1.1.6.

\section{$\underline{5.1 .1 .6 \text { Fractography }}$}

Fractography was carried out on both the $\mathrm{Al}$ cylinder bridge and the billet castings using BSE images. The distribution and morphology of porosity and inclusions was observed, as shown in Figure 5.10. 

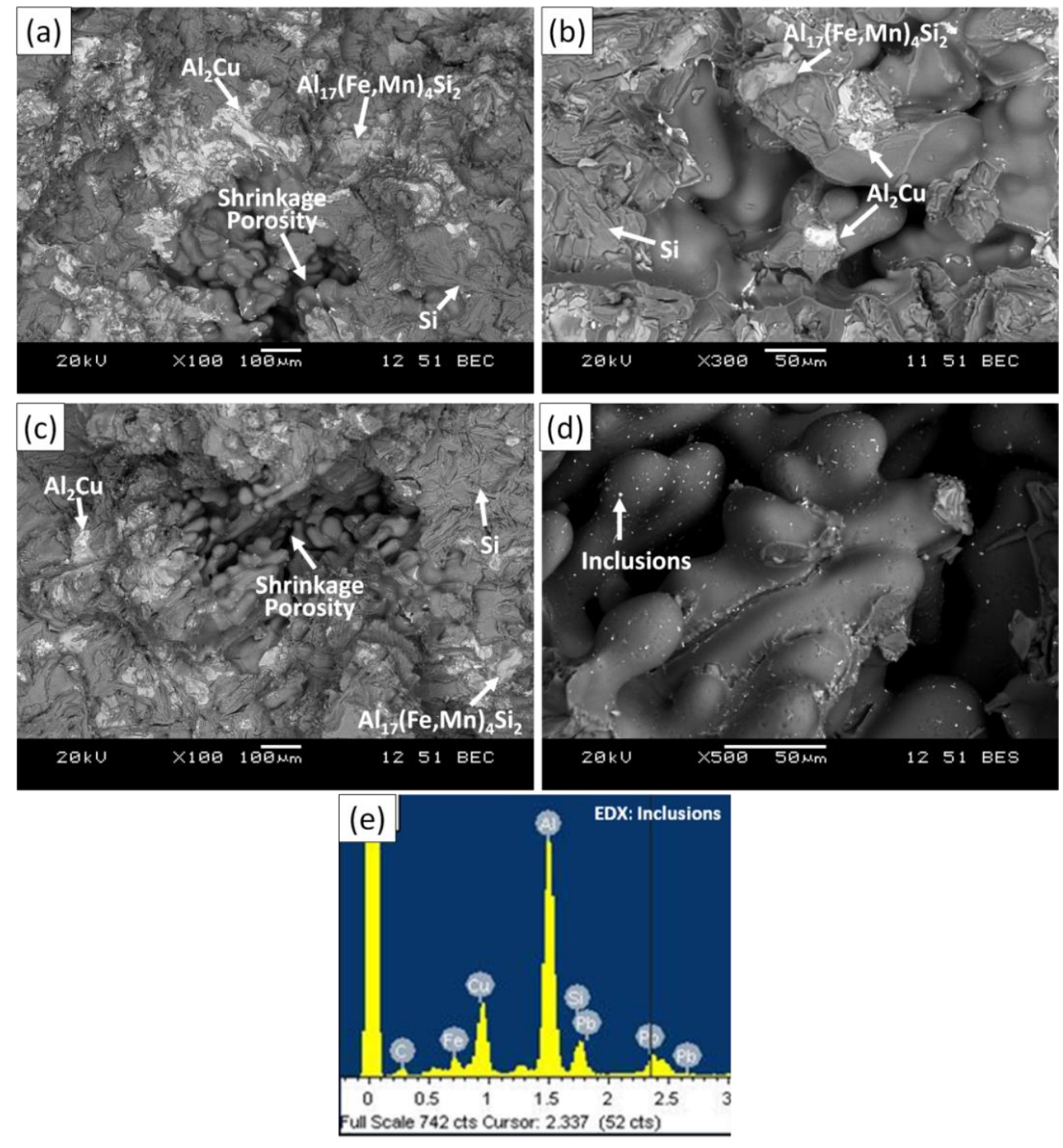

Figure 5.10: Backscattered electron images of the fracture surface for: (a) middle of cylinder bridge, (b) higher magnification image of middle cylinder section, (c) billet replicating middle of cylinder, (d) higher magnification image of billet replicating middle of cylinder, (e) EDX analysis of inclusions in billet castings.

The results from fractography for both the engine block and billet castings illustrate brittle cleavage fracture where second phase particles, such as eutectic $\mathrm{Si}, \mathrm{Al}_{17}(\mathrm{Fe}, \mathrm{Mn})_{4} \mathrm{Si}_{2}$ and $\mathrm{Al}_{2} \mathrm{Cu}$, initiated fracture. In addition, comparison of the fracture surface between the billet castings and the engine blocks suggests larger and more agglomerated shrinkage porosity in the billet castings (Figures 5.10 (a) and (c)), which supports the larger variance in average porosity for the billet castings. Furthermore, examination of the dendrites in areas of porosity revealed that the billet castings contained several inclusions (EDX analysis shown in Figure 5.10 (e)) scattered along the dendrites that were not observed in the engine block castings (Figures 5.10 (b) and (d)). Although the inclusions were primarily observed in areas of porosity, it can be deduced that these 
inclusions were scattered along interdendritic regions, which may have affected the bond between secondary phase particles and the aluminum matrix. For this reason, these inclusions likely contributed to the reduction in tensile strength for the billet castings compared to the cylinder bridge of the engine block. This supports the work of Espinoza-Cuadra et al. [109] which observed a reduction in mechanical properties caused by similar inclusions in the microstructure of 319 Al alloys.

\section{Section Summary}

The data in this section illustrated the replication of microstructure of the top, middle and bottom sections of the engine block cylinder bridge with lab-scale billet castings. Although the YS and UTS of the billet castings were appreciably different compared to the cylinder bridge, the similarity in microstructure following TSR treatment suggests that the billet castings are suitable to estimate the normalized increase in strength for different heat treatment parameters. As a result, the billets were used in Section 5.1.2 to simulate the solutionizing process on a small scale, enabling the influence of heat treatment parameters on microstructure and mechanical properties for each section of the cylinder to be determined.

\subsubsection{Solution Heat Treatment of Replicating Billet Castings}

Optimization of the SHT parameters involved applying varying solutionizing temperatures and time periods to the replicating billet castings, to determine their influence on microstructure and mechanical properties. This in-turn enabled the simulation of heat treatment induced microstructural modification for each section of the engine block cylinder bridge. This sub-section examines the microstructure of each solutionized billet casting and the tensile properties for each solutionizing parameter.

\subsubsection{Effect of SHT on Secondary Phases}

\subsection{SHT Temperature: $470{ }^{\circ} \mathrm{C}$}

Microstructural analysis of the billets replicating the top, middle and bottom of the cylinder, which were solution treated at $470{ }^{\circ} \mathrm{C}$ for $7.5 \mathrm{~h}$ is shown in Figure 5.11. In addition, the billets

which were TSR treated are also shown in Figure 5.11 for comparison. The SEM BSE images of 
the billets replicating the top and middle of the cylinder revealed a microstructure consisting of partially modified Al-Si eutectic, coarse and mainly blocky $\mathrm{Al}_{2} \mathrm{Cu}$ as well as coarse Chinese script $\mathrm{Al}_{17}(\mathrm{Fe}, \mathrm{Mn})_{4} \mathrm{Si}_{2}$ intermetallics. In contrast, due to higher cooling rate during casting, the billets replicating the bottom of the cylinder had significantly finer and more globular eutectic $\mathrm{Si}$ particles as well as fine particulate $\mathrm{Al}_{2} \mathrm{Cu}$ and $\mathrm{Al}_{17}(\mathrm{Fe}, \mathrm{Mn})_{4} \mathrm{Si}_{2}$. These microstructural features were observed for both the TSR treated billets and those solutionized at $470{ }^{\circ} \mathrm{C}$ for $7.5 \mathrm{~h}$.
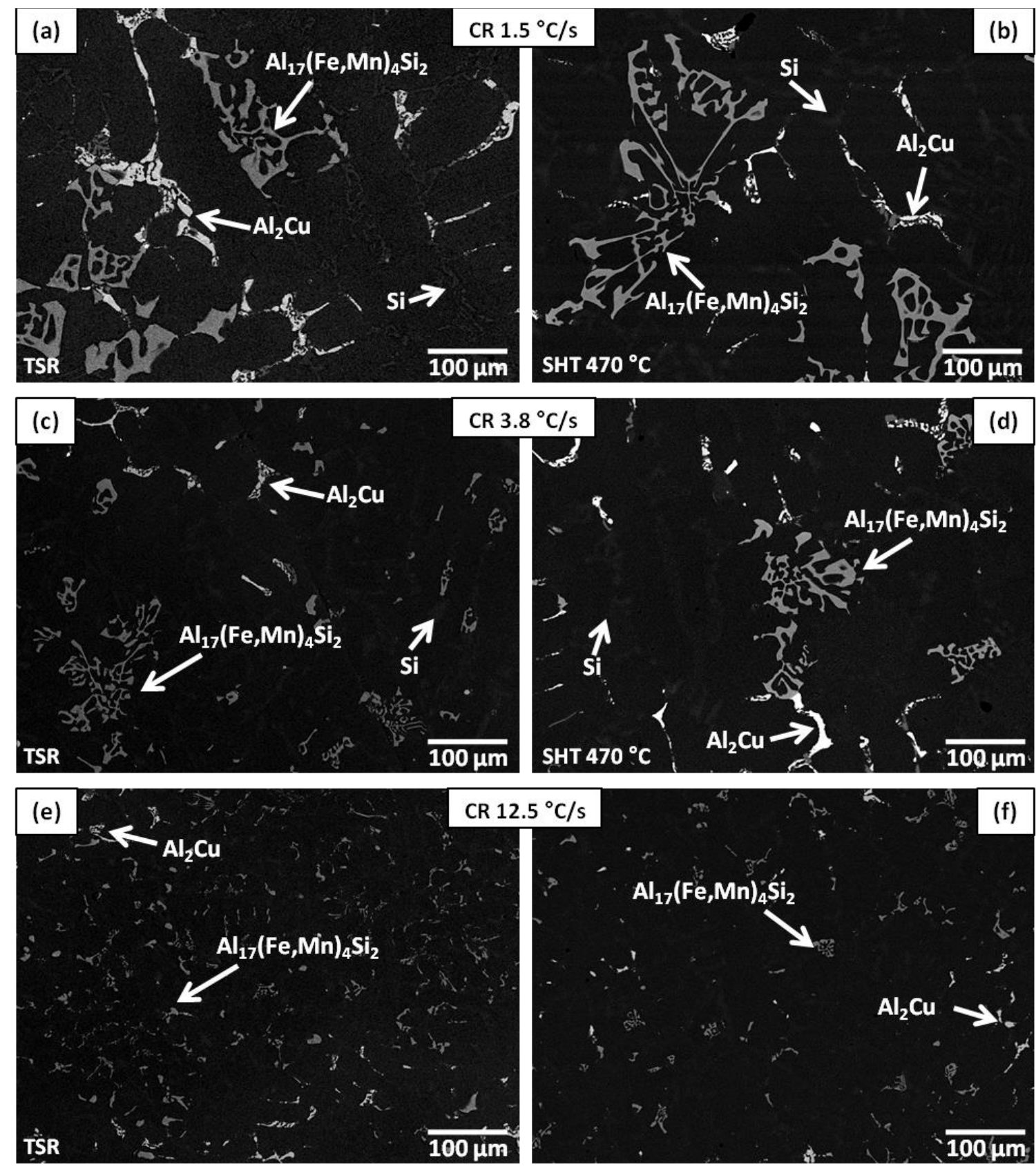

Figure 5.11: Backscattered electron images for billets replicating: (a), (c), (e) top, middle and bottom of the cylinder; TSR condition, (b), (d), (f) top, middle and bottom of the cylinder; solutionized at $470{ }^{\circ} \mathrm{C}$. 
The lack of changes in microstructure between the TSR treated and solutionized $\left(470{ }^{\circ} \mathrm{C}\right)$ billets was likely caused by sluggish dissolution of $\mathrm{Al}_{2} \mathrm{Cu}$ and $\mathrm{Al}_{5} \mathrm{Mg}_{8} \mathrm{Cu}_{2} \mathrm{Si}_{6}$. In addition, the similar Al-Si eutectic morphology to the TSR condition (Figure 5.4) indicated that fragmentation and spheroidization of eutectic Si particles was also sluggish while solutionizing at $470{ }^{\circ} \mathrm{C}$. Due to the ineffectiveness of SHT at $470{ }^{\circ} \mathrm{C}$, to further increase engine block strength in the critical cylinder bore regions and reduce the likelihood of in-service failure, higher solutionizing temperatures were examined to increase $\mathrm{Al}_{2} \mathrm{Cu}$ dissolution while avoiding incipient melting.

\subsection{SHT Temperature: $500{ }^{\circ} \mathrm{C}$}

The billets replicating the top, middle and bottom of the cylinder, solution treated at $500{ }^{\circ} \mathrm{C}$ were analyzed using optical microscopy and SEM backscattered electron images to characterize the morphology of the Al-Si eutectic as well as the intermetallic phases. The morphology of the Al-Si eutectic and intermetallic phases are shown in Figures 5.12 and 5.13, respectively.
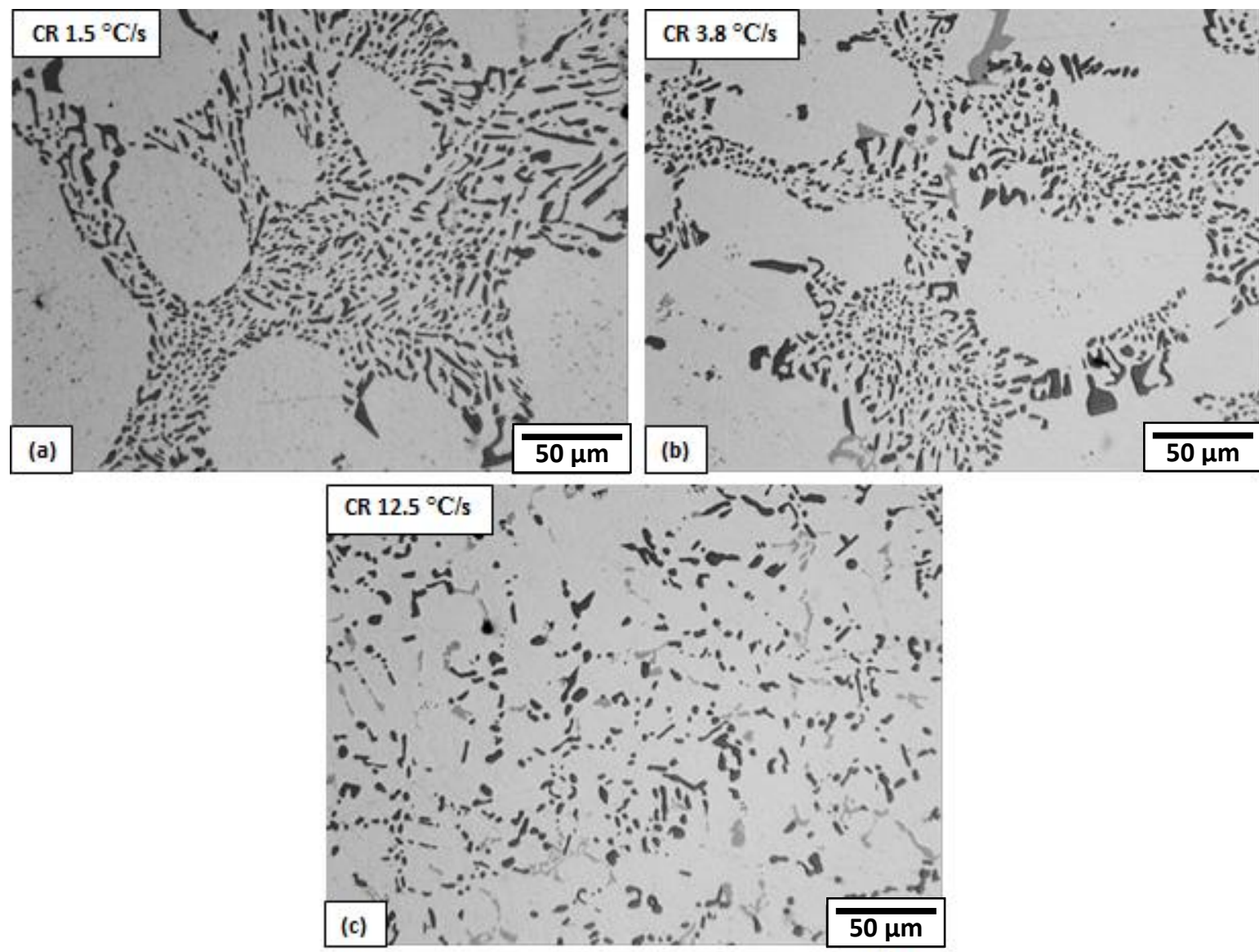

Figure 5.12: Eutectic Si morphology following SHT at $500{ }^{\circ} \mathrm{C} / 8 \mathrm{~h}$ for the billets replicating (a) top of the cylinder, (b) middle of the cylinder, (c) bottom of the cylinder. 
The optical micrographs suggest that $\mathrm{SHT}$ at $500{ }^{\circ} \mathrm{C}$ resulted in additional Al-Si eutectic modification compared to the TSR condition and to the billets solutionized at $470{ }^{\circ} \mathrm{C}$. The eutectic Si particles for all the billet castings, shown in Figure 5.12, appear to have fragmented due to SHT, which was also observed in the published literature and reviewed in Section 2.3.1.1 $[12,22,30,33-36]$. In addition, the size of the eutectic Si particles was observed to influence the effectiveness of SHT in morphological modification. For instance, the billets replicating the bottom of the cylinder had a greater degree of fragmentation of eutectic Si particles following $2 \mathrm{~h}$ of SHT at $500{ }^{\circ} \mathrm{C}$ compared to those replicating the top. Following $8 \mathrm{~h}$ of SHT at $500{ }^{\circ} \mathrm{C}$, fragmentation of eutectic Si occurred readily for all billet castings, as shown in Figure 5.12.

Analysis of the billets, solutionized at $500{ }^{\circ} \mathrm{C}$ (Figure 5.13), revealed the same intermetallic phases as the billets subjected to TSR treatment and SHT at $470{ }^{\circ} \mathrm{C}$. Furthermore, SHT at $500{ }^{\circ} \mathrm{C}$ did not affect the morphology or volume fraction of the Chinese script $\mathrm{Al}_{17}(\mathrm{Fe}, \mathrm{Mn})_{4} \mathrm{Si}_{2}$ for any investigated time period. This was likely due to insufficient heat treatment time, preventing appreciable fragmentation of $\mathrm{Al}_{17}(\mathrm{Fe}, \mathrm{Mn})_{4} \mathrm{Si}_{2}[30]$.

Solution heat treatment at $500{ }^{\circ} \mathrm{C}$ showed notable signs of $\mathrm{Al}_{2} \mathrm{Cu}$ dissolution for all billet castings, as indicated in Figure 5.13. For heat treatment times as low as $2 \mathrm{~h}$, the larger blocky $\mathrm{Al}_{2} \mathrm{Cu}$ particles appeared to have rough edges along the $\mathrm{Al}-\mathrm{Al}_{2} \mathrm{Cu}$ interface (point $\mathrm{A}$ in Figure 5.13 (d)) for the billet castings replicating the top and middle of the cylinder. This indicates that partial dissolution of these large blocky $\mathrm{Al}_{2} \mathrm{Cu}$ particles had taken place since blocky $\mathrm{Al}_{2} \mathrm{Cu}$ dissolves by radial diffusion of $\mathrm{Cu}$ along the $\mathrm{Al}-\mathrm{Al}_{2} \mathrm{Cu}$ interface [43]. In addition, smaller eutectic $\mathrm{Al}_{2} \mathrm{Cu}$ particles were fragmented and spheroidized (point $\mathrm{B}$ in Figure $5.13(\mathrm{~d})$ ), indicating that these particles were partially dissolved by SHT. Increased SHT time, up to a maximum of $8 \mathrm{~h}$, resulted in more blocky $\mathrm{Al}_{2} \mathrm{Cu}$ particles having rough edges along the $\mathrm{Al}-\mathrm{Al}_{2} \mathrm{Cu}$ interface as well as significantly smaller, more spherical fragments of eutectic $\mathrm{Al}_{2} \mathrm{Cu}$. This indicated that there was increased $\mathrm{Al}_{2} \mathrm{Cu}$ dissolution with time for the billets replicating the top and middle of the cylinder while solutionizing at $500{ }^{\circ} \mathrm{C}$. The billets replicating the bottom of the cylinder had similar microstructural trends during SHT at $500{ }^{\circ} \mathrm{C}$ to those replicating the top and middle, however, more $\mathrm{Al}_{2} \mathrm{Cu}$ dissolution occurred during TSR treatment, reducing the relative contribution of SHT. 

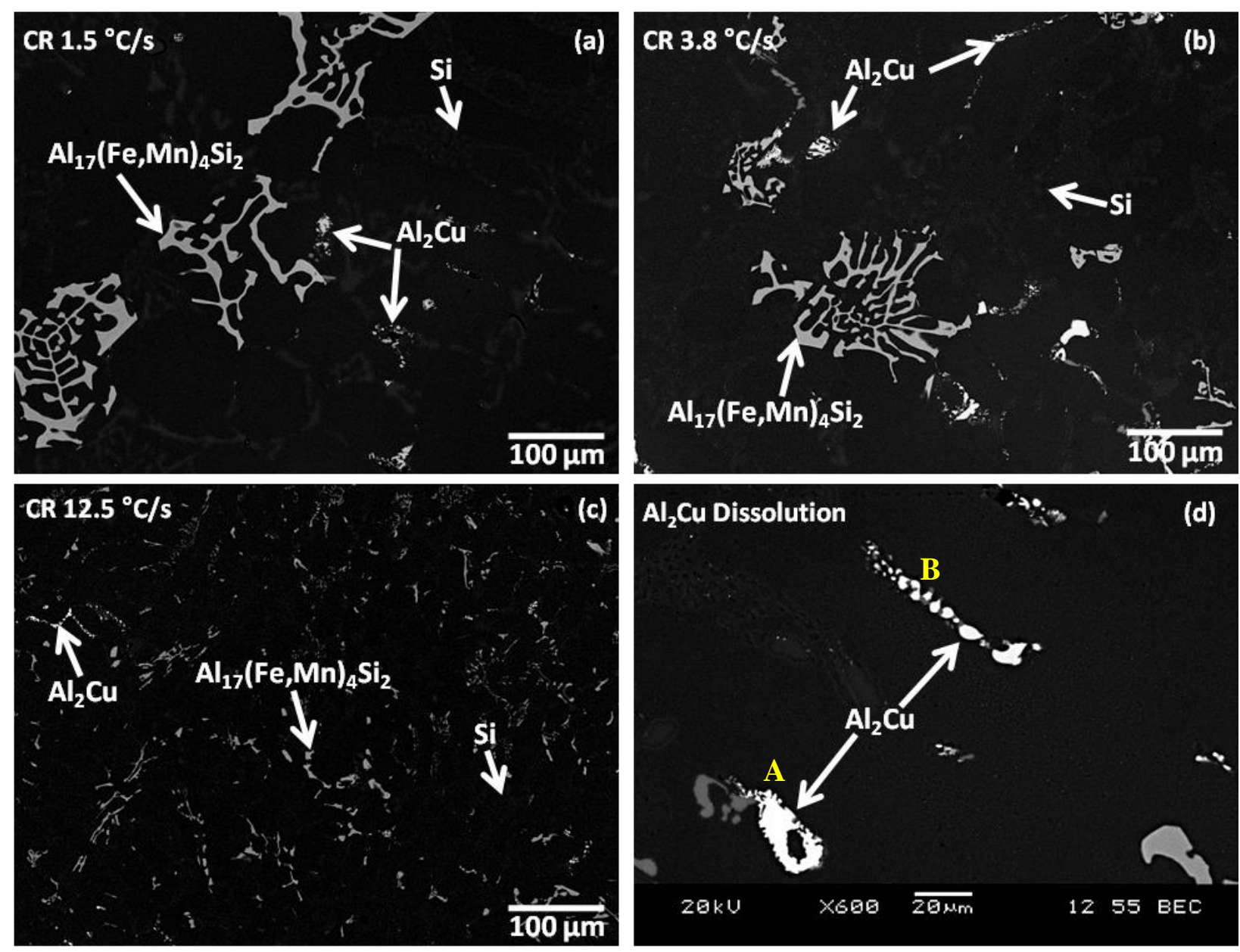

Figure 5.13: Backscattered electron images for solutionized billet castings $\left(500{ }^{\circ} \mathrm{C}\right)$ replicating: (a) Top,

(b) Middle, and (c) Bottom of cylinder, (d) Higher magnification image showing $\mathrm{Al}_{2} \mathbf{C u}$ dissolution.

The microstructural observations for the billets solutionized at $500{ }^{\circ} \mathrm{C}$ are in good agreement with the dissolution mechanisms for $\mathrm{Al}_{2} \mathrm{Cu}$ proposed by Han et al. [43], which states that large blocky $\mathrm{Al}_{2} \mathrm{Cu}$ particles dissolve by $\mathrm{Cu}$ atoms diffusing away from the particle surface (blocky $\mathrm{Al}_{2} \mathrm{Cu}$ does not change morphology due to the low interfacial energy of this phase [37]), while eutectic $\mathrm{Al}_{2} \mathrm{Cu}$ fragments, spheroidizes and dissolves. It is also important to note that since the billet castings were quenched using forced air rather than water (to conform to industrial engine block production methodology). Therefore, a portion of the dissolved $\mathrm{Cu}$ may have re-precipitated as $\mathrm{Al}_{2} \mathrm{Cu}$ which may have reduced the effectiveness of $\mathrm{Al}_{2} \mathrm{Cu}$ dissolution during SHT.

\subsubsection{3 $\mathrm{Al}{ }_{2} \mathrm{Cu}$ Volume Fraction Following $\mathrm{SHT}$ at $500{ }^{\circ} \mathrm{C}$}

The effectiveness of $\mathrm{Al}_{2} \mathrm{Cu}$ dissolution during SHT at $500{ }^{\circ} \mathrm{C}$ was quantified as a function of time using image analysis. The results, shown in Figure 5.14, compare the volume fraction of $\mathrm{Al}_{2} \mathrm{Cu}$ 
for each billet casting treated at $500{ }^{\circ} \mathrm{C}$ to those treated with the current engine block heat treatment schedule $\left(470{ }^{\circ} \mathrm{C}\right.$ for $\left.7.5 \mathrm{~h}\right)$. The error bars represent the $95 \%$ confidence interval of the $\mathrm{Al}_{2} \mathrm{Cu}$ volume fraction sample mean for each condition.

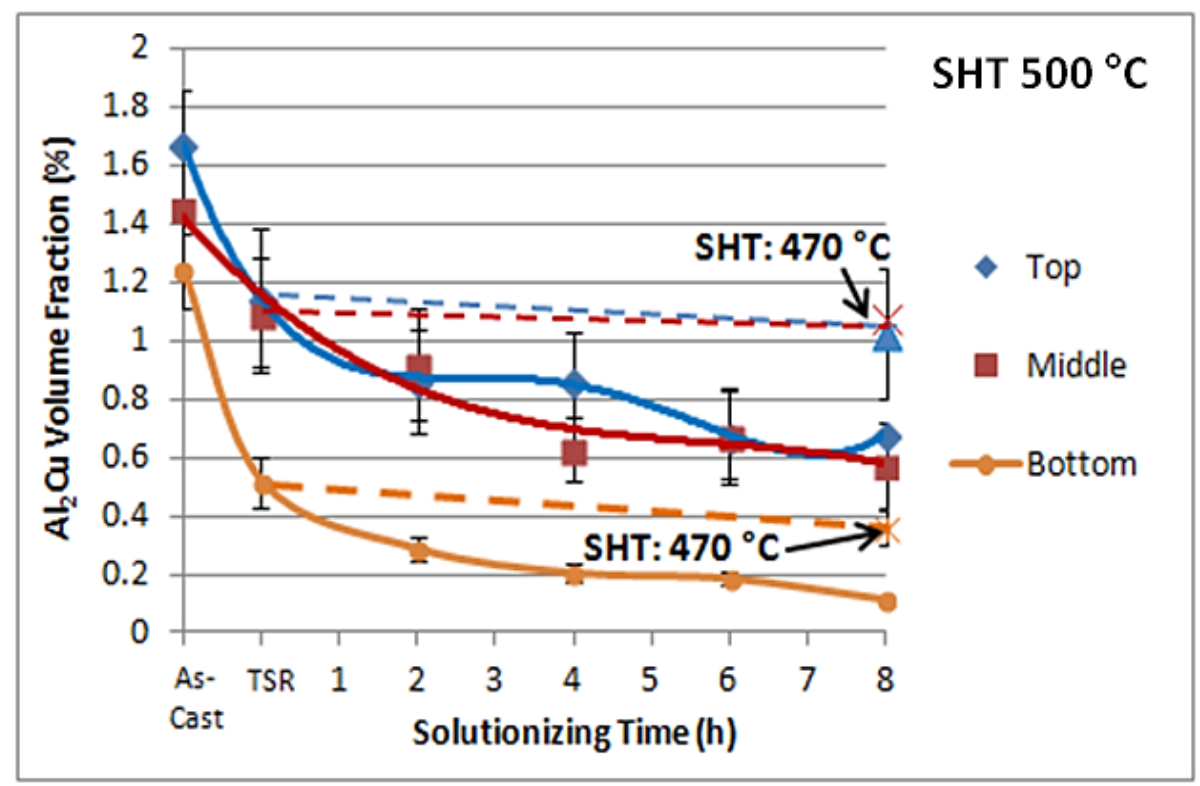

Figure 5.14: Volume fraction of $\mathrm{Al}_{2} \mathrm{Cu}$ following solution heat treatment at $500{ }^{\circ} \mathrm{C}$ for various time intervals.

The results suggest that for the billets replicating the top of the cylinder, the $\mathrm{Al}_{2} \mathrm{Cu}$ volume fraction decreased from $1.7 \%$ in the as-cast condition to $1.1 \%$ following TSR treatment. Subsequent SHT of these billets at $500{ }^{\circ} \mathrm{C}$ reduced the $\mathrm{Al}_{2} \mathrm{Cu}$ volume fraction to approximately $0.85 \%$ after $4 \mathrm{~h}$ and $0.65 \%$ after $8 \mathrm{~h}$. Similarly, the billets replicating the middle of the cylinder had the $\mathrm{Al}_{2} \mathrm{Cu}$ volume fraction reduced from $1.4 \%$ in the as-cast condition to $1.1 \%$ following TSR treatment and then gradually reduced to approximately $0.6 \%$ after $4 \mathrm{~h}$ of SHT at $500{ }^{\circ} \mathrm{C}$. Heat treatment times larger than $4 \mathrm{~h}$ at this temperature, however, did not result in significant dissolution of $\mathrm{Al}_{2} \mathrm{Cu}$.

For the billets replicating the bottom of the cylinder, the largest reduction in $\mathrm{Al}_{2} \mathrm{Cu}$ volume fraction occurred following TSR treatment with a reduction from $1.4 \%$ to $0.5 \%$. Subsequent SHT at $500{ }^{\circ} \mathrm{C}$ gradually reduced the $\mathrm{Al}_{2} \mathrm{Cu}$ volume fraction from $0.5 \%$ to $0.15 \%$ following $8 \mathrm{~h}$ of solutionizing. The relatively small $\mathrm{Al}_{2} \mathrm{Cu}$ dissolution during SHT for the billets replicating the bottom of the cylinder was due to the large $\mathrm{Al}_{2} \mathrm{Cu}$ dissolution during TSR treatment, as discussed in Section 5.1.1. The application of TSR followed by SHT had a similar effect on the microstructure as the two-stage SHT process examined by Sokolowski et al. [110]. 
The $\mathrm{Al}_{2} \mathrm{Cu}$ volume fraction and the observations from the backscattered electron images support that not only does $\mathrm{Al}_{2} \mathrm{Cu}$ dissolution increase gradually with time (specifically up to $4 \mathrm{~h}$ of heat treatment), it is also more effective than for the $470{ }^{\circ} \mathrm{C} \mathrm{SHT}$ schedule, which confirm the results of Samuel et al. [35]. This result was also expected since phase dissolution is a diffusion based process and diffusion rate increases exponentially with temperature. Finally, it is important to note that signs of incipient melting of $\mathrm{Al}_{2} \mathrm{Cu}$ and $\mathrm{Al}_{5} \mathrm{Mg}_{8} \mathrm{Cu}_{2} \mathrm{Si}_{6}$ were not observed; further indicating that $\mathrm{SHT}$ at $500{ }^{\circ} \mathrm{C}$ was effective. Higher solutionizing temperatures were examined in this research, however, to determine the maximum temperature which effectively dissolved $\mathrm{Al}_{2} \mathrm{Cu}$ without incipient melting. This is discussed in Sections 5.1.2.1.4 - 5.1.2.1.7.

\subsection{SHT Temperatures: 515 and $530{ }^{\circ} \mathrm{C}$}

The morphology of the Al-Si eutectic for the billets solutionized at 515 and $530{ }^{\circ} \mathrm{C}$ was investigated using optical microscopy and is shown in Figure 5.15. The results indicate that SHT at $515{ }^{\circ} \mathrm{C}$ (Figure 5.15 (a), (c) and (e)) resulted in significant fragmentation and spheroidization of eutectic Si particles for the billets replicating the top, middle and bottom of the cylinder. In comparison to the billets solutionized at $500{ }^{\circ} \mathrm{C}$ (Figure 5.13), the eutectic Si particles in these billets were finer and more globular, indicating that the rate of fragmentation and spheroidization was accelerated with increased temperature. For the billets solutionized at $530{ }^{\circ} \mathrm{C}$ (Figure 5.15 (b), (d) and (f)) the eutectic Si particles were relatively coarse (compared to the other solutionizing temperatures) and globular which suggest that significant fragmentation, spheroidization and coarsening of eutectic Si particles occurred while solutionizing at this temperature.

As reviewed in Section 2.3.1.1, modification of eutectic Si is achieved through fragmentation followed by spheroidization and coarsening of the particles. Heat treatment temperature is an important factor since the processes governing Al-Si eutectic modification are highly dependent on diffusion rate $[10,20,28,31-34]$. For this reason, the observed trends where solutionizing temperatures above $515^{\circ} \mathrm{C}$ had coarser and more spherical Si particles while temperatures below $515{ }^{\circ} \mathrm{C}$ showed varying degrees of Si particle fragmentation and spheroidization was expected. 

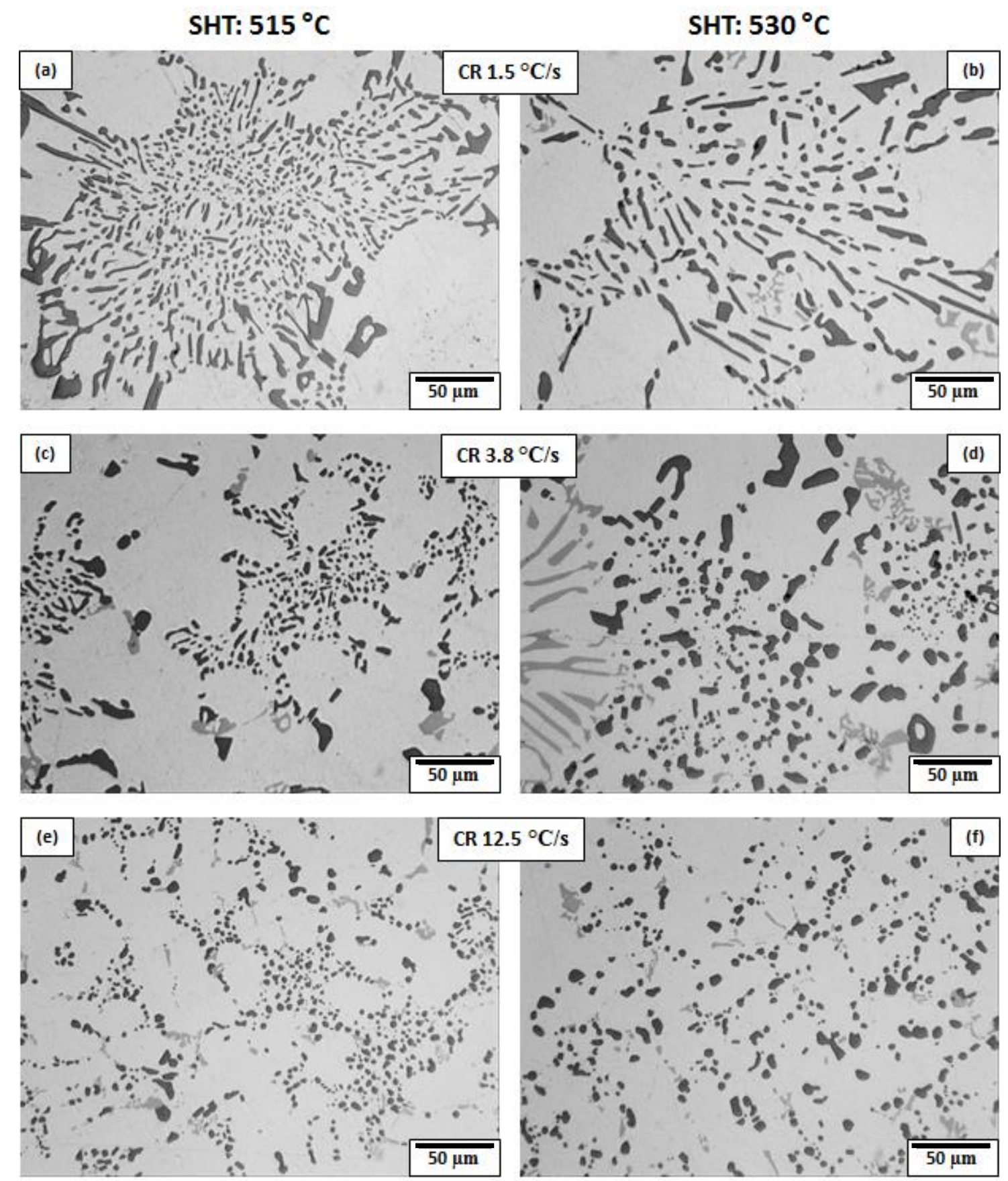

Figure 5.15: Optical micrographs for billets replicating: (a), (c), (e) top, middle and bottom of the cylinder; solutionized at $515{ }^{\circ} \mathrm{C}$, (b), (d), (f) top, middle and bottom of the cylinder; solutionized at $530{ }^{\circ} \mathrm{C}$.

Analysis of the morphology and distribution of the intermetallic phases was analyzed with BSE images (Figure 5.16) taken for solutionized (at 515 or $530{ }^{\circ} \mathrm{C}$ ) billets replicating the top, middle and bottom of the cylinder. In addition to the Al-Si eutectic clusters, shown in Figure 5.15, the microstructure of these billets contained Chinese script $\mathrm{Al}_{17}(\mathrm{Fe}, \mathrm{Mn})_{4} \mathrm{Si}_{2}$, as well as $\mathrm{Al}_{2} \mathrm{Cu}$ particles intertwining with $\mathrm{Al}_{17}(\mathrm{Fe}, \mathrm{Mn})_{4} \mathrm{Si}_{2}$ and clusters with an ultra-fine eutectic (UFE) 
morphology. These microstructural features were observed for all billet castings heat treated at 515 or $530{ }^{\circ} \mathrm{C}$, although the size of the particles was largest for the billets replicating the top of the cylinder and smallest for those replicating the bottom of the cylinder. Furthermore, the formation of UFE and the intertwining of $\mathrm{Al}_{2} \mathrm{Cu}$ and $\mathrm{Al}_{17}(\mathrm{Fe}, \mathrm{Mn})_{4} \mathrm{Si}_{2}$ occurred more readily for the billets solutionized at $530{ }^{\circ} \mathrm{C}$ compared to $515^{\circ} \mathrm{C}$.
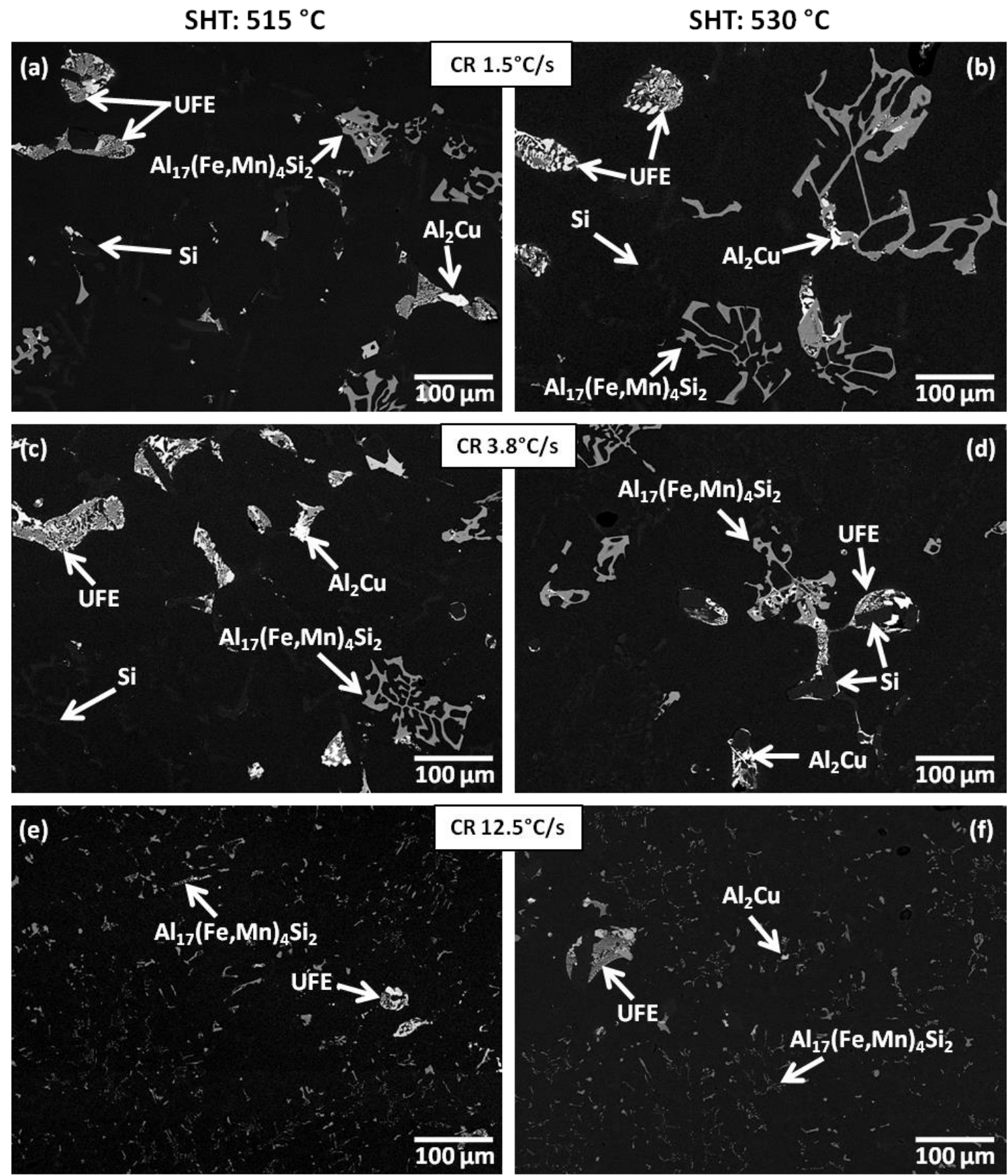

Figure 5.16: Backscattered electron images for billets replicating: (a), (c), (e) top, middle and bottom of the cylinder; solutionized at $515{ }^{\circ} \mathrm{C}$, (b), (d), (f) top, middle and bottom of the cylinder; solutionized at $530{ }^{\circ} \mathrm{C}$. 
Finally, the billets replicating the top of the cylinder were most prone to the formation of UFE and the intertwining of $\mathrm{Al}_{2} \mathrm{Cu}$ and $\mathrm{Al}_{17}(\mathrm{Fe}, \mathrm{Mn})_{4} \mathrm{Si}_{2}$ during heat treatment at 515 and $530{ }^{\circ} \mathrm{C}$, as compared to those replicating the bottom of the cylinder. The reasons for the difference in UFE volume fraction following SHT of the billets with coarse, intermediate and fine microstructures were elucidated using DSC in Section 5.1.2.2.

\subsection{Morphology of the Ultra-Fine Eutectic}

Higher magnification BSE images were taken to show morphology of the UFE clusters, which are presented in Figure 5.17. The observations in Figure 5.17 suggest that the UFE clusters contained regions of blocky $\mathrm{Al}-\mathrm{Cu}$ phase, micro-porosity and a region containing $\mathrm{Al}, \mathrm{Al}-\mathrm{Cu}$ and $\mathrm{Al}-\mathrm{Mg}-\mathrm{Cu}-\mathrm{Si}$ based phases in a complex eutectic morphology. In addition, the UFE clusters were found to either contain or be in the vicinity of relatively large polyhedral $\mathrm{Si}$ particles as shown in Figures 5.16 and 5.17.

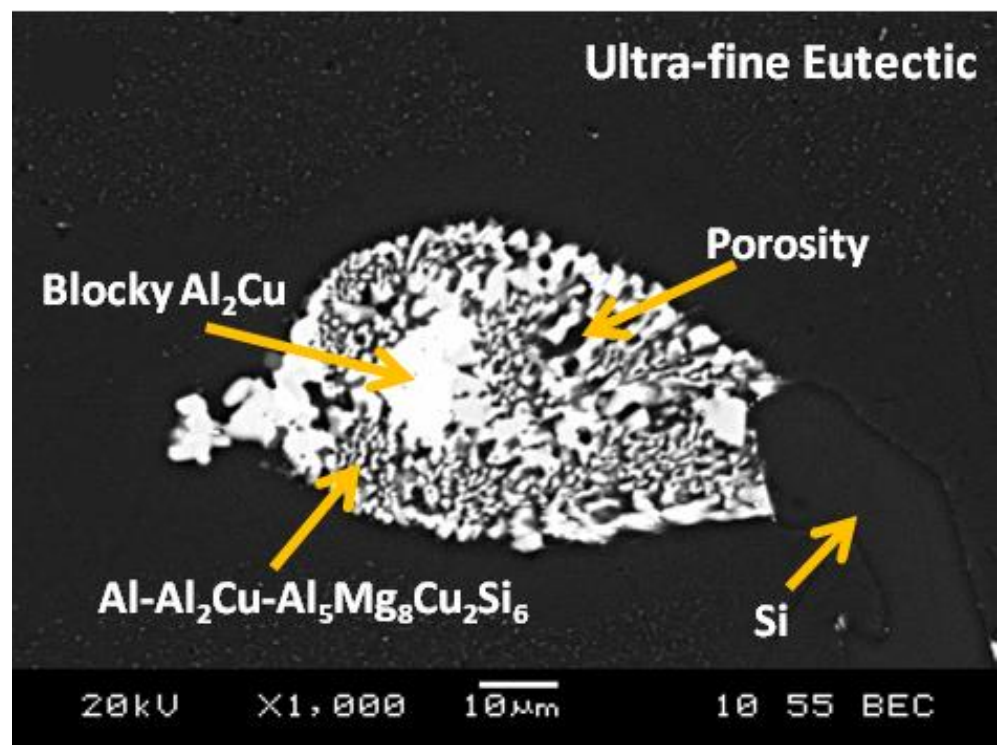

Figure 5.17: Higher magnification images showing ultra-fine eutectic (UFE) morphology.

Further analysis on the UFE clusters was carried out using EDX linescans. These results, in addition to a BSE image indicating the locations analyzed, are shown in Figure 5.18. The results in Figure 5.18 confirmed that the brighter particles were rich in $\mathrm{Al}$ and $\mathrm{Cu}$ while the gray particles in between the $\mathrm{Al}-\mathrm{Cu}$ phase particles were rich in $\mathrm{Si}, \mathrm{Mg}, \mathrm{Cu}$ and $\mathrm{Al}$. Furthermore, the darker gray regions were $\mathrm{Al}$, as shown by the spikes in $\mathrm{Al}$ concentration and reduction in $\mathrm{Cu}, \mathrm{Mg}$ and Si. According to Samuel et al. [10] and Backerud et al. [52], for Mg-bearing $319 \mathrm{Al}$ alloys, 
$\mathrm{Al}-\mathrm{Cu}$ and $\mathrm{Al}-\mathrm{Mg}-\mathrm{Cu}-\mathrm{Si}$ based phases were likely $\mathrm{Al}_{2} \mathrm{Cu}$ and $\mathrm{Al}_{5} \mathrm{Mg}_{8} \mathrm{Cu}_{2} \mathrm{Si}_{6}$, respectively. This indicates that the alternating particles within the UFE clusters may have been $\mathrm{Al}, \mathrm{Al}_{2} \mathrm{Cu}$ and $\mathrm{Al}_{5} \mathrm{Mg}_{8} \mathrm{Cu}_{2} \mathrm{Si}_{6}$.

The presence of UFE clusters in the microstructure of the billet castings indicates that incipient melting of both $\mathrm{Al}_{2} \mathrm{Cu}$ and $\mathrm{Al}_{5} \mathrm{Mg}_{8} \mathrm{Cu}_{2} \mathrm{Si}_{6}$ occurred in the interdendritic regions during SHT at 515 and $530{ }^{\circ} \mathrm{C}$. This is supported by the observations of Wang et al. [34] and Samuel [48], which suggested that incipient melting occurs in $319 \mathrm{Al}$ alloys containing $\mathrm{Mg}$ at solutionizing temperatures of $510{ }^{\circ} \mathrm{C}$ and above. The subsequent formation of UFE likely occurred during forced air cooling following SHT, where the liquid in the interdendritic regions re-solidified into the $\mathrm{Al}-\mathrm{Al}_{2} \mathrm{Cu}-\mathrm{Al}_{5} \mathrm{Mg}_{8} \mathrm{Cu}_{2} \mathrm{Si}_{6}$ complex eutectic. However, since only small pockets of liquid were present, the localized cooling rate for the re-solidification of the secondary phases was significantly higher than that during casting, leading to UFE clusters in the interdendritic regions. In addition, the relatively large Si particles within or near the UFE clusters may be due to extra $\mathrm{Si}$, not being consumed in the UFE reaction, being ejected from the melted region and forming polygonal Si particles [47].

It is important to note that previous studies by Mohamed et al. [50] and Samuel et al. [22, 47] found that structureless $\mathrm{Cu}$ rich particles form as a result of incipient melting of $\mathrm{Al}_{2} \mathrm{Cu}$ in 319 type Al alloys. Although these particles were observed sparsely in the microstructure in this study, the main microstructural feature suggesting incipient melting was the UFE clusters. The difference in phase formation following incipient melting may have been the result of different quenching methodology used in this study compared to previous studies. Previous research on heat treatment of $319 \mathrm{Al}$ alloy utilized water quenching to complete the heat treatment process, while this study used forced air cooling to conform to industrial practice for engine block production. The faster cooling rate from water quenching may have resulted in a structureless $\mathrm{Cu}$ phase by suppressing appreciable atomic diffusion within the liquid pool, effectively freezing the liquid $\mathrm{Cu}$ structure. In contrast, the air cooling used in this study following SHT, allowed sufficient time for diffusion to arrange the atoms within the liquid pool, promoting the formation of the $\mathrm{Al}-\mathrm{Al}_{2} \mathrm{Cu}-\mathrm{Al}_{5} \mathrm{Mg}_{8} \mathrm{Cu}_{2} \mathrm{Si}_{6}$ ultra-fine eutectic. 

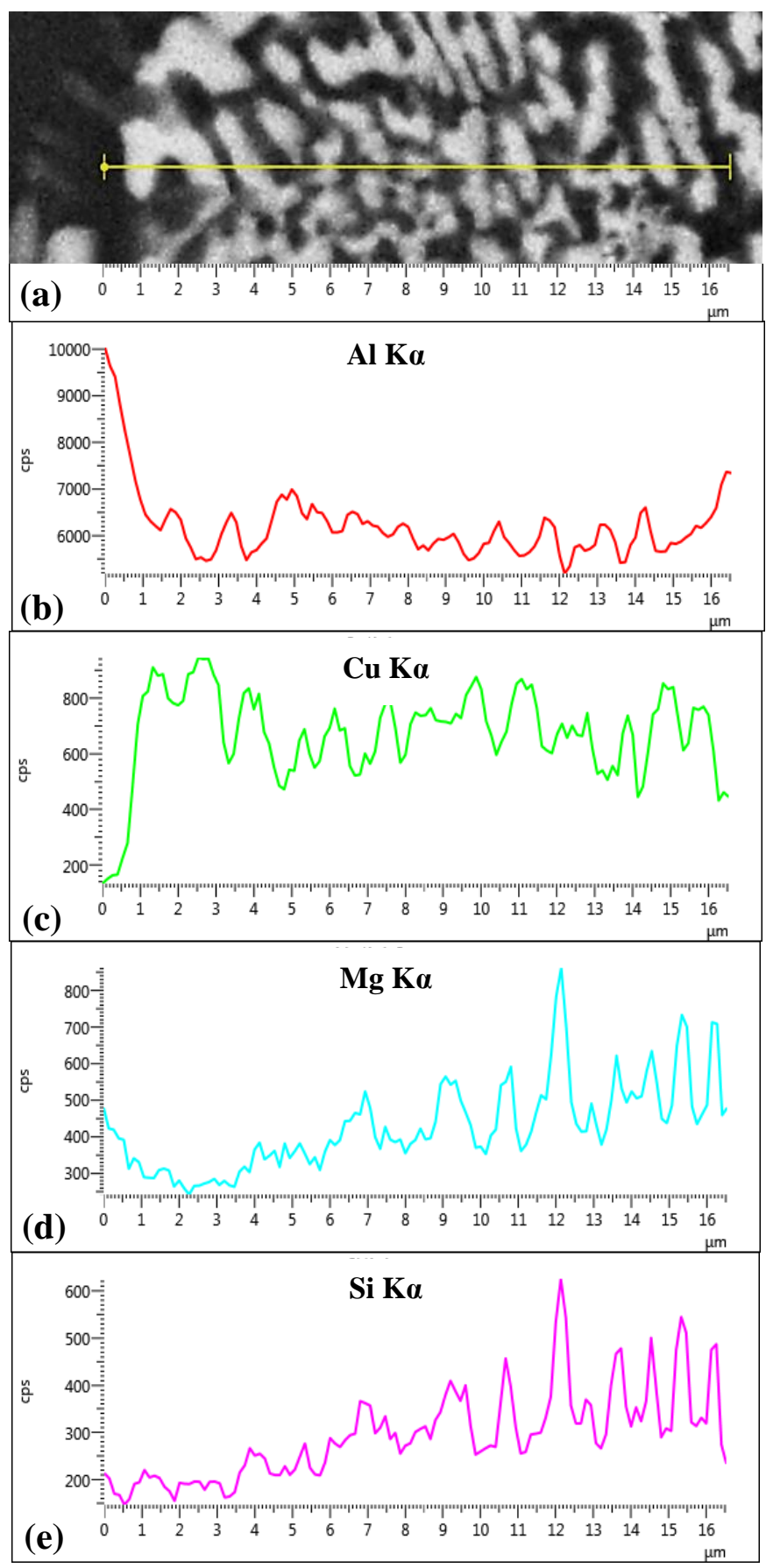

Figure 5.18: (a) Backscattered electron image showing location of line scan in UFE region; EDX linescan results along the $\mathrm{UFE}$ region for: (b) $\mathrm{Al}$, (c) $\mathrm{Cu}$, (d) $\mathrm{Mg}$, (e) $\mathrm{Si}$.

It must also be considered that the work of Wang et al. [34] and Samuel [48] also observed clusters similar to the UFE following incipient melting, even with water quenching. However, in both cases this phenomenon occurred for alloys containing approximately $0.3 \mathrm{wt} \% \mathrm{Mg}$, which is similar to the $\mathrm{Mg}$ concentration $(\sim 0.37 \mathrm{wt} \% \mathrm{Mg})$ for the $319 \mathrm{Al}$ alloy examined in this study. As 
such, the suppression of the structureless $\mathrm{Cu}$ phase in favor of UFE was likely due to both quench rate following SHT and alloy composition.

\subsection{Intertwining of Secondary Phases}

In addition to the formation of UFE clusters, SHT at 515 or $530{ }^{\circ} \mathrm{C}$ also promoted the intertwining of $\mathrm{Al}_{2} \mathrm{Cu}$ and $\mathrm{Al}_{17}(\mathrm{Fe}, \mathrm{Mn})_{4} \mathrm{Si}_{2}$. Figure 5.19 (a) presents a higher magnification $\mathrm{BSE}$ image showing the morphology of these particles while Figures 5.19 (b) and (c) show EDX spectrums indicating the composition of $\mathrm{Al}_{17}(\mathrm{Fe}, \mathrm{Mn})_{4} \mathrm{Si}_{2}$ particles that were intertwined with $\mathrm{Al}_{2} \mathrm{Cu}$ and those that were not, respectively.
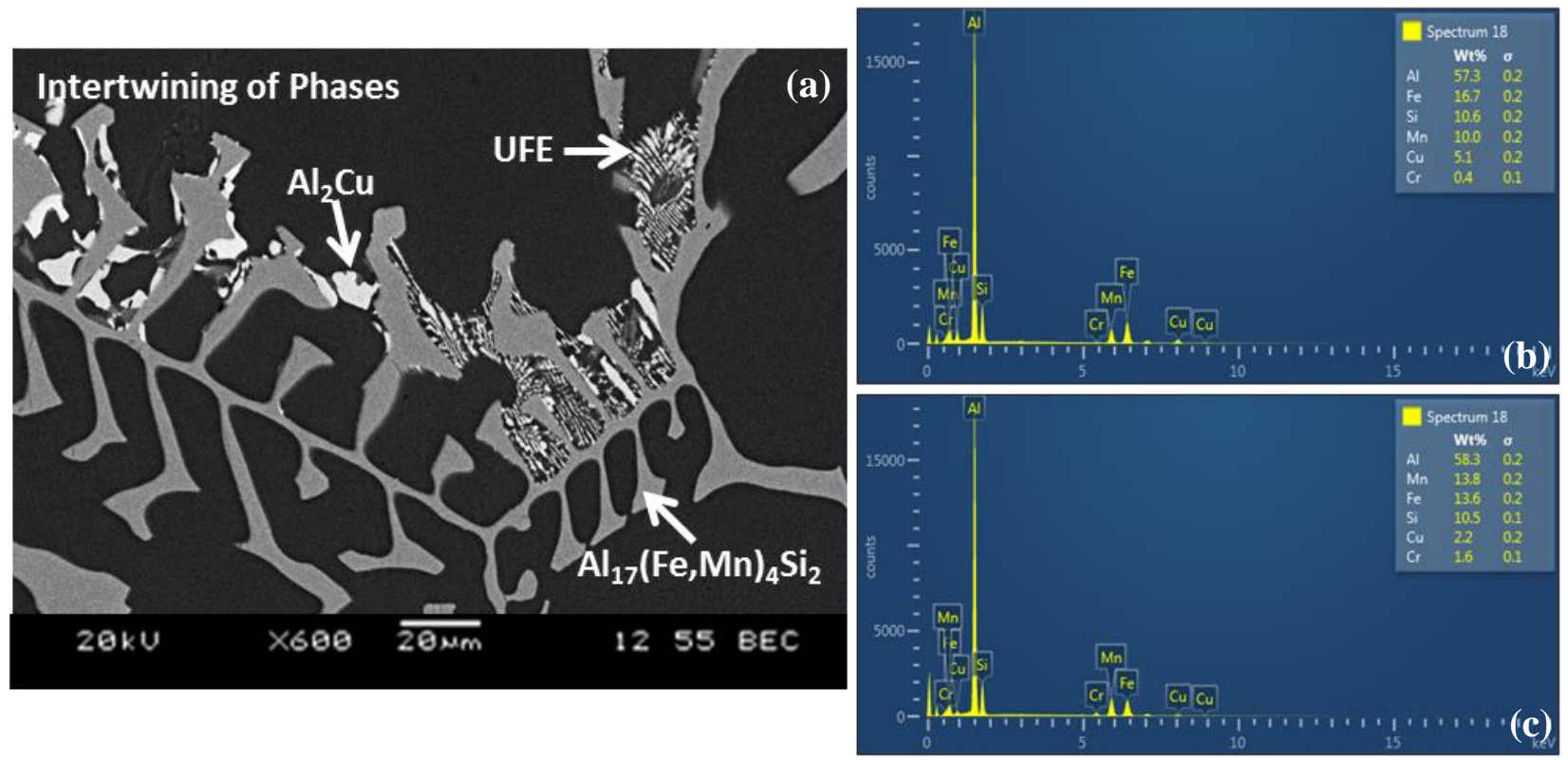

Figure 5.19: (a) Higher magnification backscattered electron image showing intertwining of $\mathrm{Al}_{2} \mathrm{Cu}$ and $\mathrm{Al}_{17}(\mathrm{Fe}, \mathrm{Mn})_{4} \mathrm{Si}_{2}$, (b) EDX spectrum showing composition of $\mathrm{Al}_{17}(\mathrm{Fe}, \mathrm{Mn})_{4} \mathrm{Si}_{2}$ with intertwined $\mathrm{Al}_{2} \mathrm{Cu},(\mathrm{c}) \mathrm{EDX}$ spectrum showing composition of $\mathrm{Al}_{17}(\mathrm{Fe}, \mathrm{Mn})_{4} \mathrm{Si}_{2}$ without intertwined $\mathrm{Al}_{2} \mathrm{Cu}$.

The results in Figure 5.19 indicate that the $\mathrm{Al}_{17}(\mathrm{Fe}, \mathrm{Mn})_{4} \mathrm{Si}_{2}$ particles which intertwined with $\mathrm{Al}_{2} \mathrm{Cu}$ contained approximately $5 \mathrm{wt} \% \mathrm{Cu}$, while those without any nearby $\mathrm{Al}_{2} \mathrm{Cu}$ contained between 2 and $2.5 \mathrm{wt} \% \mathrm{Cu}$. This analysis was confirmed by using EDX point analysis on a minimum of 5 particles on each sample, as well as multiple samples. This result suggests that the intertwining of these phases was likely the result of dissolved $\mathrm{Cu}$ within the $\mathrm{Al}_{17}(\mathrm{Fe}, \mathrm{Mn})_{4} \mathrm{Si}_{2}$ phase, coming out of solid solution with this intermetallic and moving into the Al matrix. This only occurred at solutionizing temperatures above $515{ }^{\circ} \mathrm{C}$, which may have been due to the strong interatomic bonds in this intermetallic phase, which resulted in a slow rate of $\mathrm{Cu}$ diffusion. 
Therefore, higher temperatures were required to enhance the diffusion rate of $\mathrm{Cu}$ in $\mathrm{Al}_{17}(\mathrm{Fe}, \mathrm{Mn})_{4} \mathrm{Si}_{2}$ sufficiently for $\mathrm{Cu}$ to diffuse into the $\mathrm{Al}$ matrix. Subsequently, during air quenching, the $\mathrm{Cu}$ atoms reacted with nearby $\mathrm{Al}$, which caused the precipitation of $\mathrm{Al}_{2} \mathrm{Cu}$ near the phase boundary between $\mathrm{Al}$ and $\mathrm{Al}_{17}(\mathrm{Fe}, \mathrm{Mn})_{4} \mathrm{Si}_{2}$. Previous studies by Wang et al. [34], Samuel [48], Mohamed et al. [50] and Samuel et al. [22, 47] did not observe this microstructural phenomena, even at solutionizing temperatures greater than $520^{\circ} \mathrm{C}$, which was likely the result of the difference in quenching methodologies. The slower cooling rate associated with air quenching in this study permitted appreciable time at elevated temperature for diffusion to precipitate and grow blocky $\mathrm{Al}_{2} \mathrm{Cu}$ and UFE, depending on the local composition. In contrast, water quenching likely allowed the liberated $\mathrm{Cu}$ atoms to remain in a supersaturated solid solution, thereby suppressing the formation of $\mathrm{Al}_{2} \mathrm{Cu}$ along the $\mathrm{Al}_{17}(\mathrm{Fe}, \mathrm{Mn})_{4} \mathrm{Si}_{2}$ phase boundary.

\subsubsection{7 $\mathrm{Al}{ }_{2} \mathrm{Cu}$ Volume Fraction Following $\mathrm{SHT}$ at 515 and $530{ }^{\circ} \mathrm{C}$}

The effectiveness of $\mathrm{Al}_{2} \mathrm{Cu}$ dissolution following $\mathrm{SHT}$ at 515 and $530{ }^{\circ} \mathrm{C}$ was quantified using image analysis software in conjunction with BSE images. The results are shown in Figures 5.20 (a) and (b), respectively. The error bars represent the $95 \%$ confidence interval of the $\mathrm{Al}_{2} \mathrm{Cu}$ volume fraction sample mean for each condition.

The results from solutionizing at $515{ }^{\circ} \mathrm{C}$ suggest that for the billets replicating the top of the cylinder, the $\mathrm{Al}_{2} \mathrm{Cu}$ volume fraction decreased gradually from $1.1 \%$ following TSR treatment to approximately $0.6 \%$ after 4 hours of SHT and remained constant with further solutionizing time. With respect to heat treatment at $530{ }^{\circ} \mathrm{C}$, the billets replicating the top of the cylinder had a gradually decreasing $\mathrm{Al}_{2} \mathrm{Cu}$ volume fraction, down to $0.5 \%$ following $8 \mathrm{~h}$ of SHT.

Similarly, the billets replicating the middle of the cylinder, solutionized at $515{ }^{\circ} \mathrm{C}$, had the $\mathrm{Al}_{2} \mathrm{Cu}$ volume fraction reduced from $1.1 \%$ following TSR treatment to 0.8 and $0.6 \%$ after 4 and $8 \mathrm{~h}$ of SHT, respectively. In contrast, at $530{ }^{\circ} \mathrm{C}$, the $\mathrm{Al}_{2} \mathrm{Cu}$ volume fraction continually decreased to $0.5 \%$ after $8 \mathrm{~h}$ of solutionizing.

For the billets replicating the bottom of the cylinder, SHT at $515{ }^{\circ} \mathrm{C}$ reduced the $\mathrm{Al}_{2} \mathrm{Cu}$ volume fraction gradually from $0.5 \%$ in the TSR condition to $0.1 \%$ following $8 \mathrm{~h}$ of heat treatment. When solutionized at $530{ }^{\circ} \mathrm{C}$, the billets replicating the bottom of the cylinder had the $\mathrm{Al}_{2} \mathrm{Cu}$ 
volume fraction reduced to approximately $0.1 \%$ after $2 \mathrm{~h}$ of SHT, which did not decrease any further with increased time.
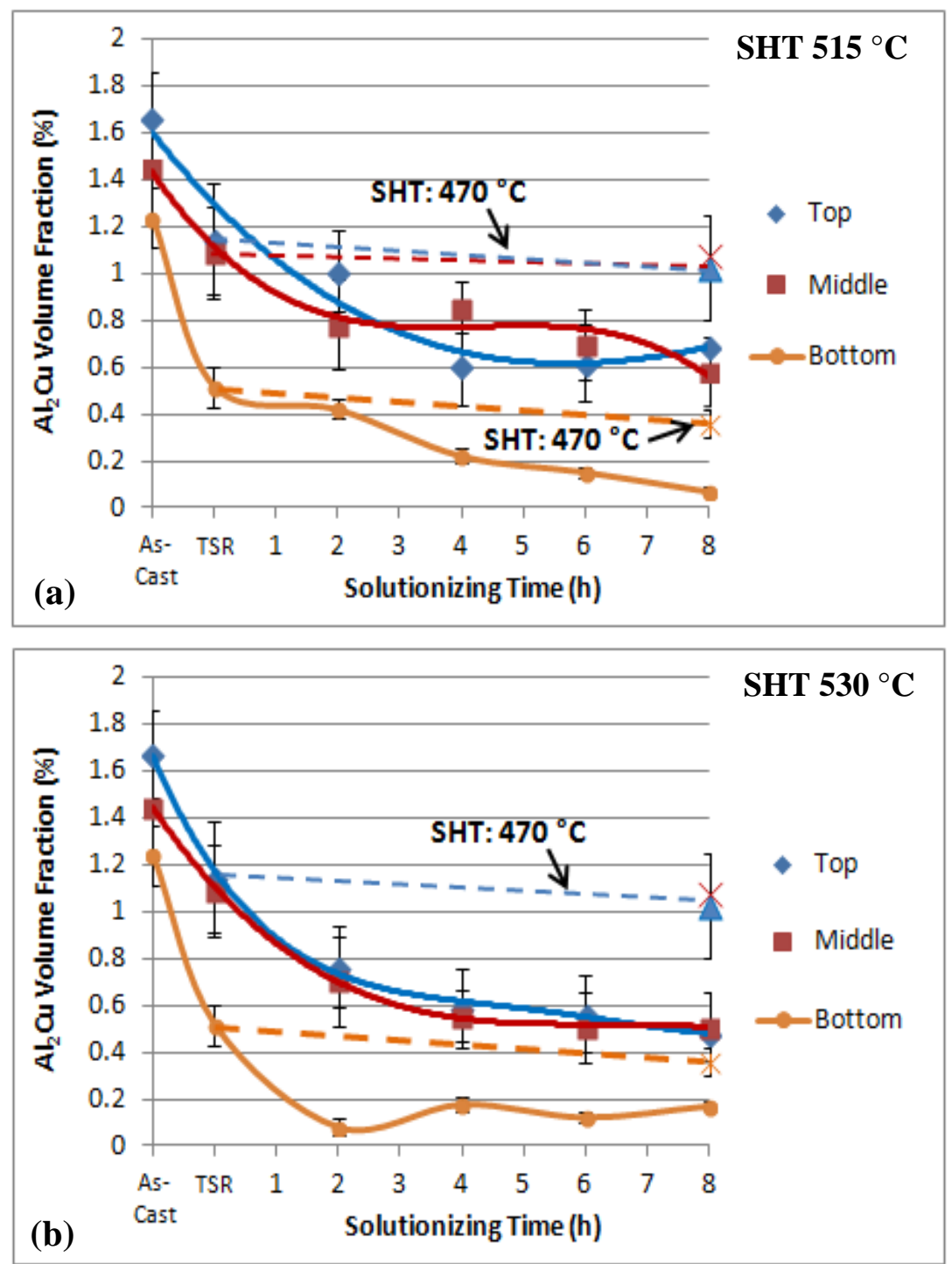

Figure 5.20: Volume fraction of $\mathrm{Al}_{2} \mathrm{Cu}$ following solution heat treatment at: (a) $515{ }^{\circ} \mathrm{C}$, (b) $530{ }^{\circ} \mathrm{C}$.

The trends observed from image analysis indicates that although there was appreciable incipient melting of $\mathrm{Al}_{2} \mathrm{Cu}$ and $\mathrm{Al}_{5} \mathrm{Mg}_{8} \mathrm{Cu}_{2} \mathrm{Si}_{6}$ in interdendritic regions, as seen in Figure 5.16, there was also significant dissolution of $\mathrm{Al}_{2} \mathrm{Cu}$. Microstructural analysis of the billets heat treated at 515 and $530{ }^{\circ} \mathrm{C}$ revealed small, fragmented $\mathrm{Al}_{2} \mathrm{Cu}$, suggesting partial dissolution of these particles. It is possible that significant $\mathrm{Al}_{2} \mathrm{Cu}$ dissolution occurred during heating of the specimen, since SHT involved a heat up time of approximately 1 hour to conform to industry practice. This is supported by Lasa and Rodriguez-Ibabe [44] which, using DSC analysis, found that for heating 
rates of $10{ }^{\circ} \mathrm{C} /$ minute or lower (similar to the heating rates in this study), significant $\mathrm{Al}_{2} \mathrm{Cu}$ dissolution occurred during heating. This reduced the amount of incipient melting when the specimen reached 515 and $530{ }^{\circ} \mathrm{C}$. It must also be noted that the volume fraction of $\mathrm{Al}_{2} \mathrm{Cu}$ was also reduced in these billets due to a small amount of polyhedral $\mathrm{Al}-\mathrm{Cu}-\mathrm{Fe}-\mathrm{Mn}-\mathrm{Si}$ particles, which was likely the structureless $\mathrm{Cu}$-rich phase observed in past research involving incipient melting of $\mathrm{Al}_{2} \mathrm{Cu}$ in $319 \mathrm{Al}$ alloys [22, 47, 48, 50]. Although the $\mathrm{Al}_{2} \mathrm{Cu}$ volume fraction was reduced more effectively by heat treatments above $515{ }^{\circ} \mathrm{C}$, the presence of UFE and the polyhedral $\mathrm{Cu}$-rich particles suggest that incipient melting took place, making these heat treatments unsuitable for use in engine block production.

\subsubsection{Analysis of Incipient Melting using Differential Scanning Calorimetry}

Microstructural analysis, shown in Figure 5.16, revealed that the volume fraction of UFE increased in billets with coarser microstructure, suggesting that these specimens were more susceptible to incipient melting. The susceptibility to incipient melting was quantified using DSC analysis (Figure 5.21) on initially TSR treated billet castings replicating the top, middle and bottom of the engine block cylinder bridge.

The results from DSC analysis and the accompanying first derivative curve (dDSC/dt) suggest that for all the billet castings, three endothermic peaks appeared during heating. These peaks are labelled sequentially in Figure 5.21 and represent the following phase transformations: (1) Melting of $\mathrm{Al}_{2} \mathrm{Cu}$ and $\mathrm{Al}_{5} \mathrm{Mg}_{8} \mathrm{Cu}_{2} \mathrm{Si}_{6}$ at $507.5 \pm 0.2{ }^{\circ} \mathrm{C}$; (2) Melting of the Al-Si eutectic at $579.7 \pm 0.7{ }^{\circ} \mathrm{C}$; (3) Melting of $\mathrm{Al}$ dendrites (liquidus point) at $598.9 \pm 0.8{ }^{\circ} \mathrm{C}$. The first endothermic peak, representing melting of $\mathrm{Al}_{2} \mathrm{Cu}$ and $\mathrm{Al}_{5} \mathrm{Mg}_{8} \mathrm{Cu}_{2} \mathrm{Si}_{6}$, was similar to that observed in DSC analysis by Samuel [48] and Wang et al. [45] for Al-Si-Cu-Mg alloys, while the temperatures of the second and third peak correspond well to the Al-Si eutectic temperature and liquidus temperature, respectively from the Al-Si phase diagram with approximately $8 \mathrm{wt} \% \mathrm{Si}$ [1] (Refer to Appendix G for the associated phase diagrams). Additionally, the melting temperatures of each phase was approximately the same for the billets replicating the top, middle and bottom of the cylinder, suggesting that microstructural refinement did not influence the onset temperature for incipient melting of this alloy. It must be noted that the large endothermic peak associated with the melting of the Al-Si eutectic likely masked the peaks associated to melting of the Fe 
bearing intermetallics. However, the first derivative curve in Figure 5.21 shows an inflection point between 535 and $550{ }^{\circ} \mathrm{C}$ which indicates a reduction in the heating rate, likely attributed to the melting (endothermic reaction) of Fe based intermetallics. This result is supported by work of Wang et al. [45] and Ovono et al. [58] which found, using DSC analysis, that melting of Fe bearing intermetallics occurred at temperatures between approximately 537 and $548{ }^{\circ} \mathrm{C}$ in the 319 Al alloy.
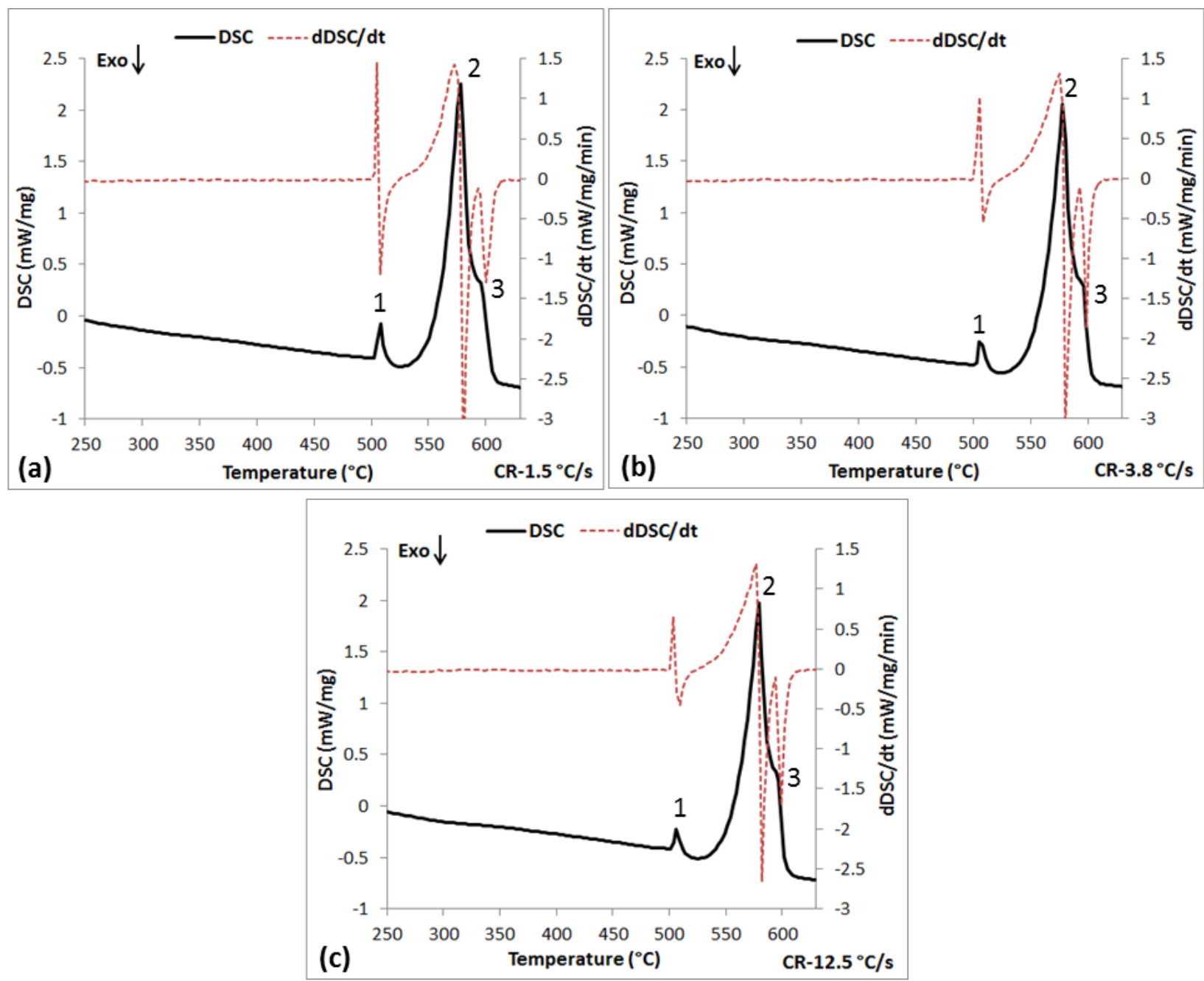

Figure 5.21: DSC analysis of billet castings replicating: (a) top of cylinder (CR-1.5 $\left.{ }^{\circ} \mathrm{C} / \mathrm{s}\right)$, (b) middle of cylinder $\left(\mathrm{CR}-3.8^{\circ} \mathrm{C} / \mathrm{s}\right)$, (c) bottom of cylinder $\left(\mathrm{CR}-12.5^{\circ} \mathrm{C} / \mathrm{s}\right)$.

Based on DSC analysis, the onset of incipient melting during SHT occurred at approximately $507^{\circ} \mathrm{C}$ for this 319 type $\mathrm{Al}$ alloy. Further, the DSC plots for each billet casting indicate that melting of $\mathrm{Al}_{2} \mathrm{Cu}$ and $\mathrm{Al}_{5} \mathrm{Mg}_{8} \mathrm{Cu}_{2} \mathrm{Si}_{6}$ continued up to approximately $525{ }^{\circ} \mathrm{C}$ (end of the first endothermic peak). This result corresponds well with microstructural analysis, since the 
$\mathrm{Al}-\mathrm{Al}_{2} \mathrm{Cu}-\mathrm{Al}_{5} \mathrm{Mg}_{8} \mathrm{Cu}_{2} \mathrm{Si}_{6} \mathrm{UFE}$ clusters (sign of incipient melting) were observed for solutionizing temperatures of 515 and $530{ }^{\circ} \mathrm{C}$, with a higher volume fraction of UFE observed following solutionizing at $530{ }^{\circ} \mathrm{C}$. Therefore, although local melting of $\mathrm{Al}_{2} \mathrm{Cu}$ and $\mathrm{Al}_{5} \mathrm{Mg}_{8} \mathrm{Cu}_{2} \mathrm{Si}_{6}$ initiated at $507^{\circ} \mathrm{C}$, it was more pronounced with increased temperature up to $525^{\circ} \mathrm{C}$, resulting in more UFE in the microstructure upon quenching.

Further analysis of the DSC curves for each billet casting revealed that the endothermic peak and the corresponding peak on the first derivative curve, representing melting of $\mathrm{Al}_{2} \mathrm{Cu}$ and $\mathrm{Al}_{5} \mathrm{Mg}_{8} \mathrm{Cu}_{2} \mathrm{Si}_{6}$, became smaller with microstructural refinement. Quantification of absorbed energy confirmed this observation as melting of $\mathrm{Al}_{2} \mathrm{Cu}$ and $\mathrm{Al}_{5} \mathrm{Mg}_{8} \mathrm{Cu}_{2} \mathrm{Si}_{6}$ for the billets replicating the top of the cylinder resulted in $14.1 \pm 2.2 \mathrm{~J} / \mathrm{g}$ of absorbed energy, whereas the billets replicating the middle and bottom of the cylinder had energy absorptions of $9.8 \pm 0.7 \mathrm{~J} / \mathrm{g}$ and $6.3 \pm 1.2 \mathrm{~J} / \mathrm{g}$, respectively. This change in energy absorption suggests that significantly less melting of $\mathrm{Al}_{2} \mathrm{Cu}$ and $\mathrm{Al}_{5} \mathrm{Mg}_{8} \mathrm{Cu}_{2} \mathrm{Si}_{6}$ occurred for the billets replicating the bottom of the cylinder compared to those replicating the top. This result confirms the microstructural observations, as the volume fraction of UFE following solutionizing at temperatures above $515{ }^{\circ} \mathrm{C}$ was significantly lower for the billets replicating the bottom of the cylinder compared to the other examined billets. This can be explained by the simulated TSR treatment being more effective in dissolving the low-melting phases for the billets replicating the bottom of the cylinder $(0.5 \mathrm{vol} \%$ $\left.\mathrm{Al}_{2} \mathrm{Cu}\right)$ compared to those replicating the top $\left(1.1 \mathrm{vol} \% \mathrm{Al}_{2} \mathrm{Cu}\right)$. Similar to the two-stage SHT process examined by Sokolowski et al. [110] and Han et al. [49], and the DSC analysis of twostage SHT by Wang et al. [45], larger initial dissolution during TSR treatment made the billets replicating the bottom of the cylinder less susceptible to incipient melting compared to the other billets, since less equilibrium $\mathrm{Al}_{2} \mathrm{Cu}$ and $\mathrm{Al}_{5} \mathrm{Mg}_{8} \mathrm{Cu}_{2} \mathrm{Si}_{6}$ were present in the microstructure at the beginning of SHT, thereby reducing the volume fraction of phases susceptible to melting. As such, it can be deduced that due to the influence of the pre-solutionizing TSR treatment, overheating during SHT of engine block castings would have a much larger effect on the mechanical properties of regions of coarse microstructure compared to those of fine microstructure. This structure-property relationship is examined in-detail in Section 5.1.2.3. 


\subsubsection{Tensile Properties of Billet Castings}

\subsection{SHT Temperatures: 470 and $500{ }^{\circ} \mathrm{C}$}

The mechanical properties of the billet castings subjected to SHT at $500{ }^{\circ} \mathrm{C}$ were assessed via ambient temperature tensile testing. The resulting YS and UTS of these billets, along with those that were as-cast, TSR treated, and solutionized at $470{ }^{\circ} \mathrm{C}$ for $7.5 \mathrm{~h}$ (for comparison purposes), are shown in Figure 5.22 (error bars represent the 95\% confidence interval of the YS and UTS sample means). It is important to note that the solutionized billets $\left(470\right.$ and $\left.500{ }^{\circ} \mathrm{C}\right)$ were also artificially aged to $\mathrm{T} 7$ temper $\left(240{ }^{\circ} \mathrm{C}\right.$ for $\left.5.5 \mathrm{~h}\right)$ to conform to industry practice, while no artificial aging treatment was given to the as-cast and TSR treated billets.

The results in Figure 5.22 (a) suggest that in the as cast condition, the YS increased from $142 \mathrm{MPa}$ for the billets replicating the top of the cylinder to 155 and $165 \mathrm{MPa}$ respectively for those replicating the middle and bottom of the cylinder. In addition, TSR treatment resulted in increased YS to 154, 166 and $200 \mathrm{MPa}$ for the billets replicating the top, middle and bottom of the cylinder respectively. Subsequent SHT of the billets in the TSR condition, using the current production parameters $\left(470{ }^{\circ} \mathrm{C}\right.$ for $\left.7.5 \mathrm{~h}\right)$, resulted in a minor increase in YS to 158,167 and $203 \mathrm{MPa}$ respectively. Relative to the current SHT schedule, solutionizing at $500{ }^{\circ} \mathrm{C}$ for $2 \mathrm{~h}$ resulted in YS increases of approximately 15, 8 and 4\% to 182, 180 and $210 \mathrm{MPa}$ for the billets replicating the top, middle and bottom of the cylinder, respectively. Solution heat treatment at $500{ }^{\circ} \mathrm{C}$ for time periods of $4 \mathrm{~h}$ or greater did not result in a significant increase in YS relative to the $2 \mathrm{~h}$ soak time, specifically for the billets replicating the top and middle of the cylinder.

Figure 5.22 (b) shows the changes in UTS with heat treatment condition. The results suggest that in the as-cast condition, the UTS increased from $152 \mathrm{MPa}$ for the billets replicating the top of the cylinder to 170 and $215 \mathrm{MPa}$ respectively for those replicating the middle and bottom of the cylinder. Following TSR treatment, the UTS of these billets increased to 166, 187 and $260 \mathrm{MPa}$, respectively. Furthermore, similar to the YS, SHT using the current production parameters did not result in a significant increase in UTS for all the billet castings. Conversely, SHT at $500{ }^{\circ} \mathrm{C}$ for $2 \mathrm{~h}$ increased the UTS to 189 and $198 \mathrm{MPa}$, respectively for the billets replicating the top and middle of the cylinder, although there was no significant difference in UTS for the billets replicating the bottom of the cylinder. In addition, increased SHT time up to $4 \mathrm{~h}$ at this 
temperature resulted in increased UTS for the billets replicating the top and middle of the cylinder to 197 and $205 \mathrm{MPa}$, respectively. Soaking times greater than $4 \mathrm{~h}$, however, did not significantly improve the UTS. It is important to note that due to the more clustered porosity and higher inclusion content in the billets compared to the engine block castings (Section 5.1.1.6), this method can only be used to estimate the normalized increase in strength due to heat treatment, not the absolute strength values for the engine block.
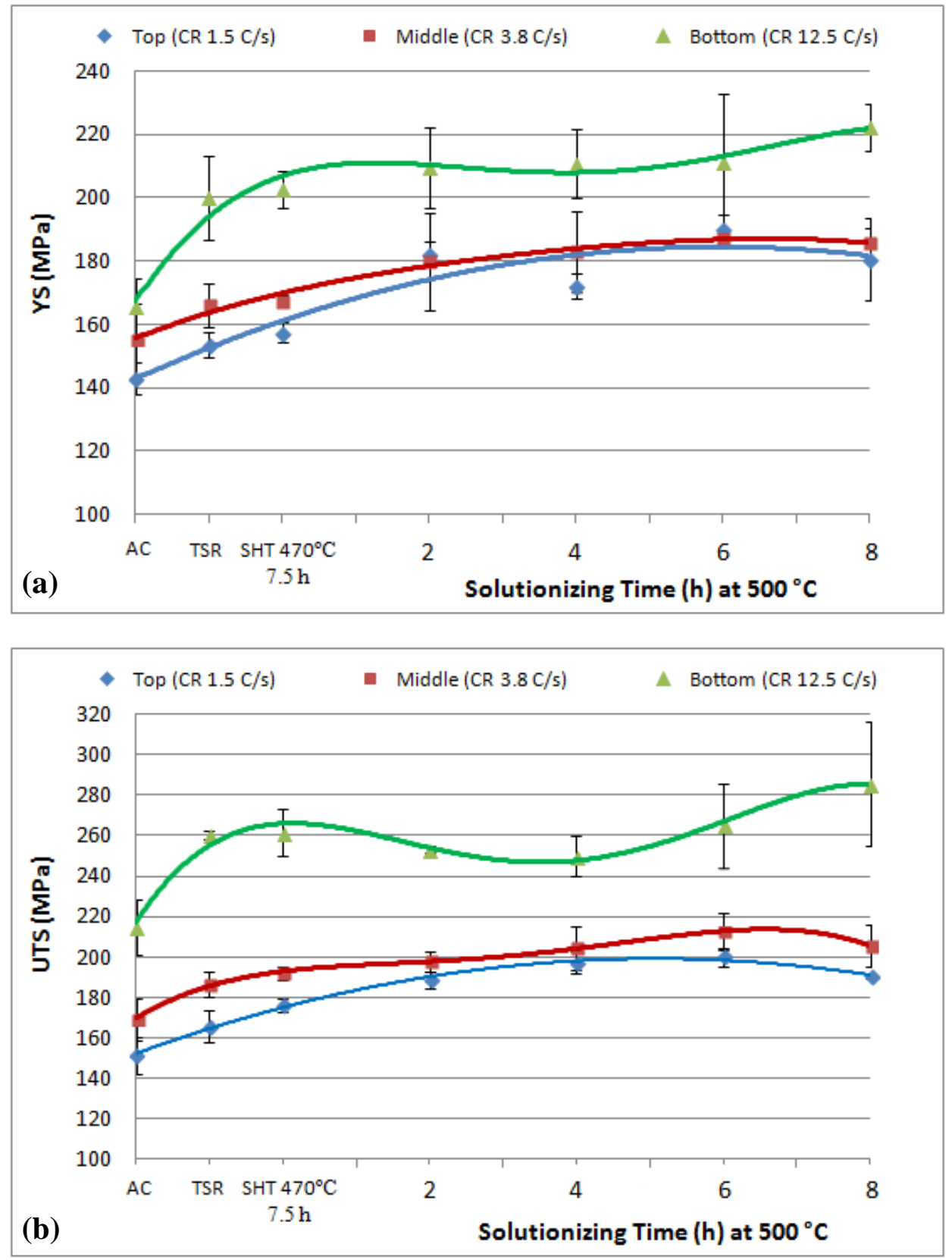

Figure 5.22: Results from tensile testing of billet castings subjected to solution heat treatment at $500{ }^{\circ} \mathrm{C}$ : (a) YS, (b) UTS. 
The change in YS and UTS with heat treatment condition was directly linked to dissolution of phases amenable to heat treatment such as $\mathrm{Al}_{2} \mathrm{Cu}$. For instance, TSR treatment resulted in a large reduction in $\mathrm{Al}_{2} \mathrm{Cu}$ volume fraction (Figure 5.14), specifically for the billets replicating the bottom of the cylinder. The dissolution of $\mathrm{Al}_{2} \mathrm{Cu}$ during TSR treatment resulted in improved YS and UTS via solution strengthening and natural aging. Furthermore, subsequent SHT at $470{ }^{\circ} \mathrm{C}$ for $7.5 \mathrm{~h}$ did not improve strength significantly since there was minimal dissolution of $\mathrm{Al}_{2} \mathrm{Cu}$ relative to the TSR condition, which limited the solute available to form age hardening precipitates during aging. Conversely, the relatively large $\mathrm{Al}_{2} \mathrm{Cu}$ dissolution while solutionizing at $500{ }^{\circ} \mathrm{C}\left(25 \%\right.$ reduction in $\mathrm{Al}_{2} \mathrm{Cu}$ volume fraction after $2 \mathrm{~h}$ of solutionizing) resulted in increased the YS and UTS, specifically for the billets replicating the top and middle of the cylinder. This strengthening effect was largest following $2 \mathrm{~h}$ of SHT, since the largest $\mathrm{Al}_{2} \mathrm{Cu}$ dissolution occurred at this time interval, as observed in Figure 5.14. For higher solutionizing times, the reduction in $\mathrm{Al}_{2} \mathrm{Cu}$ volume fraction was less pronounced, leading to smaller and more gradual increases in YS and UTS. It is important to note that for the billets replicating the bottom of the cylinder, the increase in YS and UTS was limited following SHT at $500{ }^{\circ} \mathrm{C}$ since the majority of $\mathrm{Al}_{2} \mathrm{Cu}$ was dissolved during TSR treatment. As such, following SHT there was only a small increase in solute content for these billets compared to the TSR condition, minimizing the precipitation hardening effect.

Further analysis of the tensile testing data also indicated that modification of the Al-Si eutectic morphology due to SHT at $500{ }^{\circ} \mathrm{C}$ did not have a large influence on mechanical properties. This was likely due to the small changes in morphology (fragmentation of eutectic Si particles) between the TSR and solutionized conditions, preventing a significant effect compared to dissolution of $\mathrm{Al}_{2} \mathrm{Cu}$ and subsequent precipitation hardening.

The results from tensile testing indicate that the most effective solutionizing parameter was $500{ }^{\circ} \mathrm{C}$ for $2 \mathrm{~h}$ due to the combination of the largest relative strengthening effect and the largest reduction in process time ( $75 \%$ reduction relative to the current SHT schedule), improving cost effectiveness. Although, higher solutionizing temperatures were also examined in this study, these temperatures were found to induce incipient melting, making them unsuitable for engine block production. Section 5.1.2.3.2, however, examines the influence of incipient melting and age hardening on the tensile properties of the billet castings. 


\subsection{SHT Temperatures: 515 and $530{ }^{\circ} \mathrm{C}$}

Ambient temperature tensile testing was carried out for the billets subjected to SHT at 515 and $530{ }^{\circ} \mathrm{C}$. The results are shown in Figure 5.23 (error bars represent the 95\% confidence interval of the YS and UTS sample means), along with the tensile properties of the billets treated with the most effective SHT parameters $\left(500^{\circ} \mathrm{C}\right.$ for $\left.2 \mathrm{~h}\right)$, for comparison.
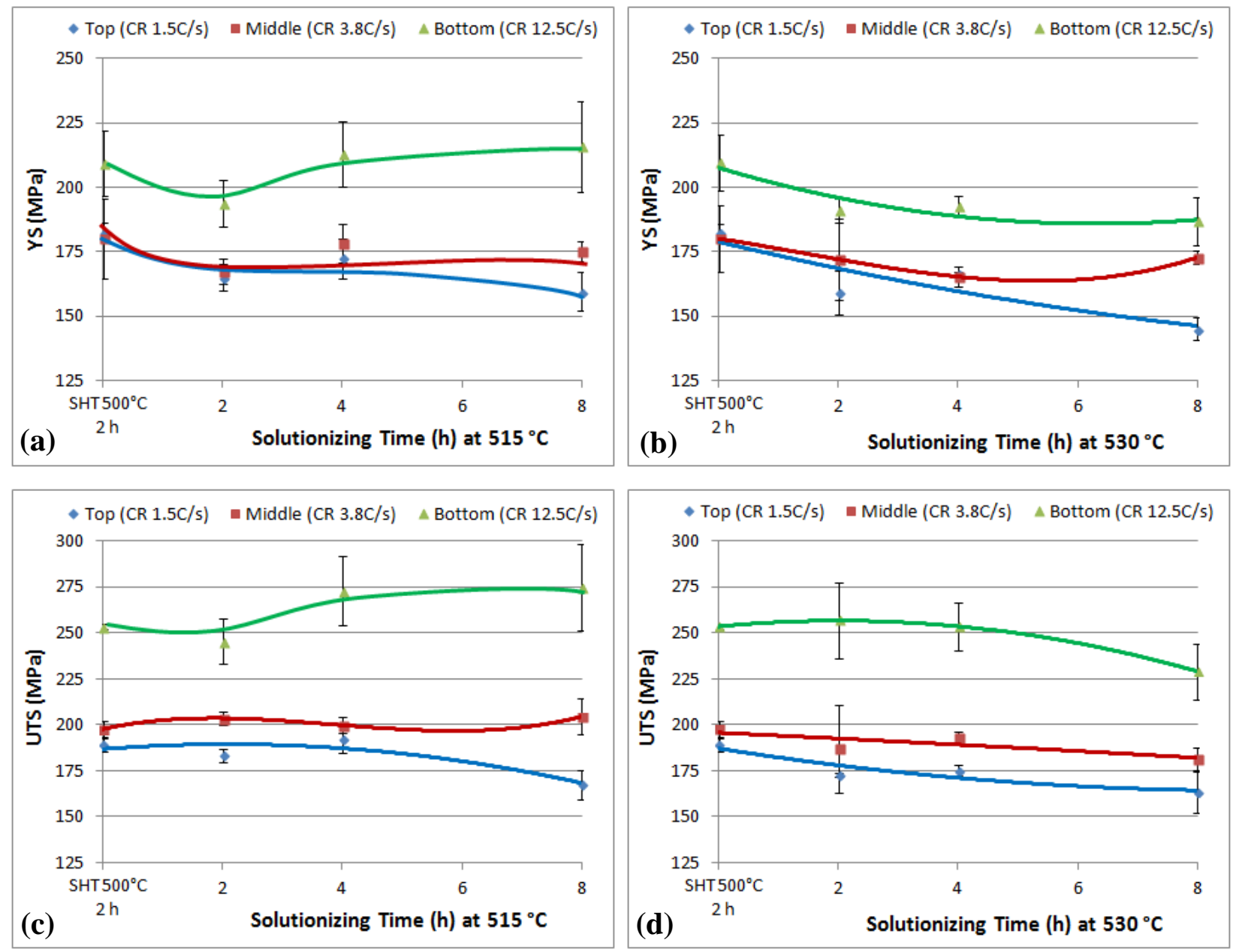

Figure 5.23: Results from tensile testing: (a) YS of billets SHT at $515^{\circ} \mathrm{C}$, (b) YS of billets SHT at $530{ }^{\circ} \mathrm{C}$, (c) UTS of billets SHT at $515{ }^{\circ} \mathrm{C}$, (d) UTS of billets SHT at $530{ }^{\circ} \mathrm{C}$.

The results in Figure 5.23 (a) suggest that the billets replicating the top and middle of the cylinder, which were solutionized at $515^{\circ} \mathrm{C}$ for $2 \mathrm{~h}$, had YS values of approximately 165 and $168 \mathrm{MPa}$, respectively. The YS of these billets increased slightly to 173 and $178 \mathrm{MPa}$, respectively following $4 \mathrm{~h}$ of $\mathrm{SHT}$ at $515^{\circ} \mathrm{C}$, and then decreased to 160 and $175 \mathrm{MPa}$, respectively following $8 \mathrm{~h}$ of heat treatment. Conversely, the YS of the billets replicating the 
bottom of the cylinder increased from $194 \mathrm{MPa}$ following $2 \mathrm{~h}$ of SHT at $515{ }^{\circ} \mathrm{C}$ to $216 \mathrm{MPa}$ following $8 \mathrm{~h}$ of SHT. In contrast to the $515{ }^{\circ} \mathrm{C}$ solutionizing temperature, SHT at $530{ }^{\circ} \mathrm{C}$ resulted in a reduction in YS with solutionizing time (Figure 5.23 (b)) for all billet castings. For instance, following $2 \mathrm{~h}$ of SHT at this temperature, the YS of the billets replicating the top, middle and bottom of the cylinder was 159, 172 and $191 \mathrm{MPa}$, respectively, which decreased to 145, 173 and $187 \mathrm{MPa}$, respectively following $8 \mathrm{~h}$ of SHT.

The UTS for the billets (Figure 5.23 (c)) replicating the top and middle ( 185 and $200 \mathrm{MPa}$, respectively) of the cylinder did not change appreciably when subjected to SHT at $515{ }^{\circ} \mathrm{C}$ for 2 and $4 \mathrm{~h}$. When subjected to $8 \mathrm{~h}$ of solutionizing at this temperature, the UTS of the billets replicating the top of the cylinder decreased to approximately $168 \mathrm{MPa}$, while the UTS of those replicating the middle of the cylinder did not change significantly. Regarding the billets replicating the bottom of the cylinder, the UTS increased from 245 to $275 \mathrm{MPa}$ for heat treatment times of 2 and $8 \mathrm{~h}$, respectively. Similar to the observations of $\mathrm{YS}$, the $530{ }^{\circ} \mathrm{C}$ solutionizing temperature resulted in decreased UTS with solutionizing time for all billet castings (Figure 5.23 (d)). Following $2 \mathrm{~h}$ of solutionizing at this temperature, the UTS for the billets replicating the top, middle and bottom of the cylinder was 173, 187 and $257 \mathrm{MPa}$, respectively, while after $8 \mathrm{~h}$, the UTS decreased to 164, 181 and $229 \mathrm{MPa}$, respectively.

Direct comparison of the results from tensile testing indicated that the YS and UTS were lower for the billets solutionized at 515 and $530{ }^{\circ} \mathrm{C}$ compared to those solutionized at $500{ }^{\circ} \mathrm{C}$, specifically for those replicating the top and middle of the cylinder. This was despite the fact that solutionizing at these temperatures resulted in more dissolution of $\mathrm{Al}_{2} \mathrm{Cu}$ and greater morphological modification of the Al-Si eutectic regions. To elucidate the reason for the reduction in tensile properties, fractography was carried out on tensile bars solutionized at 500 and $530{ }^{\circ} \mathrm{C}$, as shown in Figure 5.24. This analysis mainly utilized BSE images to observe the influence of intermetallic phases on alloy strength, since secondary electron images found that fracture was dominated by cleavage for all examined conditions. 

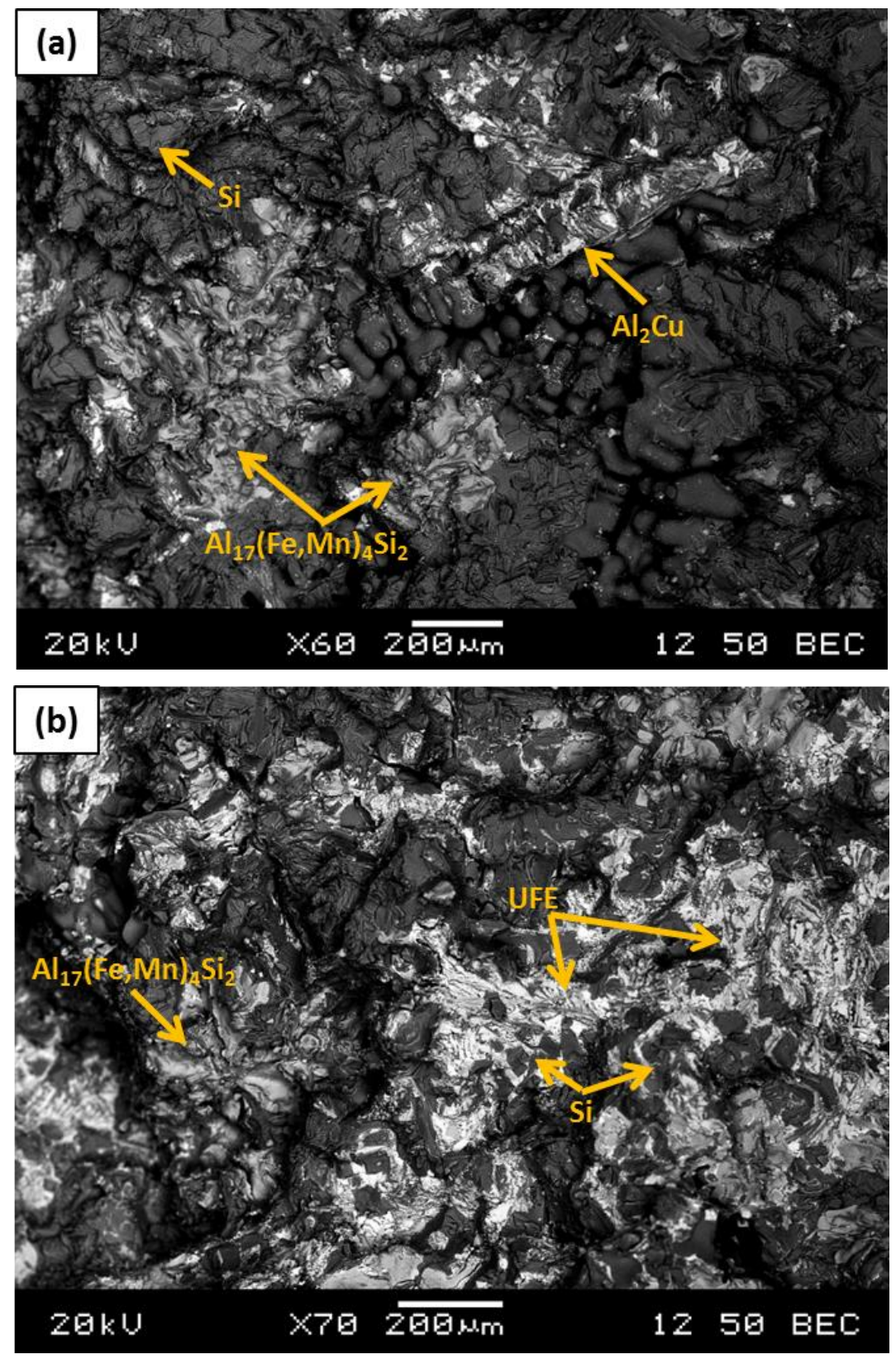

Figure 5.24: SEM BSE image of fracture surface for billets replicating middle of cylinder solutionized at: (a) $500{ }^{\circ} \mathrm{C}$, (b) $530{ }^{\circ} \mathrm{C}$.

The results in Figure 5.24 (a) indicate that for the billets solutionized at $500{ }^{\circ} \mathrm{C}$, the fracture surface contained eutectic $\mathrm{Si}, \mathrm{Al}_{17}(\mathrm{Fe}, \mathrm{Mn})_{4} \mathrm{Si}_{2}$ and the remaining undissolved $\mathrm{Al}_{2} \mathrm{Cu}$ in the interdendritic regions. In contrast, Figure 5.24 (b) suggests that the fracture surface of the billets, solutionized at $530{ }^{\circ} \mathrm{C}$, contained large quantities of the UFE clusters along with eutectic and polygonal $\mathrm{Si}$ particles and $\mathrm{Al}_{17}(\mathrm{Fe}, \mathrm{Mn})_{4} \mathrm{Si}_{2}$. The large quantity of UFE on the fracture surface indicates that these clusters acted as local stress rises which deteriorated alloy strength. Higher 
magnification BSE images, shown in Figure 5.25, indicated secondary cracks propagating through the UFE clusters and the surrounding polygonal Si crystals (formed with the UFE). This suggests that the micro-porosity embedded in the UFE likely acted as a crack nucleation site, which was exacerbated by the presence of the coarse and brittle polygonal Si particles surrounding the UFE clusters. Therefore, the large secondary cracks through the UFE particles along with the large amount of UFE on the fracture surface, indicates that the UFE clusters were deleterious to mechanical properties as cracks propagated selectively through these regions. For this reason, the larger reduction in YS and UTS when heat treating at $530{ }^{\circ} \mathrm{C}$ compared to $515{ }^{\circ} \mathrm{C}$ supports microstructural observations, since a larger volume fraction of the deleterious UFE clusters was found for the billets solutionized at $530{ }^{\circ} \mathrm{C}$ compared to those solutionized at $515^{\circ} \mathrm{C}$.

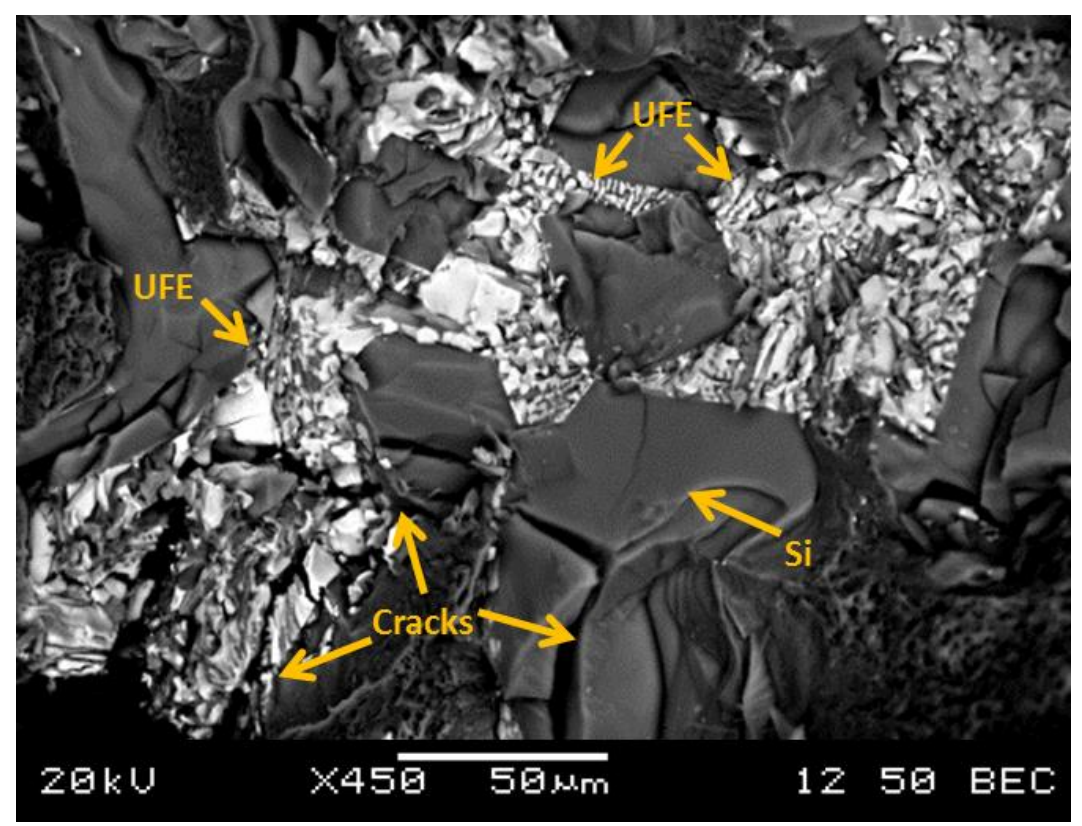

Figure 5.25: Higher magnification BSE image showing UFE morphology for billets solutionized at $530{ }^{\circ} \mathrm{C}$

The billets replicating the bottom of the cylinder had significantly less UFE than the other examined billets, as shown in Figure 5.16. This prevented the deterioration in mechanical properties at $515{ }^{\circ} \mathrm{C}$ and reduced the degree of deterioration at $530{ }^{\circ} \mathrm{C}$. Fractography for the billets replicating the bottom of the cylinder, solutionized at $530{ }^{\circ} \mathrm{C}$ was carried out (Figure 5.26) to confirm the influence of UFE volume fraction on mechanical properties. The results indicated that the fracture surface of these billets contained eutectic $\mathrm{Si}, \mathrm{Al}_{17}(\mathrm{Fe}, \mathrm{Mn})_{4} \mathrm{Si}_{2}$ and a small quantity of UFE clusters. Although the UFE clusters had secondary crack propagating in their 
vicinity (further indicating that these clusters are deleterious to mechanical properties), the relatively small amount of UFE in these billets mitigated the deleterious effect. In fact, the results confirm that the effect of incipient melting on YS and UTS was reduced with refinement in microstructure. Microstructural analysis indicated that the billets with finer microstructure were less susceptible to incipient melting since TSR treatment dissolved approximately $70 \%$ of $\mathrm{Al}_{2} \mathrm{Cu}$ prior to SHT, giving a two-stage heat treatment effect $[49,110]$. For, the billets replicating the top of the cylinder, however, TSR treatment was not as effective in dissolving these phases, which resulted in the highest quantity of UFE due to incipient melting during SHT at 515 or $530{ }^{\circ} \mathrm{C}$ and therefore had the largest reduction in YS and UTS.

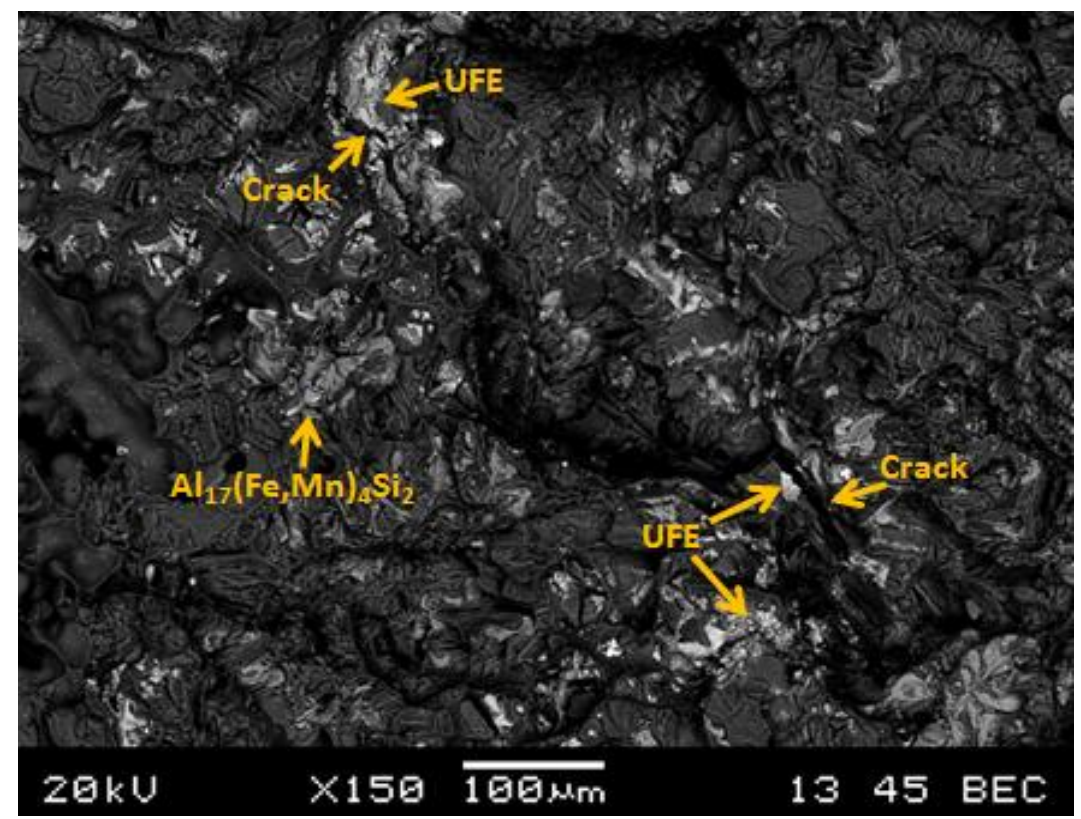

Figure 5.26: BSE image showing fracture surface of billets replicating bottom of cylinder solutionized $530{ }^{\circ} \mathrm{C}$.

\section{Section Summary}

This section applied varying solutionizing parameters to the billets replicating the microstructure of the top, middle and bottom sections of the engine block cylinder bridge. Solution heat treatment at $500{ }^{\circ} \mathrm{C}$ resulted in fragmentation and spheroidization of eutectic $\mathrm{Al}_{2} \mathrm{Cu}$ particles and rough edges along the blocky $\mathrm{Al}_{2} \mathrm{Cu}$ particle interface, suggesting partial dissolution along the phase boundary. Solutionizing for $2 \mathrm{~h}$ at $500^{\circ} \mathrm{C}$ resulted in a 15,8 and $4 \%$ increase in YS for the billets replicating the top, middle and bottom of the cylinder, respectively, which did not increase further with longer solutionizing time. Higher solutionizing temperatures caused incipient 
melting, which formed UFE clusters and deteriorated the mechanical properties. As such, the influence of different SHT parameters on microstructure and mechanical properties for each section of the cylinder bridge was estimated. These results were used in conjunction with the residual stress and strain data in Section 5.2 to determine the optimal SHT parameters for engine block production.

\subsection{Residual Stress/Strain Analysis}

This section aims to develop a more thorough understanding of how residual strain and stress relieves as a function of time during SHT and the generation of strain and stress due to thermomechanical mismatch during post-heat treatment cooling. This analysis will enable the optimal parameters to be determined to minimize residual stress within the cylinder bore region of the engine block. Development of a reference interplanar spacing $\left(\mathrm{d}_{0}\right)$ using in-situ neutron diffraction during heat treatment of initially TSR treated stress free samples is discussed in Section 5.2.1. In-situ analysis of strain relief during SHT and strain development during cooling is presented in Section 5.2.2, while ex-situ analysis comparing the residual stress profile prior to and following heat treatment is discussed in Section 5.2.3.*

\subsubsection{In-situ analysis of $d_{0}$ during SHT}

This sub-section presents the results from in-situ neutron diffraction analysis of the interplanar spacing of stress-free specimens, subjected to SHT. Microstructural and compositional analyses, used to elucidate the reasons for changes in $\mathrm{d}_{0}$ spacing during SHT, are discussed in Sections 5.2.1.1 and 5.2.1.2. The effect of thermal expansion on $\mathrm{d}_{0}$ spacing is examined in Section 5.2.1.3, while Section 5.2.1.4 shows the change in $\mathrm{d}_{0}$ as a function of time during SHT.

\footnotetext{
*Much of the data presented in this section was published in:

Lombardi, A., Sediako, D., Machin, A., Ravindran, C., MacKay, R., "Evaluating the Effect of Solution Heat Treatment on Residual Stress in Al Engine Blocks using In-situ and Ex-situ Neutron Diffraction" (under internal review).

Lombardi, A., Sediako, D., Machin, A., Ravindran, C., MacKay, R., "Transient Analysis of Residual Strain during Heat Treatment of Multi-material Engine Blocks using In-situ Neutron Diffraction”, Materials Letters, Vol. 157, pp. 50-52 (2015).

Lombardi, A., Sediako, D., Ravindran, C., MacKay, R., "In-situ Neutron Diffraction Analysis of the Stress-Free d-spacing during Solution Heat Treatment of Modified 319 Al Alloy Engine Blocks”, Canadian Metallurgical Quarterly, Vol. 54, pp. 30-37 (2015).

Lombardi, A., Sediako, D., Ravindran, C., MacKay, R., "Residual Stress Mapping along the Cylinder Bores of Al Alloy Engine Blocks Subjected to Production Solution Heat Treatment Schedule", SAE International Journal of Materials and Manufacturing, Vol. 7, pp. 415-420 (2014).
} 


\section{$\underline{\text { 5.2.1.1 Microstructure }}$}

Secondary phase analysis was carried out on TSR and solutionized (470, 500 and $\left.530{ }^{\circ} \mathrm{C}\right)$ "match stick" samples, extracted from the top and bottom of the engine block cylinder bridge, using BSE images as shown in Figure 5.27. The microstructure at the top of the cylinder for engine blocks in the TSR and SHT $\left(470{ }^{\circ} \mathrm{C}\right)$ conditions contained partially modified Al-Si eutectic, Chinese script $\mathrm{Al}_{17}(\mathrm{Fe}, \mathrm{Mn})_{4} \mathrm{Si}_{2}$ and blocky $\mathrm{Al}_{2} \mathrm{Cu}$ clustered with $\mathrm{Al}_{5} \mathrm{Mg}_{8} \mathrm{Cu}_{2} \mathrm{Si}_{6}$, which was similar to that observed in the billets replicating the top of the cylinder (Section 5.1.2.1.1). The microstructure at the bottom of the cylinder for the TSR treated and solution treated $\left(470{ }^{\circ} \mathrm{C}\right)$ engine blocks contained significantly refined and globular eutectic $\mathrm{Si}$ particles, as well as particulate $\mathrm{Al}_{17}(\mathrm{Fe}, \mathrm{Mn})_{4} \mathrm{Si}_{2}, \mathrm{Al}_{5} \mathrm{Mg}_{8} \mathrm{Cu}_{2} \mathrm{Si}_{6}$ and $\mathrm{Al}_{2} \mathrm{Cu}$. This was also similar to the observations for the billets replicating the bottom of the cylinder, shown in Section 5.1.2.1.1.

Heat treatment of the top of the cylinder bridge at $500{ }^{\circ} \mathrm{C}$ (Figure 5.27 (e)) resulted in notable fragmentation and partial dissolution of $\mathrm{Al}_{2} \mathrm{Cu}$ particles. However, no significant changes in $\mathrm{Al}_{17}(\mathrm{Fe}, \mathrm{Mn})_{4} \mathrm{Si}_{2}$ and $\mathrm{Al}_{5} \mathrm{Mg}_{8} \mathrm{Cu}_{2} \mathrm{Si}_{6}$ morphology were observed following heat treatment at this temperature. At the bottom of the cylinder, microstructural changes did not occur while heat treating at $500{ }^{\circ} \mathrm{C}$ (Figure 5.27 (f)), which was likely due to the low volume fraction of $\mathrm{Al}_{2} \mathrm{Cu}$ present in this region of the cylinder in the TSR condition.

Heat treatment of the top and bottom of the cylinder at $530{ }^{\circ} \mathrm{C}$, however, resulted in a large morphological modification of secondary phase particles. The top of the cylinder contained $\mathrm{Al}_{17}(\mathrm{Fe}, \mathrm{Mn})_{4} \mathrm{Si}_{2}$ intertwined with $\mathrm{Al}_{2} \mathrm{Cu}$ particles, as shown in Figure 5.27 (g). In addition, UFE clusters, similar to those found in for the billet castings solutionized at this temperature (Section 5.1.2.1.4), were also observed in the vicinity of polyhedral Si particles. This indicates that particles of $\mathrm{Al}_{2} \mathrm{Cu}$ and $\mathrm{Al}_{5} \mathrm{Mg}_{8} \mathrm{Cu}_{2} \mathrm{Si}_{6}$ may have undergone incipient melting, resulting in the formation of UFE clusters upon re-solidification. Similarly, the bottom of the cylinder, also had small UFE clusters in the microstructure, but with a significantly lower volume fraction compared to the top of the cylinder (Figure $5.27(\mathrm{~h})$ ). This further indicates that incipient melting of $\mathrm{Al}_{2} \mathrm{Cu}$ and $\mathrm{Al}_{5} \mathrm{Mg}_{8} \mathrm{Cu}_{2} \mathrm{Si}_{6}$ may also have occurred at the bottom of the cylinder, however, the fine microstructure in this region allowed significant dissolution of these phases during TSR treatment, reducing the susceptibility of incipient melting. These results confirm the phenomena observed in the analysis of SHT using the billet casting method in Section 5.1.2. 

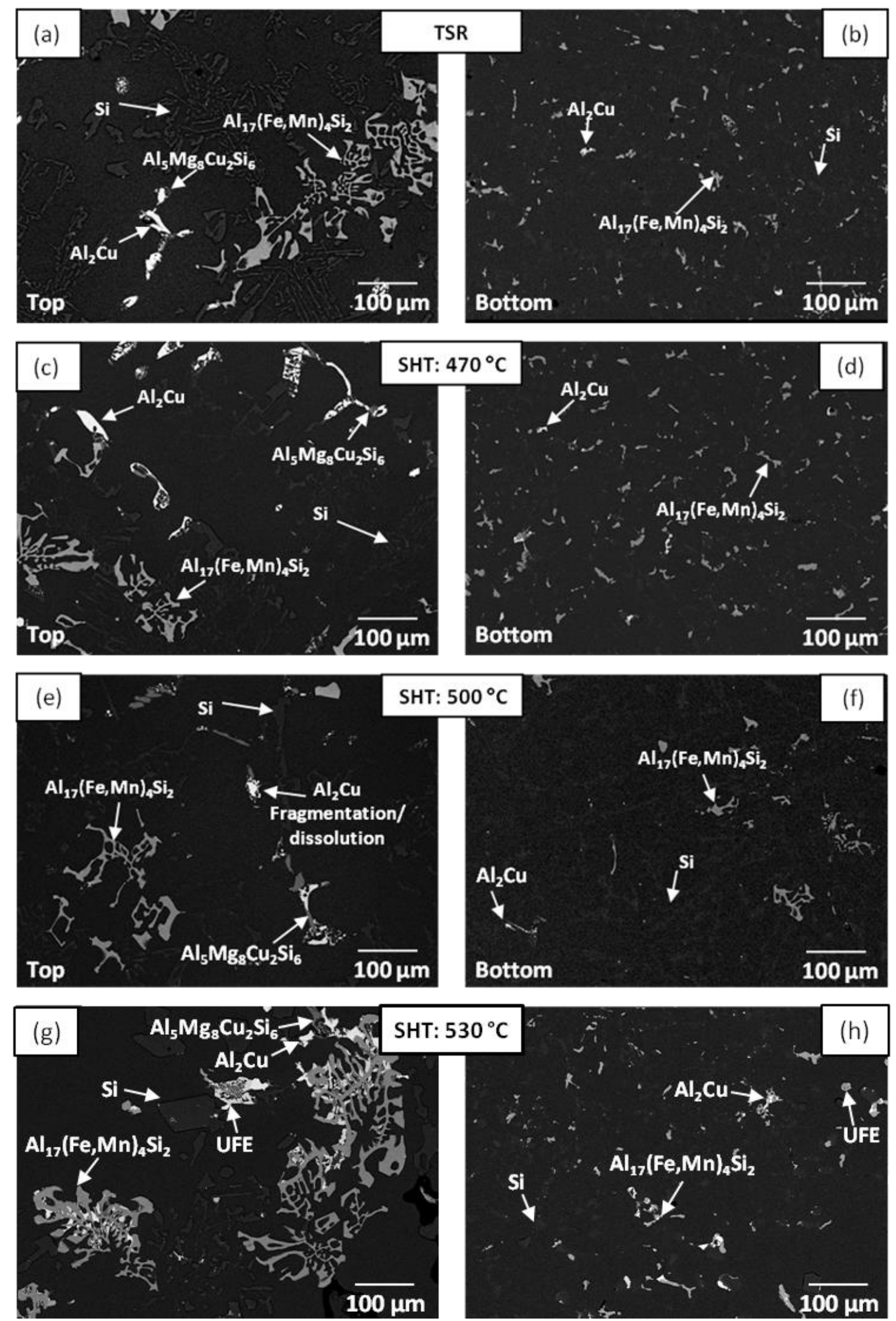

Figure 5.27: Backscattered electron images of the top and bottom of cylinder bridge, respectively for: (a) and (b) TSR condition, (c) and (d) SHT $470{ }^{\circ} \mathrm{C}$, (e) and (f) SHT $500{ }^{\circ} \mathrm{C}$, (g) and (h) SHT $530{ }^{\circ} \mathrm{C}$. 
The influence of SHT on the $\mathrm{Al}_{2} \mathrm{Cu}$ volume fraction was quantified using image analysis software. The results, shown in Figure 5.28, indicate that at the top of the cylinder, the $\mathrm{Al}_{2} \mathrm{Cu}$ volume fraction remained relatively constant at approximately $1.1 \%$ following heat treatment at $470{ }^{\circ} \mathrm{C}$. In contrast, SHT at temperatures of 500 and $530{ }^{\circ} \mathrm{C}$ reduced the $\mathrm{Al}_{2} \mathrm{Cu}$ volume fraction to approximately 0.75 and $0.61 \%$, respectively. The bottom of the cylinder did not have a significant change in $\mathrm{Al}_{2} \mathrm{Cu}$ volume fraction for all solutionizing temperatures, which was likely the result of the low $\mathrm{Al}_{2} \mathrm{Cu}$ volume fraction ( $\left.0.3 \%\right)$ in the TSR condition, preventing any appreciable dissolution. The results for the $\mathrm{Al}_{2} \mathrm{Cu}$ volume fraction for the top and bottom of the cylinder were similar to that found for each respective billet casting in Figures 5.14 and 5.20.

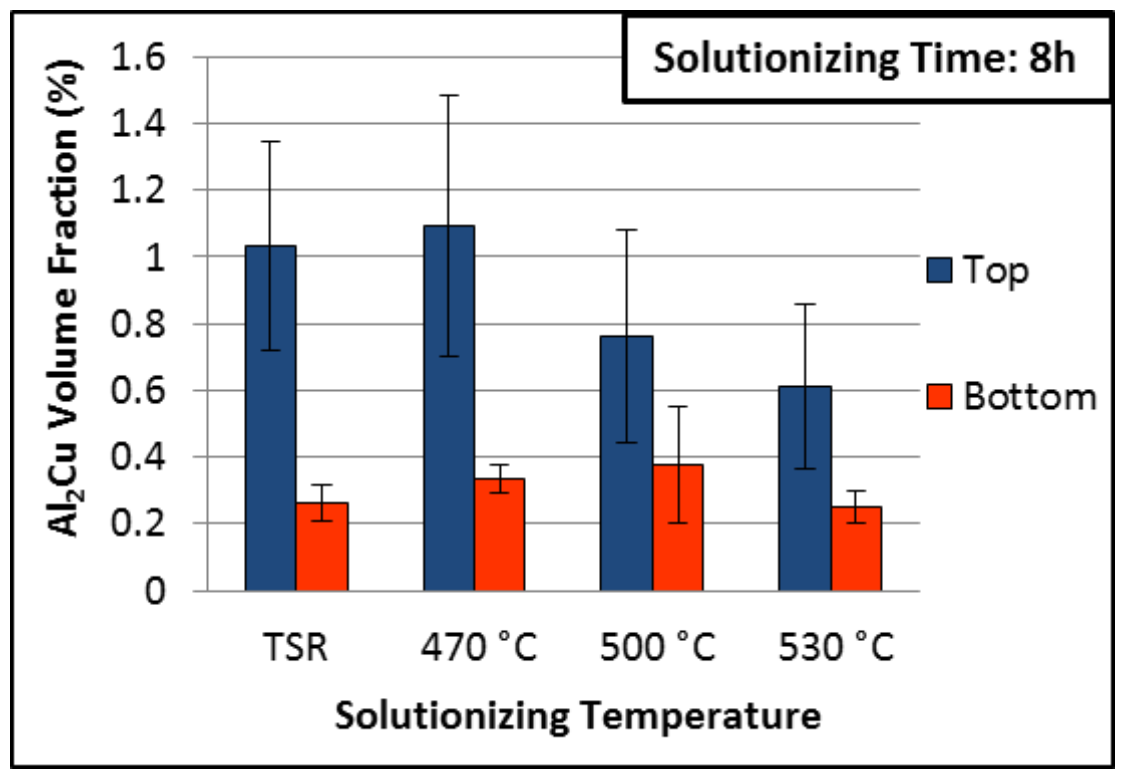

Figure 5.28: Quantitative image analysis showing volume fraction of $\mathrm{Al}_{2} \mathrm{Cu}$.

The reduction in $\mathrm{Al}_{2} \mathrm{Cu}$ volume fraction at the top of the cylinder with increased solutionizing temperature confirms the results that sluggish dissolution of $\mathrm{Al}_{2} \mathrm{Cu}$ occurs at solutionizing temperatures below $480{ }^{\circ} \mathrm{C}$ for the $319 \mathrm{Al}$ alloy [35], while temperatures above $500{ }^{\circ} \mathrm{C}$ were more effective in dissolving this phase. Furthermore, it is important to note that the reduction in $\mathrm{Al}_{2} \mathrm{Cu}$ volume fraction following heat treatment at $530{ }^{\circ} \mathrm{C}$ was partially caused by incipient melting rather than dissolution, which may influence the amount of dissolved solute. This is discussed in Section 5.2.1.2.

It must be pointed out that the high temperature TSR treatment (required to remove the casting from the mould) was found to cause partial dissolution of $\mathrm{Al}_{2} \mathrm{Cu}$ (volume fraction reduced by 
$\sim 25 \%$ at the top of the cylinder and $\sim 60 \%$ at the bottom) using replicating billet castings in Section 5.1.2.1.1. This likely reduced the effect of SHT on phase dissolution and subsequently $\mathrm{d}_{0}$ spacing. However, since TSR treatment did not completely dissolve $\mathrm{Al}_{2} \mathrm{Cu}$, a time dependant relationship between temperature, time and $\mathrm{d}_{0}$ spacing during SHT was required for use as an accurate baseline in residual stress measurements.

\subsubsection{Composition of $\alpha-A l$ Dendrites}

To relate the microstructural changes during SHT to the measured $\mathrm{d}_{0}$ spacing, the composition of the primary $\alpha-\mathrm{Al}$ dendrites was measured via WDS analysis. The results for the top of the cylinder bridge (Figure 5.29 (a)) suggest that the $\mathrm{Cu}$ concentration remained relatively constant ( 3.7 wt\%) during SHT at $470{ }^{\circ} \mathrm{C}$ compared to the TSR condition, which confirmed the sluggish dissolution of $\mathrm{Al}_{2} \mathrm{Cu}$ at this temperature. Solution heat treatment at 500 and $530{ }^{\circ} \mathrm{C}$ resulted in a gradual increase in $\mathrm{Cu}$ content up to approximately $4.15 \mathrm{wt} \%$, confirming that dissolution of $\mathrm{Al}_{2} \mathrm{Cu}$ occurred more readily at higher solutionizing temperatures. Conversely, the bottom of the cylinder (Figure 5.29 (b)) showed increased $\mathrm{Cu}$ concentration from approximately $3.6 \mathrm{wt} \%$ in the TSR condition to approximately $4 \mathrm{wt} \%$ for the samples solution treated at $470{ }^{\circ} \mathrm{C}$. The $\mathrm{Cu}$ concentration did not change significantly at higher SHT temperatures. The lack of change in $\mathrm{Cu}$ concentration with increased solutionizing temperature at the bottom of the cylinder was likely the result of low $\mathrm{Al}_{2} \mathrm{Cu}$ volume fraction prior to heat treatment (Figure 5.28), which limited significant $\mathrm{Al}_{2} \mathrm{Cu}$ dissolution.

Analysis of the $\alpha$-Al dendrite composition also revealed that for the top and bottom of the cylinder, the $\mathrm{Si}$ and $\mathrm{Mg}$ concentration increased with increasing solutionizing temperature. This result suggests that the $\mathrm{Al}_{5} \mathrm{Mg}_{8} \mathrm{Cu}_{2} \mathrm{Si}_{6}$ phase, found in clusters with $\mathrm{Al}_{2} \mathrm{Cu}$, dissolved more readily at higher solutionizing temperatures, leading to an enrichment of $\mathrm{Si}$ and $\mathrm{Mg}$ in solid solution.

It is important to note, that the concentration of alloying elements is high considering the overall alloy composition. This indicates that inaccuracies in the WDS analysis may have led to an overestimation in the concentration of alloying elements in the matrix. However, since this analysis was carried out under the same conditions (all samples were inserted into the microprobe simultaneously), the relative trends for concentration change with heat treatment temperature, which were related to changes in $\mathrm{d}_{0}$ spacing in Section 5.2.1.4, can be considered reliable. 

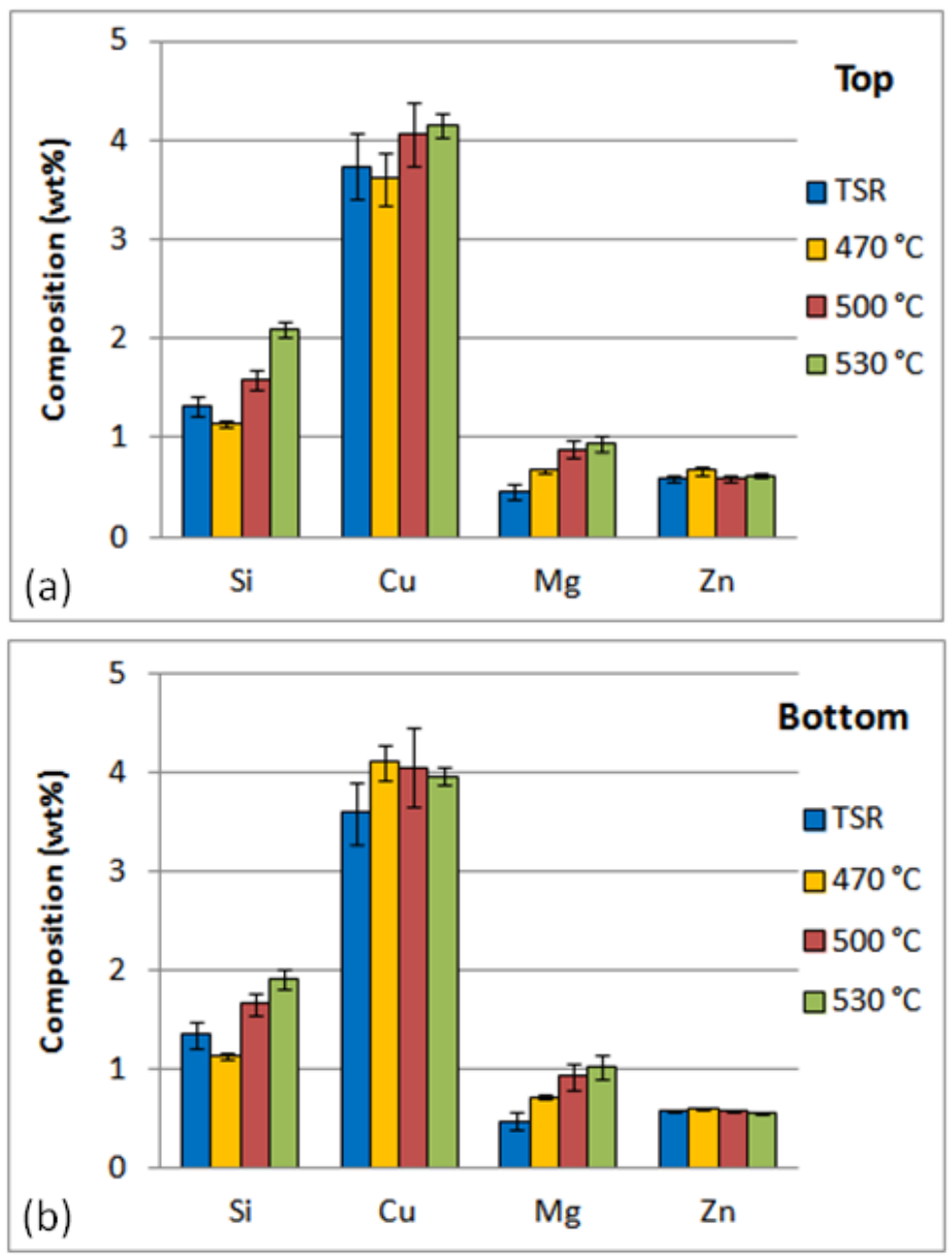

Figure 5.29: WDS analysis showing the composition of the aluminum matrix following solution heat treatment for (a) top of cylinder, (b) bottom of cylinder.

\subsubsection{Effect of Thermal Expansion on $\mathrm{d}_{0}$ Spacing}

The influence of SHT on the $\mathrm{d}_{0}$ spacing is important to establish an accurate reference point, which accounts for thermal expansion and phase dissolution, for in-situ residual strain measurements. Figure 5.30 shows the change in interplanar spacing of the Al (311) and (331) planes with increasing temperature, obtained using neutron diffraction (accuracy in d-spacing up to the fifth decimal place in angstroms). The error bars were very small relative to the scale of the measurements, and so were not shown in Figure 5.30. Furthermore, in order to isolate the influence of thermal expansion, the $\mathrm{d}_{0}$ values in Figure 5.30 are those measured during the heat up process at the beginning of heat treatment, mitigating the potential effects of phase dissolution. 


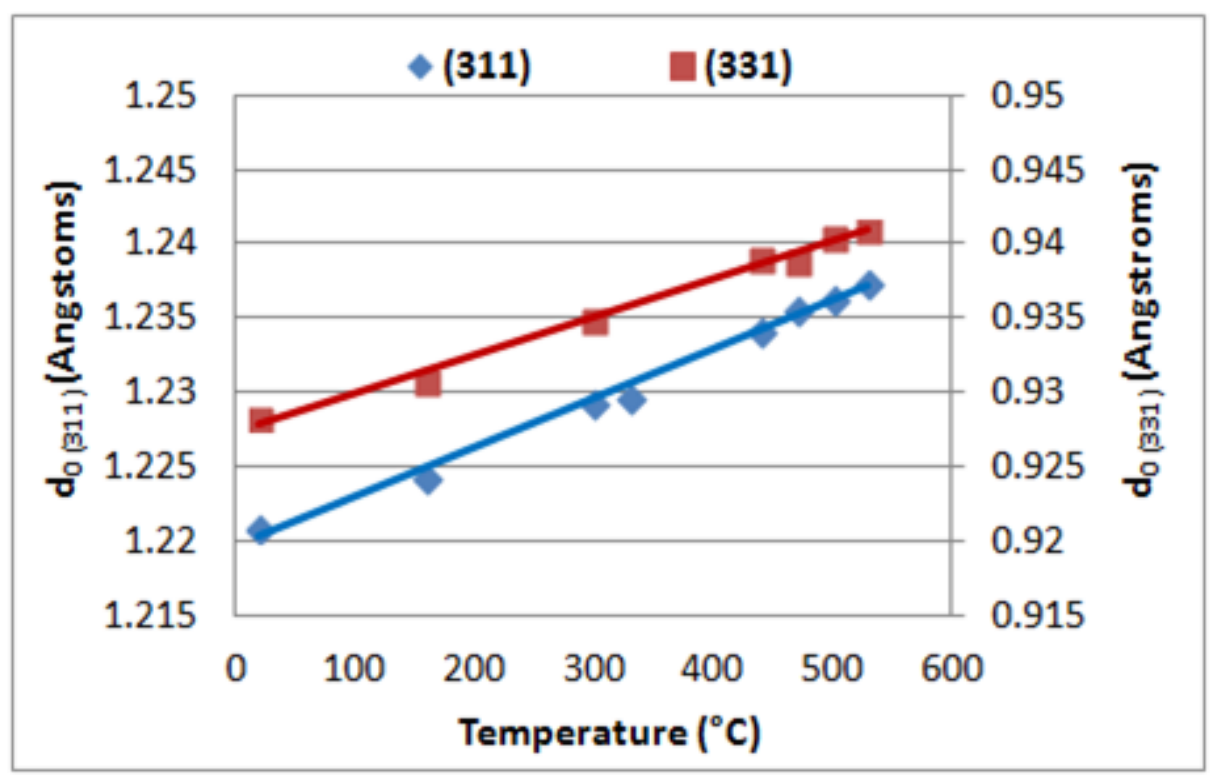

Figure 5.30: Influence of thermal expansion on $d_{0}$ for the (311) and (331) planes during solution heat treatment.

The results in Figure 5.30 suggest that the change in $\mathrm{d}_{0}$ spacing from $1.2210 \AA$ at $20{ }^{\circ} \mathrm{C}$ to $1.2374 \AA$ at $530{ }^{\circ} \mathrm{C}$ for the (311) planes was linearly related with temperature. Similarly, for the (331) planes, the change in $\mathrm{d}_{0}$ from $0.9283 \AA$ at $20{ }^{\circ} \mathrm{C}$ to $0.9411 \AA$ at $530{ }^{\circ} \mathrm{C}$ was also linearly related with temperature. This trend was observed for both the top and bottom sections of the cylinder bridge. In addition, the coefficient of thermal expansion for this modified 319 alloy was found to be approximately $25.4 \times 10^{-6} \mathrm{~m} \mathrm{~m}^{-1} \mathrm{~K}^{-1}$ when using the data obtained from the (311) planes and $25.6 \times 10^{-6} \mathrm{~m} \mathrm{~m}^{-1} \mathrm{~K}^{-1}$ using the (331) planes. When considering experimental error, these values are relatively close, illustrating that the thermal properties of these engine castings are isotropic. Furthermore, the coefficients of thermal expansion, found in this study, were higher than that previously reported for the 319 alloy $\left(23.5 \times 10^{-6} \mathrm{~m} \mathrm{~m}^{-1} \mathrm{~K}^{-1}\right) .{ }^{1}$ However, the difference in composition, compared to the standard $319 \mathrm{Al}$ alloy may have slightly influenced the thermal properties.

\subsubsection{Variation in $\mathrm{d}_{0}$ Spacing during $\mathrm{SHT}$}

The influence of microstructural modification (phase dissolution and incipient melting) on the $\mathrm{d}_{0}$ spacing for the (311) and (331) planes was also analyzed via in-situ neutron diffraction at each solutionizing temperature for approximately 8 hours. The results for the (311) planes at the top and bottom of the cylinder are shown in Figures 5.31 (a) and (b), respectively, while the results 
for the (331) planes at the top and bottom of the cylinder are shown in Figures 5.31 (c) and (d), respectively.
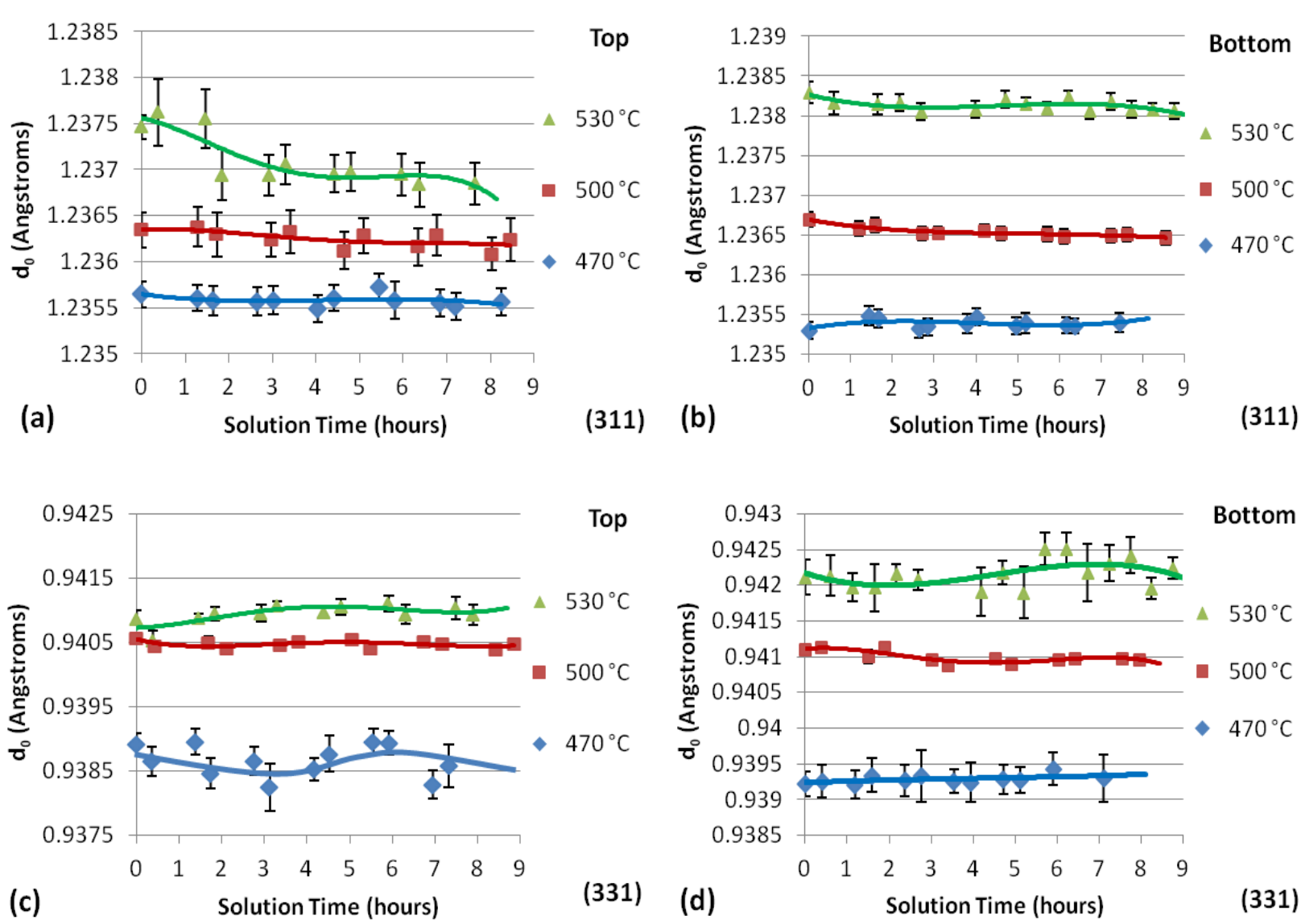

Figure 5.31: Variation in $d_{0}$ with time at each solutionizing temperature for (a) (311) plane - top of cylinder, (b) (311) plane - bottom of cylinder, (c) (331) plane - top of cylinder, (d) (331) plane - bottom of cylinder.

In-situ neutron diffraction analysis of $\mathrm{d}_{0}$ for the (311) planes indicated that SHT of the top of the cylinder at 470 and $500{ }^{\circ} \mathrm{C}$ caused minimal changes in $\mathrm{d}_{0}$ spacing with time. Conversely, heat treatment at $530{ }^{\circ} \mathrm{C}$ resulted in a relatively gradual reduction in $(311) \mathrm{d}_{0}$ spacing from $1.2376 \AA$ at the beginning of heat treatment to $1.2368 \AA$ at the end. Solution heat treatment of the bottom of the cylinder, however, did not result in a significant change in $\mathrm{d}_{0}$ for the (311) planes.

Analysis of the (331) planes at the top of the cylinder also showed that the changes in $\mathrm{d}_{0}$ with time at solutionizing temperatures of 470 and $500{ }^{\circ} \mathrm{C}$ were minimal, although there was more data scatter for the (331) planes compared to the (311) planes at the top of the cylinder for the $470{ }^{\circ} \mathrm{C}$ treatment. At $530{ }^{\circ} \mathrm{C}$, the $\mathrm{d}_{0}$ spacing of the (311) and (331) planes reacted differently to solution treatment. While the (311) planes contracted gradually with time, the (331) planes 
slightly expanded from $0.9407 \AA$ at the beginning of heat treatment to $0.9411 \AA \AA$ at the end. Similar to the (311) planes, the $\mathrm{d}_{0}$ spacing for the (331) planes did not change significantly with time during heat treatment for the bottom of the cylinder.

To explain the changes in $\mathrm{d}_{0}$ during SHT, this data was related to the microstructure and $\alpha-\mathrm{Al}$ matrix composition, observed before and after heat treatment. At the top of the cylinder, the relatively small changes in $\mathrm{d}_{0}$ for both the (311) and (331) planes while heat treating at $470{ }^{\circ} \mathrm{C}$ correlated well with the observed microstructure since there was limited $\mathrm{Al}_{2} \mathrm{Cu}$ dissolution which resulted in similar $\alpha$-Al matrix composition to the TSR condition. Similarly, at $500{ }^{\circ} \mathrm{C}$, the changes in $\mathrm{d}_{0}$ for both analysed planes were relatively small during heat treatment. However, $\mathrm{Al}_{2} \mathrm{Cu}$ dissolution and thus increased $\mathrm{Cu}$ content in the $\alpha$-Al matrix was observed at this solutionizing temperature. Therefore, the expected contraction in $\mathrm{d}_{0}$ was likely mitigated by the increased $\mathrm{Mg}$ content (dissolution of $\mathrm{Al}_{5} \mathrm{Mg}_{8} \mathrm{Cu}_{2} \mathrm{Si}_{6}$ ). This result is supported by the work of Hunsicker [5], which indicated that the lattice expansion per unit of dissolved $\mathrm{Mg}$ is higher than the contraction per unit of dissolved $\mathrm{Cu}$. As such, the higher increase in $\mathrm{Cu}$ concentration compared to $\mathrm{Mg}$ in the $\alpha$ - $\mathrm{Al}$ matrix during heat treatment at $500{ }^{\circ} \mathrm{C}$ resulted in a slight contraction with solutionizing time.

In comparison, SHT at $530{ }^{\circ} \mathrm{C}$ caused a relatively large contraction in $\mathrm{d}_{0}$ for the (311) plane and a slight expansion in $\mathrm{d}_{0}$ spacing for the (331) plane as a function of time. Since the concentration of $\mathrm{Cu}$ and $\mathrm{Mg}$ within the $\alpha$-Al matrix did not increase significantly between SHT at 500 and $530{ }^{\circ} \mathrm{C}$, these changes in lattice spacing were likely caused by incipient melting of $\mathrm{Al}_{2} \mathrm{Cu}$ and $\mathrm{Al}_{5} \mathrm{Mg}_{8} \mathrm{Cu}_{2} \mathrm{Si}_{6}$ while solutionizing at $530{ }^{\circ} \mathrm{C}$. Since these $\mathrm{d}_{0}$ measurements were performed in-situ during SHT, small pools of interdendritic liquid was present as a result of this incipient melting, which likely imparted localized stresses on the adjacent Al lattice due to volume expansion of interdendritic liquid during incipient melting. This may have influenced the measured d-spacing of the "match stick" samples. The influence of incipient melting on the $\mathrm{d}_{0}$ measurements was also supported by the fact that these contrasting trends (i.e. contraction in (311) and expansion in (331)) were only observed at $530{ }^{\circ} \mathrm{C}$, while at lower solutionizing temperatures where incipient melting did not occur, similar changes in $d_{0}$ spacing with solutionizing time was observed for both planes. 
In contrast to the top of the cylinder, the bottom did not experience significant changes in $\mathrm{d}_{0}$ spacing for both the (311) and (331) planes, which was likely due to limited dissolution of $\mathrm{Al}_{2} \mathrm{Cu}$, resulting in similar $\mathrm{Cu}$ concentration for all investigated solutionizing temperatures. In addition, the bottom of the cylinder had significantly less incipient melting at $530{ }^{\circ} \mathrm{C}$ than the top, as shown in Figure 5.27 and confirmed using DSC on replicating billet castings in Section 5.1.2.2. This explains the similar trends in the $\mathrm{d}_{0}$ profiles for both planes for the specimens extracted from the bottom of the cylinder while solutionizing at $530{ }^{\circ} \mathrm{C}$, and further supports that incipient melting influenced the $\mathrm{d}_{0}$ spacing at this temperature for the top of the cylinder.

Direct comparison between the influence of thermal expansion and microstructural modification on $\mathrm{d}_{0}$ spacing indicates that thermal expansion has a significantly larger influence on the $\mathrm{Al}$ lattice. For instance, thermal expansion resulted in $\mathrm{d}_{0}$ expansion of up to $1.3 \%$ at $530{ }^{\circ} \mathrm{C}$ (compared to ambient temperature). Microstructural modification on the other hand accounted for (311) $\mathrm{d}_{0}$ contractions of up to $0.065 \%$ and (331) $\mathrm{d}_{0}$ expansion of $0.043 \%$ at $530{ }^{\circ} \mathrm{C}$. The relatively limited phase transformation induced changes in $d_{0}$ were due to the small changes in solute concentration in the $\alpha-\mathrm{Al}$ dendrites during heat treatment, whereas the high temperatures associated with SHT resulted in a large influence from thermal expansion.

\section{Section Summary}

This section utilized in-situ neutron diffraction to determine the change in $\mathrm{d}_{0}$ spacing as a function of time at different SHT temperatures and develop a robust reference point for strain analysis. It was determined that thermal expansion had a larger influence on $\mathrm{d}_{0}$ spacing than the time dependant phase dissolution or microstructural modification associated with SHT. This was likely due to a combination of a small increase in solute concentration during heat treatment (due to dissolution of $\mathrm{Cu}$ and $\mathrm{Mg}$ bearing secondary phase particles) and the opposing effects of additional $\mathrm{Cu}$ (contraction) and $\mathrm{Mg}$ (expansion) in solid solution with Al. Furthermore, microstructural analysis confirmed that solutionizing at $530{ }^{\circ} \mathrm{C}$ resulted in incipient melting. For this reason, in-situ strain analysis was only carried out at 470 and $500{ }^{\circ} \mathrm{C}$, as shown in Section 5.2.2. 


\subsubsection{In-situ Residual Strain Analysis during SHT}

In this sub-section, the results from in-situ neutron diffraction residual strain analysis are discussed. The transient residual strain relief profiles during SHT are examined in Section 5.2.2.1, while residual strain development as a function of temperature during post-heat treatment cooling is shown in Section 5.2.2.2.

\subsubsection{Residual Strain Relief during Elevated Temperature Soaking}

\subsection{SHT Temperature $470^{\circ} \mathrm{C}$}

In-situ neutron diffraction was used to analyze the relief of residual axial strain as a function of time during SHT. The results are shown in Figure 5.32. To calculate strain, the measured $d_{0}$ values from Figure 5.31 were used (not the trendline) for each corresponding soaking time. Linear interpolation of this data was used for time periods where the strain readings did not correspond directly to an associated $\mathrm{d}_{0}$.

For the $470{ }^{\circ} \mathrm{C}$ heat treatment, the axial strain decreased slightly during engine heat up from 1500 microstrain in the TSR condition to 1400 microstrain following $0.3 \mathrm{~h}$ at the soaking temperature (plus approximately $1.1 \mathrm{~h}$ of heating to this temperature). Subsequently, the residual strain decreased from 1400 to 800 microstrain for the time period between 0.3 and $0.7 \mathrm{~h}$, suggesting an increased rate of strain relief compared to during heat up. For the time period between 1 and 4.25 $\mathrm{h}$, a more gradual and linear relief of strain occurred until all tensile strain was completely relaxed. At higher soaking times, the strain remained relatively constant with a slightly compressive magnitude of approximately 150 microstrain.

It is important to note that due to the high temperatures (close to or exceeding alloy solidus temperature of $495{ }^{\circ} \mathrm{C}$ ) involved with these experiments, the intensity of the Bragg peaks were significantly reduced due to the Debye-Waller factor [111], resulting in strain values scattered around the trend line with relatively large error bars.

Solution heat treatment at $470{ }^{\circ} \mathrm{C}$ resulted in a negligible relief of strain instantaneously during engine heat up as elucidated by the small difference in strain magnitude between the pre-SHT condition and the first strain reading $(\mathrm{t}=0.3 \mathrm{~h})$. However, it is well established that the YS of the 
Al alloys decreases with increased temperature due to the weakening of interatomic bonds, specifically when the alloy solidus temperature is approached. Therefore, the minimal strain relief during heat up may have been as a result of the gray iron liners (which remain relatively rigid at this temperature compared to the surrounding $\mathrm{Al}$ alloy) reinforcing the cylinder bridge region, minimizing the associated instantaneous plastic deformation that accompanies relief of residual stress and strain.

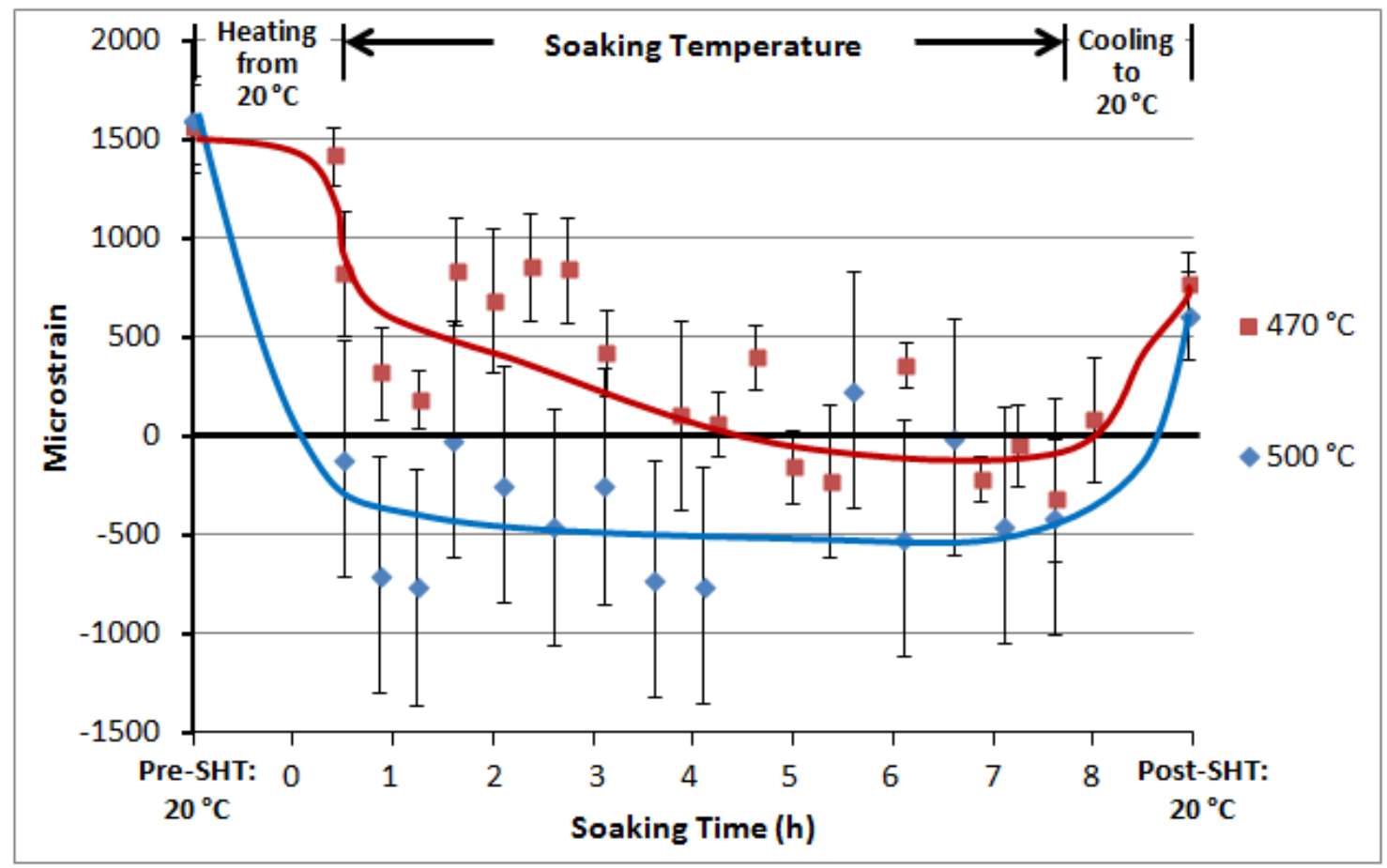

Figure 5.32: Axial residual strain relief as a function of time during solution heat treatment of Al engine blocks.

The residual strain relief profile while solutionizing at $470{ }^{\circ} \mathrm{C}$ suggests that relief was predominantly caused by creep due to the gradual, time dependant nature of the strain relief. Creep deformation, although plastic in nature and cannot be directly measured with neutron diffraction, is accompanied by the gradual relaxation of elastic strain, which was detected in Figure 5.32. In addition, Figure 5.32 indicates a high initial strain relief rate within the first hour at the soaking temperature (average of 1400 microstrain/hour), which was followed by a slower rate of strain relief (average of $\sim 180$ microstrain/hour) thereafter, until approximately $4.25 \mathrm{~h}$ where all tensile strains were relieved. The strain relief profile in Figure 5.32 is similar to that of the relatively rapid initial deformation profile associated to primary creep, followed by a slower and relatively linear profile from steady-state (secondary) creep. 
Although it is widely accepted that primary and secondary creep are predominantly responsible for the relief of residual strain during heat treatment [83, 85-87] several creep mechanisms are possible. To further investigate and predict the creep mechanisms responsible for relief of residual strain during SHT at $470{ }^{\circ} \mathrm{C}$, a creep deformation-mechanism map for pure Al (Figure 5.33), developed by Frost and Ashby [112], was consulted. While not completely representative of the $319 \mathrm{Al}$ alloy, this map allowed the general creep mechanism to be determined based on the applied (residual) stress level and specimen temperature. The use of this map required an estimate of the residual stress $(\sigma)$ and its associated maximum shear stress $(\tau)$ value. This shear stress was then normalized to the shear modulus $(\mathrm{G})$ of the $319 \mathrm{Al}$ alloy at $470{ }^{\circ} \mathrm{C}$ (determined as approximately $15.25 \mathrm{GPa}$ using data provided by Dr. D. Sediako, NRC-Canadian Neutron Beam Centre).

The principal axial stress was estimated (Equation 14) using a ratio between the current $\left(\varepsilon_{\mathrm{A}}\right)$ and initial $\left(\varepsilon_{0}\right)$ axial strain, which was then related to the initial (pre-SHT) axial stress $\left(\sigma_{0, \mathrm{~A}}\right)$, measured using neutron diffraction (Section 5.2.3). This value was then multiplied by the ratio between the modulus of elasticity at $470{ }^{\circ} \mathrm{C}\left(\mathrm{E}_{\mathrm{HT}}\right)$ and that at ambient temperature $\left(\mathrm{E}_{\mathrm{AT}}\right)$ to compensate for the reduction in alloy stiffness from increased temperature. This calculation assumed that the residual strain in the hoop and radial directions relieved proportionally to the axial strain observed in Figure 5.32 (equipment constraints prevented simultaneous hoop, axial and radial measurements directly during heat treatment). Under the same assumption, the hoop and radial stresses were also estimated using Equation 14. The change in axial strain and the calculated (estimated) principal residual stresses at various soaking times are shown in Table 5.1.

$$
\sigma_{H, R, A}=\frac{\varepsilon_{A}}{\varepsilon_{0}} \frac{E_{H T}}{E_{A T}} \sigma_{0, H, R, A}
$$

The creep deformation mechanism map required the normalized shear stress. For this reason, the estimated principal stresses were converted to its associated maximum shear stress using Mohr's circle (sample calculation shown in Appendix H). Although three-dimensional analysis results in three shear stress values, the maximum shear stress was selected and used in the calculation of the normalized shear stress since this maximum value likely had the largest influence on creep (shown in Table 5.1). 
Table 5.1: Estimated residual stresses in principal direction along with maximum shear stress and normalized shear stress for each heat treatment time $\left(\mathrm{SHT} 470{ }^{\circ} \mathrm{C}\right)$.

\begin{tabular}{|c|c|c|c|c|c|c|}
\hline & \multicolumn{3}{|c|}{ Estimated from Equation (14) } & & \\
\hline $\begin{array}{c}\text { Soaking } \\
\text { Time (h) }\end{array}$ & $\begin{array}{c}\boldsymbol{\varepsilon}_{\mathbf{A}} \text { from } \\
\text { Trendline } \\
\text { (microstrain) }\end{array}$ & $\begin{array}{c}\boldsymbol{\sigma}_{\mathbf{A}} \\
(\mathbf{M P a})\end{array}$ & $\begin{array}{c}\boldsymbol{\sigma}_{\mathbf{H}} \\
(\mathbf{M P a})\end{array}$ & $\begin{array}{c}\boldsymbol{\sigma}_{\mathbf{R}} \\
(\mathbf{M P a})\end{array}$ & $\begin{array}{c}\boldsymbol{\tau}_{\max } \\
(\mathbf{M P a})\end{array}$ & $\begin{array}{c}\text { Normalized } \\
\text { Shear Stress } \\
(\boldsymbol{\tau} / \mathbf{G})\end{array}$ \\
\hline Pre-SHT & 1560 & 205 & 215 & 90 & 63 & - \\
\hline 0.35 & 1420 & 107 & 112 & 47 & 33 & $2.2 \times 10^{-3}$ \\
\hline 0.65 & 825 & 62 & 66 & 28 & 19 & $1.3 \times 10^{-3}$ \\
\hline 1.0 & 615 & 47 & 49 & 20 & 15 & $9.8 \times 10^{-4}$ \\
\hline 2.0 & 420 & 32 & 33 & 14 & 10 & $6.6 \times 10^{-4}$ \\
\hline 3.0 & 260 & 20 & 21 & 9 & 6 & $3.9 \times 10^{-4}$ \\
\hline 3.9 & 110 & 8 & 9 & 4 & 3 & $2.0 \times 10^{-4}$ \\
\hline 4.25 & 60 & 5 & 5 & 2 & 2 & $1.3 \times 10^{-4}$ \\
\hline
\end{tabular}

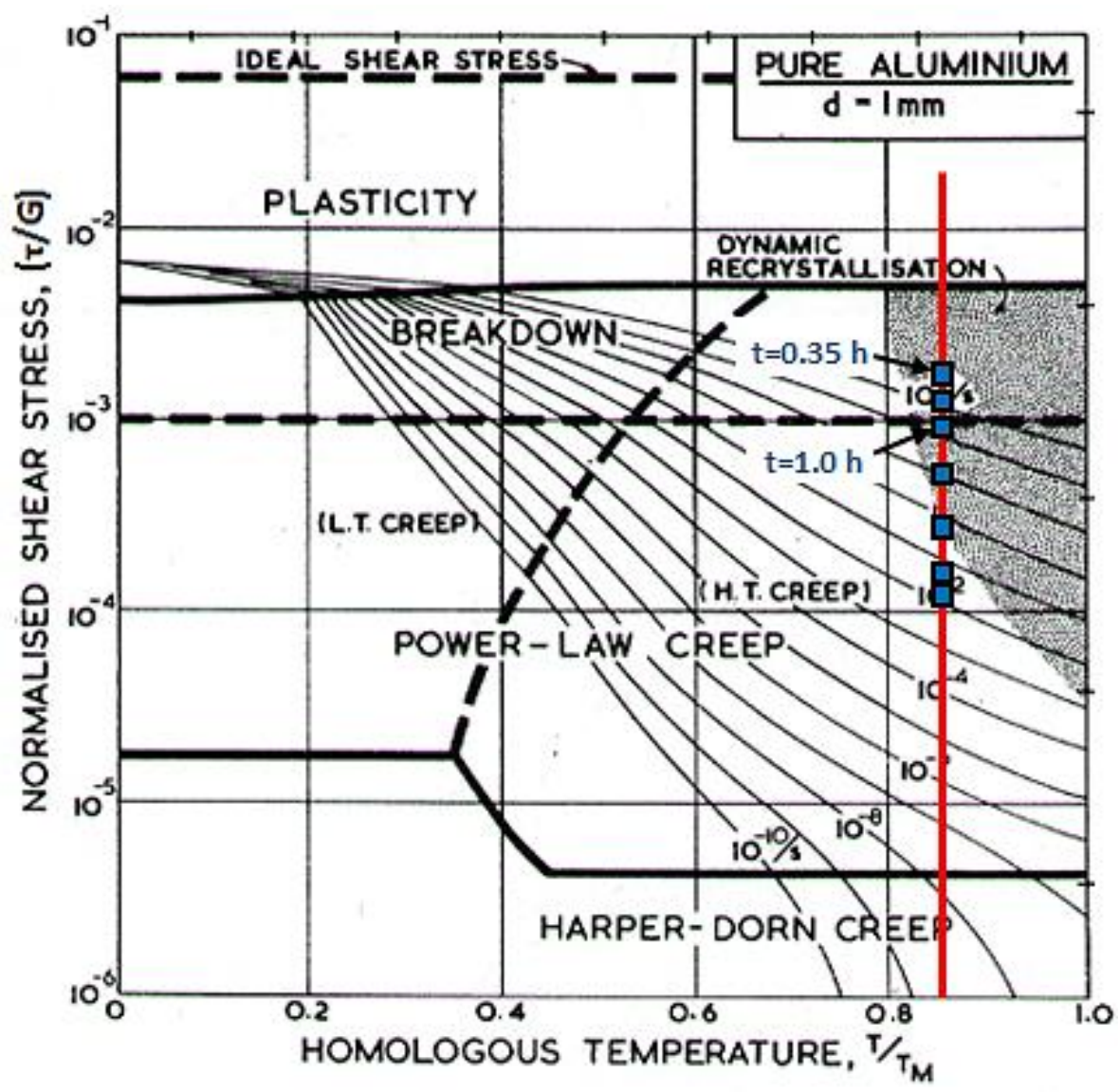

Figure 5.33: Creep Deformation-mechanism maps for pure Al with grain size of $1000 \mu \mathrm{m}$ [112].

The normalized shear stresses from Table 5.1 were plotted on the deformation mechanism map in Figure 5.33 at a homologous temperature $\left(\mathrm{T} / \mathrm{T}_{\mathrm{m}}\right.$ ) of approximately 0.85 (when using the liquidus 
temperature of $868 \mathrm{~K}\left(595{ }^{\circ} \mathrm{C}\right)$ in place of the melting temperature). These results indicate that the dislocation creep mechanism, which progresses by dislocation glide and aided by dislocation climb, was probably responsible for relief of residual strain throughout the SHT process. In addition, Figure 5.33 also suggests that due to the relatively high normalized shear stress and homologous temperature, strain relief initially followed the power-law breakdown relationship (subsection of dislocation creep), which proceeded until approximately $1 \mathrm{~h}$ of solutionizing. Following approximately $1 \mathrm{~h}$ of solutionizing, the creep mechanism map indicates that the reduction in residual stress with increased solutionizing time likely caused a transition to the power-law creep relationship, which is another subsection of the dislocation creep mechanism. This transition to power-law creep may have also reduced creep rate since the strain relief rate was slower for solutionizing times greater than $1 \mathrm{~h}$. However, it is unknown if this reduction in strain relief rate was predominantly caused by the transition to power-law relationship or if it was due to the transition from primary to steady-state creep. For solutionizing times above $4.25 \mathrm{~h}$, the complete relief of tensile strain prevented any further creep, as evidenced by the near zero strains for the remainder of SHT.

The relief of residual stresses and strains was observed during heat treatment by Rolph et al. [83] (in-situ, neutron diffraction) and Godlewski et al. [87] (ex-situ, strain gauges), although the rate of stress relief was significantly lower in these studies compared to the current research due to the lower homologous temperatures associated to artificial aging. This further supports that creep was responsible for strain relief as creep rate is exponentially dependant on temperature. Therefore, the higher creep rates translate into significantly faster strain relief in the current research compared to that of Rolph et al. [83] and Godlewski et al. [87]. It is important to note that Godlewski et al. [87] also attributed relief of residual stress and strain to the dislocation creep mechanism, as was suggested in the current research.

Although this analysis, based on homologous temperature and normalized stress, enabled the estimation of the creep mechanism responsible for residual stress and strain relief, additional research on creep of this alloy at temperatures and stress levels close to those observed in this in-situ heat treatment experiment are required. The determination of the creep rate resulting from each creep mechanism is necessary to confirm the mechanisms responsible for residual stress relief during heat treatment and develop accurate predictive models. 


\subsection{SHT Temperature $500^{\circ} \mathrm{C}$}

Solution heat treatment at $500{ }^{\circ} \mathrm{C}$ resulted in a more rapid relief of residual axial strain compared to the $470{ }^{\circ} \mathrm{C}$ soaking temperature, as shown in Figure 5.32. For instance, the residual strain reduced from approximately 1600 microstrain prior to SHT (TSR condition) to approximately zero following $0.5 \mathrm{~h}$ at $500{ }^{\circ} \mathrm{C}$ (plus approximately $1.25 \mathrm{~h}$ of heating to this temperature). Furthermore, increased time at this soaking temperature resulted in the development of compressive strain with a magnitude of approximately 500 microstrain.

For this experiment, the estimation of the creep mechanism responsible for strain relief, similar to Section 5.2.2.1.1, could not be carried out since all strain was relieved prior to the first strain measurement from neutron diffraction. However, based on the observations from the $470{ }^{\circ} \mathrm{C} \mathrm{SHT}$ experiment, it can be deduced that similar mechanisms were responsible for residual strain relief at $500{ }^{\circ} \mathrm{C}$. For instance, it is unlikely that the complete relief of strain was instantaneous since the gray iron liners were still relatively rigid at this temperature, preventing large scale plastic deformation in the cylinder bore region. The higher temperature may have led to increased thermal softening, which allowed more instantaneous strain relief than found at $470{ }^{\circ} \mathrm{C}$, but not likely complete relief. This indicates that creep was probably responsible for a large portion of the residual strain relief. Furthermore, it is well established that creep rate is greatly accelerated by the increased temperature due to increased diffusion rate and thermal softening of the alloy. For this reason, a significantly accelerated creep rate, compared to SHT at $470{ }^{\circ} \mathrm{C}$, likely resulted in all strain being relieved in less than $0.5 \mathrm{~h}$ (first strain measurement in Figure 5.32).

It is also important to note that SHT at $500{ }^{\circ} \mathrm{C}$ led to a larger magnitude of compressive strain than at $470{ }^{\circ} \mathrm{C}$, following the relaxation of all tensile strain. This was due to increased restriction to free expansion imposed on $\mathrm{Al}$ by the gray iron liners. The restriction to free $\mathrm{Al}$ alloy expansion was the result of small ribs throughout the depth of the cylinder which were intended to provide mechanical interlocking between the liners and the Al cylinder bore. However, since gray iron expands more slowly than $\mathrm{Al}$, these ribs restricted $\mathrm{Al}$ thermal expansion at high temperature, which developed compressive thermal strain. To further support this reasoning, the difference in thermal strain between the $470\left(\mathrm{~T}_{1}\right)$ and $500{ }^{\circ} \mathrm{C}\left(\mathrm{T}_{2}\right)$ heat treatments $(\Delta \varepsilon)$ was calculated (Equation 15-a) using the thermal strain equation (Equation 15-b) that accounts for the difference 
of thermal expansion coefficient between the $\mathrm{Al}\left(\alpha_{\mathrm{Al}}=2.74 \times 10^{-5} \mathrm{~K}^{-1}[78]\right)$ and the gray iron liners $\left(\alpha_{\mathrm{Fe}}=1.6 \times 10^{-5} \mathrm{~K}^{-1}[78]\right)$ at these temperatures.

$$
\begin{gathered}
\Delta \varepsilon=\varepsilon\left(T=500{ }^{\circ} \mathrm{C}\right)-\varepsilon\left(T=470{ }^{\circ} \mathrm{C}\right) \\
\Delta \varepsilon=\left(\alpha_{A l}-\alpha_{F e}\right)\left(T_{2}-T_{1}\right)
\end{gathered}
$$

This calculation resulted in an additional 340 microstrain at $500^{\circ} \mathrm{C}$ compared to $470{ }^{\circ} \mathrm{C}$, due to the difference in thermo-mechanical mismatch at the Al-Fe interface between these two solutionizing temperatures. This calculated value was close to the difference in compressive strain found during SHT at 470 and $500{ }^{\circ} \mathrm{C}$ (Figure 5.32), supporting that the additional compression at $500{ }^{\circ} \mathrm{C}$ was due to increased restriction to $\mathrm{Al}$ expansion by the gray iron liners. The magnitude of compressive strain at the end of heat treatment is an important consideration influencing the post-heat treatment residual strain and stress magnitude, as discussed in Sections 5.2.2.2 and 5.2.3.

\subsubsection{Residual Strain Development during Cooling}

The results in Figure 5.32 indicate that although SHT completely relaxed tensile residual strain within the cylinder bridge for both investigated solutionizing temperatures, post-heat treatment cooling to ambient temperature caused the development of tensile residual strain. For instance, the engine blocks heat treated at 470 and $500{ }^{\circ} \mathrm{C}$ had tensile residual strains of approximately 800 and 600 microstrain, respectively following SHT. The difference in strain between these engine blocks was likely influenced by the strain level prior to cooling. In the case of the engine block heat treated at $470{ }^{\circ} \mathrm{C}$, the strain value was slightly compressive ( 150 microstrain) prior to cooling. In contrast, the engine block heat treated at $500{ }^{\circ} \mathrm{C}$ had a compressive strain magnitude of approximately 500 microstrain. The superposition between the tensile strain developed during engine block cooling and the compressive strain prior to cooling resulted in a lower axial strain magnitude at ambient temperature for the engine block solutionized at $500{ }^{\circ} \mathrm{C}$.

To further investigate the development of tensile residual strain during cooling, in-situ neutron diffraction was used to quantify strain development as a function of temperature, as shown in Figure 5.34. Engine block cooling was performed while wrapped in kaowool insulation, resulting 
in cooling rates of less than $1{ }^{\circ} \mathrm{C} /$ minute. Therefore, the residual stress and strain development can be assumed to be due to thermo-mechanical mismatch between the Al engine block and the gray iron liners, since thermal gradients were minimized.

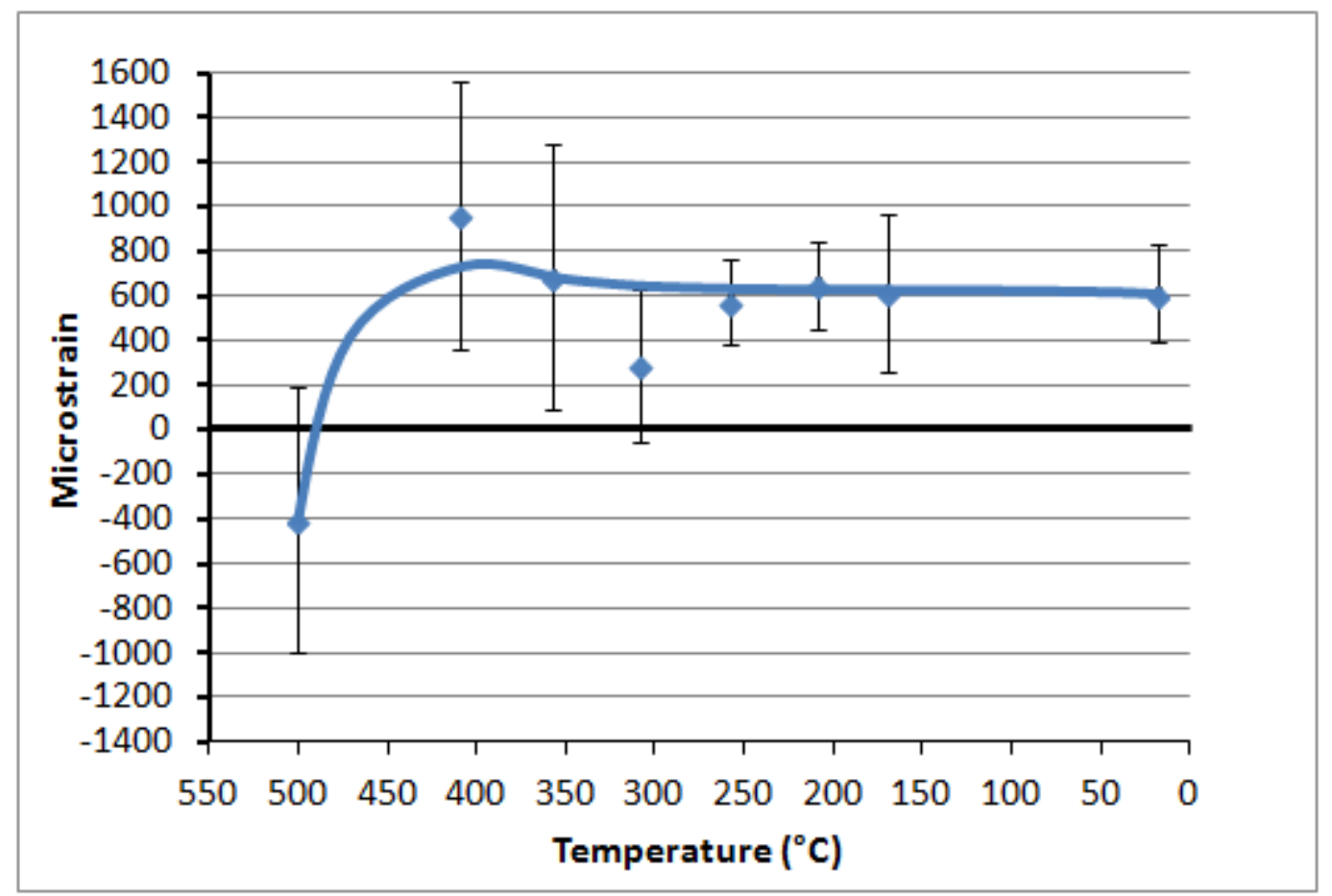

Figure 5.34: Axial residual strain development as a function of temperature during post-heat treatment cooling.

Figure 5.34 indicates that cooling from 500 to $400{ }^{\circ} \mathrm{C}$ resulted in the development of tensile residual strain. In this temperature segment, the strain changed from compressive to tensile with magnitudes of 400 and 900 microstrain, respectively. Further cooling down to ambient temperature resulted in a relatively constant strain magnitude of approximately 600 microstrain. Due to the large error associated with these measurements, it was assumed that the strain does not change significantly with reduced temperature below $350{ }^{\circ} \mathrm{C}$.

The initial transition from compressive strain to tensile strain near the beginning of the cooling process was due to the interaction between the gray iron cylinder liners and the surrounding 319 $\mathrm{Al}$ alloy. At the end of high temperature solutionizing, the strain in the cylinder bridge was compressive due to the restriction of free $\mathrm{Al}$ expansion, as described in Section 5.2.2.1. During initial cooling, however, this compressive strain was released and tensile strain developed since there was a restriction to free $\mathrm{Al}$ contraction imposed by the gray iron cylinder liners. 
Creep may have also influenced how the residual axial strain developed during post-heat treatment cooling. According to Equation 15-b, residual strain generation due to thermomechanical mismatch should occur linearly with temperature, which results in an ever-increasing strain magnitude with decreasing temperature. However, as observed in Figure 5.34, the strain magnitude reached a plateau at approximately $400{ }^{\circ} \mathrm{C}$ and was relatively constant for the remainder of the cooling process. This was likely caused by significant redistribution of the generated tensile strain via creep, as the engine block was exposed to high temperatures for prolonged time periods (the time between each point in Figure 5.34 was greater than $1 \mathrm{~h}$ ). Equation 16 shows the typical relationship for steady-state creep rate $(\dot{\varepsilon})$ [62], which was used to illustrate the exponential dependence of both stress and temperature on creep rate. It is important to note that this analysis is qualitative and additional research on creep of this $319 \mathrm{Al}$ alloy is required to determine the appropriate creep mechanism, quantify the creep rates and further support this hypothesis.

$$
\dot{\varepsilon}=K \sigma^{n} e^{\left(\frac{-Q_{c}}{R T}\right)}
$$

Where, $\mathrm{K}$ is a material constant, $\mathrm{n}$ is the stress exponent ( 4.4 for $\mathrm{Al}[113]), \sigma$ is the residual stress magnitude, $\mathrm{Q}_{\mathrm{c}}$ is the activation energy for creep (approximated as $144 \mathrm{~kJ} / \mathrm{mol}$, which is the activation energy for self-diffusion of Al [113]), $\mathrm{R}$ is the gas constant and $\mathrm{T}$ is the specimen temperature (in absolute units).

Based on the data in Figure 5.34 and the creep relationship in Equation 16, it can be postulated that the very low tensile residual strain immediately following elevated temperature soaking likely prevented a large influence of creep initially, permitting a rapid generation of tensile residual strain. However, as the tensile strain developed, creep became more prominent specifically in the $400{ }^{\circ} \mathrm{C}$ range which had a combination of high stress and temperature. This is shown qualitatively in Figure 5.35, which plots the creep rate using Equation 16 at temperatures and stresses found in Figure 5.34 (strain was correlated to stress in similar fashion to Table 5.1). This plot is qualitative since creep data is required to accurately determine the material constants $\left(\mathrm{K}, \mathrm{n}\right.$ and $\left.\mathrm{Q}_{\mathrm{c}}\right)$ for this alloy under similar conditions. It can therefore be reasoned, that this high creep rate, coupled with the significant time at high temperature caused a plateau in the tensile residual strain development curve. It can also be deduced that at lower temperatures there was 
likely a limit to the amount of strain developed by thermo-mechanical mismatch, as was observed by Reihle et al. [79]. This explains why the strain magnitude continued to remain constant even though the influence of creep exponentially reduced at these temperatures.

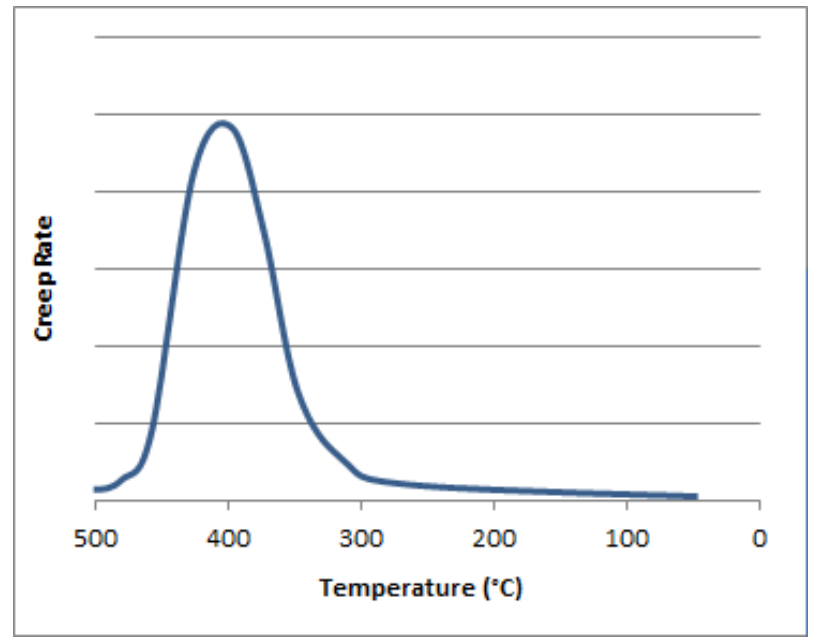

Figure 5.35: Qualitative representation of creep rate using the temperatures and residual stress levels from neutron diffraction in the creep equation.

The strain development profile in Figure 5.34 was significantly different than that observed by Reihle et al. [79] (shown in Figure 2.17), which examined hoop strain development as a function of temperature during casting of $319 \mathrm{Al}$ alloy around a cylindrical steel sleeve, inserted into both sand and steel moulds. Reihle et al. [79] found that cooling between 350 and $250{ }^{\circ} \mathrm{C}$, resulted in a relatively linear increase in strain while between 250 and $150{ }^{\circ} \mathrm{C}$, the strain generation rate plateaued, resulting in minimal additional strain. However, in the experiments of Reihle et al. [79], the cooling rate between 350 and $150{ }^{\circ} \mathrm{C}$ averaged to approximately $8{ }^{\circ} \mathrm{C} /$ minute for the sand mould and $40{ }^{\circ} \mathrm{C} /$ minute in the steel mould, which did not give sufficient time at elevated temperature for creep to balance the development of tensile stress. This permitted a more gradual development of strain due to thermo-mechanical mismatch, as opposed to the observations in the current study.

Previous research by Carrera et al. [78] and Su et al. [80] had postulated that the large difference in thermal expansion coefficient between $\mathrm{Al}$ and gray iron leads to tensile stress development in $\mathrm{Al}$ engine blocks containing gray iron cylinder liners during cooling (following casting or heat treatment). The results from this study confirms this theory, however, further research is required to generate additional data enabling confirmation that creep indeed influenced stress 
development, as well as observe the influence of cooling rate on stress development as a function of temperature during quenching.

\section{Section Summary}

In-situ neutron diffraction was used in this section to develop an in-depth understanding of residual strain relief as a function of time during SHT. It was found that for both solutionizing temperatures, residual strain was completely relieved, although relief was greatly accelerated at $500{ }^{\circ} \mathrm{C}$ compared to $470{ }^{\circ} \mathrm{C}$. Based on the normalized shear stress and homologous temperatures, the relief mechanism was postulated to be dislocation creep, specifically the power-law breakdown relationship initially followed by a transition to the power-law relationship. It was also theorized that the gray iron cylinder liners influenced the relief of strain in Al by preventing instantaneous strain relief during engine heating.

This section also applied in-situ neutron diffraction to quantify the development of tensile strain as a function of temperature during post-heat treatment cooling. The strain was found to develop at high temperatures and remain relatively constant for the remainder of the cooling process. It is proposed that the strain generation profile was due to a competing process between strain development from thermo-mechanical mismatch and strain redistribution/relief due to creep.

The main limitations of this analysis were that it was confined to a single location (depth of 50 $\mathrm{mm}$ ) within the cylinder bridge and only one strain component (axial) was measured. To address these limitations, Section 5.2.3 presents the results from ex-situ neutron diffraction, which was used to map the residual stress along the cylinder in the hoop, radial and axial orientations and develop an understanding of residual stress relaxation in other locations of the cylinder bridge.

\subsubsection{Ex-situ Residual Stress Analysis}

This sub-section analyzed the post-heat treatment residual stress profiles using ex-situ neutron diffraction. Sections 5.2.3.1 and 5.2.3.2 examined the residual stress profiles along the cylinder bridge prior to and following the in-situ SHT analysis respectively, while Section 5.2.3.3 discussed the residual stress profiles in a production T4 treated engine block. 


\subsubsection{Residual Stress Prior to In-situ SHT}

Residual stress was measured from top to bottom of the cylinder bridge prior-to and following the in-situ strain analysis during SHT that was discussed in Section 5.2.2. The results showing the residual stress maps for the engine blocks prior to SHT at 470 and $500{ }^{\circ} \mathrm{C}$ are shown in Figures 5.36 (a) and (b) respectively. These engine blocks are denoted as TSR A and B, respectively.

The residual stress profiles for engine blocks TSR A and B indicate relatively high tensile stress, specifically in the hoop and axial orientations. For both these engine blocks, the hoop direction had the highest tensile stress magnitude followed by the axial and radial stress components. Furthermore, TSR B had a higher tensile stress magnitude compared to TSR A. This is illustrated by the hoop stress in TSR B varying around the 200-250 MPa range throughout the cylinder bridge, while that of TSR A varied between 160 and $200 \mathrm{MPa}$ along the cylinder. Similarly, the axial stress in engine TSR B varied between 130 and $190 \mathrm{MPa}$ along the depth of the cylinder, while for TSR A it varied between 100 and $150 \mathrm{MPa}$. The radial stress varied between $50 \mathrm{MPa}$ tensile and $50 \mathrm{MPa}$ compressive throughout the depth of the cylinder bores for both engine blocks. The difference in residual stress magnitude between these engine blocks (exposed to the same processing history) was likely due to the variability of the manufacturing process between

produced components, as the stress profiles have similar trends and when considering the error in measurements, similar magnitudes of stress.

The relatively high tensile residual stress in the TSR engine blocks indicates that there was significant restriction to free-Al alloy contraction imposed by the gray iron cylinder liners following solidification. The hoop orientation had the largest restriction to free $\mathrm{Al}$ contraction as evidenced by the largest tensile residual stress magnitude. This was due to tangential restriction to $\mathrm{Al}$ contraction along the circumference of the gray iron liners throughout the cylinder. The axial orientation contains tensile residual stress due to restriction to contraction by anchors (ribs) throughout the cylinder, designed to mechanically lock the liners into place within the cylinder bores. Finally, the radial component, since there is no mechanical restriction to free Al contraction in this orientation and due to the small section thickness, did not have a significant build-up of residual stress, which is manifested by low tensile stress magnitudes in the TSR condition. 
The restriction to free $\mathrm{Al}$ contraction was expected as the gray iron cylinder liners were cast-in, which as Carrera et al. [78] discovered, lead to large tensile residual stress generation during casting. Carrera et al. [78] also found that the gray iron liners that were press-fit into the cylinder bores following casting had compressive stress in the cylinder bore region of the engine block. This further supports the argument that thermo-mechanical mismatch was the largest contributor to tensile stress development in the cylinder bore region of these engine blocks during cooling.

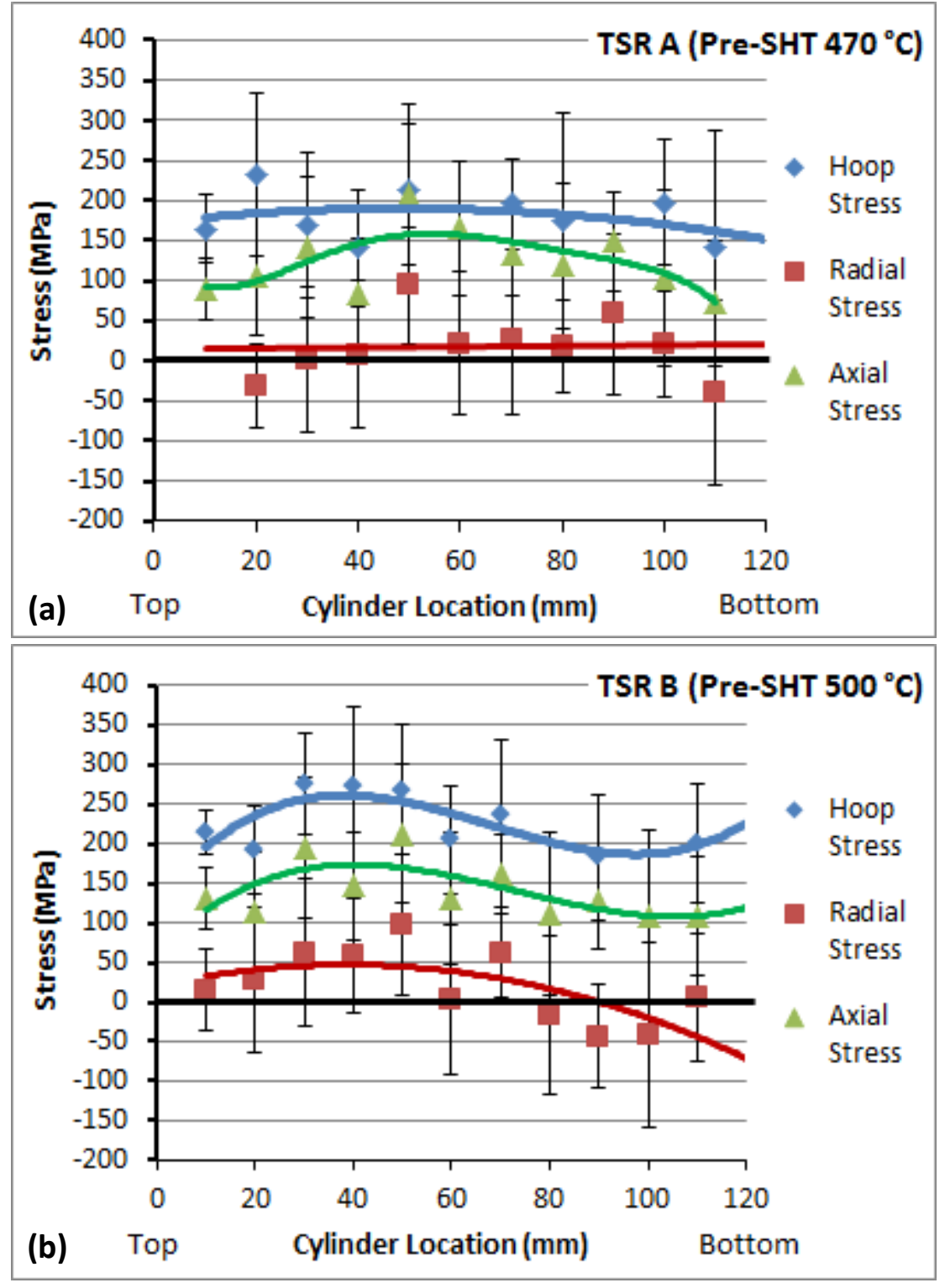

Figure 5.36: Residual stress profiles for: (a) TSR A, (b) TSR B. 


\subsubsection{Residual Stress Following In-situ SHT}

At the conclusion of the in-situ strain analysis during SHT and the subsequent cooling to ambient temperature, residual stress was measured from top to bottom of the cylinder bridge in the hoop radial and axial directions. The residual stress profiles for the engine blocks solutionized at 470 and $500{ }^{\circ} \mathrm{C}$ are shown in Figures 5.37 (a) and (b) respectively. It is important to note that the engine blocks solutionized at 470 and $500{ }^{\circ} \mathrm{C}$ are the same blocks as those denoted TSR A and B, respectively in Section 5.2.3.1.

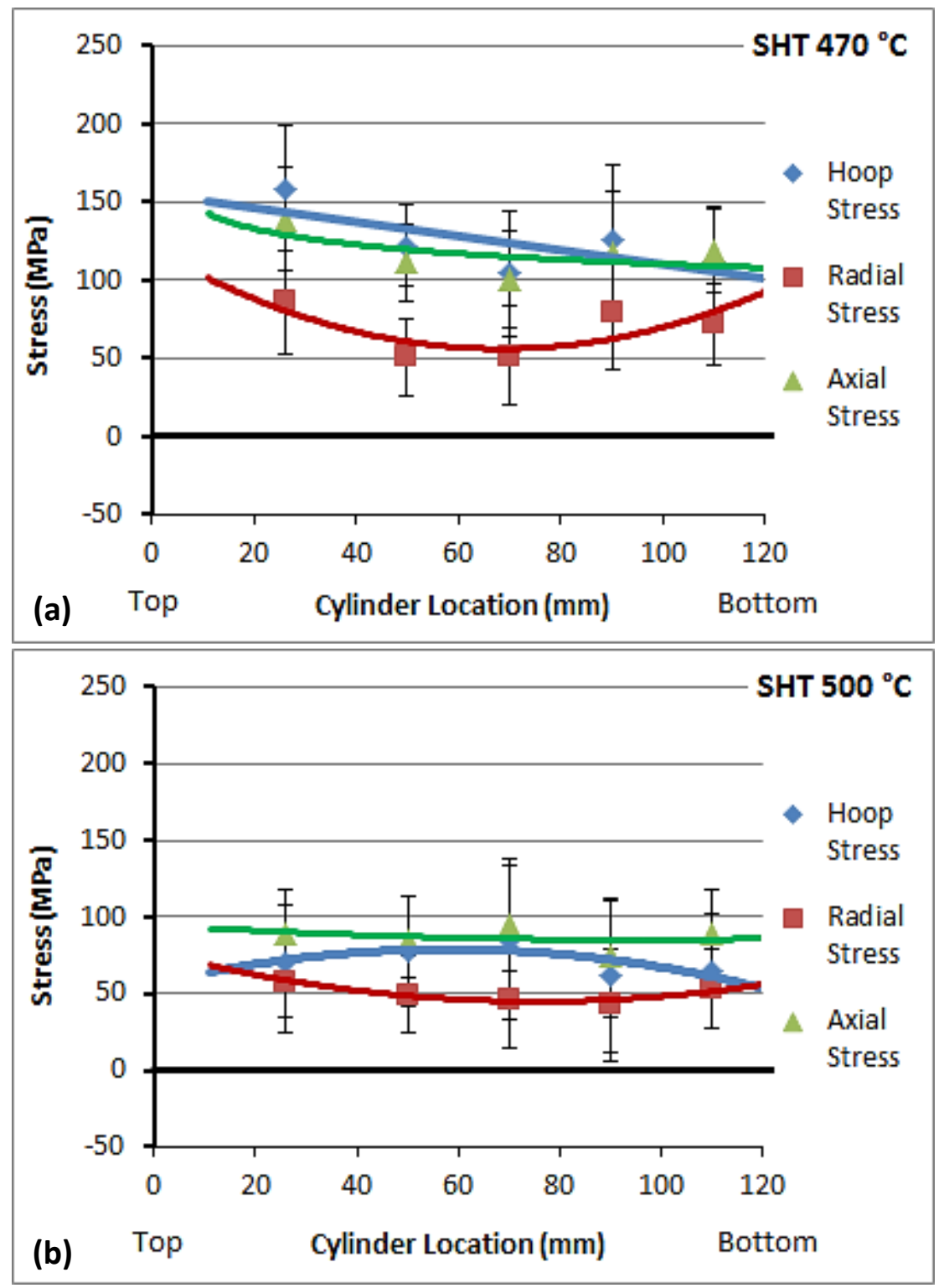

Figure 5.37: Residual stress profiles for the engine blocks following SHT at (a) $470{ }^{\circ} \mathrm{C}$, (b) $500{ }^{\circ} \mathrm{C}$. 
The residual stress profiles following SHT at $470{ }^{\circ} \mathrm{C}$ (Figure 5.37 (a)) indicate a large reduction in tensile stress compared to the pre-SHT (TSR A) condition. The hoop stress in the cylinder bridge following SHT at $470{ }^{\circ} \mathrm{C}$ had a tensile stress magnitude of approximately $150 \mathrm{MPa}$ near the top of the cylinder, which decreased gradually to $110 \mathrm{MPa}$ at the bottom of the cylinder. Similarly, the tensile axial stress magnitude was approximately $140 \mathrm{MPa}$ at the top of the cylinder and gradually decreased to $120 \mathrm{MPa}$ at the bottom of the cylinder. The radial stress in this engine block varied between 50 and $80 \mathrm{MPa}$ along the depth of the cylinder bridge.

The engine block solutionized at $500{ }^{\circ} \mathrm{C}$ (Figure 5.37 (b)) also had a large reduction in residual stress compared to the pre-SHT (TSR B) condition. For this engine block, the hoop stress following SHT at $500{ }^{\circ} \mathrm{C}$ was tensile with magnitudes varying between 60 and $80 \mathrm{MPa}$ throughout the depth of the cylinder bridge. The axial and radial stresses were relatively constant along the cylinder bridge with magnitudes of approximately 90 and $50 \mathrm{MPa}$, respectively.

Comparison between the residual stress profiles in the TSR and solutionized conditions (for both temperatures) indicated that heat treatment resulted in similar relief of residual stress throughout the entire cylinder bridge. This was exhibited in Figures 5.36 and 5.37, which showed that the residual axial stress following SHT was reduced by similar amounts throughout the cylinder (giving relatively uniform stress profile with cylinder depth), as compared to the TSR condition. Considering that there is a significant microstructural refinement at the bottom of the cylinder compared to the top, as discussed in Sections 4.2.1 and 5.1.1, this indicates that the relief of residual stress and strain was not dependent on microstructure. The high homologous temperatures that the engine blocks were exposed to during solutionizing eliminated microstructural dependence due to extensive thermal softening, allowing creep to proceed with minimal resistance. It can be deduced, however, that at artificial aging temperatures $(\sim 170$ $240{ }^{\circ} \mathrm{C}$ ), strain relief may have a stronger microstructural dependence, although additional research is required to develop this correlation.

Another observation that emerges from Figures 5.36 and 5.37 is that the relief of residual stress during SHT was likely similar for the hoop and axial directions. The similar stress profiles with respect to cylinder depth between these principal stress components following SHT at both temperatures indicates that complete relief of stress occurred during SHT and that cooling to 
ambient temperature caused the partial regeneration of tensile stress, similar to that observed in Figure 5.32. Therefore, it is probable that the axial strain relief relationship as a function of time can be used to estimate the relief of hoop stress during SHT (as was done in Table 5.1). In contrast, the radial stress likely was not relieved significantly (based on comparing Figures 5.36 and 5.37) due to the relatively low initial stress compared to the hoop and axial components.

Further comparisons between Figures 5.37 (a) and (b) also indicate that the engine blocks solutionized at $500{ }^{\circ} \mathrm{C}$ had lower tensile stress magnitudes along the cylinder bridge, specifically in the hoop and axial directions. The reason for this difference in stress between these engine blocks was elucidated in the in-situ strain analysis shown in Figure 5.32. As explained in Section 5.2.2.2, solutionizing at $500{ }^{\circ} \mathrm{C}$ resulted in a greater degree of compressive stress being imposed on the cylinder bridge at the later stages of heat treatment compared to the engine solutionized at $470{ }^{\circ} \mathrm{C}$. For this reason, tensile stress development during cooling, when superimposed on this higher compressive stress, resulted in a lower tensile stress magnitude. Although the analysis in Figure 5.32 was carried out only in the axial direction and at the $50 \mathrm{~mm}$ cylinder depth, the similar trends of the stress profiles throughout the cylinder for all orientations indicates that the same reasoning applies to the other principle stress directions and to all locations of the cylinder bridge.

Analysis of the residual stress profiles for the TSR treated and solutionized engine blocks also reveals that cooling following solidification leads to a greater development of tensile stress compared to post-SHT cooling. Since the restriction to free Al alloy contraction by the gray iron cylinder liners occurred in both cases, the difference in tensile stress development was due to additional factors. For instance, during casting, the gray iron cylinder liners were initially approximately $300{ }^{\circ} \mathrm{C}$ cooler than the pouring temperature of the $\mathrm{Al}$ alloy, which could have led to a localized chill effect along the Al-Fe interface, resulting in thermal gradients radially through the cylinder bridge during solidification and cooling. In addition, thermal gradients of significantly larger magnitude, compared to those generated from the cylinder liners, were likely induced axially along the cylinder bridge by the bulkhead chill plate, as evidenced by the refinement in microstructure with cylinder depth. These thermal gradients, induced by the cylinder liners and mould chills, combined with the thermo-mechanical mismatch effect to generate large tensile residual stress following casting. Conversely, in the solutionizing process, 
the engine blocks no longer contained these "chills" as the casting was removed from the mould and the cylinder liners had approximately the same temperature as the surrounding Al alloy. For this reason, the thermal gradients induced during casting were no longer present and all stress was generated by thermo-mechanical mismatch only (specifically in this experiment where the cooling rate was $<1{ }^{\circ} \mathrm{C} /$ minute), resulting in a significantly lower stress magnitude compared to the TSR condition.

The ex-situ neutron diffraction results in this section clearly illustrated the residual stress profiles following SHT for very slow cooling rates to isolate the thermo-mechanical mismatch mechanism of tensile stress development. However, engine block heat treatments are not concluded by cooling at these low rates. For this reason, ex-situ neutron diffraction was applied to a production T4 treated Al alloy engine block, as discussed in Section 5.2.3.3, to observe the influence of the forced air quenching process on the residual stress profiles.

\subsubsection{Residual Stress Following Production T4 Treatment}

Residual stress mapping of the engine block subjected to the production SHT (T4) schedule $\left(470{ }^{\circ} \mathrm{C}\right.$ for $7.5 \mathrm{~h}$, forced air quench) was carried out from top to bottom along the $\mathrm{Al}$ cylinder bridge, as shown in Figure 5.38.

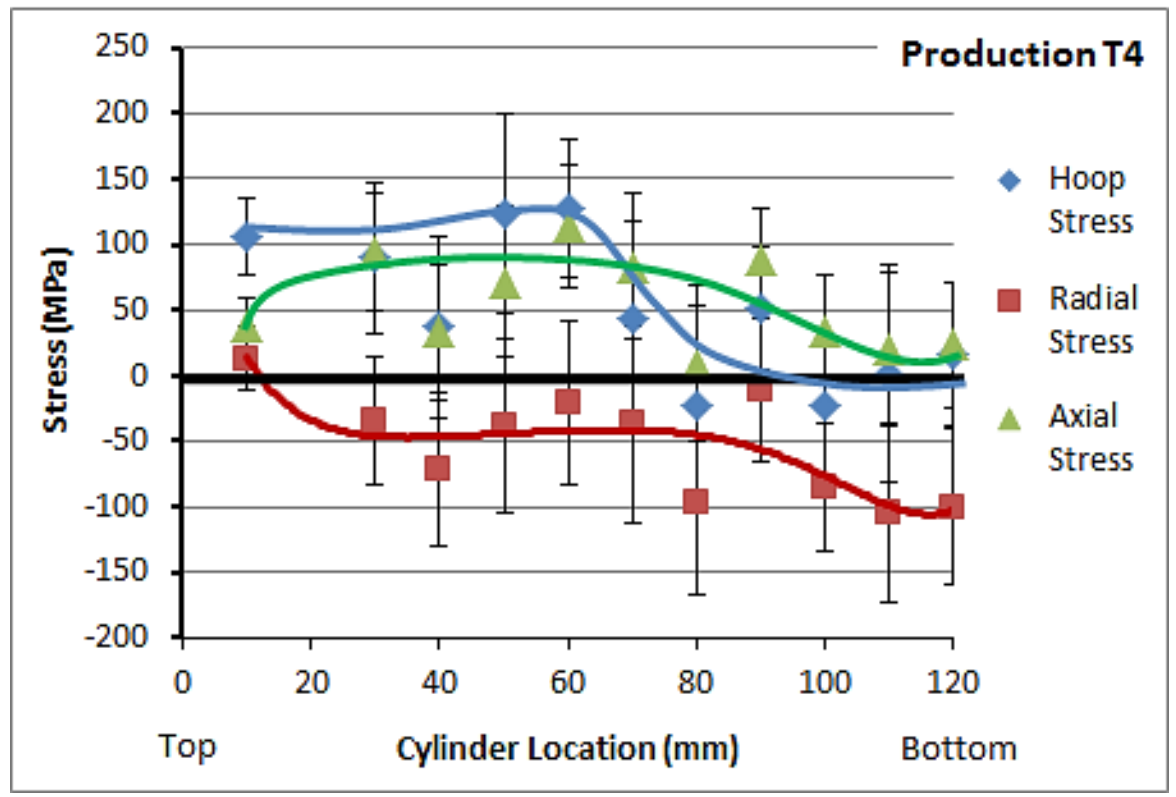

Figure 5.38: Residual stress profiles along cylinder bridge of Al engine blocks solutionized with production heat treatment and quenching schedule. 
The engine block subjected to the production T4 schedule was found to have tensile hoop and axial residual stress while the radial stress was compressive for most of the cylinder depth. The hoop stress had a magnitude varying between 110 and $130 \mathrm{MPa}$ for cylinder depths up to $60 \mathrm{~mm}$. The hoop stress then gradually decreased to approximately zero at the bottom of the cylinder. The axial component had a stress magnitude of $40 \mathrm{MPa}$ at the top of the cylinder, which increased to $90 \mathrm{MPa}$ at a depth of $60 \mathrm{~mm}$ and then decreased to approximately $10 \mathrm{MPa}$ at the bottom of the cylinder. Finally, the radial stress had a tensile magnitude of approximately $10 \mathrm{MPa}$ at the top of the cylinder, while the remainder of the cylinder depth was compressive with the stress magnitude increasing gradually to $110 \mathrm{MPa}$ at the bottom of the cylinder.

Similar to the engine blocks analyzed in Section 5.2.3.2, the application of the production T4 heat treatment schedule resulted in a significant relaxation of tensile residual stress (relative to the TSR condition) in all three principal stress directions. As confirmed by the in-situ strain analysis, shown in Figure 5.32, SHT at $470{ }^{\circ} \mathrm{C}$ caused the complete relief of tensile residual stress for soaking times greater than $4.5 \mathrm{~h}$. Since the production T4 treatment had a soaking time of $7.5 \mathrm{~h}$, the stress was completely relieved during this heat treatment. The in-situ strain analysis also determined that there was a partial regeneration of tensile residual stress during subsequent cooling to ambient temperature. However, unlike the stress profiles in Figure 5.37 (a), which had a relatively constant stress magnitude, the production $\mathrm{T} 4$ treated block had a relatively large variation in stress with cylinder depth. This variation in stress with cylinder depth was attributed to a temperature gradient imparted on the engine block by the forced air quench. To illustrate this concept, CFD simulations of the forced air quenching process were carried out using the parameters employed in engine production. The resulting temperature profiles are shown in Figure 5.39 (a), while the simulated cooling rates along the bridge between cylinders 4 and 6 are shown in Figure 5.39 (b).

The CFD simulation indicated that at the (4-6) cylinder bridge, there was a faster cooling rate near the top of the cylinder, which gradually decreased with cylinder depth. For instance, Figure 5.39 (b) shows that in the first $60 \mathrm{~s}$ of quenching, the average cooling rate at the top of the cylinder (10 mm depth) was $115^{\circ} \mathrm{C} /$ minute, while for the cylinder depths of 40, 80 and $120 \mathrm{~mm}$ (bottom of cylinder), the average cooling rates were approximately 95,80 and $70{ }^{\circ} \mathrm{C} /$ minute, respectively. Although the cooling rates equilibrated with cylinder depth for higher quenching 
times, this initial variation in cooling rate resulted in certain areas of the cylinder remaining hotter than others. This was clearly shown in Figure 5.39, where the (4-6) cylinder bridge temperature at the end of the three minute quench was approximately $260,275,290$ and $310{ }^{\circ} \mathrm{C}$ for cylinder depths of 10, 40, 80 and $120 \mathrm{~mm}$, respectively. The cooling rates were not uniform throughout the depth of the cylinder during quenching since the air initially came in contact with the deck face (near the top of the cylinder) resulting in a faster cooling rate (higher convective heat transfer coefficient) near the top of the cylinder compared to the bottom.
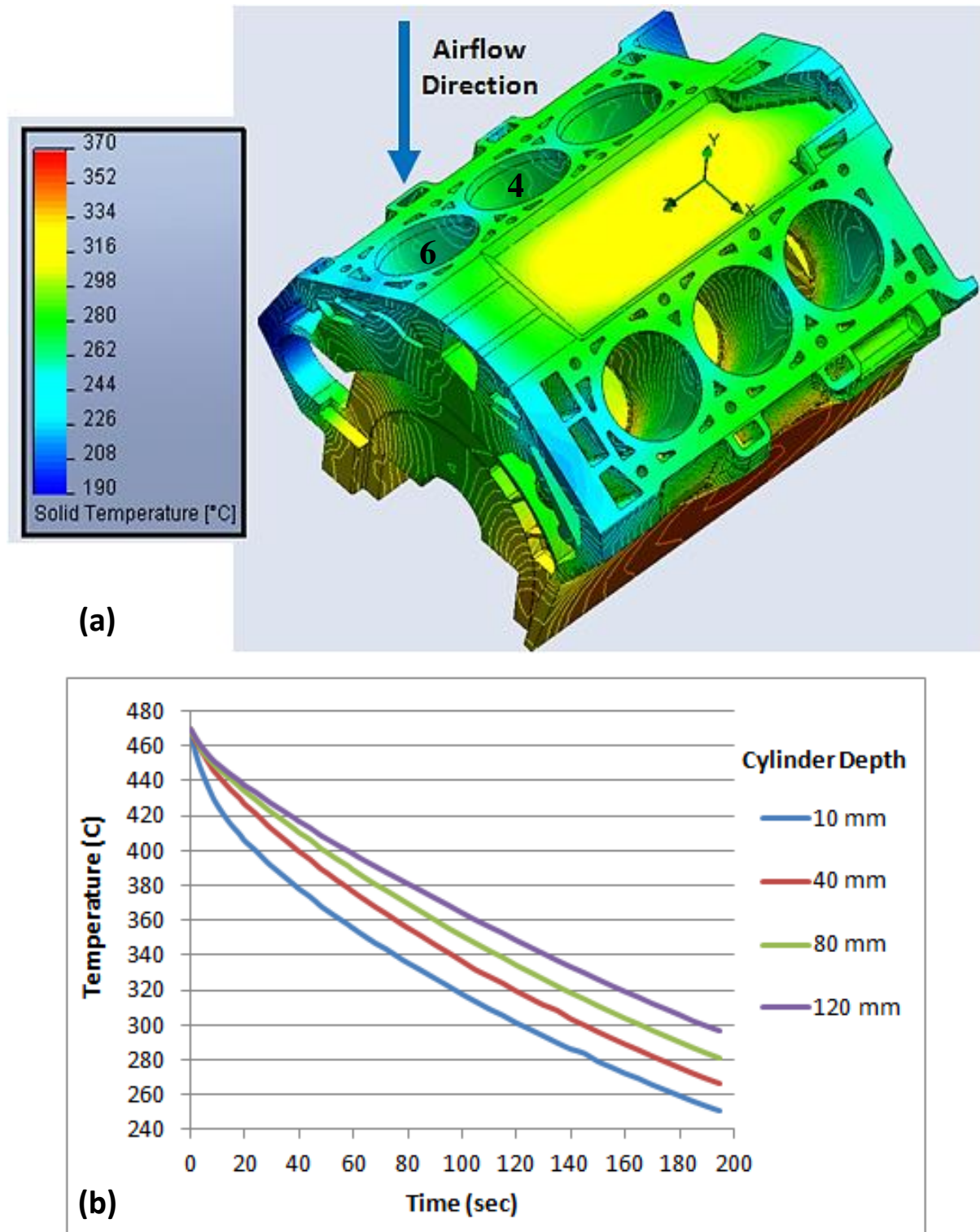

Figure 5.39: (a) Results from CFD simulation showing temperature profiles at the end ( $\sim 3$ minutes) of the forced air quenching process, (b) simulated cooling rate of the (4-6) cylinder bridge during quenching. 
In relation to residual stress development in the production T4 treated engine block, the regions near the top of the cylinder had larger local thermal gradients leading to more tensile stress generation, while the bottom of cylinder remained at high temperature longer, reducing the thermal gradients and the residual stress magnitude. In-contrast, the slow cooling rate in the engine blocks subjected to the in-situ SHT experiments resulted in a uniform temperature distribution, preventing significant stress formation due to thermal gradients. It is important to note that the fast cooling rate in the production T4 treated engine blocks likely mitigated the redistribution of stress required to equalized the stress magnitude along the cylinder, while the block subjected to the in-situ SHT experiment likely had stress redistribution due to the slow cooling rate (allowing engine to be at elevated temperature for an extended time period).

Based on the results of this study, it can be postulated that additional stress development from thermal gradients was offset by reduced thermo-mechanical mismatch due to the faster cooling of the gray iron liners relative to the surrounding $\mathrm{Al}$ as discussed in Section 4.4.1. It can also be deduced that there is a threshold of cooling rate, below which higher cooling rates reduce tensile residual stress by mitigating thermo-mechanical mismatch, and beyond which the thermal gradients become excessive, leading to increased tensile stress development.

Another important observation that emerges when comparing the residual stress profiles of these engine blocks is that the production T4 treated engine block had compressive radial stresses, which were not observed in the engine block exposed to the in-situ SHT experiment. This further points to the reduced stress uniformity in the production T4 engine block, since the radial stresses in the engine blocks exposed to the in-situ SHT experiment were closer in magnitude to the axial and hoop stresses. The reduction in stress uniformity may have also been due to the faster cooling rate following SHT for the production T4 engine block, preventing significant stress redistribution and resulting in large discrepancies in residual stress throughout the cylinder bridge and between principal stress directions.

Although this study illustrates the development of tensile residual stresses during quenching, the interaction between the thermal gradient mechanism and the thermo-mechanical mismatch mechanism is likely complex and highly dependent on the cooling rate due to the non-uniform geometry of the engine block. For this reason an in-depth investigation with varying cooling rates 
is required to fully understand this interaction and its influence on the stress profiles throughout the cylinder depth.

\section{Section Summary}

Ex-situ neutron diffraction was applied in this section to observe the residual stress profiles along the entire cylinder depth in the hoop, axial and radial directions. Since the in-situ strain analysis in the previous section was restricted to the axial direction and one cylinder location, the ex-situ analysis was required to further understand the effect of SHT on residual stress in each principal direction at all cylinder depths. It was determined that the residual stress profiles were relatively uniform in magnitude with cylinder depth, suggesting that SHT resulted in similar residual stress relief at all cylinder locations and stress directions. Furthermore, comparison of the residual stress profiles in the engine blocks subjected to the in-situ SHT experiments, with those from the production T4 treated engine block indicated that the forced air quench resulted in significant stress variation with cylinder depth, although the maximum stress magnitudes were similar. The results point to a complex interaction between stresses induced via thermo-mechanical mismatch and thermal gradients, which is highly dependent on the quench rate.

\subsection{Optimal Solution Heat Treatment Schedule}

The objective of this dissertation was to first determine the cause of in-service cylinder distortion, then devise a method to prevent this occurrence. As discussed in Chapter 4, distortion was the result of highly tensile residual stress relative to the $\mathrm{Al}$ alloy $\mathrm{YS}$ at the engine operating temperature. For this reason, the second part of this study focused on developing a further understanding on how heat treatment influences microstructure, mechanical properties and residual stress. The aim was to optimize the SHT process to increase the tensile properties of the alloy, while simultaneously relaxing the tensile residual stress in the cylinder bore region of the engine block.

The results obtained from the replicating billet castings clearly suggest that $\mathrm{SHT}$ at $500{ }^{\circ} \mathrm{C}$ for $2 \mathrm{~h}$ was the optimal solutionizing parameter with regards to dissolution of $\mathrm{Al}_{2} \mathrm{Cu}$, prevention of incipient melting and increase in YS and UTS. Considering that the implementation of these solutionizing parameters would result in a 15-20\% increase in YS compared to the current SHT 
schedule (maintaining the same production T7 aging schedule of $240{ }^{\circ} \mathrm{C}$ for $5.5 \mathrm{~h}$ ), while also reducing the process time by approximately $75 \%$, it is clear the these parameters would result in improved engine block casting integrity, improved productivity and reduced production cost. Other solutionizing parameters were also investigated, however, these parameters were either not justifiable $\left(500{ }^{\circ} \mathrm{C}\right.$ for $4 \mathrm{~h}$ or more) when considering the combination of benefit (increased strength) to increased cost, or they induced incipient melting (SHT at 515 or $530{ }^{\circ} \mathrm{C}$ ) which rapidly deteriorated component strength.

Analysis of residual strain and stress also indicated that SHT was effective in relaxing tensile residual stress. The results from in-situ neutron diffraction clearly showed that complete relief of residual strain was achieved after approximately $4.5 \mathrm{~h}$ at $470{ }^{\circ} \mathrm{C}$, while solutionizing at $500{ }^{\circ} \mathrm{C}$ caused complete strain relief in less than $0.5 \mathrm{~h}$. Furthermore, post-SHT analysis using ex-situ neutron diffraction showed that the magnitude of residual stress in all principal stress directions was lower for the engine blocks solutionized at $500{ }^{\circ} \mathrm{C}$ compared to those solutionized at $470{ }^{\circ} \mathrm{C}$. Considering that the comparison of the engine block solutionized at $470{ }^{\circ} \mathrm{C}$ with the production T4 treated engine block (which had a significantly higher quench rate) gave similar maximum stress magnitude but higher variability with cylinder depth, it can be reasonably assumed that using forced air quenching in conjunction with SHT at $500{ }^{\circ} \mathrm{C}$ will similarly result in lower stress magnitude throughout the cylinder bridge as compared to the current production SHT schedule. Combining the analysis from the billet casting experiments and in-situ/ex-situ neutron diffraction, an optimal heat treatment schedule was developed and is shown in Table 5.2.

Table 5.2: Recommended (optimal) heat treatment schedule for engine block production.

\begin{tabular}{cc}
\hline Process & Parameters \\
\hline Thermal Sand Reclamation & $495{ }^{\circ} \mathrm{C}$ for $1 \mathrm{~h}$ \\
Solution Heat Treatment & $500{ }^{\circ} \mathrm{C}$ for $2 \mathrm{~h}$ \\
Forced Air Cooling & Cooling rate greater than $100{ }^{\circ} \mathrm{C} /$ minute \\
Aging to T7 Temper & $240{ }^{\circ} \mathrm{C}$ for $5.5 \mathrm{~h}$ \\
(plus $1 \mathrm{~h}$ heating time)
\end{tabular}


It is clear that implementing the SHT parameters of $500{ }^{\circ} \mathrm{C}$ for $2 \mathrm{~h}$, while maintaining the same T7 artificial aging parameters currently used in production, will result in an appreciable increase in engine block strength and a reduction in tensile residual stress. This will reduce the susceptibility of in-service cylinder distortion, as per the results in Chapter 4. For this reason, the data obtained from this study confirms that this is the optimal SHT schedule for the production of these V6 Al alloy engine blocks containing cast-in gray iron cylinder liners. 


\section{Chapter 6: Conclusions}

This research was conducted with a view to first determining the cause of cylinder bore distortion by relating the microstructure, mechanical properties and residual stress to the measured macro distortion. Subsequently, the SHT parameters were varied to develop a better understanding on the influence of heat treatment on microstructure, mechanical properties and residual stress relief to improve engine block integrity (reduce the susceptibility of distortion) and process efficiency. The following are the conclusions drawn from this research:

\subsection{Cause of Cylinder Distortion}

1. The distorted and undistorted engine blocks had no significant difference in size, shape, distribution and volume fraction of secondary phase particles (interdendritic regions) and contained fully stabilized $\theta-\mathrm{Al}_{2} \mathrm{Cu}$ age hardening precipitates (within $\alpha$-Al dendrites). The thermally stable microstructures indicated that distortion was not caused by the phase transformation induced thermal growth mechanism.

2. Distortion was likely the result of the combination of tensile residual stresses and service stresses. These combined stresses likely exceeded the $319 \mathrm{Al}$ alloy YS at the engine operating temperature leading to instantaneous plastic deformation. In addition, creep may have also contributed to in-service distortion due to the high residual stress level (near the alloy YS) at elevated temperature (operating temperature of $180{ }^{\circ} \mathrm{C}(453 \mathrm{~K})$ is equal to $0.52 \mathrm{~T}_{\mathrm{m}}$ which is above $0.4 \mathrm{~T}_{\mathrm{m}}$ ).

3. Maximum in-service distortion occurred at the middle of the cylinder $(\sim 40 \mu \mathrm{m}$ at a depth of 50-60 mm) which had a combination of high tensile residual stress and coarse microstructure. Regions in the cylinder bores containing either coarse microstructures with low residual stress (top: $\sim 17 \mu \mathrm{m}$ of distortion) or fine microstructures with high residual stress (bottom: $\sim 5 \mu \mathrm{m}$ of distortion) were not prone to significant distortion. 


\subsection{Optimization of Heat Treatment Parameters}

\section{$\underline{\text { Microstructure and Mechanical Properties }}$}

1. Microstructural replication of the top, middle and bottom of the cylinder was successfully achieved using billet castings with cooling rates of approximately $1.5,3.8$ and $12.5{ }^{\circ} \mathrm{C} / \mathrm{s}$, respectively. This permitted the optimization of the engine block SHT process in a lab-scale, while considering the influence of coarse-to-fine microstructure with cylinder depth.

2. The simulated TSR treatment partially dissolved $\mathrm{Al}_{2} \mathrm{Cu}$ for all examined billets. Subsequent SHT using the current solutionizing parameters $\left(470{ }^{\circ} \mathrm{C}\right.$ for $\left.7.5 \mathrm{~h}\right)$ resulted in sluggish $\mathrm{Al}_{2} \mathrm{Cu}$ dissolution ( $10 \%$ reduction in $\mathrm{Al}_{2} \mathrm{Cu}$ volume fraction). However, when the SHT temperature was increased to $500{ }^{\circ} \mathrm{C}$, the $\mathrm{Al}_{2} \mathrm{Cu}$ volume fraction was reduced by an additional 40, 45 and $70 \%$ relative to the TSR condition, for the billets replicating the top, middle and bottom of the cylinder respectively.

3. Solution treatment at $500{ }^{\circ} \mathrm{C}$ for $2 \mathrm{~h}$, was determined as the optimal parameters to increase alloy strength and reduce production time. These SHT parameters resulted in a 15,8 , and $4 \%$ increase in YS for the billets replicating the top, middle and bottom of the cylinder respectively (T7 condition) relative to the current SHT parameters. Higher solutionizing times were less cost effective due to the smaller and more gradual increases in strength, as a result of the less pronounced $\mathrm{Al}_{2} \mathrm{Cu}$ dissolution

4. Solutionizing at 515 and $530{ }^{\circ} \mathrm{C}$ resulted in incipient melting of $\mathrm{Al}_{2} \mathrm{Cu}$ and $\mathrm{Al}_{5} \mathrm{Mg}_{8} \mathrm{Cu}_{2} \mathrm{Si}_{6}$ (DSC analysis confirmed that incipient melting occurred at $\sim 507{ }^{\circ} \mathrm{C}$ ), causing the formation of $\mathrm{Al}-\mathrm{Al}_{2} \mathrm{Cu}-\mathrm{Al}_{5} \mathrm{Mg}_{8} \mathrm{Cu}_{2} \mathrm{Si}_{6}$ ultra-fine eutectic (UFE) clusters in interdendritic regions. The UFE clusters contained micro-porosity which acted as crack initiation sites and reduced YS and UTS of all billet castings. Due to incipient melting, these temperatures are not suitable for the engine block heat treatment process. 


\section{$\underline{\text { In-situ Residual Strain Analysis }}$}

1. Instantaneous relief of residual strain during engine block heating (due to decreased YS) did not occur. This was attributed to the presence of the gray iron cylinder liners which reinforced the cylinder bore region and prevented instantaneous strain relief.

2. Residual axial strain relieved gradually during SHT at $470{ }^{\circ} \mathrm{C}$ with complete relief of strain occurring following $4.25 \mathrm{~h}$ of soaking. At $500{ }^{\circ} \mathrm{C}$, complete relief of tensile strain occurred in under $0.5 \mathrm{~h}$. The large temperature effect and the gradual relief of strain indicate that creep was predominantly responsible for strain relief during SHT.

3. Engine block cooling, following SHT caused a generation of tensile residual axial strain, with the strain developing when cooling from 500 to $400{ }^{\circ} \mathrm{C}$. Below $400{ }^{\circ} \mathrm{C}$, the strain remained relatively constant with decreasing temperature. The slow cooling rate $\left(<1{ }^{\circ} \mathrm{C} / \mathrm{s}\right)$ for this process indicated that tensile strain development was caused solely by thermomechanical mismatch between the gray iron liners and the surrounding $\mathrm{Al}$ alloy.

\section{$\underline{E x \text {-situ Residual Stress Analysis }}$}

1. Ex-situ neutron diffraction following the in-situ SHT analysis showed a significant reduction in tensile residual stress in the hoop, axial and radial directions. The stress magnitudes in all orientations were relatively uniform throughout the depth of the cylinder bridge, suggesting that stress and strain relief in all cylinder locations and in all principal stress directions were similar to that observed in the axial orientation with in-situ neutron diffraction.

2. The residual stress profiles showed that following SHT, the engine blocks solutionized at $500{ }^{\circ} \mathrm{C}$ had lower residual stress magnitude throughout the depth of the cylinder bridge compared to those held at $470{ }^{\circ} \mathrm{C}$. This was attributed to larger compressive stresses at the end of SHT at $500{ }^{\circ} \mathrm{C}$. These compressive stresses partially counteracted tensile stress development during engine block cooling.

3. The production T4 treated engine blocks had residual stress profiles that were significantly less uniform along the cylinder compared to the engine blocks which were 
solutionized at the neutron spectrometer. The forced air quench resulted in thermal gradients (as confirmed using CFD simulations) which promoted more stress development in specific locations, while the faster cooling rate mitigated the redistribution of stress required to equalize the stress magnitude along the cylinder.

\subsection{Contributions of Dissertation}

The experimental analysis in this dissertation assisted in the development of an in-depth understanding into the relationship between heat treatment parameters, microstructure, mechanical properties and residual stress. In addition, this relationship was used to determine the cause of cylinder distortion in $\mathrm{Al}$ engine blocks containing cast-in gray iron liners, enabling future preventative measures (via process optimization) to be implemented. The novel aspects investigated in this dissertation are listed below.

1. Development of a scientific explanation for distortion through analysis of microstructure, mechanical properties and residual stress (via neutron diffraction) in distorted and undistorted service tested engine blocks.

2. Comprehensive study on the influence of solutionizing temperature and time, as well as air quenching, on microstructure, mechanical properties and residual stress in components with microstructural variations.

3. Pioneering research using in-situ neutron diffraction to develop a comprehensive understanding of tensile residual stress relief as a function of soaking time at different solutionizing temperatures in components containing materials with dissimilar thermo-mechanical properties. This research opens a new analytical approach for the investigation of residual stress relief, enabling the optimization of manufacturing processes to improve component integrity and process efficiency.

The data generated in this dissertation will be of great use in the development of theory, specifically the interaction effects in components with dissimilar materials (academia) as well as assisting in optimizing the heat treatment processes with the aim of eliminating distortion and reducing processing cost (industry). 


\section{Chapter 7: Recommendations for Future Work}

The data and analysis in this dissertation advanced the understanding of mechanisms responsible for cylinder distortion in $\mathrm{Al}$ alloy engine blocks containing gray iron cylinder liners. It also developed a further understanding on the influence of heat treatment on microstructure, mechanical properties and residual stress in components containing highly dissimilar materials. However, this research resulted in new questions. Future experiments are recommended to address these questions, as outlined below, to further enhance the knowledge in the field.

1. Analysis of microstructure, mechanical properties and residual stress of engine blocks with significantly higher distortion magnitude $(>>50 \mu \mathrm{m})$

2. Apply recommended (modified) heat treatment schedule to production engine block and carry out service testing using engine dynamometer, confirming influence on distortion.

3. Study the influence of varying artificial aging parameters on microstructure and mechanical properties to fully optimize T7 heat treatment process.

4. In-situ neutron diffraction analysis examining the relief of residual strain as a function of time during artificial aging to T6 and T7 tempers.

5. Creep testing of this modified $319 \mathrm{Al}$ alloy near the solutionizing temperatures and at applied stress levels equivalent to the measured residual stress, which will confirm creep as a mechanism responsible for residual stress relief during heat treatment.

6. In-situ neutron diffraction analysis investigating the development of tensile residual stress along the cylinder bores during quenching with varying cooling rates.

7. In-situ and ex-situ neutron diffraction residual stress mapping in linerless $\mathrm{Al}$ alloy engine blocks (thermal spray processed) at each production stage, enabling comparison with engine blocks containing gray cast iron cylinder liners. 


\section{Appendix A:}

Summary of Heat Treatment Conditions for the 319 Al Alloy 
Table A.1: Summary of microstructure and properties associated to each heat treatment condition in the 319 Al alloy.

\section{Designation Description Microstructure $\quad$ Properties}

T4 treated and naturally aged [1]

Supersaturated solid solution of $\mathrm{Cu}$ in the $\mathrm{Al}$ dendrites. $[31,32]$

- $\quad$ Slight increase in YS and UTS over as-cast condition [9]

- Low dimensional stability in elevated temperature applications

[6]

Fine (50-100 nm) distribution of coherent or semi-coherent

Solution heat

T6 treated and artificially aged [1] $\mathrm{Cu}$-rich metastable precipitates ( $\theta$ ' and $\left.\theta^{\prime}\right)$ within $\mathrm{Al}$ dendrites. Also contains fine, metastable $\mathrm{Mg}$-rich precipitates ( $\beta$ ' and/or Q') [31, 32, 54, 56, 57].

Sparse distribution of coarser

Solution heat

T7 treated, overaged and stabilized [1] (200-500 nm) and incoherent $\mathrm{Cu}$-rich precipitates $(\theta)$. Also contains coarser (>500 nm) Mg-rich precipitates. [54, 56, 58, 60]
- Peak treatment condition with regards to maximizing YS and UTS

[9]

- Low dimensional stability in elevated temperature applications

[6]

- Significant reduction in YS and UTS as compared to the T6 condition

[9]

- High dimensional stability in elevated temperature applications

[6] 


\section{Appendix B:}

Uncertainty Calculations for Neutron Diffraction Residual Strain and

Stress Analysis 
Residual stress and strain measurements using neutron diffraction consisted of several calculations utilizing the raw diffraction data. The data obtained from neutron diffraction is a diffraction peak, which plots the diffracted neutron intensity (counts) against the angle of diffraction $(2 \varphi)$. The peak position, with respect to the angle of diffraction, is the central position of the diffraction peak and was determined by fitting a Gaussian distribution through the neutron data, as shown in Figure B.1. The Gaussian peak fitting was done using a Fortran program written at $\mathrm{CNBC}$. In addition, the uncertainty in peak position $(\Delta \varphi)$ was also calculated following the application of the Gaussian distribution to the data.

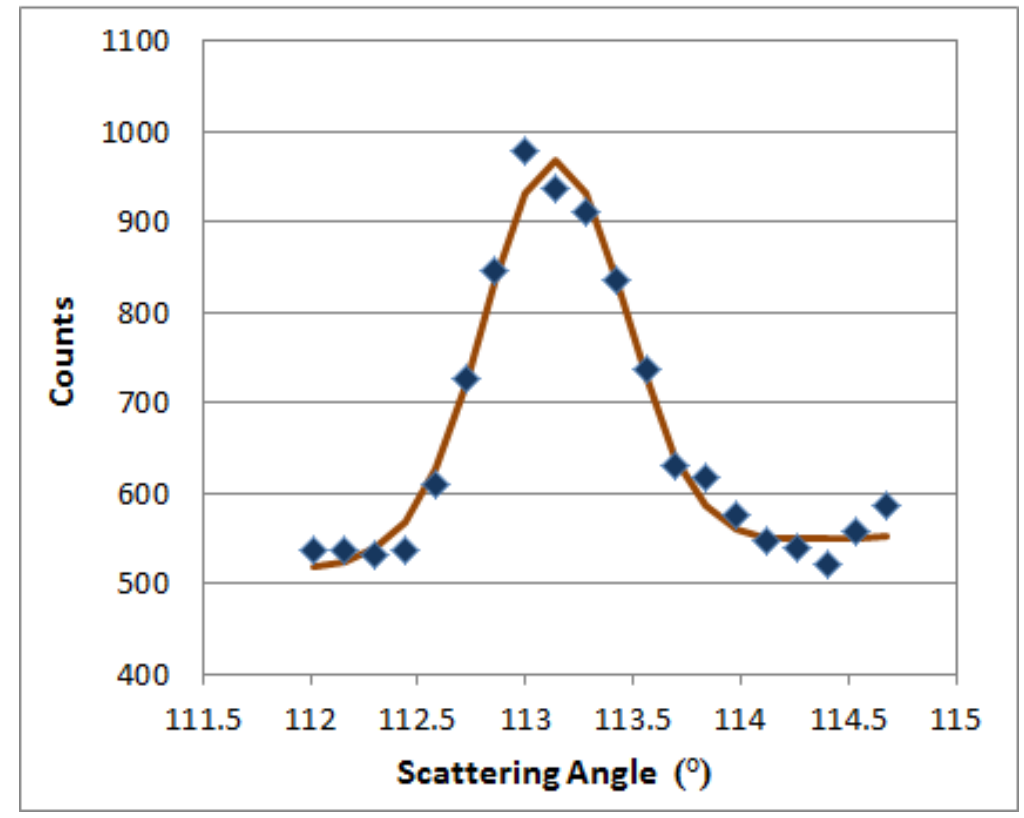

Figure B.1: Sample of diffraction data obtained for the Al (331) plane using neutron diffraction.

The peak position, determined from the diffraction data for a known neutron wavelength $(\lambda)$, was then used to calculate the interplanar spacing $\left(d_{h k l}\right)$ using Bragg's law. Uncertainty in the interplanar spacing was calculated using Equation B-1.

$$
\Delta d_{h k l}=\frac{\lambda}{2 \sin (\varphi+\Delta \varphi)}-d_{h k l}
$$

Following the calculation of $\mathrm{d}_{\mathrm{hkl}}$ and $\Delta \mathrm{d}_{\mathrm{hkl}}$, the uncertainty in lattice strain in the hoop, radial and axial directions $\left(\Delta \varepsilon_{\mathrm{H}, \mathrm{R}, \mathrm{A}}\right)$ was calculated using Equation B-2. The lattice strain in the three principal stress directions $\left(\varepsilon_{\mathrm{H}, \mathrm{R}, \mathrm{A}}\right)$ was calculated using the "peak shift" method, shown in Equation 8. 


$$
\Delta \varepsilon_{H, R, A}=\frac{\left(d_{h k l}+\Delta d_{h k l}\right)-d_{0, h k l}}{d_{0, h k l}}-\varepsilon_{H, R, A}
$$

Uncertainty in the residual stress measurements for the hoop, radial and axial directions was calculated using Equation B-3 along with the lattice strain, strain uncertainty, modulus of elasticity (E) and Poisson's ratio (v). The residual stress in the three principal stress directions $\left(\sigma_{\mathrm{H}, \mathrm{R}, \mathrm{A}}\right)$ was calculated using generalized Hooke's law as shown in Equation 9.

$\Delta \sigma_{H, R, A}=\left\{\frac{E}{1+v}\left[\left(\varepsilon_{H, R, A}+\Delta \varepsilon_{H, R, A}\right)+\frac{v}{1-2 v}\right]\left[\left(\varepsilon_{H}+\Delta \varepsilon_{H}\right)+\left(\varepsilon_{R}+\Delta \varepsilon_{R}\right)+\left(\varepsilon_{A}+\Delta \varepsilon_{A}\right)\right]\right\}-\sigma_{H, R, A}$ 


\section{Appendix C:}

Cooling Curves for Replicating Billet Casting Solidification 


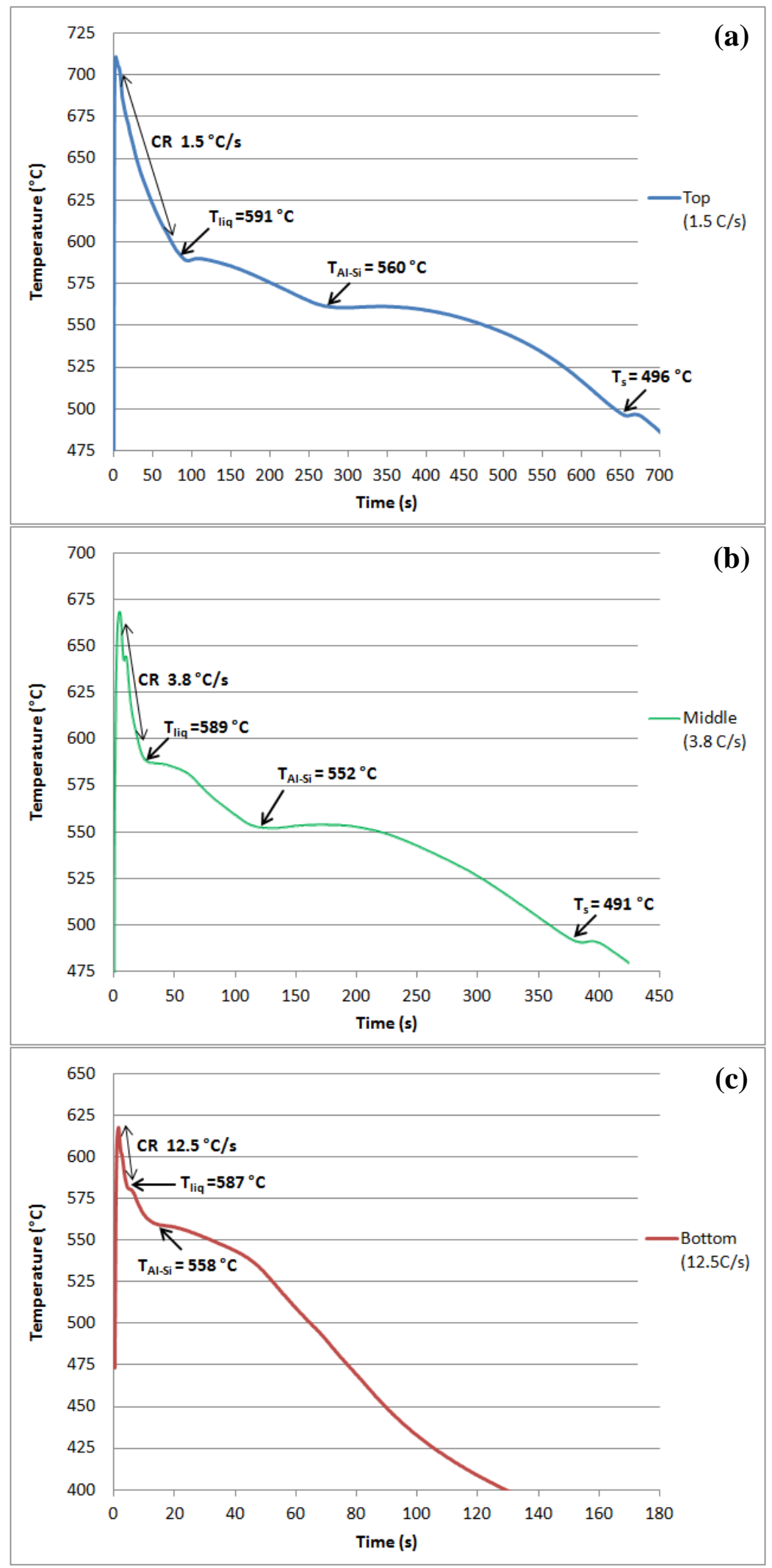

Figure C.1: Cooling curves during solidification of the billets replicating: (a) top of cylinder, (b) middle of cylinder, (c) bottom of cylinder. 


\section{Appendix D:}

Thermal Profiles of Billet Casting Heat Treatment Cycle 


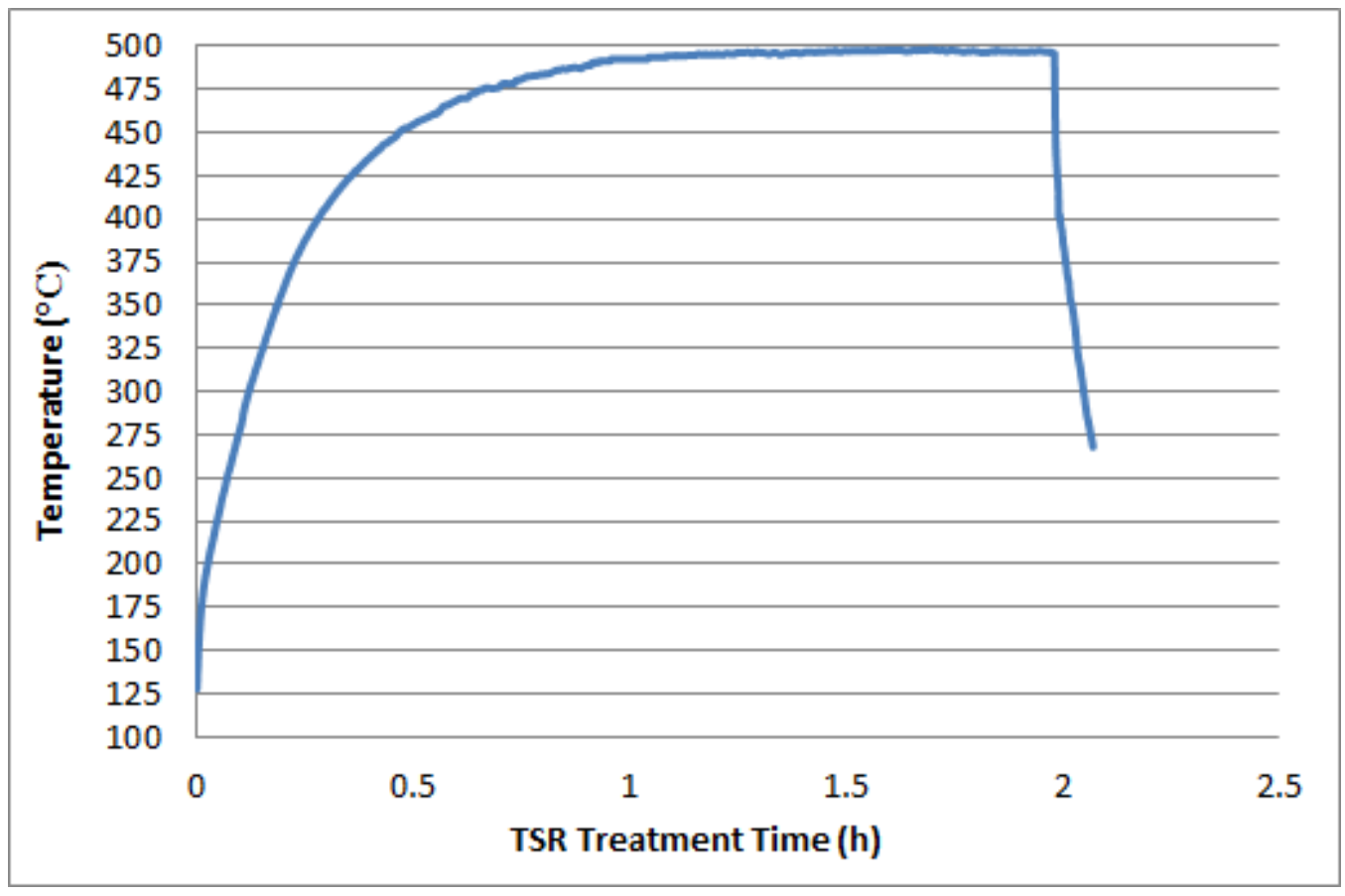

Figure D.1: Representative billet casting simulated TSR treatment cycle.

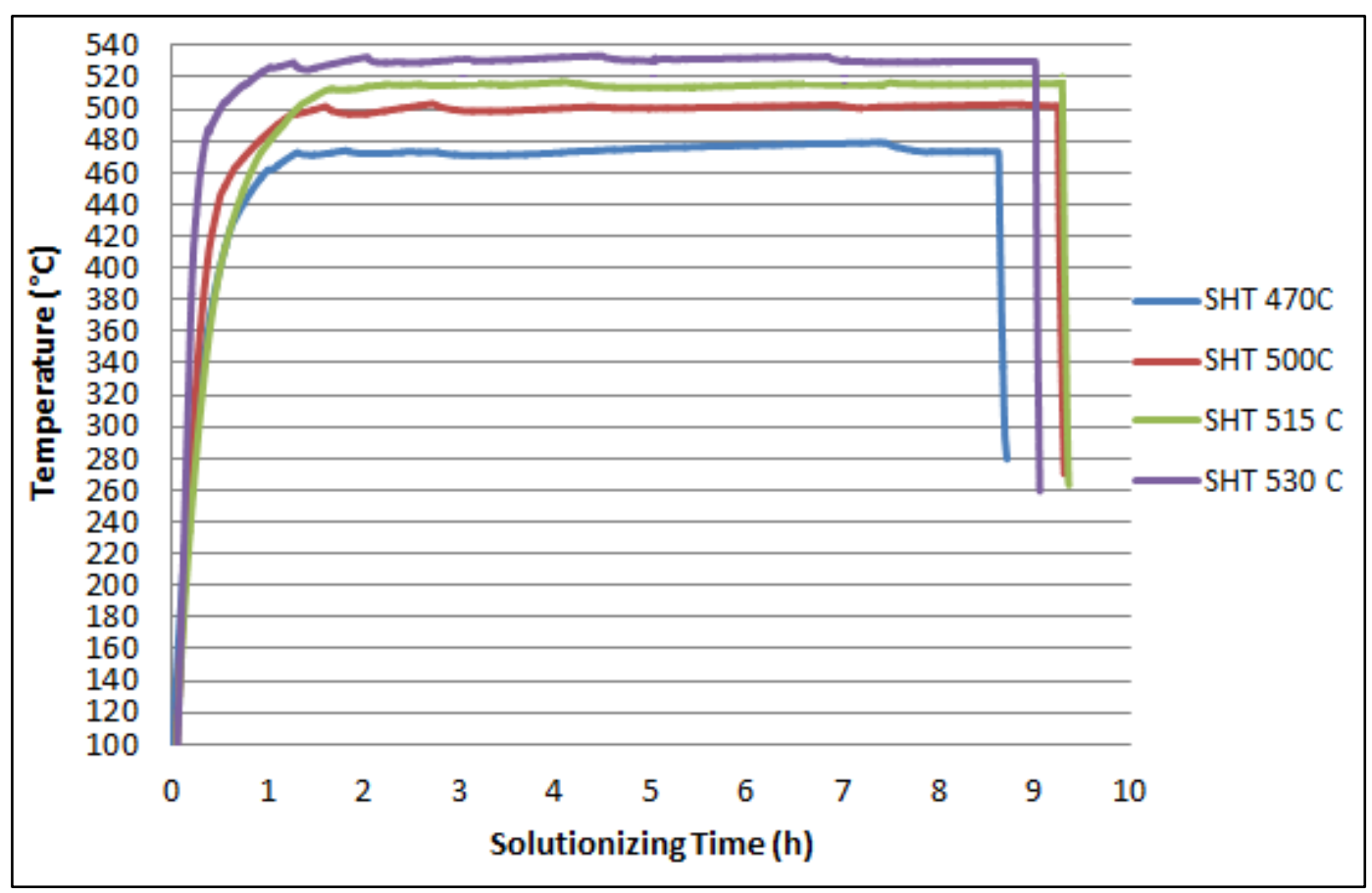

Figure D.2: Representative billet casting solution heat treatment and quenching cycle. 


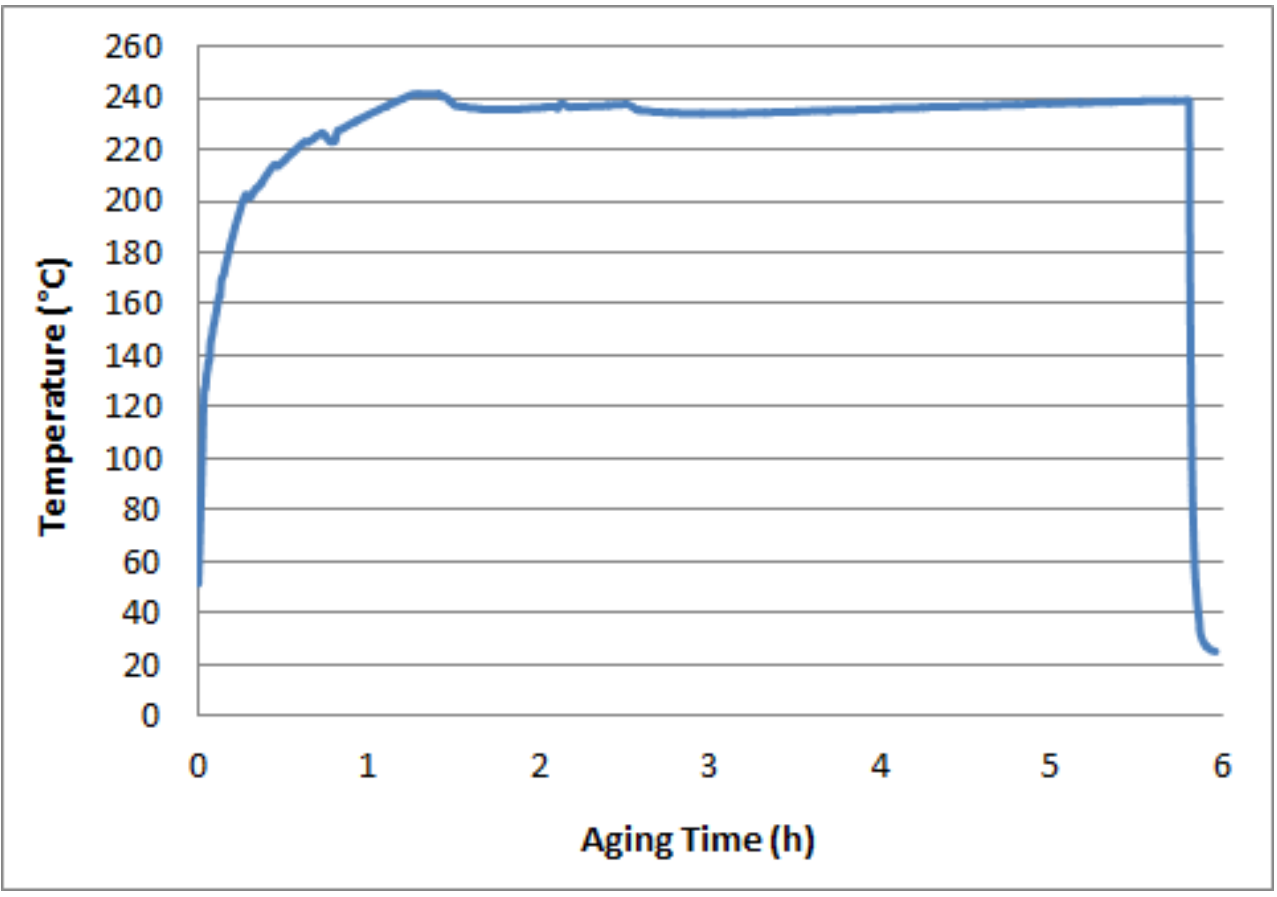

Figure D.3: Representative billet casting $\mathbf{T} 7$ aging cycle. 


\section{Appendix E:}

Engine Block Heating Profiles during In-situ Neutron Diffraction 


\section{E.1 Heat Transfer Simulation of Engine Heat-up}

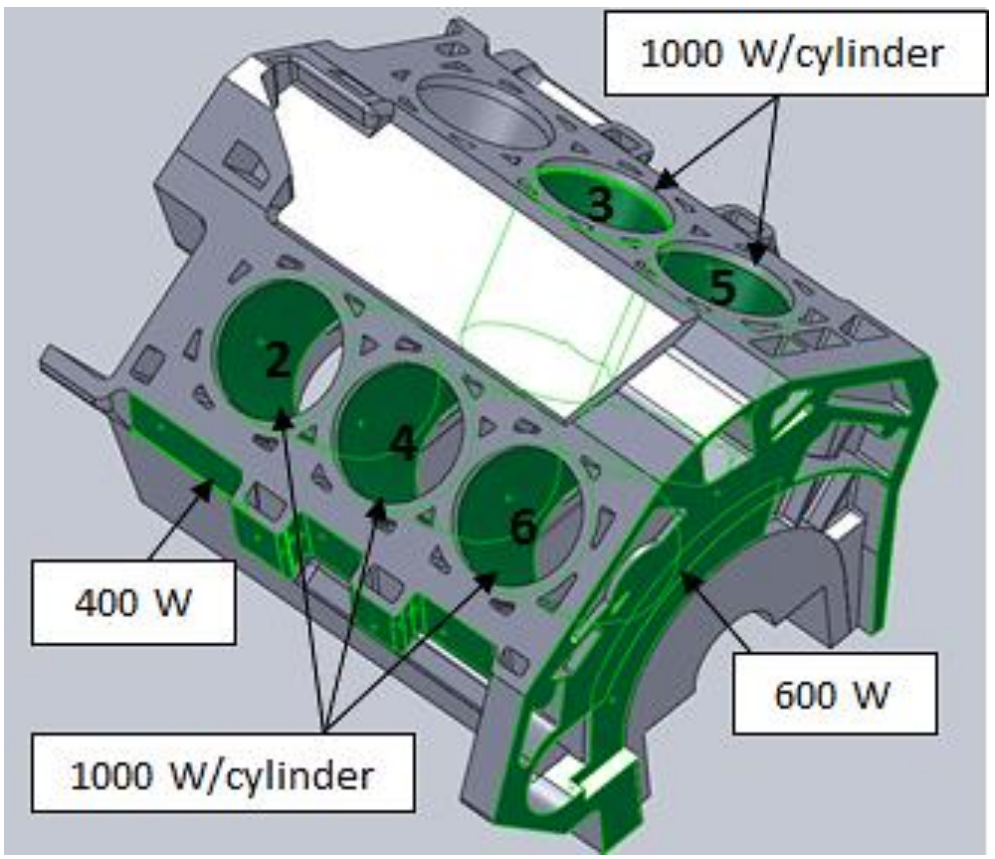

Figure E.1: Engine block model showing heater locations and magnitude of heat flux for finite volume conduction heat-up simulation.

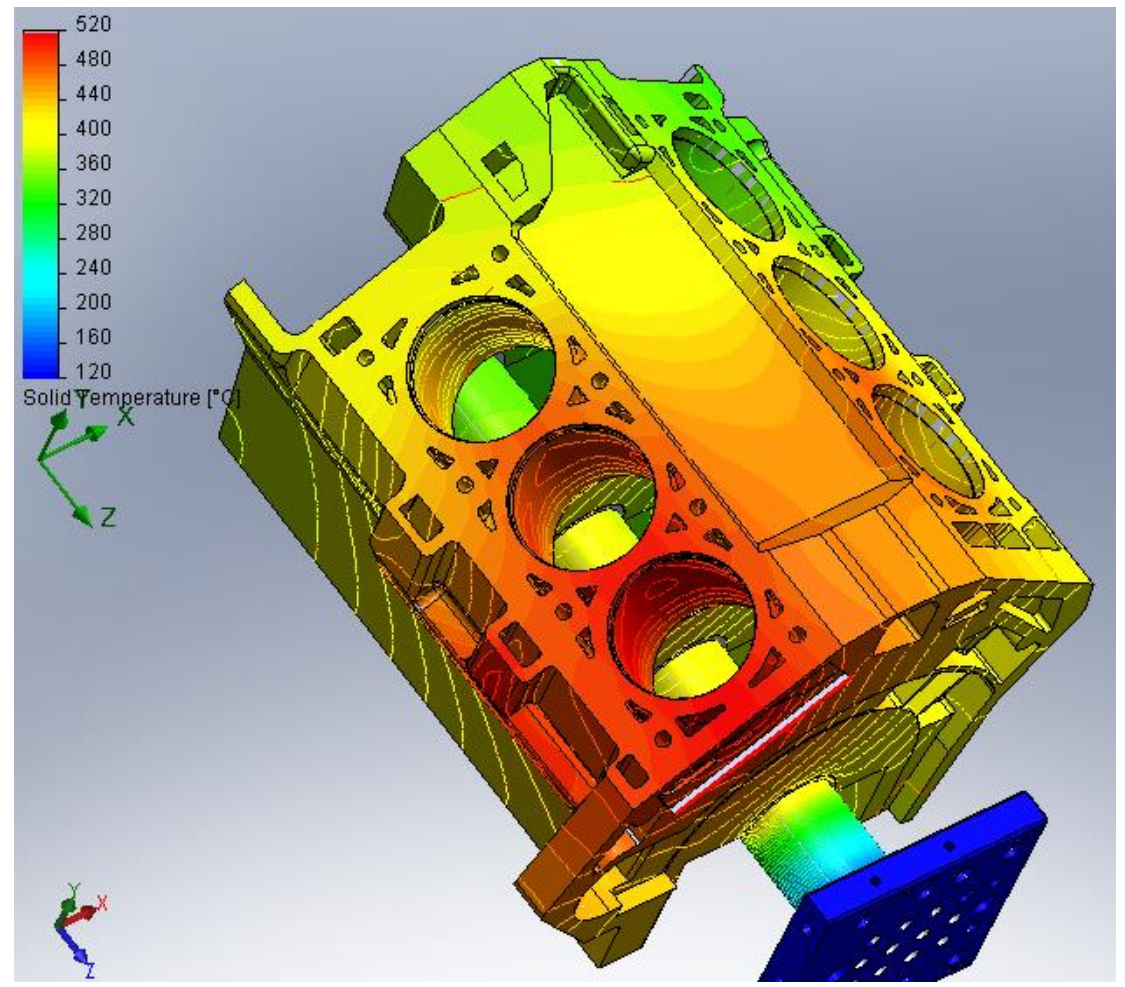

Figure E.2: Result from Finite Volume Conduction Simulation for 1h of heating. 


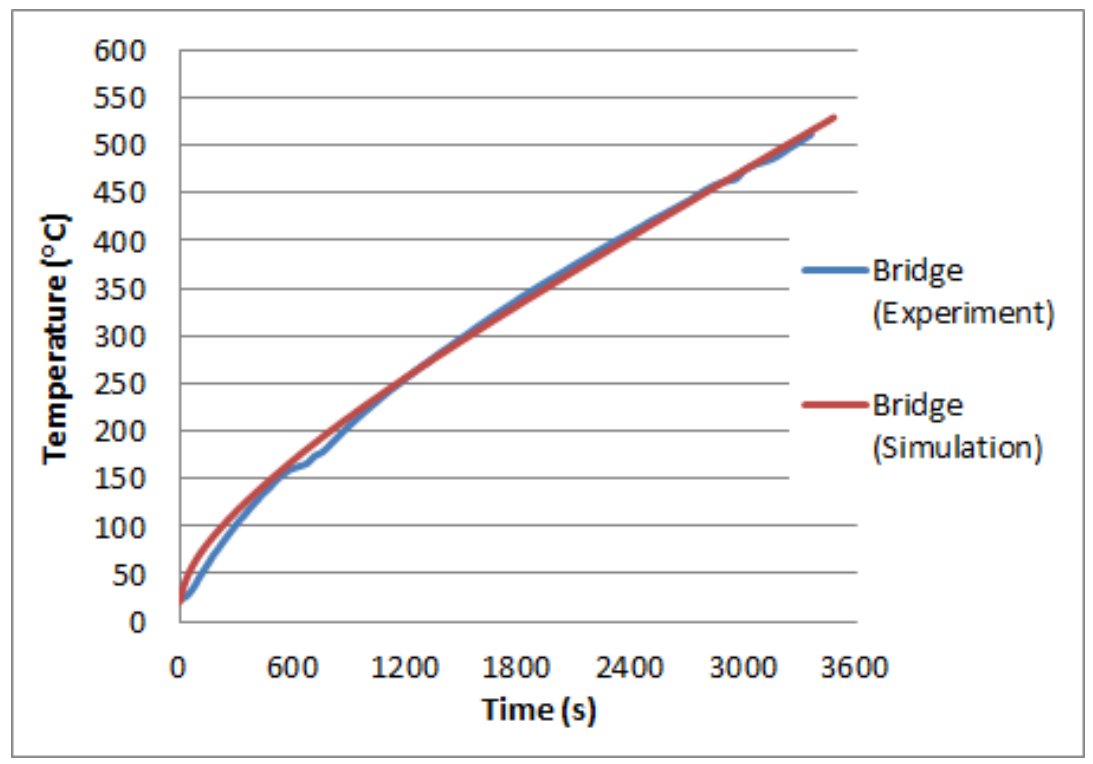

Figure E.3: Comparison between experimental and simulated engine heat up at the (4-6) cylinder bridge.

\section{E.2 Heat Treatment Temperature Profile}

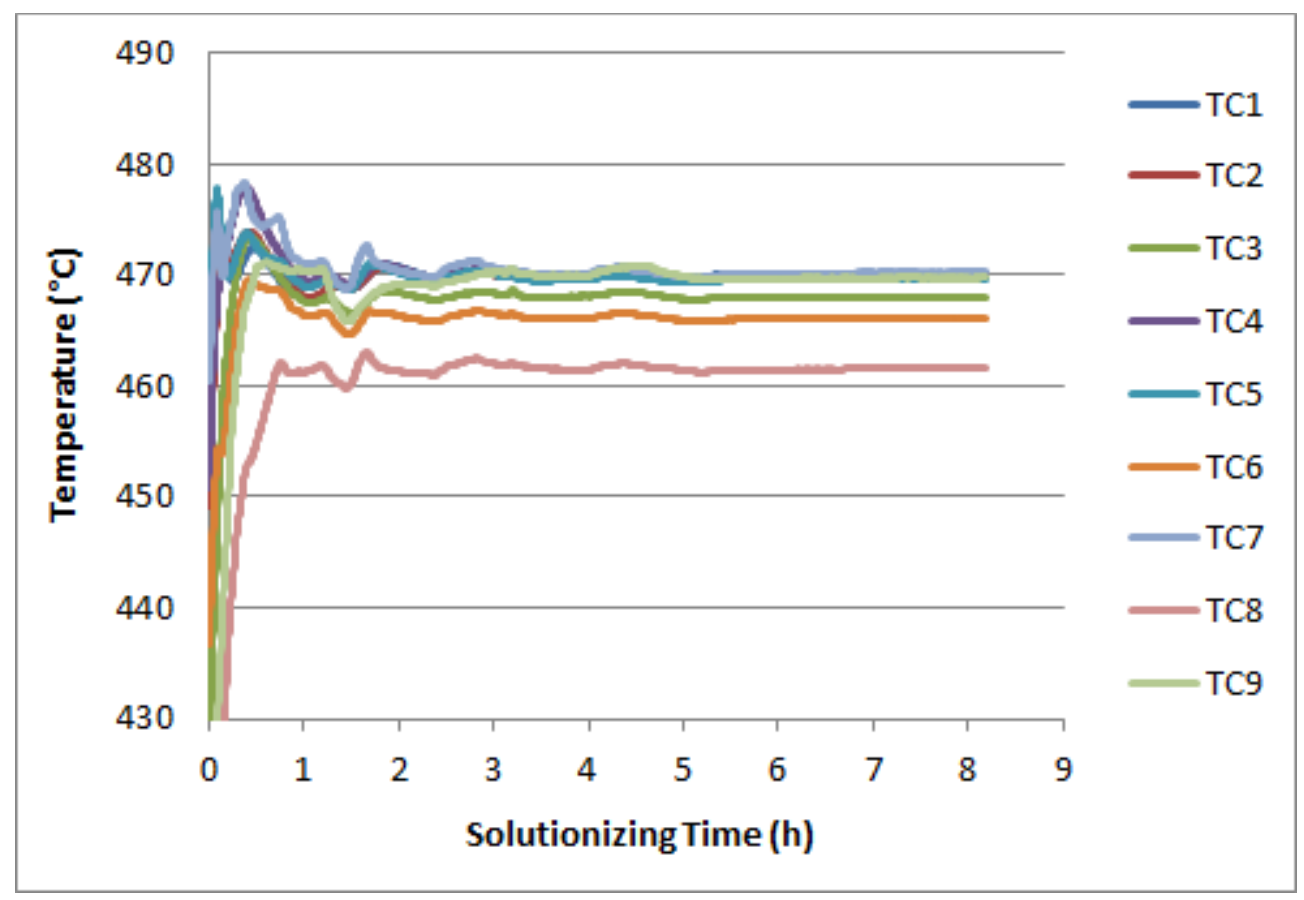

Figure E.4: Temperature profiles for the $470{ }^{\circ} \mathrm{C}$ in-situ heat treatment experiment at the engine locations outlined in Figure 3.13. 


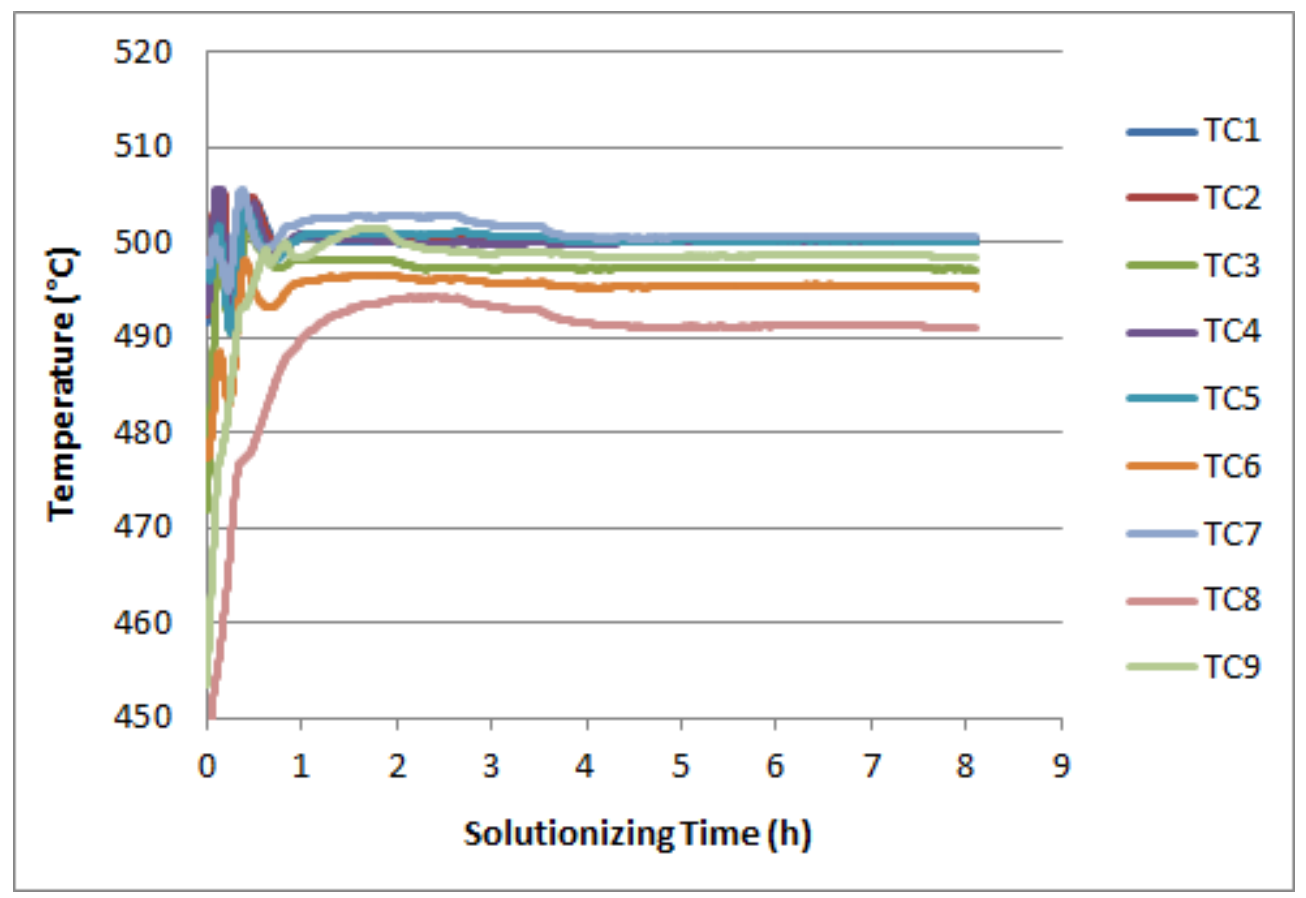

Figure E.5: Temperature profiles for the $500{ }^{\circ} \mathrm{C}$ in-situ heat treatment experiment at the engine locations outlined in Figure 3.13.

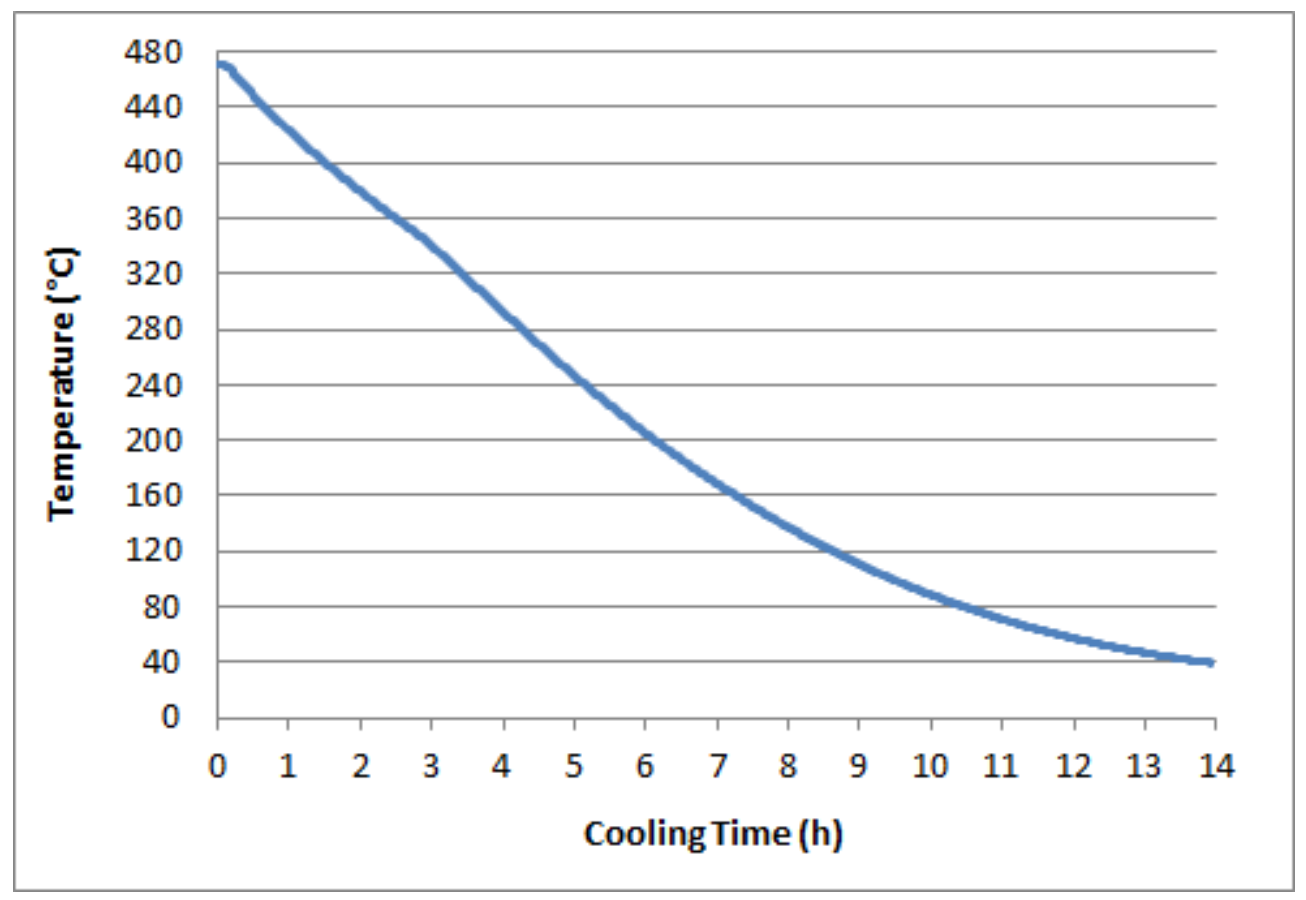

Figure E.6: Temperature profile of the (4-6) cylinder bridge during post-SHT cooling. 


\section{Appendix F:}

Calculations of Confidence Limits of Estimated Mean Values 
Experiments of evaluation were used to estimate the population mean $(\mu)$ pertaining to the size and amount of microstructural constituents as well as the mechanical properties of the engine blocks or replicating billet castings in each treatment condition. In order to observe if the microstructure and mechanical properties of the engine blocks and billet castings were influenced by heat treatment, the $95 \%$ upper and lower confidence limits of the population mean were determined. Since the population standard deviation $(\sigma)$ was unknown during experimentation and the sample size was relatively small $(<\sim 50)$, the confidence limits were determined using the relationships shown in Equations E-1 and E-2.

$$
\begin{aligned}
& \mu_{\text {lower }}=\bar{x}-\left(\frac{S t_{\alpha / 2 ; v}}{\sqrt{N}}\right) \\
& \mu_{\text {upper }}=\bar{x}+\left(\frac{S t_{\alpha / 2 ; v}}{\sqrt{N}}\right)
\end{aligned}
$$

Where,

$\mathrm{N}=$ Sample size

$\bar{x}=$ Sample mean

$\mathrm{S}=$ Sample standard deviation

$t_{\alpha / 2 ; v}=$ Student " $\mathrm{t}$ " distribution with significance level, $\alpha$, and $v=\mathrm{N}-1$ degrees of freedom 


\section{Appendix G:}

\section{Al Alloy Phase Diagrams}




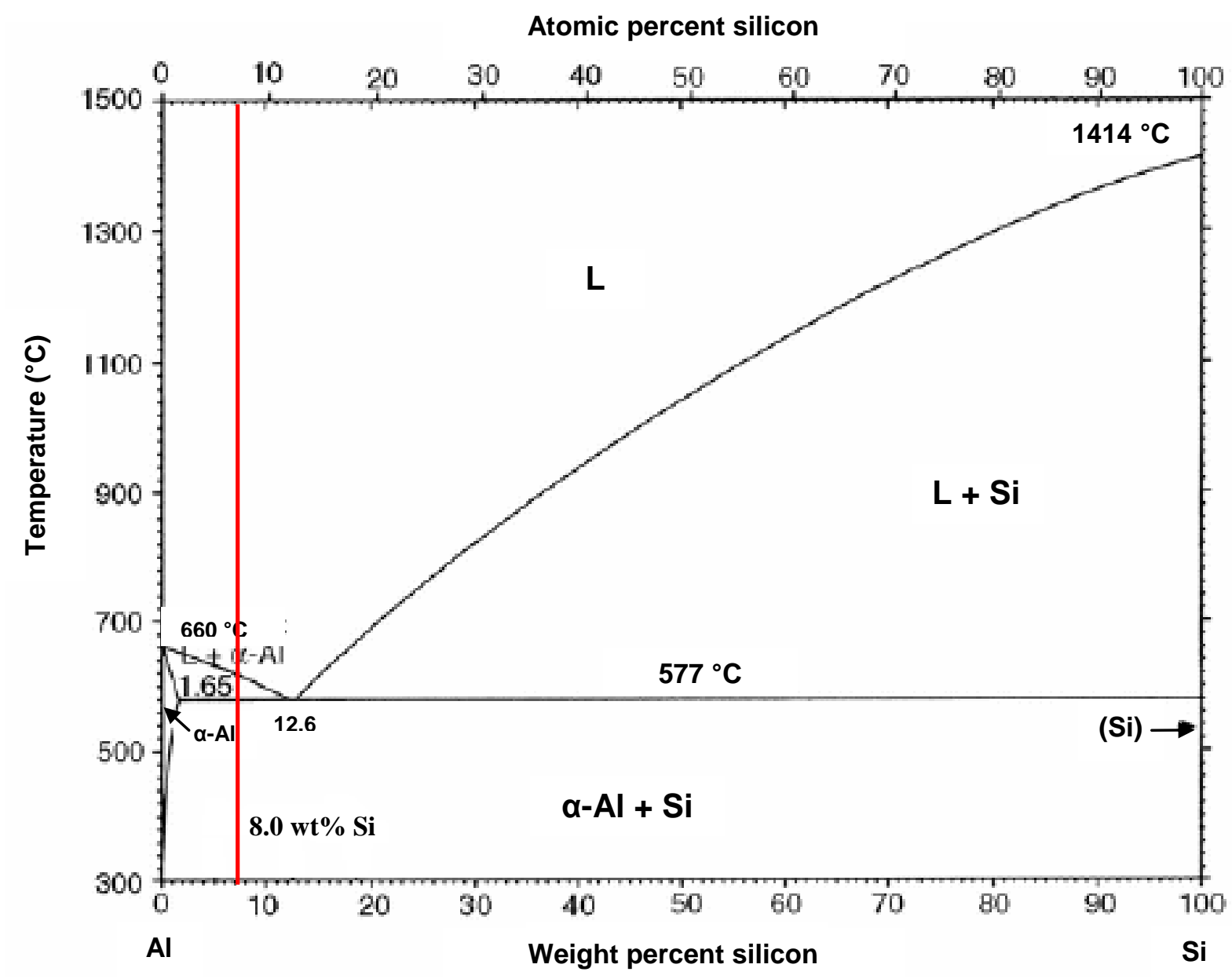

Figure G.1: Aluminum-silicon binary phase diagram [1]. 


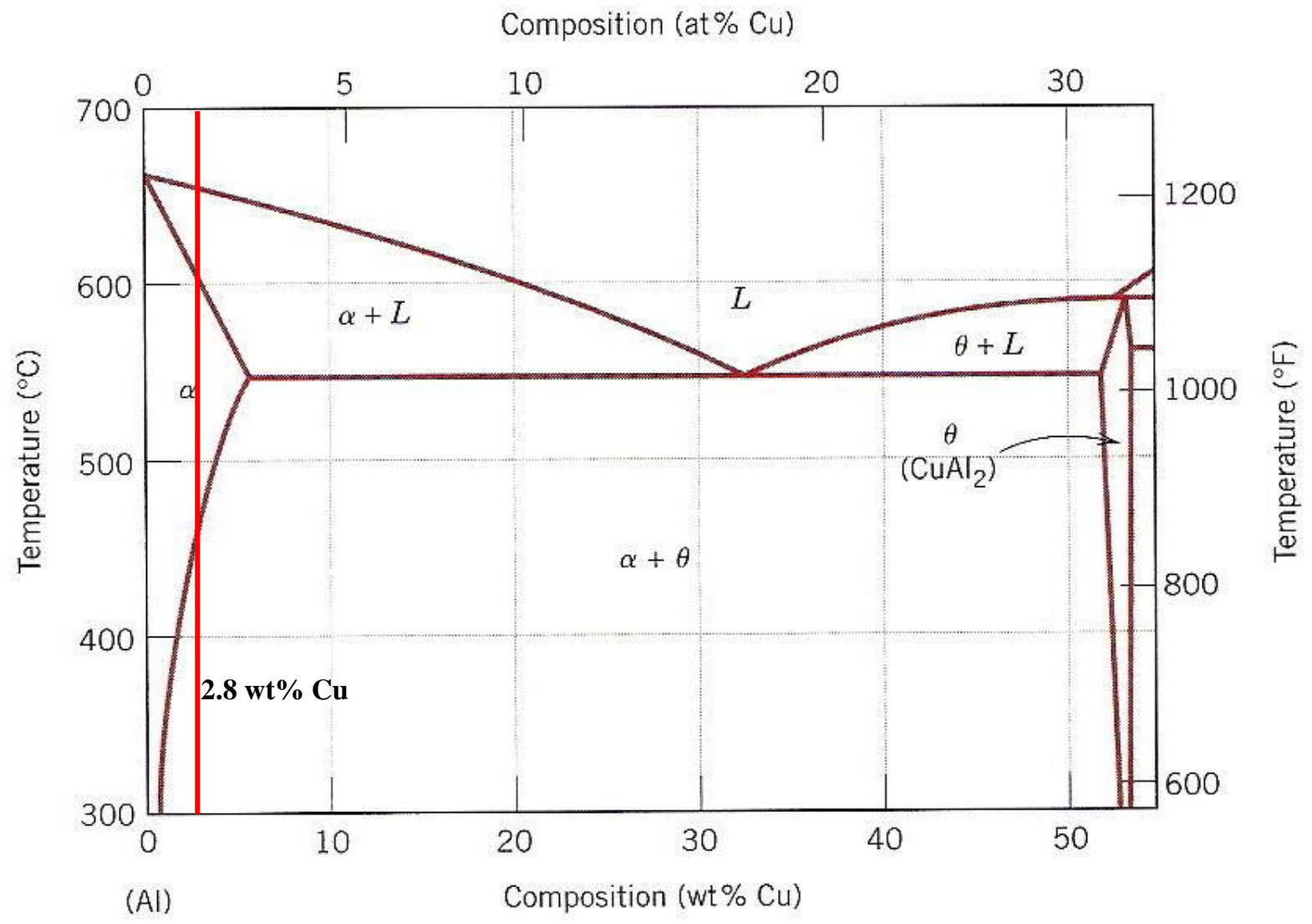

Figure G.2: Aluminum rich portion of the Al-Cu binary phase diagram [1]. 


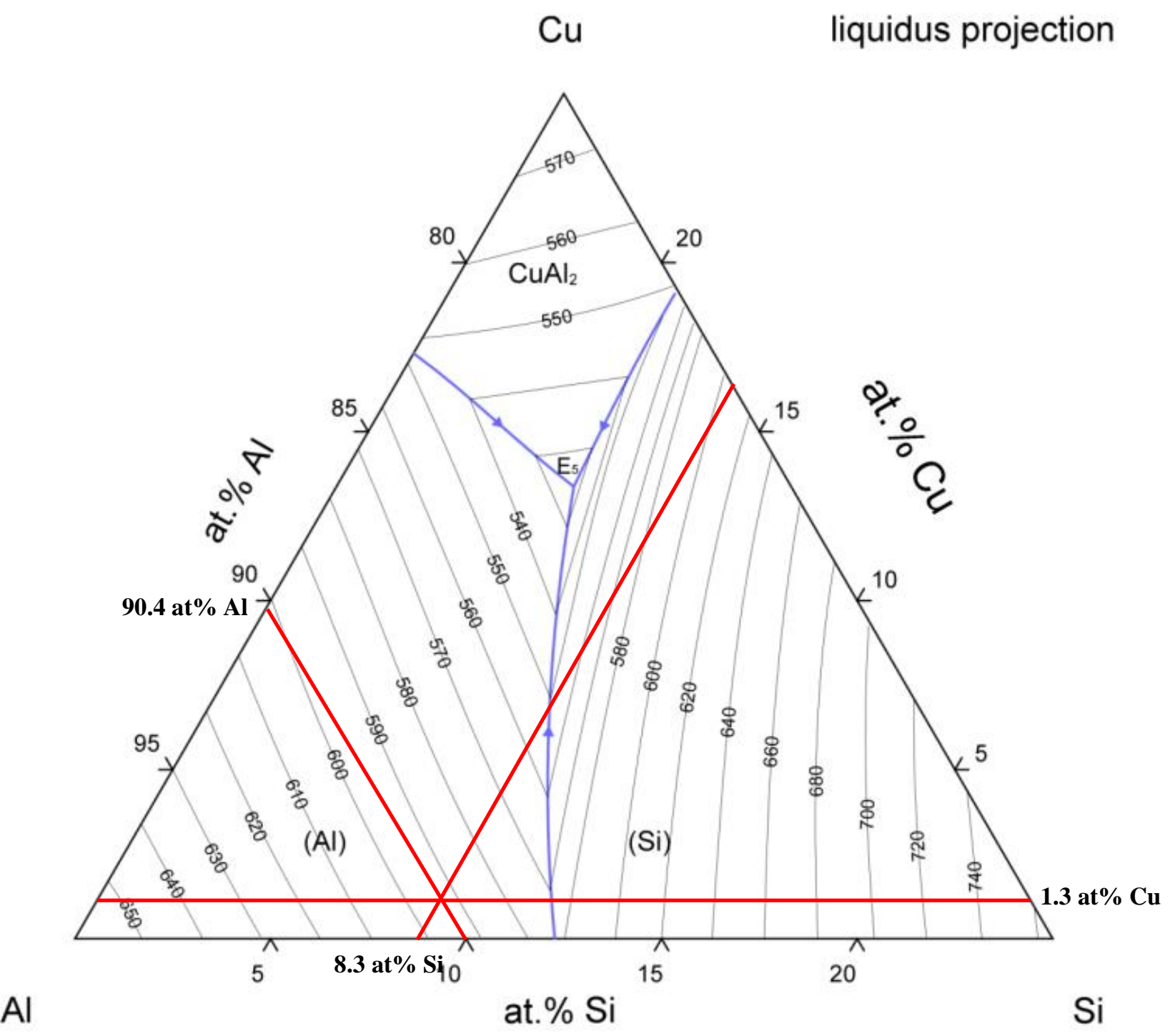

Figure G.3: Aluminum-silicon-copper ternary phase diagram [114]. 


\section{Appendix H:}

Calculation of Shear Stress using Mohr's Circle 
The application of Mohr's circle was carried out to convert the principal residual stresses, calculated from measurements of principal residual strain using neutron diffraction, into shear stresses for use on the creep deformation mechanism map (Figure 5.31).

Since principal stresses were measured using neutron diffraction, in this analysis $\tau_{x y}=\tau_{y z}=\tau_{x z}=0$. Therefore, the measured stresses can be directly plotted on the abscissa of the $\sigma-\tau$ diagram. To illustrate a representative Mohr's circle for three dimensional stress analysis, a sample calculation where the hoop $\left(\sigma_{1}\right)$, axial $\left(\sigma_{2}\right)$ and radial $\left(\sigma_{3}\right)$ stresses were estimated at 215, 205 and $90 \mathrm{MPa}$, respectively (from Table 5.1) is shown in Figure H.1. The equations used to calculate shear stress in this scenario are shown in Equations H-1 to H-3 [115].

$$
\begin{aligned}
& \tau_{1}=\frac{1}{2}\left(\sigma_{2}-\sigma_{3}\right) \\
& \tau_{2}=\frac{1}{2}\left(\sigma_{1}-\sigma_{3}\right) \\
& \tau_{3}=\frac{1}{2}\left(\sigma_{1}-\sigma_{2}\right)
\end{aligned}
$$

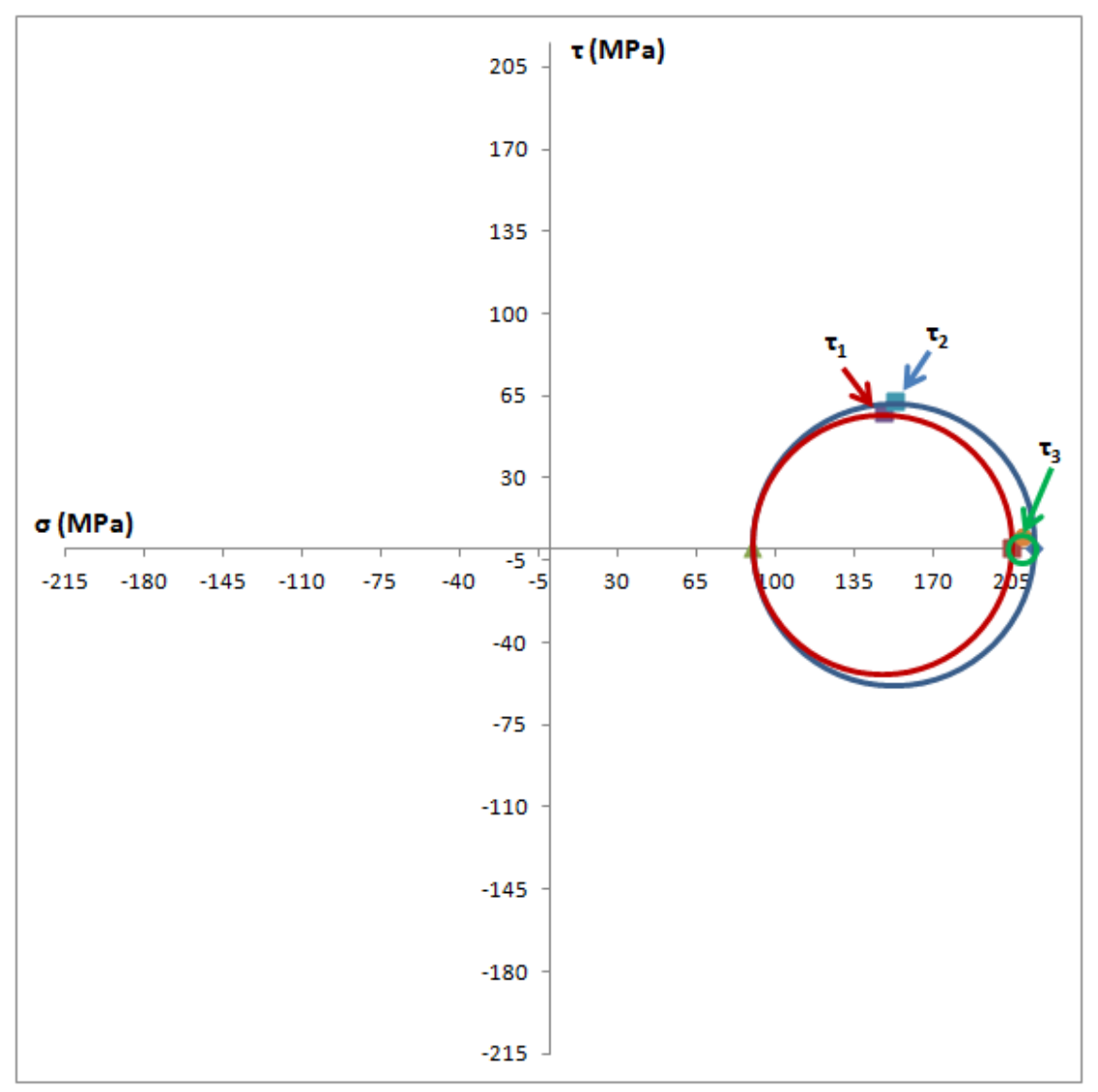

Figure H.1: Sample 3-D Mohr's circle plot for residual stress state. 


\section{Appendix l:}

Academic Achievements 


\section{I.1 Peer-Reviewed Journal Publications}

1. Lombardi, A., Sediako, D., Machin, A., Ravindran, C. and MacKay, R., "Evaluating the Effect of Solution Heat Treatment on Residual Stress in Al Engine Blocks using In-situ and Ex-situ Neutron Diffraction" (under internal review).

2. Lombardi, A., Sediako, D., Machin, A., Ravindran, C. and MacKay, R., "Transient Analysis of Residual Strain during Heat Treatment of Multi-material Engine Blocks using In-situ Neutron Diffraction", Materials Letters, Vol. 157, pp. 50-52 (2015). UniversityGovernment-Industry Collaboration

3. Lombardi, A., Ravindran, C. and MacKay, R., "Optimization of the Solution Heat Treatment Process to Improve Mechanical Properties of 319 Al Alloy Engine Blocks using the Billet Casting Method", Materials Science and Engineering A. Vol. 633, pp. 125-135 (2015). University-Industry Collaboration

4. Lombardi, A., Ravindran, C. and MacKay, R., "Application of the Billet Casting Method to Determine the Onset of Incipient Melting of 319 Al Alloy Engine Blocks", Journal of Materials Engineering and Performance, Vol. 24, pp. 2179-2184 (2015). (Invited paper: Special issue for Innovation in Processing of Light Metals for Transportation Industries-A Symposium in Honor of C. Ravi Ravindran). University-Industry Collaboration

5. Lombardi, A., Sediako, D., Ravindran, C. and MacKay, R., "In-situ Neutron Diffraction Analysis of the Stress-Free d-spacing during Solution Heat Treatment of Modified $319 \mathrm{Al}$ Alloy Engine Blocks", Canadian Metallurgical Quarterly, Vol. 54, pp. 30-37 (2015) (Invited paper: Special issue on Neutron Diffraction and Hydroelectric). UniversityGovernment-Industry Collaboration

6. Lombardi, A., Ravindran, C., Sediako, D. and MacKay, R., "Determining the Mechanism of In-Service Cylinder Distortion in Aluminum Engine Blocks with Cast-in Gray Iron Liners", Metallurgical and Materials Transactions A., Vol. 45, pp. 6291-6303 (2014). (ASM International Student Paper Award) University-Government-Industry Collaboration

7. Lombardi, A., Ravindran, C. and MacKay, R., "Improvements in Mechanical Properties of 319 Al Alloy Engine Blocks through Cost-Effective Heat Treatment", Journal of Materials Engineering and Performance, Vol. 23, pp. 2766-2771 (2014) (Invited paper based on ASM/HTS Bodycote Best Paper in Heat Treating). University-Industry Collaboration

8. Lombardi, A., Sediako, D., Ravindran, C. and MacKay, R., "Residual Stress Mapping along the Cylinder Bores of Al Alloy Engine Blocks Subjected to Production Solution Heat Treatment Schedule", SAE International Journal of Materials and Manufacturing, Vol. 7, pp. 415-420 (2014). University-Government-Industry Collaboration

9. Lombardi, A., D'Elia, F., Ravindran, C. and MacKay, R., "Replication of Engine Block Cylinder Bridge Microstructure and Mechanical Properties with Lab Scale 319 Al Alloy Billet Castings", Materials Characterization, Vol. 87, pp. 125-137 (2014). UniversityIndustry Collaboration 
10. Lombardi, A., Ravindran, C., Sediako, D. and MacKay, R., "Analysis of Residual Strain Profiles in Distorted Aluminum Engine Blocks by Neutron Diffraction", SAE International Journal of Materials and Manufacturing, Vol. 6, pp. 135-140 (2013). University-Government-Industry Collaboration

11. Lombardi, A., D’Elia, F., Ravindran, C., Sediako, D., Murty, B.S. and MacKay, R., "Interplay between Residual Stresses, Microstructure, Process Variables and Engine Block Casting Integrity", Metallurgical and Materials Transactions A., Vol. 43, pp. 52585270 (2012). Inter-University-Government-Industry Collaboration

12. Lombardi, A., Sediako, D., D'Elia, F., Ravindran, C. and MacKay, R., "Neutron Diffraction Study on Residual Stress in Aluminum Engine Blocks Following Machining and Service Testing", SAE International Journal of Materials and Manufacturing, Vol. 5, pp. 115-121 (2012). University-Government-Industry Collaboration

13. Lombardi, A., D'Elia, F., Machin, A., Ravindran, C. and MacKay, R., "Variation in Microstructure and Mechanical Properties Along the Cylinder Bores of a Modified 319 Type Al Alloy Engine Block with Cast-in Iron Liners" AFS Transactions, Vol. 119, pp. 229-238 (2011). University-Industry Collaboration

14. Lombardi, A., D'Elia, F., Ravindran, C., Murty, B.S. and MacKay, R., "Analysis of the Secondary Phases in the Microstructure of 319 Type Al Alloy Engine Blocks using Electron Microscopy and Nanoindentation", Transactions of the Indian Institute of Metals, Vol. 64, pp. 7-11 (2011). Inter-University-Industry Collaboration

15. Sediako, D., D'Elia, F., Lombardi, A., Machin, A., Ravindran, C., Hubbard, C. and MacKay, R., "Analysis of Residual Stress Profiles in the Cylinder Web Region of an AsCast V6 Al Engine Block with Cast-In Fe Liners Using Neutron Diffraction", SAE International Journal of Materials and Manufacturing, Vol. 4, pp. 138-151 (2011). University-Inter-Government-Industry Collaboration

16. Lombardi, A., Lun Sin, S. and Ravindran, C., "Influence of Silicon on the Microstructure and Mechanical Properties of Lost Foam cast AE42 Magnesium Alloy", AFS Transactions, Vol. 118, pp. 331-338 (2010).

17. Lun Sin, S., Lombardi, A. and Ravindran, C., "Influence of Calcium on the Castability, Microstructure and Mechanical Properties of Lost Foam cast AE42 Magnesium Alloy", AFS Transactions, Vol. 117, pp. 651-658 (2009).

\section{I.2 Conference Proceedings}

1. D'Elia, F., Lombardi, A., Ravindran, C., Sediako, D. and Rao, K.P., “Assessment of Hot Cracking during TIG Welding of B206 Aluminum Alloy", TMS Annual Meeting, San Diego, CA, USA, February 16-20, 2014.

2. Lombardi, A., Sediako, D., Ravindran, C. and MacKay, R., "Analysis of the Stress-Free Interplanar Spacing during Solution Heat Treatment of 319 Al Alloy Engine Blocks using In-Situ Neutron Diffraction", MS\&T 2013: Applied Neutron Scattering Symposium, Montreal, Quebec, Canada, October 27-31, 2013. 
3. Lombardi, A., Lun Sin, S. and Ravindran, C., "Effect of Silicon on the Microstructure and Tensile Properties of AE42 Magnesium Alloy", $9^{\text {th }}$ International Conference on Magnesium Alloys and their Applications, Vancouver, British Columbia, Canada, July 8-12, 2012.

4. Sediako, D., Lombardi, A., D'Elia, F., Ravindran, C., Machin, A., Rogge, R.B. and MacKay, R., "Residual Stress Mapping in the Interbore Region of a Heat Treated Aluminum Engine Block", COM 2011 Conference Proceedings, Montreal, Quebec, Canada, October 2-5, 2011.

5. Sediako, D., D’Elia, F., Lombardi, A., Machin, A., Ravindran, C., Hubbard, C. and MacKay, R., "Application of Neutron Diffraction in Analysis of Residual Stress Profiles in the Cylinder Web Region of an As-cast V6 Al Engine Block with Cast-in Fe Liners", TMS Annual Meeting, San Diego, CA,USA, February 27 - March 3, 2011.

\section{I.3 Conference Presentations}

1. Lombardi, A., Machin, A., Sediako, D., Ravindran, C. and MacKay, R., "Analysis of Time-dependant Residual Stress Relief during Solution Heat Treatment of Al Engine Blocks using In-situ Neutron Diffraction”, SAE World Congress, Detroit, MI, USA, April 21-23, 2015.

2. Lombardi, A., Ravindran, C., Sediako, D. and MacKay, R., "Improving Al Alloy Engine Block Casting Integrity via Heat Treatment Optimization", MS\&T 2014: Innovation in Processing of Light Metals for Transportation Industries-A Symposium in Honor of C. Ravi Ravindran, Pittsburgh, PA. USA, October 12-16, 2014.

3. Lombardi, A., Sediako, D., Ravindran, C. and MacKay, R., "Residual Stress Mapping along the Cylinder Bores of Al Alloy Engine Blocks Subjected to Production Solution Heat Treatment Schedule", SAE World Congress, Detroit, MI, USA, April 8-10, 2014.

4. Lombardi, A., Ravindran, C., Sediako, D. and MacKay, R., "Analysis of Residual Strain Profiles in Distorted Aluminum Engine Blocks by Neutron Diffraction", SAE World Congress, Detroit, MI, USA, April 16-18, 2013.

5. Lombardi, A., D'Elia, F., Machin, A., Ravindran, C. and MacKay, R., "Variation in Microstructure and Mechanical Properties along the Cylinders of V6 Al Engine Blocks", Canadian Materials Science Conference, Kelowna, British Columbia, Canada, June 2224, 2011.

6. Lombardi, A., D'Elia, F., Ravindran, C., Murty, B.S. and MacKay, R., "Analysis of Secondary Phases in 319 Type Al Alloy Engine Blocks", International Symposium of Research Scholars, Chennai, India, December 20-22, 2010.

7. Lombardi, A., D'Elia, F., Ravindran, C., Murty, B.S. and MacKay, R., "Characterization of Microstructure and Mechanical Properties of A319 Aluminum Engine Blocks", Indian Institute of Metals National Metallurgists Day - Annual Technical Meeting, Bangalore, India, November 14-16, 2010. 
8. Lombardi, A., Lun Sin, S. and Ravindran, C., "Influence of Silicon on the Microstructure and Mechanical Properties of Lost Foam cast AE42 Magnesium Alloy", $114^{\text {th }}$ AFS Metalcasting Congress, Orlando, FL, USA, March 20-23, 2010.

\section{I.4 Scholarships, Awards and Fellowships}

1. 2015 ASM International Student Paper Contest Award

2. 2014-15 Ryerson University Graduate Seminar Award

3. 2015 NSERC Post-Doctoral Fellowship (PDF) Award

(Ranked Top 10 in Canada for Chemical, Biomedical and Materials Science Engineering Stream)

4. 2014-15 Ryerson University-YSGS Doctoral Completion Award

5. 2014 Ontario Graduate Scholarship (OGS)

6. 2014 CIM-MetSoc Doctoral Student Scholarship

7. 2014 ASM/HTS Bodycote Best Paper in Heat Treatment Award

8. 2014 FEF George Barker Memorial Scholarship

9. 2012 AUTO21 Test Drive Competition Award

10. 2012 CFA Non-ferrous Association Scholarship

11. 2012 FEF George Barker Memorial Scholarship

12. 2011 NSERC Alexander Graham Bell Canada Graduate Scholarship (CGS-D)

13. 2011 Ontario Graduate Scholarship (OGS) (Declined)

14. 2011 AUTO21 HQP Poster Competition $\left(5^{\text {th }}\right.$ Prize $)$

15. 2010 NSERC CGS Michael Smith Foreign Study Supplement

16. 2010 Ontario Graduate Scholarship (OGS)

17. 2010 AUTO21 HQP Poster Competition, $4^{\text {th }}$ overall, best in materials theme.

18. 2009 FEF George Barker Memorial Scholarship

19. 2009 NSERC Alexander Graham Bell Canada Graduate Scholarship (CGS-M)

20. 2009 NSERC Undergraduate Student Research Award

21. 2009 AFS-Ontario Scholarship

22. 2008 NSERC Undergraduate Student Research Award

23. 2008 J. L. Beaton Award

24. 2008 George Wong Achievement Award

25. 2007 Jeld-Wen Achievement Award 


\section{References}

1. Davis, J.R., “ASM Specialty Handbook: Aluminum and Aluminum Alloys", ASM International, Materials Park, OH, USA (1993).

2. Klier, T. and Linn, J., "Corporate Average Fuel Economy and the Market for New Vehicles”, Dianne Publishing Co., Darby, PA, USA (2011).

3. Heisler, H., "Advanced Engine Technology", Butterworth-Heinemann, Oxford, U.K. (2001).

4. Li, M., Vijayaraghavan, R., Wolverton, C. and Allison, J.E., "Simulation of Local Microstructures and Thermal Growth of a Cast 319 Aluminum Alloy Component, $1^{\text {st }}$ International Symposium on Metallurgical Modeling for Aluminum Alloys, Pittsburgh, PA, USA, October 13-15 (2003).

5. Hunsicker, H.Y., "Dimensional Changes in Heat Treating Aluminum Alloys", Metallurgical and Materials Transactions A., vol. 11, pp.759-773 (1980).

6. Boileau, J.M., Cloutier, C.A., Godlewski, L.A., Reeber-Symanksi, P.A., Wolverton, C. and Allison, J.E., "The Dimensional Stability of Cast 319 Aluminum”, SAE Transactions, vol. 112, pp. 385-395 (2003).

7. Busby, A. and Archibald, J., "Expanded Opportunities for Precision Sand Casting Utilizing Coldbox Binders", AFS Transactions, Vol. 113, pp. 344-355 (2005).

8. Byczynski, G. and MacKay, R., "The Nemak Cosworth Casting Process-Innovation", Shape Casting: 3rd International Symposium, pp. 199-206 (2009).

9. Tavitas-Medrano, F.J., Gruzleski, J.E., Samuel, F.H., Valtierra, S. and Doty, H.W., "Effect of Mg and Sr-Modification on the Mechanical Properties of 319-type Aluminum Cast Alloys Subjected to Artificial Aging", Materials Science and Engineering A., vol.480, pp. 356-364 (2008).

10. Samuel, F.H., Ouellete, P., Samuel, A.M. and Doty, H.W., "Effect of $\mathrm{Mg}$ and $\mathrm{Sr}$ Additions on the Formation of Intermetallics in Al-6 wt pet Si- 3.5 wt pct $\mathrm{Cu}-(0.45)$ to (0.8) wt pct Fe 319-type Alloys", Metallurgical and Materials Transactions A, Vol. 29, pp. 2871-2884 (1998).

11. Hegde, S. and Prahbu, K., "Modification of Eutectic Silicon in Al-Si Alloys", Journal of Materials Science, vol. 43, pp. 3009-3027 (2008).

12. Li, Z., Samuel, A.M., Samuel, F.H., Ravindran, C. and Valtierra, S., "Effect of Alloying Elements on the Segregation and Dissolution of $\mathrm{CuAl}_{2}$ Phase in Al-Si-Cu 319 Alloys", Journal of Materials Science, vol. 38, pp. 1203-1218 (2003).

13. Apelian, D., Sigworth, G. and Whaler, K., "Assessment of Grain Refinement and Modification of Al-Si Foundry Alloys by Thermal Analysis", AFS Transactions, vol. 92, pp. 297-307 (1984).

14. Dahle, A.K., Nogita, K., McDonald, S.D., Dinnis, C. and Lu, L., "Eutectic Modification and Microstructure Development in Al-Si Alloys", Materials Science and Engineering A., vol. 413-414, pp. 243-248 (2005). 
15. Cook, R., "Modification of Aluminum-Silicon Foundry Alloys", Technical Report: London \& Scandinavian Metallurgical Co Limited, London, England (1998).

16. Ogris, E., Wahlen, A., Luchinger, H. and Uggowitzer, P.J., "On the Silicon Spheroidization in Al-Si Alloys", Journal of Light Metals, vol. 2, pp.263-269 (2002).

17. Li, J.H., Barrirero, J., Engstler, M., Aboulfadl, H., Mucklich, F. and Schumacher, P., "Nucleation and Growth of Eutectic Si in Al-Si Alloys with Na Addition", Metallurgical and Materials Transactions A., vol. 46, pp. 1300-1311 (2015).

18. Fatahalla, N., Hafiz, M. and Abdulkhalek, M., "Effect of Microstructure on the Mechanical Properties and Fracture of Commercial Hypoeutectic Al-Si Alloy Modified with Na, Sb and Sr", Journal of Materials Science, vol. 34, pp. 3555-3564 (1999).

19. Sokolowski, J.H., Djurdjevic, M.B., Kierkus, C.A. and Northwood, D.O., "Improvement of 319 Aluminum Alloy Casting Durability by High Temperature Solution Treatment", Journal of Materials Processing Technology, vol. 109, pp. 174-180 (2001).

20. Lasa, L. and Rodriguez-Ibabe, J., "Evolution of the Main Intermetallic Phases in Al-Si-Cu-Mg Casting Alloys during Solution Heat Treatment", Journal of Materials Science, vol. 39, pp. 1343-1355 (2004).

21. Ibrahim, M.F., Samuel, E., Samuel, A.M., Al-Ahmari, A.M.A. and Samuel, F.H., "Metallurgical Parameters Controlling the Microstructure and Hardness of Al-Si-Cu-Mg Base Alloys", Materials and Design, vol. 32, pp. 2130-2142 (2011).

22. Samuel, A.M., Doty, H.W., Valtierra, S. and Samuel, F.H., "Effect of Mg Addition on Microstructure of 319 Type Alloys, International Journal of Cast Metals Research, vol. 26, pp. 354-363 (2013).

23. Hwang, J., Banerjee, R., Doty, H.W. and Kaufman, M., "The Effect of Mg on the Structure and Properties of Type 319 Aluminum Casting Alloys", Acta Materialia, vol. 57, pp. 1308-1317 (2009).

24. Samuel, A.M., Ouellet, P., Samuel, F.H. and Doty, H.W., "Microstructural Interpretation of Thermal Analysis of Commercial 319 Al Alloy with Mg and Sr Additions", AFS Transactions, vol. 105, pp. 951-962 (1997).

25. Chakrabarti, A., "Casting Technology and Cast Alloys", Prentice-Hall of India, New Delhi (2005).

26. Hwang, J., Doty, H.W. and Kaufman, M., "The Effects of Mn Additions on the Microstructure and Mechanical Properties of $\mathrm{Al}-\mathrm{Si}-\mathrm{Cu}$ Casting Alloys", Materials Science and Engineering A, vol. 488, pp. 496-504 (2008).

27. Narayanan, L., Samuel, F.H. and Gruzleski, J.E., "Crystallization Behavior of IronContaining Intermetallic Compounds in 319 Aluminum Alloy", Metallurgical and Materials Transactions A, vol. 25, pp. 1761-1773 (1994).

28. Hwang, J., Doty, H.W. and Kaufman, M., "Crystallographic Studies on the IronContaining Intermetallic Phases in the 319-type Aluminum Casting Alloys", Philosophical Magazine, Vol. 88, pp. 607-619 (2008).

29. Albonetti, R., "Porosity and Intermetallic Formation in Lost Foam Casting of 356 Alloy", M.E.Sc. Thesis, University of Western Ontario, London, Ontario, Canada (1997). 
30. Garcia-Garcia, G., Espinoza-Cuadra, J. and Mancha-Molinar, H., "Copper Content and Cooling Rate Effects over Second Phase Particles Behavior in Industrial Aluminum-Silicon Alloy 319”, Materials \& Design, Vol. 28, pp. 428-433 (2007).

31. Rajan, T.V., Sharma, C.P. and Sharma, A., "Heat Treatment Principles and Techniques", Prentice-Hall of India, New Delhi, pp. 341-345 (1999).

32. Sharma, R.C., "Phase Transformations in Materials", CBS Publishers and Distributers, New Delhi, pp. 151-156 (2002).

33. Cerri, E., Evangelista, E., Spigarelli, S., Cavaliere, P. and DeRiccardis, F., "Effects of Thermal Treatments on Microstructure and Mechanical Properties in a Thixocast 319 Aluminum Alloy", Materials Science and Engineering A., vol. 284, pp. 254-260 (2000).

34. Wang, P.S., Lee, S.L., Lin, J.C. and Jahn, M.T., "Effects of Solution Temperature on Mechanical Properties of 319.0 Casting Alloys Containing Trace Beryllium”, Journal of Materials Research, vol. 15, pp 2027-2035 (2000).

35. Samuel, A.M., Gauthier, J. and Samuel, F.H., "Microstructural Aspects of the Dissolution and Melting of $\mathrm{Al}_{2} \mathrm{Cu}$ Phase in Al-Si Alloys During Solution Heat Treatment", Metallurgical and Materials Transactions A., vol. 27, pp. 1785-1798 (1996).

36. Shivakumar, S., Ricci Jr., S., Keller, C. and Apelian, D., "Effect of Solution Treatment Parameters on Tensile Properties of Cast Aluminum Alloys", Journal of Heat Treating, vol. 8, pp. 63-70 (1990).

37. Chaudhury, S.K. and Apelian, D., "Fluidized Bed Heat Treatment of Cast Al-Si-Cu-Mg Alloys", Metallurgical and Materials Transactions A., vol. 37, pp. 2295-2311 (2006).

38. Gauthier, J., Louchez, P.R. and Samuel, F.H., "Heat Treatment of 319.2 Aluminum Automotive Alloy: Part 1 Solution Heat Treatment", Cast Metals, vol. 8, pp. 91-114 (1994).

39. Toda, H., Nishimura, T., Uesugi, K., Suzuki, Y. and Kobayashi, M., "Influence of HighTemperature Solution Treatments on Mechanical Properties of an Al-Si-Cu Aluminum Alloy”, Acta Materialia, vol. 58, pp. 2014-2025 (2010).

40. Han, Y.M., Samuel, A.M., Doty, H.W., Valtierra, S. and Samuel, F.H., "Optimizing the Tensile Properties of Al-Si-Cu-Mg 319-type Alloys: Role of Solution Heat Treatment”, Materials and Design, vol. 58, pp.426-438 (2014).

41. Sjolander, E. and Seifeddine, S., "Optimization of Solution Treatment of Cast Al-7Si$0.3 \mathrm{Mg}$ and $\mathrm{Al}-8 \mathrm{Si}-3 \mathrm{Cu}-0.5 \mathrm{Mg}$ Alloys”, Metallurgical and Materials Transactions A., vol. 45, pp. 1916-1927 (2014).

42. Colley, L.J., Wells, M.A., MacKay, R. and Kasprzak, W., "Dissolution of Second Phase Particles in 319-Type Aluminum Alloy", Heat Treat 2011, Proceedings of the $26^{\text {th }}$ Heat Treating Society Conference, pp.189-198 (2011).

43. Han, Y.M., Samuel, A.M., Samuel, F.H., Valtierra, S. and Doty, H.W., "Effect of Solution Heat Treatment type on the Dissolution of Copper Phases in Al-Si-Cu-Mg type Alloys", AFS Transactions, Vol. 116, pp. 79-90 (2008). 
44. Lasa, L. and Rodriguez-Ibabe, J.M., "Characterization of the Dissolution of the $\mathrm{Al}_{2} \mathrm{Cu}$ Phase in Two Al-Si-Cu-Mg Alloys using Calorimetry", Materials Characterization, vol. 48, pp. 371-378 (2002).

45. Wang, G., Bian, X., Wang, W. and Zhang, J., "Influence of $\mathrm{Cu}$ and Minor Elements on Solution Treatment of Al-Si-Cu-Mg Cast Alloys", Materials Letters, vol. 57, pp. 40834087 (2003).

46. Han, Y.M., Samuel, A.M., Samuel, F.H. and Doty, H.W., "Dissolution of $\mathrm{Al}_{2} \mathrm{Cu}$ Phase in Non-Modified and Sr Modified 319 Type Alloys", International Journal of Cast Metals Research, vol. 21, pp.387-393 (2008).

47. Samuel, A.M., Doty, H.W., Valtierra, S. and Samuel, F.H., "Defects Related to Incipient Melting in Al-Si-Cu-Mg Alloys", Materials and Design, vol. 52, pp. 947-956 (2013).

48. Samuel, F.H., "Incipient melting of $\mathrm{Al}_{5} \mathrm{Mg}_{8} \mathrm{Si}_{6} \mathrm{Cu}_{2}$ and $\mathrm{Al}_{2} \mathrm{Cu}$ Intermetallics in Unmodified and Strontium-modified Al-Si-Cu-Mg (319) Alloys during Solution Heat Treatment", Journal of Materials Science, Vol. 33, pp. 2283-2297 (1998).

49. Han, Y.M., Samuel, A.M., Samuel, F.H. and Doty, H.W., "Microstructure Characteristics in Non-Modified and Sr-Modified Al-Si-Cu-Mg 319 Type Alloys", International Journal of Cast Metals Research, vol. 21, pp.371-380 (2008).

50. Mohamed, A.M.A., Samuel, F.H. and Al Kahtani, S., "Influence of Mg and Solution Heat Treatment on the Occurrence of Incipient Melting in Al-Si-Cu-Mg Alloys", Materials Science and Engineering A., vol. 543, pp. 22-34 (2012).

51. Fuoco, R. and Correa, E.R., "Incipient Melting during Solution Heat Treatment of Al-SiMg and Al-Si-Cu-Mg Alloys", AFS Transactions, vol. 110, pp.417-433 (2002).

52. Backerud, L., Chai, G. and Tamminen, J., "Solidification Characteristics of Aluminum Alloys", vol.2: Foundry Alloys, AFS/SKANALUMINIUM, Des Plaines, IL, (1990).

53. Sjolander, E. and Seifeddine, S., "Artificial Aging of Al-Si-Cu-Mg Casting Alloys", Materials Science and Engineering A., vol. 528, pp. $7402-7409$ (2011).

54. Tash, M., Samuel, F.H., Mucciardi, F. and Doty, H.W., "Effect of Metallurgical Parameters on the Hardness and Microstructural Characterization of As-Cast and Heat Treated 356 and 319 Aluminum Alloys”, Materials Science and Engineering A., vol. 443, pp.185-201 (2007).

55. Polmear, I., "Light Alloys, Metallurgy of the Light Metals", $3^{\text {rd }}$ Edition, Butterworth-Heinemann, Melbourne (1995).

56. Wang, G., Bian, X., Qiao, J. and Zhang, J., "Effect of Be on the Aging Behavior of an Al-Si-Cu-Mg Cast Alloy", Journal of Materials Engineering and Performance, Vol. 13, pp. 99-102 (2004).

57. Ouellet, P. and Samuel, F.H., "Effect of $\mathrm{Mg}$ on the Aging Behaviour of Al-Si-Cu 319 Type Aluminum Casting Alloys", Journal of Materials Science, vol. 34, pp. 4671-4697 (1999).

58. Ovono, D.O., Guillot, I. and Massinon, D., "The Microstructure and Precipitation Kinetics of a Cast Aluminum Alloy”, Scripta Materialia, vol. 55, pp. 259-262 (2006). 
59. Weakley-Bollin, S.C., Donlon, W., Wolverton, C., Jones, J.W. and Allison, J.E., "Modelling the Age-Hardening Behaviour of Al-Si-Cu Alloys", Metallurgical and Materials Transactions A., vol. 35, pp. 2407-2418 (2004).

60. Yao, J.Y., Edwards, G.A. and Graham, D.A., "Precipitation and Age-Hardening in Al-SiCu-Mg-Fe Casting Alloys", Materials Science Forum, vol. 217-222, pp. 777-782 (1996).

61. Tavitas-Medrano, F.J., Mohamed, A.M.A., Gruzleski, J.E., Samuel, F.H. and Doty, H.W., "Precipitation Hardening in Cast Al-Si-Cu-Mg Alloy", Journal of Materials Science, vol. 45, pp. 641-651 (2010).

62. Callister Jr. and W.D., Rethwisch, D.G., "Materials Science and Engineering An Introduction", $9^{\text {th }}$ Edition, John Wiley \& Sons, Hoboken, NJ, USA (2014).

63. Gerold, V., "Precipitation Hardening. In: Nabarro, F.R.N. (Ed.), Dislocations in Solids" North-Holland Publishing Company, Amsterdam, pp. 222 (1979).

64. Dieter, G., "Mechanical Metallurgy", $2^{\text {nd }}$ Edition, McGraw-Hill International, London, England (1981).

65. Gloria, D., Hernandez, F., Valtierra, S. and Cisneros, M.A., "Dimensional Changes during Heat Treating of an Automotive 319 Alloy", 20 $0^{\text {th }}$ ASM Heat Treating Conference, St. Louis, MO, October 9 -12 (2000).

66. Withers, P. and Bhadeshia, H.K.D.H., "Residual Stress Part 2 - Nature and Origins", Materials Science and Technology, vol. 17, pp. 356-375 (2004).

67. Robinson, J.S. and Tanner, D.A., "The Magnitude of Heat Treatment Induced Residual Stresses and the Thermal Stress Relief of Aluminum Alloys", Materials Science Forum, vol. 404-407, pp. 355-360 (2002).

68. Barson, J. and Rolfe, S., "Fracture and Fatigue Control in Structures: Applications of Fracture Mechanics", ASTM International, West Conshohocken, PA (1999).

69. Boley, B. and Weiner, J., "Theory of Thermal Stresses", John Wiley and Sons., New York, NY (1960).

70. Shen, Y., "Constrained Deformation of Materials: Devices, Heterogeneous Structures and Thermo-Mechanical Modelling", Springer Science + Business Media (2010).

71. Withers, P.J., "Residual Stress and its Role in Failure", Reports on Progress in Physics, vol. 70, pp. 2211-2264 (2007).

72. Godlewski, L.A., Su, X., Allison, J.E., Gustafson, P. and Pollock, T.M., "A Test Method for Quantifying Residual Stress due to Heat Treatment in Metals", SAE World Congress, Detroit, MI, USA, April 3-6 (2006).

73. Robinson, J.S., Tanner, D.A., Truman, C.E., Paradowska, A.M. and Wimpory, R.C., "The Influence of Quench Sensitivity on Residual Stresses in the Aluminum Alloys 7010 and 7075", Materials Characterization, vol. 65, pp. 73-85 (2012).

74. Robinson, J.S. and Tanner, D.A., "Reducing Residual Stress in 7050 Aluminum Alloy Die Forgings by Heat Treatment”, Journal of Materials Engineering and Technology, vol. 130, pp. 1-8 (2008). 
75. Robinson, J.S. and Tanner, D.A., "Residual Stress Development and Relief in High Strength Aluminum Alloys using Standard and Retrogression Thermal Treatments", Materials Science and Technology, vol. 19, pp. 512-518 (2003).

76. Li, K., Xiao, B. and Wang, Q., "Residual Stresses in As-Quenched Aluminum Castings", SAE World Congress, Detroit, MI, USA, April 14-17 (2008).

77. Tiryakioglu, M. and Totten, G., "Quenching Aluminum Components in Water: Problems and Alternatives", Heat Treating: Proceedings of the $18^{\text {th }}$ Conference, October $12^{\text {th }}-15^{\text {th }}$ (1998).

78. Carrera, E., Rodriguez, A., Talamantes, J., Valtierra, S. and Colas, R., "Measurement of Residual Stresses in Cast Aluminum Engine Blocks", Journal of Materials Processing Technology, Vol. 189, pp. 206-210 (2007).

79. Reihle, M., Hofmann, M., Wasmuth, U., Volk, W., Hoffmann, H. and Petry, W., "In-situ Strain Measurements during Casting using Neutron Diffraction", Materials Science Forum, vol. 768-769, pp. 484-491 (2014).

80. Su, X., Jan, J., Lasecki, J. and Allison, J., "Thermal and Residual Stress Analysis of an Engine Block with Cast-in Liners", $1^{\text {st }}$ International Symposium on Metallurgical Modelling for Aluminum Alloys, Pittsburgh, U.S.A., October 13-15 (2003).

81. Sediako, D., D’Elia, F., Lombardi, A., Machin, A., Ravindran, C., Hubbard, C. and MacKay, R., "Analysis of Residual Stress Profiles in the Cylinder Web Region of an AsCast V6 Al Engine Block with Cast-In Fe Liners Using Neutron Diffraction", SAE International Journal of Materials and Manufacturing, vol. 4, pp.138-151 (2011).

82. Lados, D.A., Apelian, D. and Wang, L., "Minimization of Residual Stress in Heat Treated Al-Si-Mg Alloys using Uphill Quenching: Mechanisms and Effects on Static and Dynamic Properties", Materials Science and Engineering A., vol. 527, pp. 3159-3165 (2010).

83. Rolph, J., Evans, A., Paradowska, A., Hofmann, M., Hardy, M. and Preuss, M., "Stress Relaxation through Aging Heat Treatment-A Comparison between In-situ and Ex-situ Neutron Diffraction”, Comptes Rendus Physique, vol. 13, pp. 307-315 (2012).

84. Wu, C. and Makhlouf, M., "Modelling the Distortion and Residual Stresses Caused by Heat Treating Aluminum Alloy Cast Components", Proceedings of $6^{\text {th }}$ International Quenching and Control of Distortion Conference, Chicago, IL, USA, September 9-13 (2012).

85. Chen, B., Skouras, A., Wang, Y.Q., Kelleher, J.F., Zhang, S.Y., Smith, D.J., Flewitt, P.E.J. and Pavier, M.J., "In-situ Neutron Diffraction Measurement of Residual Stress Relaxation in a Welded Steel Pipe during Heat Treatment", Materials Science and Engineering A., vol. 590, pp. 374-383 (2014).

86. Holzapfel, H., Schulze, V., Vohringer, O. and Macherauch, E., "Residual Stress Relaxation in an AISI 4140 Steel due to Quasistatic and Cyclic Loading at Higher Temperatures", Materials Science and Engineering A., vol. 248, pp. 9-18 (1998). 
87. Godlewski, L.A., Su, X., Pollock, T.M. and Allison, J.E., "The Effect of Aging on the Relaxation of Residual Stress in Cast Aluminum", Metallurgical and Materials Transactions A., vol. 44, pp. 4809-4818 (2013).

88. Wiesner, D.J., Watkins, T.R., Ely, T.M., Spooner, S., Hubbard, C. and Williams, J.C., "Residual Stress Measurements of Cast Aluminum Engine Blocks using Diffraction", International Centre for Diffraction Data, Advances in X-ray Analysis, vol. 48, pp. 136142 (2005).

89. Lombardi, A. "A Study of Cylinder Bore Distortion in V6 Aluminum Alloy Engine Blocks", M.A.Sc. Thesis, Ryerson University, Toronto, Ontario, Canada (2011).

90. Meadows, J.D., "Measurement of Geometric Tolerances in Manufactuing", Marcel Dekker Inc., New York (1998).

91. Simpson, R., "The Use of Chills as a Means of Influencing Solidification in Lost Foam Cast Aluminum Alloy 356", M.E.Sc. Thesis, University of Western Ontario, London, Ontario, Canada (1997).

92. Unlu, N., "Preparation of High Quality Al TEM Specimens via a Double-jet Electropolishing Technique", Materials Characterization, Vol. 59, pp. 547-553 (2008).

93. ASTM B557, "Standard Test Methods for Tension Testing Wrought and Cast Aluminum and Magnesium Alloy Products", ASTM International, West Conshohocken, PA (2006).

94. Withers, P.J., "Mapping Residual and Internal Stresses in Materials by Neutron Diffraction", Comptes Rendus Physique, vol. 8, pp. 806-820 (2007).

95. Withers, P. and Bhadeshia, H.K.D.H., "Residual Stress Part 1-Measurement Techniques", Materials Science and Technology, Vol. 17, pp. 355-365 (2004).

96. ISO/TS 21432: "Non-Destructive Testing - Standard Test Method for Determining Residual Stresses by Neutron Diffraction", $1^{\text {st }}$ Edition, (2005).

97. Clausen, B., Lorentzen, T. and Leffers, T., "Self-Consistent Modelling of the Plastic Deformation of F.C.C. Polycrystals and its Implications for Diffraction Measurements of Internal Stresses" Acta Materialia, vol. 46, pp. 3087-3098 (1998).

98. "Thermal Conductivity of Metals", Retrieved June 11, 2013 from http://www.engineeringtoolbox.com/thermal-conductivity-metals-d_858.html

99. "Thermocouple Tolerances Reference Guide", Retrieved July 22, 2015 from http://www.omega.ca/toc_asp/frameset.html?book=Temperature\&file=tc_colorcodes

100. Dassault Systemes Solidworks Corporation, "Solidworks Flow Simulation 2011 Technical Reference" (2011).

101. Oosthuizen, P.H. and Naylor, D., "An Introduction to Convective Heat Transfer Analysis", WCB/McGraw-Hill (1999).

102. Torres, R., Esparza, J., Velasco, E., Garcia-Luna, S. and Colas, R., "Characterisation of an Aluminum Engine Block", International Journal of Microstructure and Materials Properties, vol. 1, pp. 129-138 (2006).

103. Totten, G., "Handbook of Residual Stress and Deformation of Steel", ASM International, Materials Park, OH (2002). 
104. Vazquez-Lopez, C., Calderone, A., Rodriguez, M.E., Velasco, E., Cano, S., Colas, R. and Valtierra, S., "Influence of Dendrite Arm Spacing on the Thermal Conductivity of an Aluminum-Silicon Casting Alloy", Journal of Materials Research, vol. 15, pp. 85-91 (2000).

105. Spear, R.E. and Gardner, G.R., "Dendrite Cell Size", AFS Transactions, vol. 71, pp. 209215 (1963).

106. Caceres, C.H., Davidson, C.J. and Griffiths, J.R., "The Deformation and Fracture Behavior of an Al-Si-Mg Casting Alloy", Materials Science and Engineering A., vol. 197, pp.171-179 (1995).

107. Djurdjevic, M., MacKay, R., Ren, Q. and Sokolowski, J.H., "Effect of Cu and Si on the Microstructural Properties in the 3xx.x Alloy Series", Proceedings of the TMS Annual Meeting, Seattle, WA., USA, February 17-21, 2002.

108. Haro, S., Ramirez, J., Dwivedi, D.K. and Martinez, E., "Influence of Solutionizing and Aging Temperatures on Microstructure and Mechanical Properties of Cast Al-Si-Cu Alloy”, Materials Science and Technology, vol. 25, pp. 886-891 (2009).

109. Espinoza-Cuadra, J., Garcia-Garcia, G. and Mancha-Molinar, H., "Influence of Defects on Strength of Industrial Aluminum Alloy Al-Si 319”, Materials and Design, vol. 28, pp. 1039-1044 (2007).

110. Sokolowski, J.H., Sun, X-C., Byczynski, G., Northwood, D.O., Penrod, D.E., Thomas, R. and Esseltine, A., "The Removal of Copper-Phase Segregation and the Subsequent Improvement in Mechanical Properties of Cast 319 Aluminum Alloys by a Two-Stage Solution Heat Treatment”, Journal of Materials Processing Technology, vol. 53, pp. 385392 (1995).

111. Fultz, B. and Howe, J.M., "Transmission Electron Microscopy and Diffractometry of Materials, $4^{\text {th }}$ Edition", Springer-Verlag, Berlin (2013).

112. Frost, H.J. and Ashby, M.F., "Deformation-Mechanism Maps, the Plasticity and Creep of Metals and Ceramics", Pergamon Press, Oxford (1982).

113. Farkoosh, A.R. and Pekguleryuz, M., "Enhanced Mechanical Properties of an Al-Si-Cu$\mathrm{Mg}$ Alloy at $300{ }^{\circ} \mathrm{C}$ : Effects of $\mathrm{Mg}$ and the Q-precipitate Phase", Materials Science and Engineering A., vol. 621, pp. 277-286 (2015).

114. Lukas, H.L., “Aluminum-Silicon-Copper”, Ternary Alloys, Vol. 5, pp. 11-21 (1992).

115. Budynas, R.G. and Nisbett, J.K., "Shigley's Mechanical Engineering Design", $8^{\text {th }}$ Edition, McGraw-Hill, New York (2008). 